
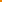
Cover Image and Design

Image by WClarke. CC BY-SA 4.0. Design by Simon Ellis.

\author{
Publication Design \\ Harmony Bench and Simon Ellis, \\ after Barry Roal Carlsen, University of Wisconsin-Madison
}

The International Journal of Screendance

is published by The Ohio State University Libraries

with support from Centre for Dance Research (C-DaRE), Coventry University

ISSN 2154-6878

Website: http://screendancejournal.org 


\section{The International Journal of Screendance}

Spring 2019 • Volume 10

ISSN 2154-6878

\section{EDITORS}

Harmony Bench and Simon Ellis 


\section{The International Journal of Screendance Editorial Board}

\author{
DR. ANN COOPER ALBRIGHT \\ Professor of Theater and Dance \\ Oberlin College \\ ELLEN BROMBERG \\ Associate Professor, Department of \\ Modern Dance \\ University of Utah \\ DR. HARMONY BENCH \\ Assistant Professor, Department of Dance \\ The Ohio State University \\ DR. ERIN BRANNIGAN \\ Senior Lecturer, Dance \\ University of New South Wales \\ DR. SIMON ELLIS \\ Senior Research Fellow \\ Centre for Dance Research (C-DaRE) \\ Coventry University \\ DR. FRANK GRAY \\ Director of Screen Archive South East \\ (SASE) \\ University of Brighton \\ CLAUDIA KAPPENBERG \\ Principal Lecturer, Performance and \\ Visual Art; School of Arts and Media \\ University of Brighton
}

\author{
KATRINA MCPHERSON \\ Independent artist \\ Glenferness, UK
}

MIRANDA PENNELL

Independent film and video artist

London, UK

DOUGLAS ROSENBERG

Professor of Art, Department of Art

University of Wisconsin-Madison

DR. THERON SCHMIDT

Lecturer in Theatre and Liberal Arts

King's College London

\section{SILVINA SZPERLING}

Director, Internacional Festival de

Videodanza

Buenos Aires, Argentina

DR. SARAH WHATLEY

Professor of Dance, Coventry School of

Art and Design

Coventry University

\section{MARISA ZANOTTI}

Senior Lecturer, Dance

University of Chichester 


\section{Table of Contents: \\ Screendance Now}

IJSD Volume 10

1 Editorial: Screendance Now

Harmony Bench and Simon Ellis

11 From the Incoming Editors

Kyra Norman and Marisa Zanotti

Articles

15 The Dance-In and the Re/production of White Corporeality

Anthea Kraut

52 Trans-Screens of Gender and Jewishness in Jill Soloway's Transparent: PostNetwork TV and the Screendance Scene

Hannah Schwadron

74 Mr. Gaga: Embodying the Exceptionalism of Ohad Naharin Meghan Quinlan

94 Digital Dance Criticism: Screens as Choreographic Apparatus Kate Mattingly

Provocations and Viewpoints

127 How Screendance Was Invented While We Were Busy Claiming It Wasn't Katja Vaghi

134 A Note Towards

Claudia Kappenberg

138 Red Shoes

Erin Brannigan

141 On Watching Screendance

Sherril Dodds

146 Digital Spaces, Analogue Thinking: Some Thoughts on Screendance Marisa Zanotti 
Interviews

159 What Are We Doing?

Douglas Rosenberg and Simon Ellis

164 Pathways, Histories, and ScreenDance Diaries: Sarah Elgart in Conversation Sarah Elgart and Harmony Bench

Reviews

171 Reflecting on Light Moves Festival of Screendance 2018

Katrina McPherson

178 Consuming Dance: Choreography and Advertising by Colleen Dunagan Xiomara Forbez

183 Charles Atlas edited by Lauren Wittels

Kyle Bukhari

189 Dance's Duet with the Camera: Motion Pictures edited by Telory D. Arendell and Ruth Barnes

Elisa Frasson

195 Making Video Dance: A Step-by-Step Guide to Creating Dance for the Screen (2nd ed) by Katrina McPherson

Robin Gee 


\section{Editorial: Screendance Now}

Harmony Bench, The Ohio State University

Simon Ellis, C-DaRE (Centre for Dance Research), Coventry University

Keywords: screendance, editorial, identity, culture

In the IJSD call for papers in May 2018, we wrote:

The first volume of IJSD asserted ... that "Screendance has not yet been invented." Volume 10 of IJSD presents an opportunity to reflect on screendance now. Where do we find ourselves as a field? ${ }^{1}$

It is not surprising then that many of the contributions in Volume 10 deal directly and indirectly with questions of screendance's identity. Whereas in Volume 5-a themed call on community and screendance ${ }^{2}$ - the contributions examined the ways in which we are drawn together as a community of artists and scholars, here in Volume 10, we see traces and evidence of a field morphing and adapting, continuing to question its own value and values, and drawing new and shifting boundaries around its identity. One of the founding principles of IJSD, which Doug Rosenberg has articulated so well, is that that field of screendance is capacious enough to include "any dance on any screen." ${ }^{3}$ While we have been at the helm of this journal, we have remained grounded in the histories and aesthetic practices of dance film, while also actively making space for dance in popular television, film, music video, and internet cultures. We have been gratified to support the explosion of dance across media platforms with the expansive focus of this journal.

Faced with the provocation that inaugurated IJSD — that screendance has not yet been invented-and our own call to consider screendance now, we find ourselves everunable to define just what it is that we study in this field. Any dance (but what counts as dance?) on any screen (what counts as screen?). As co-editors, we have delighted in this ambiguity, and have purposefully refused easy categorization. There is undoubtedly a desire by many screendance people to stabilize or know screendance; to be able to cordon off its edges. Maybe some of us even want to understand or know ourselves (and our practices) through the act of understanding the field of screendance and its disciplines. We want an identity that is legible to the institutions with(in) which we work. What do we imagine will be cleaned up if we might some day in the future agree on the limits and boundaries of screendance's identity, and the practices of which it is comprised? But there is also resistance to such knowability from within the screendance community, indeed if resistance has any value in a digital world: 
There is no resistance in a digital environment-only on or off. Anything inbetween is relegated to one or the other, anyway. We can't attenuate the digital. There is no volume knob. There are no knobs at all; there are only switches. In a digital media environment there is no resistance, only opposition.

- Douglas Rushkoff ${ }^{4}$

If this journal is not then an act of resistance, we understand it to embody a key paradox: that screendance's edges can never be identified, maintained, or claimed, and that these non-existent edges are in turn bound by these digital pages. That is, the presence of a journal in any field inevitably marks its boundaries. The desire to make sense of phenomena and things is powerful. A scholarly journal is in some way a means to make sense of a field. But it does this work while also responding to what the field is doing (or rather, what the people in the field are doing and submitting). At each step, we are responding to contributions subjectively and with desire; desire to make sense, to build a fence around the field of screendance. But, curiously, and most importantly, it is a fence that is shifting and porous; a fence that includes and distinguishes. There is no pattern here in this field of screendance, no identity, there is no thing or regularity to be seen. Nevertheless, that work of construction or imagination, of clustering around particular ideas, themes and senses, is valuable. It is cultural work. In the thousands of decisions that go into the writing of each submission, in the thousands of decisions that go into editing and publishing each volume, we are making and shaping the field as we ourselves are being made and shaped.

[Culture] shapes the minds of individuals as well. It's individual expression inheres in meaning making, assigning meanings to things in different settings on particular occasions. Meaning making involves situating encounters with the world in their appropriate culture contexts in order to know 'what they are about.'

- Jerome Bruner ${ }^{5}$

What then are the "appropriate culture contexts" for our field of screendance? Or, better still, which are the inappropriate contexts? The strength of any demarcation is that it helps us to express difference, but it also affords the danger of looking inwards and tribalism. If a culture "is the sum of all things about which humanity can choose to differ" ${ }^{\prime \prime}$ then how might the field of screendance-and all its recognisable and unrecognisable mangle of practices - continue to look outwards beyond what is known or understood? The time will always be ripe to increase the porosity of the edges of screendance practice and scholarship.

As we make way for a new editorial team, we feel a second paradox keenly: that even as we have embraced a broad concept for screendance, external pressures may impose a 
coherent identity on screendance that its practitioners and scholars have not chosen for themselves, or that the broad adoption of digital visual media will make our artistic and intellectual contributions moot. We are reminded of Hamish MacPherson's provocation in Volume 6 that perhaps there is no place for screendance because now every place is one of screendance:

... I only have to look around at my peers and see they are already making short films and putting them online, and these are part of their practice and their work as much as dancing and writing and talking and all kinds of things. So I wonder what place there is for screendance, with all its established forms and boundaries and requirements. How does it relate to ways that people are using video technology to capture and present and produce movement right now? Genuine question.

- Hamish MacPherson ${ }^{7}$

What does it even mean to speak of screendance now, when we carry screens everywhere with us, indeed, when we no longer seem able to escape our screens? We can imagine that the practices, disciplines, and people that are screendance are akin to what science historian Hans-Jörg Rheinberger refers to as an experimental system. He writes that:

Experimental systems don't come in isolation. As a rule, they are part of broader landscapes, or cultures of experimentation. They form ensembles with a patchwork structure. ${ }^{8}$

Screendance is unequivocally part of a broader patchwork of influences and culture; it works with and across ideas, practices, form, structures, tastes, and fashions. We (Harmony and Simon that is) see opportunities to look outwards in this multifarious (and experimental) collection or patchwork. The practice of writing to and about screendance is also able to reflect the "experimental goings-on", ${ }^{9}$ and we like to imagine that the writing in this volume represents a point of departure from conversations about what does or doesn't qualify as screendance-a time for screendance to understand the certainties of our past, our practices, and recognize (or reach outwards) into the uncertainties, and into future newness and difference. Ten volumes into this journal, we think we are only just starting to peer into the thickness of the world of screendance: its practices, ideas, writing, reflection, curiosities and concerns. What new or unaccounted for questions may yet be revealed in the work we are making, watching, and thinking and writing about? And will this work require that we let go of or reinvest in concepts of dance and screen for these questions to emerge?

In her book Cinema and Sensation (2007), Martine Beugnet draws attention to the aesthetics of sensation, where the materiality of a film is "given precedence over its expository and mimetic/realistic functions." ${ }^{10}$ She writes that to foreground the 
materiality of the medium "is to unsettle the frontier between subject and object, figure and ground". ${ }^{11}$ Such unsettling is important, Beugnet says, because it challenges the "representation of the self as a separate entity." 12

Reconfiguring the centrality of the figure or subject in film forces us to confront versions of ourselves that are less important and even less autonomous. We become humans in the periphery. Such selves are stripped bare; embodied illusions of a grand and certain past with its misplaced memories of the clear borders between me and you, us and them, and what is and what is not. Beugnet herself describes the lack of familiarity with what we see in film as a place where the "moving image is not merely ... in the service of a discourse, but a discourse in itself - and an embodied one at that." 13 These are invaluable words for the collection of diffuse practices and influences that we call on as being screendance. For all our efforts (as artists and scholars in the field of screendance) to make claims for and on behalf of others-to make screendance the figure and subject-it is the uncertain and embodied moving images on the periphery, on the edges of what we can take notice of and understand, that fuel this field. They are the experiments - in writing, moving, and filming - that both define and undermine our identity. Such a diffuse identity is a place of both precarity and strength.

But as our contributing authors show, ambiguity is not without consequence; it is a stance, not a solution. The articles in this volume, which span television drama, documentary, online dance criticism, and Hollywood films, all weave a consideration of ethical (um)mooring in these fields of representation throughout their overall inquiry.

Anthea Kraut turns to Hollywood's archives to uncover the history of the "dance-in," the uncredited dancing doubles that stand-in for celebrities, whose labor props up Hollywood's physical economy, even as they remain unseen. Central to Kraut's analysis of the slippery role dance-ins play is the gendered, racial, and representational politics embedded in the relationships between actress Betty Grable and her long-time dancein Angie Blue, both white, the white choreographer Hermes Pan, and the African American dance coach Marie Bryant. Insofar as the white star performer coheres as an individuated subject, it is because she stands in the place of her predecessors: coaches, captains, and choreographers, as well as her own replacement, the dance-in. All have disappeared behind her image. Tracking the way movement passes from body to body in the Hollywood system, Kraut proposes that we understand this process as both surrogation and recorporealization, and that we "read white star bodies not as autonomous and self-contained but as relational, malleable, and indexical of black corporeality." 14

Hannah Schwadron proposes that we consider screendance scenes within televisual aesthetics, by which she means moments of heightened emotion that strategically employ both camera and bodily movement, bringing a more 'artistic' style of visual composition to mainstream audiences. Schwadron argues that screendance scenes can 
support critical transitions within the narrative, and she particularly calls out a kind of "trans-ness" in such moments in Jill Soloway's hit television show Transparent. In Schwadron's essay, body and camera work together to move the characters across time and space in an effort to both reveal and heal cross-generational traumas inherited among Jewish communities and gender and sexual minorities. In the casting of Jeffrey Tambor as Maura, however, Schwadron encourages us to consider the ethics of what she calls "trans-face," and how it sits within a longer history of Jewish participation in American minstrelsy. This history, and what Schwadron describes as a "murky middle ground" that conflates "Jewish and transgender stories"15 requires us to grapple with how to ethically represent transgendered characters on screen-a charge that becomes more pronounced in light of Tambor's alleged sexual harassment of transwomen on set.

Megan Quinlan analyzes the celebrated documentary film Mr. Gaga, asking how the film's framing of Israeli choreographer Ohad Naharin as "exceptional" obscures or excuses his questionable and even abusive behavior. While documentary films never present an unbiased view of their subjects, Quinlan contends that dance sequences are employed to change the mood, redirect attention, or offer sensationalism rather than confront some of the more uncomfortable aspects of Naharin's style. This not only has the effect of undermining any criticality, it forcibly decontextualizes and depoliticizes Naharin's work. Naharin's exceptionalism comes to a head with the revelation late in the film that the story he tells of how he came to dance-through a desire to communicate with his twin, who did not speak - is a fabrication. Quinlan argues that this narrative epitomizes Naharin's relationship to his choreography, "which he similarly views as unstable and constantly available for revision." ${ }^{16}$ Rather than accede to Naharin's "playful" approach to truth, however, Quinlan weighs the value of this story in a posttruth era.

Kate Mattingly discusses the changing landscape of dance criticism, and how this discourse has moved online. She analyzes three different dance writing platforms and the values espoused by their authors. Pushing against the notion that digital technologies erode the level of discussion by opening the field to more voices, Mattingly challenges the prestige of so-called "canon criticism" in favor of more inclusive models of dance writing. She draws our attention to regimes of value in what she calls the "choreographic apparatus" of dance criticism, which is to say, the ways dance criticism has historically established the terms, concepts, and frames for discussing and evaluating dance. In contradistinction, she offers a consideration of dialogical digital platforms that host multiple voices and perspectives, including those of the artists themselves. In so doing, Mattingly calls upon readers to critically examine the role and position of the dance critic, reconfiguring criticism as a shared activity that “organizes, nurtures, and promotes creative work...in a symbiotic relationship with contemporary performance." 17 
Each of the articles in this volume prompts us to consider the value and values of screendance practices as we move forward as a field. The provocations have more of a retrospective take.

In her provocation, Katja Vaghi turns our attention back to the first volume of IJSD and its claim that screendance has not yet been invented. But times have changed for Vaghi and she now understands the field to be in rare (and independent) health, with higher education courses, scholarly discourse, and blossoming festivals. Her concern though is that there is a danger in institutionalizing the field and an aesthetic. We asked Claudia Kappenberg, who was co-editor of Volume 1, to respond to Vaghi's provocation. In her response, Kappenberg suggests that screendance's strength is in its incompleteness; that we will always be inventing it "over and over again." 18 She imagines that screendance will be less concerned with its form and history, and will start to look outwards to the politics and experiences that help us understand our lives and practices.

We also asked Erin Brannigan and Sherril Dodds to write brief provocations for this volume. Both are strongly connected to screendance writing and scholarship, and both remain key figures in how it is that we might look at and understand screendance practice. Brannigan evocatively blends her deep connection to early 21 st century screendance curation, personal memories, experimental film, and the expansion of choreography from dancing. It's playful, serious and surprisingly poignant. Dodds takes a more direct route and looks into what happens when we call something screendance; that how we look changes what we see, and that this transformation shapes the field itself.

Incoming co-editor Marisa Zanotti uses her provocation to think through how screendance has changed in the last 10 years. She writes of the technology (both the tools we use and the spaces we present in and on), the expansion of screendance practices, and economies of time and space. She finds herself questioning the speed at which she is working, but is also nourished by the potential of more complex "mediated bodily experiences." ${ }^{19}$

Co-editor Simon Ellis interviews IJSD's founding co-editor Doug Rosenberg to get his take on the field since Volume 1 in 2010. Rosenberg wonders about the tendency to prevaricate in scholarly writing, and states his preference for manifesto-driven writing. He sees manifestos as being capable of driving change, and in the interview he also reveals a certain restlessness with the field in which films that are more experimental are swamped by the volume of films that maintain the status quo.

Co-editor Harmony Bench interviews the choreographer Sarah Elgart about her work in and around screendance, particularly her column ScreenDance Diaries with the Los Angeles online magazine Cultural Weekly. Elgart describes her history and work across 
commercial and arts sectors, and the important role screendance plays in the cultural and movement literacies of the contemporary moment.

There are five reviews in this volume of IJSD. Katrina McPherson reviews the 2018 edition of Light Moves Festival of Screendance in Limerick and is particularly struck by the screening of Dziga Vertov's Man With A Movie Camera (1929) with a newly commissioned score by Neil O'Connor and Dunk Murphy. Xiomara Forbez reviews Colleen Dunagan's Consuming Dance: Choreography and Advertising and notes the extent to which the advertising world embraces or perhaps appropriates dance in an attempt to have advertisements become something more than-or other to-just a means to sell something. Kyle Bukhari reviews the volume on Charles Atlas edited by Lauren Wittels, and likes the multi-voiced approach to Atlas's work, including a recent interview especially for the volume with Atlas himself. Elisa Frasson responds to Telory D. Arendell and Ruth Barnes' edited volume Dance's Duet with the Camera: Motion Pictures, remarking on the editors' desire to balance the relationship between the dance and the film. Finally, Robin Gee brings this section full-circle by reviewing the 2nd edition of Katrina McPherson's Making Video Dance. Gee remarks on the key updates of the book, including experimental screendance processes, using scores to develop movement, exercises for teaching, and the companion website.

These then are the last few sentences we will write as co-editors of IJSD. It has been, as you can imagine, rewarding and challenging. In our tenure, we moved the journal from the University of Wisconsin to The Ohio State University and, with an eye toward sustainability, moved it entirely online. We adopted creative commons licensing to ensure that the ideas contained in these pages can circulate without paywalls so as to serve the screendance community at its furthest reaches. We thank Maureen Walsh and the Libraries at OSU for assistance with each of these steps. A heartfelt thank you to authors, reviewers, and copy-editors (in V10 it was Claire Ridge and Carol Breen at CDaRE), to the editorial board for their support, and most of all to people like you who read the journal. It is you that we have tried to keep in mind at all stages of the process, each year. We have tried to make the journal "international" as the IJSD's title states, and recognize that there is still much to do here. As we welcome Kyra Norman and Marisa Zanotti as the incoming co-editors of IJSD, we hope they will achieve greater success in this area than we have. After five years as co-editors, we are anxious to see what will unfold under their stewardship. We leave Kyra and Marisa with a journal that has tried to be as malleable and fluid as screendance itself, and we look forward to cheering from the sidelines as they draw the journal and its readers and contributors into a next generation with different tones, possibilities, insights, and practices. It has truly been a pleasure to serve this community. 


\section{Biographies}

Harmony Bench is Associate Professor in the Department of Dance at The Ohio State University. From 2014-2019, she has been co-editor of The International Journal of Screendance with Simon Ellis. She is currently at work on a collaborative research project with Kate Elswit, funded by the Arts and Humanities Research Council, which brings data visualization and computational tools of analysis to bear on dance history in the study of mid-century African American choreographer Katherine Dunham. https://dunhamsdata.org/.

\section{Email: bench.9@osu.edu}

Website: http://www.harmonybench.com

Simon Ellis is a choreographer, dancer, and film-maker. He is from New Zealand but now lives in London, and is an Associate Professor at the Centre for Dance Research at Coventry University. He is particularly interested in the limits and possibilities of collaboration in choreographic processes.

Email: simon.ellis@coventry.ac.uk

Website: http://www.skellis.info

\section{Notes}

${ }^{1}$ Harmony Bench and Simon Ellis, International Journal of Screendance Volume 10:

"Screendance Now" Open Call For Papers.

${ }^{2}$ Harmony Bench and Simon Ellis (eds). "Community and Screendance."

${ }^{3}$ Douglas Rosenberg, Screendance, 117.

${ }^{4}$ Rushkoff, Team Human, Chapter 41 (no page number).

${ }^{5}$ Jerome Bruner, The Culture of Education, 3.

${ }^{6}$ Brian Eno, A Year With Swollen Appendices, 317.

${ }^{7}$ Hamish MacPherson, What Are Screendance Competitions Even For?, 180.

${ }^{8}$ Hans-Jörg Rheinberger, Forming and Being Informed, 204.

${ }^{9}$ Idem, 203.

${ }^{10}$ Martine Beugnet, Cinema and Sensation, 14. 
${ }^{11}$ Idem, 63.

12 Ibid.

${ }^{13}$ Idem, 59.

${ }^{14}$ Anthea Kraut, "The Dance-In," 34.

${ }^{15}$ Hannah Schwadron, "Trans-Screens of Gender and Jewishness," 64.

${ }^{16}$ Meghan Quinlan, "Mr. Gaga," 88.

${ }^{17}$ Kate Mattingly, “Digital Dance Criticism,” 100.

${ }^{18}$ Claudia Kappenberg, "A Note Towards," 134.

${ }^{19}$ Marisa Zanotti, “Digital Spaces,” 152.

\section{References}

Bench, Harmony and Ellis Simon (eds). "Community and Screendance": International Journal of Screendance Volume 5" (2015). https://doi.org/10.18061/ijsd.v5i0

. "International Journal of Screendance Volume 10: 'Screendance Now' Open Call For Papers" 21 May 2018.

https://screendance.wordpress.com/2018/05/21/international-journal-ofscreendance-volume-10-screendance-now-open-call-for-papers.

Beugnet, Martine. Cinema and Sensation: French Film and the Art of Transgression. Edinburgh: Edinburgh Univ. Press, 2007.

Bruner, Jerome. The Culture of Education. Harvard University Press, 1996.

Eno, Brian. A Year with Swollen Appendices. London: Faber and Faber, 1996.

Kappenberg, Claudia. "A Note Towards." The International Journal of Screendance 10 (2019). https://doi.org/10.18061/ijsd.v10i0.6653

Kraut, Anthea. "The Dance-In and the Re/production of White Corporeality." The International Journal of Screendance 10 (2019).

https://doi.org/10.18061/ijsd.v10i0.6514

MacPherson, Hamish. "What Are Screendance Competitions Even For? A Response to the 2015 Leeds International Film Festival Screendance Competition." The International Journal of Screendance 6 (2016). https://doi.org/10.18061/ijsd.v6i0.5063 
Man With A Movie Camera. Dir. Dziga Vertov. Film. Soviet Union. 1929.

Mattingly, Kate. "Digital Dance Criticism: Screens as Choreographic Apparatus." The International Journal of Screendance 10 (2019).

https://doi.org/10.18061/ijsd.v10i0.6524

Quilan, Meghan. "Mr. Gaga: Embodying the Exceptionalism of Ohad Naharin." The International Journal of Screendance 10 (2019).

https://doi.org/10.18061/ijsd.v10i0.6525

Rheinberger, Hans-Jörg, and Michael Schwab. 'Forming and Being Informed'. In Experimental Systems: Future Knowledge in Artistic Research, 198-219. Orpheus Institute Series. Leuven: Leuven University Press, 2013.

Rosenberg, Douglas. Screendance: Inscribing the Ephemeral Image. Oxford and New York: Oxford University Press, 2012.

Rushkoff, Douglas. Team Human. New York: W.W. Norton \& Company, Inc, 2019.

Schwab, Michael (ed). Experimental Systems: Future Knowledge in Artistic Research. Leuven: Leuven University Press, 2013.

Shwadron, Hannah. "Trans-Screens of Gender and Jewishness in Jill Soloway's Transparent: Post-Network TV and the Screendance Scene." The International Journal of Screendance 10 (2019). https://doi.org/10.18061/ijsd.v10i0.6522

Zanotti, Marisa, "Digital Spaces, Analogue Thinking: Some Thoughts on Screendance." The International Journal of Screendance 10 (2019).

https://doi.org/10.18061/ijsd.v10i0.6569 


\title{
From the Incoming Editors
}

\author{
Kyra Norman, University of Falmouth \\ Marisa Zanotti, University of Chichester
}

It is with great pleasure, and many questions, that we embark on editing The International Journal of Screendance. With IJSD's first volume in 2010, editors Douglas Rosenberg and Claudia Kappenberg made a clear case for the value to artists engaging with dance and moving images practices of a publication that would interrogate and articulate "the practice in print." ${ }^{11}$ As editors they established many of the parameters which continue to shape the journal today: a commitment to interdisciplinarity, intellectual rigor, and the fostering of a welcoming environment where new writers enter into conversation with established thinkers, and landmark texts that have shaped our discipline(s) are re-printed alongside the testing of still-forming positions. We are grateful that Doug and Claudia continue to contribute to the discussions around our shared visions for this project, and we look forward to continuing these conversations as to the purpose and potential of this publication.

With Volume 5 in 2015, Harmony Bench and Simon Ellis assumed the editorship, and we are grateful for, and inspired by, their diligent and creative approach to the role. In particular, we are grateful for their commitment to bringing screendance practices into dialogue with the wider world through themed issues and invited guest writers. We would also like to acknowledge their considerable work in supporting those submitting articles to the journal: through robust criticism and a nurturing generosity they have helped to foster a new generation of writers facing up to the challenges of writing in response to the spectrum of practices generated in the field.

In 2019 our experience of screen media has shifted; 'screen space' can now mean any number of different formats, platforms and viewer engagements, and consequently this expands the possibilities for screendance as a cultural practice, both through the affects it creates and the communities it serves. In 2018, the collective Future Mellon / Not Yet $\mathrm{Art}^{2}$ and the cultural association VeNe ${ }^{3}$ launched a festival, Screendance Landscapes, ${ }^{4}$ that included an archival program (curated by Danza Archive $\mathrm{ViSi}^{5}$ and $\mathrm{VeNe}$ ) which revealed an extraordinary cache of experimental screen dances and animations, first shown on Italy's RAI Uno channel in the late 1980s. It is in such a combination-of artists finding ways to make and share their work, and of the discovery of archival works that cause us to rethink our own perspectives on screendance's history and possible trajectories - that we find our inspiration as incoming editors. Undoubtedly there are many more instances across the world of radical screendance practices, communities, and archives, and we are excited to discover more. We are aware that our readership and submissions are currently drawn mainly from the UK and USA, and one of our 
principal concerns in taking on this editorship is to engage and reflect an international and inclusive community of readers, writers and artists. With that in mind, in our first issue as editors (Volume 11 to be published in 2020) we will invite insights into hidden legacies and how they might lead us to imagine and create screendance futures.

\section{Biographies}

Marisa Zanotti is an award-winning filmmaker who has been exploring ideas around bodies, screens and perception through analogue and digital technologies since the 1990s. She has a long-term collaboration with the editor lan Ballantyne and has created screen dance projects with choreographers including Ben Wright (2012) and Lea Anderson (The Pan's People Papers (2015), Edits Film (2014). Recent projects include the VR installation project We Are All Made of Stars, a collaboration with classical composer Matthew Whiteside. Marisa is a Reader in Digital Technologies and Choreography at University of Chichester.

Email:m.zanotti@chi.ac.uk

Website: www.marisazanotti.net

Kyra Norman is a choreographer and researcher working in dance, theatre and film. She approaches her work with an expansive sense of choreographic possibility, and a commitment to bringing dance into conversation with the world around us. Alongside her work as a lecturer in Dance \& Choreography at Falmouth, Kyra has an ongoing artistic practice, working as a performer, choreographer and writer, and as a project manager for interdisciplinary arts events.

Email kyra.norman@falmouth.ac.uk

Website: https://www.falmouth.ac.uk/staff/dr-kyra-norman

\section{Notes}

${ }^{1}$ Rosenberg and Kappenberg, "Screendance: The Practice in Print," 3.

${ }^{2}$ See www.futuremellon.com

${ }^{3}$ See www.facebook.com/VeNe-231267557311891/ 
${ }^{4}$ The Screendance Landscapes film festival was held April 16-17, 2018 in Venice, Italy. For their program, see docs.wixstatic.com/ugd/547f18_e119b6ae15564b72bf036a6b77d63baf.pdf

${ }^{5}$ See www.danzarchivio.it/collezione

\section{References}

Rosenberg, Douglas and Claudia Kappenberg. "Screendance: The Practice in Print," The International Journal of Screendance 1 (Spring 2010): 1-4.

https://doi.org/10.18061/ijsd.v1i0.6380 
ARTICLES 


\title{
The Dance-In and the Re/production of White Corporeality
}

\author{
Anthea Kraut, University of California, Riverside
}

\begin{abstract}
This essay examines the figure of the "dance-in," a stand-in who dances in place of a star prior to filming, focusing on two women who acted as surrogates and dance coaches for the mid-twentieth century white film star Betty Grable: a white woman named Angie Blue and an African American woman named Marie Bryant. Bringing together film studies theories of indexicality, performance studies theories of surrogation, and critical race theories of flesh and body, I argue that the dance-in helps expose how the fiction of white corporeality as a bounded and autonomous mode of being is maintained.
\end{abstract}

Keywords: dance-in, white corporeality, surrogation, indexicality, Betty Grable, Angie Blue, Marie Bryant

In 1935, the Los Angeles Times ran a seventy-word article under the headline "Dance Stand-In," explaining a new phenomenon in Hollywood:

"Stand-ins," persons who take the places of stars while the cameras are being properly focused, have become an accepted fact around the studio sets. Now comes Shirley Temple, youngest star of them all, with a new kind of stand-in - a dance stand-in. Marilyn Harper, one of the Meglin Kiddies, is Shirley's dance stand-in. Marilyn goes through all the terpsichorean motions for Shirley until she is ready to take her place. ${ }^{1}$

The need for "dance stand-ins," sometimes referred to as "dance-ins," coincided with the rise of the film musical and the increased occurrence of dance in film, ushered in by the advent of sound in Hollywood. ${ }^{2}$ Key to the operation of movie-making but seldom heralded, dance-ins joined the ranks of other "Hollywood unknowns" - extras, standins, doubles - who were "relegated to the margins of the film industry" and almost never credited. ${ }^{3}$

In her compelling article "Missing Persons and Bodies of Evidence," Ann Chisholm traces the emergence of stand-ins, whose work saved the energies and labor of stars, to the film industry's growing reliance on rehearsals and its move "toward efficiency and replication" in the 1920s. ${ }^{4}$ Her focus is on the paradoxical ways stand-ins and their close relative, body doubles, have been crucial to the production of film and film stars even as they are continually disavowed or disparaged as "second-rate physical cop[ies]." Dwelling on this contradiction, Chisholm highlights the ambiguities and slippages The International Journal of Screendance 10 (2019).

https://doi.org/10.18061/ijsd.v10i0.6514 
generated by these "supplementary bodies," who are simultaneously marginal and vital, alternate between presence and absence, and are both in excess of and substitutes for stars. ${ }^{5}$

Unlike a stand-in, the body (or body parts) of a double appears on screen, masquerading as that of the star. The use of doubles accordingly necessitates some sleight-of-hand film editing designed to trick spectators. ${ }^{6}$ In the case of dance doubles, ${ }^{7}$ this deception can become controversial. 2011, for example, saw a scandal erupt when American Ballet Theater's Sarah Lane spoke openly about her role as Oscar-winning actress Natalie Portman's double in the 2010 film Black Swan, exposing the "façade" propagated by Foxlight Searchlight that Portman did ninety percent of her own dancing. ${ }^{8}$ Because the double creates questions about whose body we are seeing on screen, it destabilizes the assumed correspondence between a star's on-screen image and her off-screen corporeality. In film studies, this destabilization is part of a larger issue that has been described as the "politics of indexicality," which I will return to below.

If stand-ins' and dance-ins' lack of on-screen visibility ${ }^{9}$ means they don't require the same kind of cinematic subterfuge, they are no less capable of producing slippages. This is evident in the very language of the LA Times's announcement of the dance stand-in's emergence. Take the last sentence of the article:10 "Marilyn goes through all the terpsichorean motions for Shirley until she is ready to take her place." The "she" here is clearly Temple, but whose place is Temple taking? That of Harper, her dance-in? Or her own (rightful) place as star? This imprecision allows us to read "her" in a double sense: when the star takes her place before the camera, she is taking both her own and her dance-in's place. To belabor this even further, recall that the first sentence in the article defines stand-ins as those who take the place of stars. Both stars and stand-ins, then, perform the action of taking an/other's place, and, in the case of dance-ins, this two-way place-taking precedes and determines any dancing we ultimately see on screen.

Even if coincidental, the uncertain referentiality of pronouns in the Times piece might be seen as symptomatic of the dance-in's ambiguity more broadly - her position, that is, betwixt and between live performance and film. Put simply, the dance-in has a peculiar ontological status. Subject to the filmic apparatus without necessarily ever appearing on screen, dance-ins blur the lines, or exist at the nexus, between the live and the technologically mediated. As such, they should be regarded as interstitial, intermedial, and interdisciplinary figures, qualities that others have argued are inherent to screendance itself. ${ }^{11}$ And it is precisely this liminal disciplinary status that makes the dance-in such a productive site for screendance.

As Sherril Dodds, Harmony Bench, and Douglas Rosenberg have all shown, screendance is a particularly rich field for interrogations of the body. In Dodds's influential formulation, "the presentation of a 'live body' is unavoidably transformed when it becomes a 'screen body."'12 During this process of what Rosenberg calls 
"recorporealization," screendance has the potential to shift our understanding of bodies, including by "unmooring" notions of the body "from somatic and corporeal absolutes." ${ }^{13}$ Scholars of digital media have been especially attuned to the ways the post-film era "has irrevocably shifted our sense of the real body." ${ }^{14}$ Because dance-ins exist at the critical juncture between the live and the screen, they encourage us to think more expansively about recorporealization and to complicate our approaches to live and screen bodies alike.

This essay pursues the implications of the dance-in through a case study of the white 1940s Hollywood icon Betty Grable and two women who danced in her place. Grable's whiteness is central rather than incidental to my investigation, for her dependence on "supplementary bodies" challenges the ostensible singularity and integrity of the star's white body..$^{15}$ Taking a "behind the screens" approach ${ }^{16}$ to Grable's image, I hope to demonstrate that dance-ins are important to screendance not only for the ways they "push... at the boundaries of...traditionally wrought disciplines"17 but also for the ways they push at the boundaries that mark white corporeality as a privileged mode of being.

To make that case, I first place into dialogue concepts from screendance and film studies, dance and performance studies, and critical race theory. Given the acts of substitution that define her work, the dance-in lends herself to analysis in terms of performance studies notions of surrogation and doubling. And given the corporeal slippages that tend to accompany those substitutions, the dance-in is well situated to contribute to debates in dance studies, performance studies, and critical race studies about the status and constructedness of "the body" as an apparently autonomous entity. These debates in turn intersect with film studies concerns about the in/stability of the film image as an "index" of a pre-filmic body.

After laying this theoretical groundwork, I then examine the specific inter-corporeal entanglements between Grable's on-screen dancing body and a white woman named Angie Blue, who served as her official dance-in. Dance-ins, as will become clear, share a familial resemblance not only with extras, stand-ins, and body doubles but also with the choreographers, choreographers' assistants, and dance instructors who work off camera to shape stars' bodies, usually without credit. ${ }^{18}$ Considering how steeped Hollywood dancing was in Africanist influences, ${ }^{19}$ it is perhaps inevitable that tracing Grable's relationship to her white dance-in winds up uncovering the star's genealogical links to dancers of color as well. In Grable's case, I will show, an African American dance coach named Marie Bryant functioned in ways that were similar to Blue; both women helped recorporealize Grable's body through a series of power-laden exchanges. Together, Blue and Bryant provide a window onto the larger racialized and gendered ecology of unseen dance artists on which the white star's filmic image rests. Ultimately, I hope to show, the invisibility that was part of the conditions of re/producing the star's white dancing body on screen cannot be disentangled from the invisibility that was part of the conditions of re/producing white supremacy. 


\section{Whiteness, Corporeality, and Indexicality}

Before peeling back the layers of Grable's on-screen corporeality, it is necessary to double back to the fact that, according to the LA Times article, Shirley Temple was among the first to benefit from a dancing stand-in. The most popular child star of the 1930s, Temple was the personification of innocent white femininity. ${ }^{20}$ That the dancein emerged in service of Temple encourages us to ask how this supplemental body functioned as a technology of gendered whiteness. ${ }^{21}$ Just as Teresa De Lauretis has argued that the cinematic apparatus is part of the technology of gender - that gender is "not a property of bodies" but the "product of various social technologies"22 - so too I want to explore how the dance-in serves as a technology of race as it intersects with gender.

It is by now widely accepted that whiteness is constructed and that, in the U.S., film has played an outsized role in framing whiteness as a universal norm and aesthetic ideal. ${ }^{23}$ Appropriately, then, film scholars have been at the forefront of theorizing whiteness. While Michael Rogin, for example, has pointed to the donning and removing of blackface as a crucial mode of producing whiteness on screen, Richard Dyer has exposed how movie lighting creates "a look that assumes, privileges and constructs an image of white people," and how idealized images of white women in film are fashioned through lighting techniques that make them appear to glow. ${ }^{24}$ It is significant in this regard that one of stand-ins' primary functions was to allow cinematographers to determine the proper lighting for the star and that they were thus required to approximate the "height, weight, and coloring" of the star. ${ }^{25}$ Although little is known about Marilyn Harper, Temple's dance stand-in, ${ }^{26}$ both she and Temple got their start with Meglin's Kiddies, a Los Angeles-based dance studio (actually a collection of studios) that groomed white children for show business. An online clip of a 1933 vaudeville act featuring "Meglin's Famous Kiddies" shows a sea of white children tap dancing and performing acrobatic tricks. ${ }^{27}$ An entire industry stood ready to supply dancers who could visually match Temple on film..$^{28}$

But the white stand-in who dances in place of a white star does more than just resemble that star, and her dance labor offers insight into how whiteness is re/produced in ways that exceed the replication of white physical appearance or the performance of blackface. One way of understanding that reproduction is as an act of surrogation. I invoke here performance studies scholar Joseph Roach's influential theorization of performance as "the process of trying out various candidates in different situations the doomed search for originals by continuously auditioning stand-ins. ${ }^{29}$ For Roach, surrogation describes the re-production of the social fabric in a broad sense, "the enactment of cultural memory by substitution" as "survivors attempt to fit satisfactory alternates" into "the cavities created by loss through death or other forms of departure." ${ }^{30}$ If one of the primary functions and effects of mainstream film in the U.S. has been to uphold the dominance of the white social fabric, then we might approach 
the reproduction of idealized white femininity via the dance-in as surrogation on both a macro- and micro-scale.

Roach's notion of surrogation has not been without critique. Performance studies scholar Diana Taylor, for one, argues that because as a model, surrogation depends on an assertion of cultural continuity enabled by the erasure of antecedents, notions of performance as "doubling, replication, and proliferation" are more apt. ${ }^{31}$ My understanding of the dance-in, however, is that she blurs the lines between surrogation and doubling, as well as those between the original and the copy. As I hope to show, even while the dance-in's labor must be invisibilized ${ }^{32}$ in order for the star to assume her rightful place, the stand-in's dancing, at least in some cases, bleeds into and reshapes the body of the star. In other words, to draw together concepts from performance studies and screendance studies, surrogation begets recorporealization. Recalling the language of the LA Times piece, the white "her" that we finally see on screen should be approached not as a singular "her" but as an assemblage of multiple bodies' terpsichorean motions.

In approaching "her" as a multiplicity, I engage work across several fields that has increasingly placed pressure on the notion of the bounded, individuated body. While the camera's ability to "multipl[y] the self on screen" makes corporeal proliferation a matter of course from a screendance perspective, ${ }^{33}$ the dance-in's liminal status makes it worth considering challenges to corporeal discreteness from scholars not explicitly concerned with technological mediation. Philosophers like Erin Manning and Jose Gil, for example, have theorized the body as always relational, always "more than one." "The body' is a misnomer," Manning writes. "Nothing so stable, so certain of itself ever survives the complexity of worlding." She approaches the body instead as "a transition point" and "the amalgamation of a series of tendencies and proclivities." ${ }^{\text {"34 }}$

Critical race theorists, meanwhile, have long submitted "the body" to incisive critique. Of particular note here is Hortense Spillers's 1987 essay, "Mama's Baby, Papa's Maybe: An American Grammar Book," which takes on the 1960s Moynihan Report and its problematic casting of the "Negro family" as pathological due to the prevalence of female-led households. Spillers insists that we approach the intersection of gender and race through a different genealogical lens: the "socio-political order of the New World" and the "willful and violent...severing of the captive body from its motive will" for capitalist purposes. ${ }^{35}$ For the enslaved, the resulting "American grammar" of reproduction both disrupted the patriarchal order (since children born to enslaved women inherited the condition of their mother) and evacuated "kinship" of its meaning "since it can be invaded at any given and arbitrary moment by the property relations." ${ }^{36}$

In one of Spillers' most frequently cited passages, she makes a distinction between "body" and "flesh" and suggests that this distinction is "the central one between captive and liberated subject-positions." "In that sense," she proposes, "before the 'body' there 
is the 'flesh,' that zero degree of social conceptualization that does not escape concealment under the brush of discourse, or the reflexes of iconography. ${ }^{137}$ In his study of the aesthetic practice of Black Pentecostal breath, Ashon Crawley interprets Spillers to mean that "Flesh designates a borderless, discontinuous object, previous to its being sexed, previous to its being raced. As Spillers would have it, the 'body' that comes after the flesh is produced through rhetoric, through discourse." This "body," he offers, "is a categorical coherence, it is a theological-philosophical concept of enclosure, a grammar and logic producing something like bodily integrity." ${ }^{138}$ Whether or not we subscribe to the notion of flesh as a pre-discursive realm, Spillers's differentiation of flesh and body resonates in provocative ways with approaches to corporeality in dance studies. ${ }^{39} \mathrm{Her}$ ideas are also a potent reminder that, when we take "the body" as self-evident, we fail to see how racial projects have done their work through the disparate ways they fashion "bodies" out of flesh.

To wit, Spillers' insights have a direct bearing on understandings of white embodiment. ${ }^{40}$ Taking a cue from Spillers, for example, Eva Cherniavsky has proposed that we approach race as "the radically uneven capacity of bodies to serve as the shell (the organic container) of the subjects they embody."${ }^{\prime 41}$ In her formulation, one of the key privileges of whiteness is "incorporated embodiment," the "articulation of bodily form for the subject at risk of dispersal."42 The fiction of bodily integrity, in other words, has been a site of racialization and an instrument of white supremacy, protecting whites from the incursions of capital that defined the terms of African Americans' entry into the U.S.

These critical race approaches to body and flesh are relevant to my examination of Hollywood dance-ins in at least two ways. First, to the extent that dance-ins helped construct seemingly coherent images of white dancing film stars, they provide another avenue through which to understand how white embodiment comes to assume its idealized and privileged form. That is, the unseen and distributed work that it takes to re/produce white dancing bodies for the screen may serve as a microcosm of the construction of white corporeality more broadly. ${ }^{43}$ Second and relatedly, the slippage between flesh and body that Spillers highlights echoes a recurrent concern of media theorists: the slippage between on-screen image and off-screen referent. ${ }^{44}$ As film scholars like Kara Keeling and Mary Ann Doane have addressed, the shift from celluloid to digital film has created a certain anxiety, or "identity crisis," around the question of indexicality ${ }^{45}$ In Keeling's succinct explanation of the crisis, "The filmic regime of the image claims to be an index of that reality, thereby encouraging identification between the image and its presumed referent, while the digital complicates that schema of identification by calling into question the very notion of a 'prefilmic reality' to which the digital image might lay claim." ${ }^{\prime 4}$ Yet as Keeling goes on to say, even a glancing familiarity with representations of blackness in cinema gives the lie to the idea of film as an index of reality. "Where images of blacks are concerned," she argues, "cinema's 
indexical identity has always been in crisis or, at least, it has always been interrogated and undermined." 47

Keeling's observation helps cast my study of Hollywood dance-ins in the middle of the twentieth century as a return to a historical moment in which white bodies on film were still presumed to have stable referents. ${ }^{48}$ My premise is that, even in a pre-digital era, the relationship between on-screen image and off-screen materialities was far more complicated than it appeared. Keeling's argument, it is worth noting, rests on black spectators' ability to recognize the fallacy of screen images of black bodies. ${ }^{49}$ Conversely, images of white dancing stars from the so-called Golden Age of the Hollywood musical ${ }^{50}$ continue to be regarded as "truthful" representations of their unique physicalities. Scholar Erin Brannigan, for instance, has argued not only that (white) stars' bodies were the "film musical's primary, unifying element" but also that those images were determined primarily by stars' "corporeal specificity," which she terms their "gestural idiolect or idiogest." corporeal signature ${ }^{52}$ and certainly do not mean to refute the idea that dancers have distinctive ways of moving. Rather, I'm interested in investigating what and whom the notion that the filmic image of a dancing star is a direct reflection of their "idiogest" might obscure. Using the construction of Betty Grable's white dancing body as a test case, and building on the work of the above theorists, I ask whose flesh Grable's iconically white and seemingly coherent body was simultaneously indexing and concealing.

\section{"Doing Angie"}

In the 1940s, the actress, singer, and dancer Betty Grable (1916-1973) was a reliable boxoffice draw in Twentieth Century Fox Technicolor musicals, the highest-paid female star (and therefore the highest paid woman in the U.S.), ${ }^{53}$ and the reigning "pin-up girl," whose photographic image was distributed to five million servicemen during World War II. Her legs reportedly insured for over a million dollars with Lloyds of London, the "blonde and snow-white" Grable epitomized white womanhood and "all things American." ${ }^{44}$ Reminding us that "the war in the Pacific was a race war," historian Robert Westbrook cites a Time magazine report that "soldiers preferred Grable to other [less blonde] pin-ups 'in direct ratio to their remoteness from civilization."' Grable's "obvious whiteness," Westbrook concludes, made her the "superior image of American womanhood." 55 


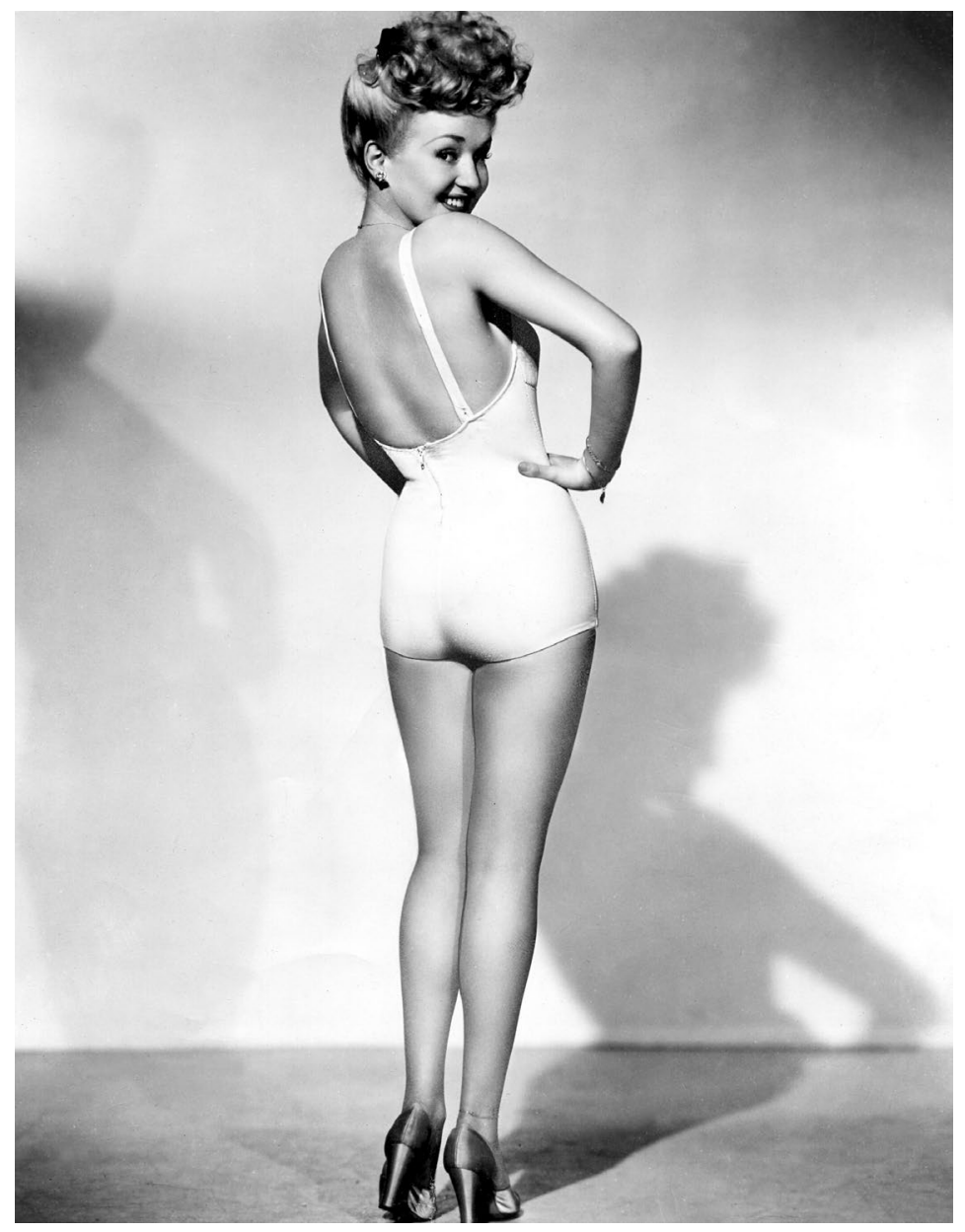

Betty Grable in her famous 1943 pin-up pose. Courtesy Photofest.

Throughout the 1940s, a white woman named Angela (Angie) Blue (1914-2004) served as Grable's dance-in. An uncredited dancer in a number of 1930s films and later under contract as a dance director at Twentieth Century Fox Studios, Blue auditioned for a part as a chorus girl in the 1934 Fred Astaire-Ginger Rogers film The Gay Divorcee, which led to an encounter with Hermes Pan, the prolific white Hollywood choreographer best known for his work with Astaire. ${ }^{56}$ Pan considered Blue a "marvelous dancer" with a "quirky gaminesque quality," and by 1937 , she became his assistant. ${ }^{57}$ Particularly useful to Pan, Blue was "pliable": as he later recalled, "I could grab her by the hand and throw her into position and she'd just do it...I could turn her around and whip her like a piece of clay and she would fall into things. She was like putty." ${ }^{158}$ With Spillers' flesh/body distinction in mind, we might say that, for Pan, Blue was all flesh, and that her lack of "categorical coherence" was what gave her value as a choreographer's assistant. When Pan began creating choreography for Grable in 1941, the blonde Blue was a natural choice to serve as Grable's dance-in, and the two women developed a close friendship that lasted for years..$^{59}$

Because Grable preferred not to be involved in the choreographic process, Pan relied on Blue to help work out Grable's routines. "Betty Grable hated to rehearse and 
admitted it," Pan told biographer John Franceschina. "She'd say, 'Oh, just show it to me and I'll do it."' ${ }^{\prime 60}$ Consequently, "working with Betty Grable involved Pan and Angie Blue creating complete routines ahead of time and teaching them to her, much in the same way they might work with a dancing chorus." ${ }^{\prime 61}$ Though Grable trained in dance from an early age and danced in nearly all of her films, assessments of her dancing were decidedly mixed. "She really was not a great tap dancer," Pan once claimed, "and she couldn't do great ballet. But she could move, and she had very beautiful legs, and...[h]er color was beautiful." ${ }^{12}$ Never one to inflate her abilities, Grable maintained that she was only an average dancer, and she was content to just do "what she was told." ${ }^{163}$

For Grable, learning choreography was thus a process of mimicking Blue. Just as Pan stood in for Ginger Rogers when he worked out routines with Fred Astaire, Blue would "be Grable" when she and Pan worked out routines for Grable. Once the choreography was set, "Betty Grable was... instructed by Pan to 'do Angie."' In fact, a 1991 article about Pan reported that "the famous Grable itty-bitty walk as well as the bathing suit, hands on hips, over the shoulder pin-up of the 1940s was simply her 'doing Angie."'164

This is a rather remarkable revelation in its inversion of the presumed relationship between star/original and stand-in/copy. Among the unofficial "rules" for stand-ins listed in a 1938 article about Bette Davis's stand-in, Sally Sage, was the following: "Study your star. Be able to copy her walk and her stance. ${ }^{\prime 65}$ In Grable's case, by contrast, the star's job was to study and imitate her proxy. There is, then, both an exactness and a muddiness to performance-as-surrogation in this case: because Grable's performance depends quite literally on "trying out" the physicality of her stand-in, it is not clear who is the surrogate for whom. Standing in for her own dance-in, Grable inserts her body into the choreographic score Blue helped establish, even as Blue presumably rehearses that score as if she were Grable.

The claim that Grable's over-the-shoulder pose was an impersonation of Blue is especially striking, for this was the shot of Grable that was distributed as a pin-up poster to American servicemen across the globe as an emblem of white femininity worth protecting. Grable's most Grable-like image, that is, was the result of the star reproducing the corporeality of her uncredited dance-in. On one hand, this fact underscores the constructedness of whiteness and supports arguments like film scholar Sean Redmond's that whiteness only exists as "a trace, an imprint or an echo of itself." "Whiteness is a photograph of itself," he forcefully asserts. ${ }^{66}$ On the other hand, the recognition that this most iconic image of Grable bears the traces of Blue's body (or is it her flesh?) highlights the indexical ambiguity that inheres in whiteness-as-photograph. Indeed, parsing whom the "her" in the photo references is far from straightforward. ${ }^{67}$ If it would seem to matter very much that the photo indexes Grable's insured flesh, does it matter less that it also indexes Blue's corporeal shape? And lest we are tempted to locate the traces of Blue's presence in the silhouettes that also appear in the photo - a literalization of stand-ins' role as "star's shadows" ${ }^{168}$ - those shadows, as we shall see, 
index additional unseen flesh. Modifying Redmond, we might say that whiteness is a photograph of multiple corporealities that only appear to cohere as the singularity of "itself."

\section{The Other Betty}

As I have tried to suggest, attention to the role of the dance-in is useful precisely insofar as it muddies the question of whose bodies (or flesh) a star might be indexing. And because, in contrast to doubles, dance-ins don't typically take stars' place on screen, they invite us to think more broadly about the off-screen acts of surrogation and recorporealization - the emulating, the doubling, the blurring of physicalities - that are concealed behind bodies that seem self-referential and coherent. Rather than reify Blue as the sole pre-filmic source or "true" index of Grable's on-screen dancing body, in the remainder of this essay I want to situate both "hers" (Blue and Grable) within a longer chain of inter-racial, inter-corporeal reproductions.

Of course film choreographers, who were predominantly white men in the Golden Age of the Hollywood musical, were major players in the inter-corporeal exchanges that shaped on-screen bodies. ${ }^{69}$ But even if Pan's characterization of Blue as "putty"-like positions him as the sculptor of her flesh, to take his dancing body as a point of origin would be to overlook the African American sources that undergirded the formation of his corporeality. A 1991 profile of Pan in The Dancing Times opens with the following:

In 1915, when Hermes Pan was six years old, the family mammy, a big black woman who was called Aunt Betty, took the boy home with her one night to her apartment in the black ghetto of Nashville known, as it was in many cities in the American South, as Black Bottom. It was there that the child was first exposed to what was called "gut-bucket" jazz and the shuffles and footslapping dancing of the local black Americans. His reaction was an exhilaration which he recalled seventy years later, his eyes still lighting up with joy at the memory, as nothing short of "sensual." That was Pan's first exposure to what he knew as "dance." 


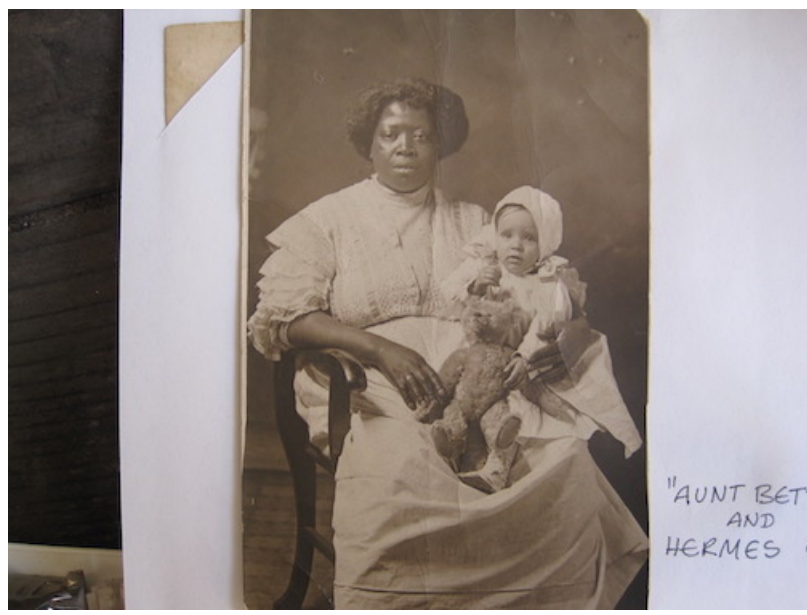

"Aunt" Betty and an infant Hermes Pan, circa 1910. From the Collection of Vasso Pan Meade.

This is by now a familiar story in American dance, proving once again Brenda Dixon Gottschild's argument about the Africanist influences on the development of all manner of U.S. dance genres..$^{71}$ But the presence of a "mammy" in the narrative of Pan's dance origins adds another layer to the story. A photograph of an infant Pan seated on the lap of his "Aunt" Betty, likely taken around 1910, appears in Franceschina's biography of Pan. ${ }^{72}$ These photographic and recollected traces of Aunt Betty are stark reminders of the centrality of another kind of surrogation to U.S. racial formations: the long history of black women serving as surrogate mothers for white children. They also return us again to Spillers, who begins her essay citing the litany of ways that black women in the U.S. have been marked, including as "Aunty." Such "confounded identities," she argues, construct bodily tropes out of black flesh and deprive black women of individualized personhood. ${ }^{73}$

In her critical analysis of shifting depictions of the mammy figure in U.S. culture, Kimberly Wallace-Sanders writes that the "mammy's body serves as a tendon between the races, connecting the muscle of African American slave labor with the skeletal power structure of white southern aristocracy. ${ }^{1174}$ In like manner, Aunt Betty serves as the connective tissue between black surrogate motherhood and the structures that enabled white reproductions of African American dance. For, as the anecdote about Pan's exposure to jazz dance goes on to note, Pan's first dance lesson entailed "imitating the steps" he and his sister "learned from the family's black houseboy, Tommy," who, according to some reports, was Betty's biological son. ${ }^{75}$ Pan's case thus exemplifies the collision of multiple kinds of surrogation and reproduction. This collision makes it possible to draw a line between the two Betty's: the Greek American Pan family's black domestic employee (not afforded a last name) and the white film star, who, in "doing Angie," was repeating a pattern of imitation with cross-racial antecedents. Looked at through this lens, Grable's famous pin-up posture - arms akimbo, leaning into one hip, shoulders twisted - becomes not only a coy, come-hither pose but an asymmetrical, Africanist one. ${ }^{76}$ Awareness of Pan's Aunt Betty, meanwhile, encourages us to train our 
eyes on the flesh of other black surrogates who were lurking in the shadows - and indexed by the on-screen images - of white film stars.

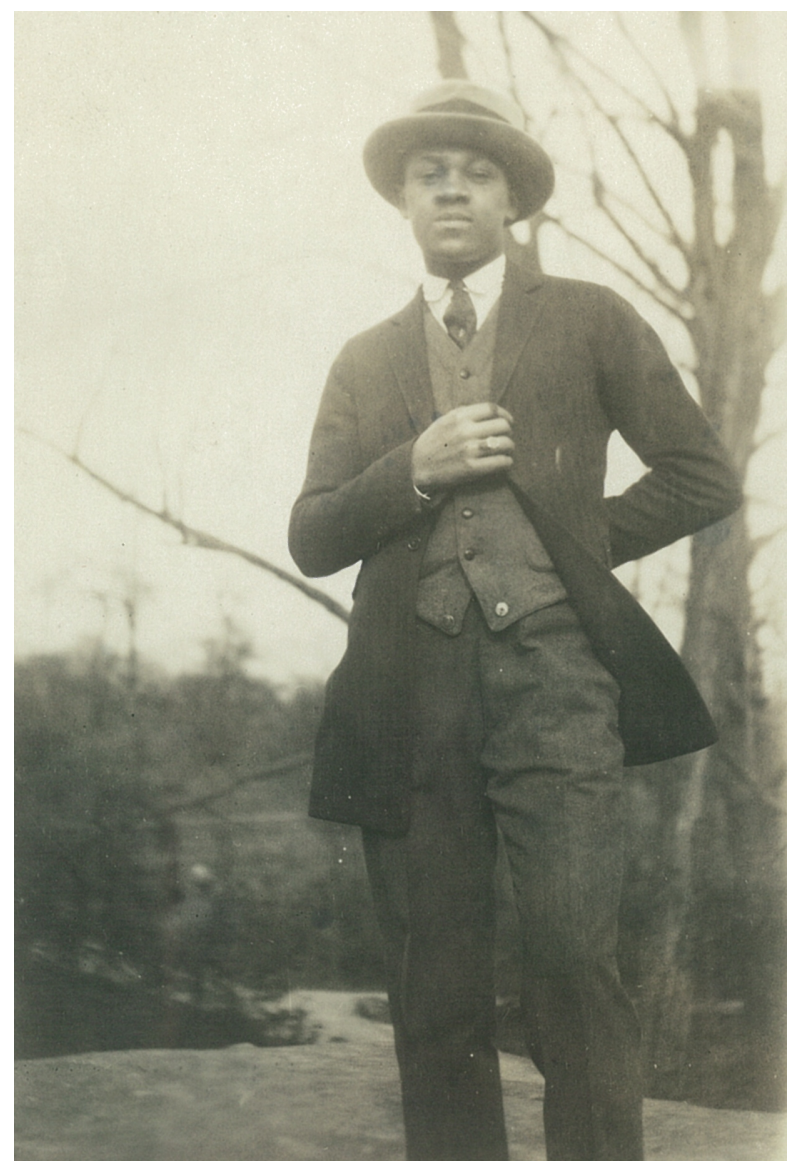

Sam Clark, Hermes Pan's first dance instructor. From the Collection of Vasso Pan Meade.

\section{Marie Bryant and Betty's Buns}

A little more digging reveals that, as Grable's career went on, her reproductions of black corporealities became increasingly direct. A three-part 1950 article in Ebony magazine discloses the pivotal behind-the-screen role played by the African American Marie Bryant (1919-1978) in Grable's later dance performances. A supremely talented dancer, as well as a singer and choreographer, Bryant toured with Duke Ellington, danced in the chorus of some Lena Horne films, and taught at dance schools run by Katherine Dunham and Eugene Loring. ${ }^{77}$ Ellington, Gene Kelly, and Hollywood dance director Nick Castle separately described her as one of the best dancers they had ever seen. ${ }^{78}$ Evidence of her skill survives on screen, such as her appearance in an uncredited role with Harold Nicholas in the 1944 film Carolina Blues. ${ }^{79}$

Proclaiming her the "first Negro to crack the technical side of Hollywood with the official title of assistant dance director," the feature in Ebony documents Bryant's work teaching dance routines to white Hollywood stars like Grable, Vera Ellen, Paulette Goddard, Ava 
Gardner, and Bob Hope, as well as teaching "more art and less come-on" to burlesque dancers. Bryant credited Gene Kelly with being the first to hire her to coach film performers. Grable and her husband evidently discovered Bryant when she was headlining at the Los Angeles Cotton Club; Grable subsequently asked Bryant to help stage dances for the 1950 film Wabash Avenue, whose choreography is credited to the white dance director Billy Daniel. Bryant also worked as an assistant dance director to Jack Cole on Grable's 1951 film Meet Me After the Show. ${ }^{80}$

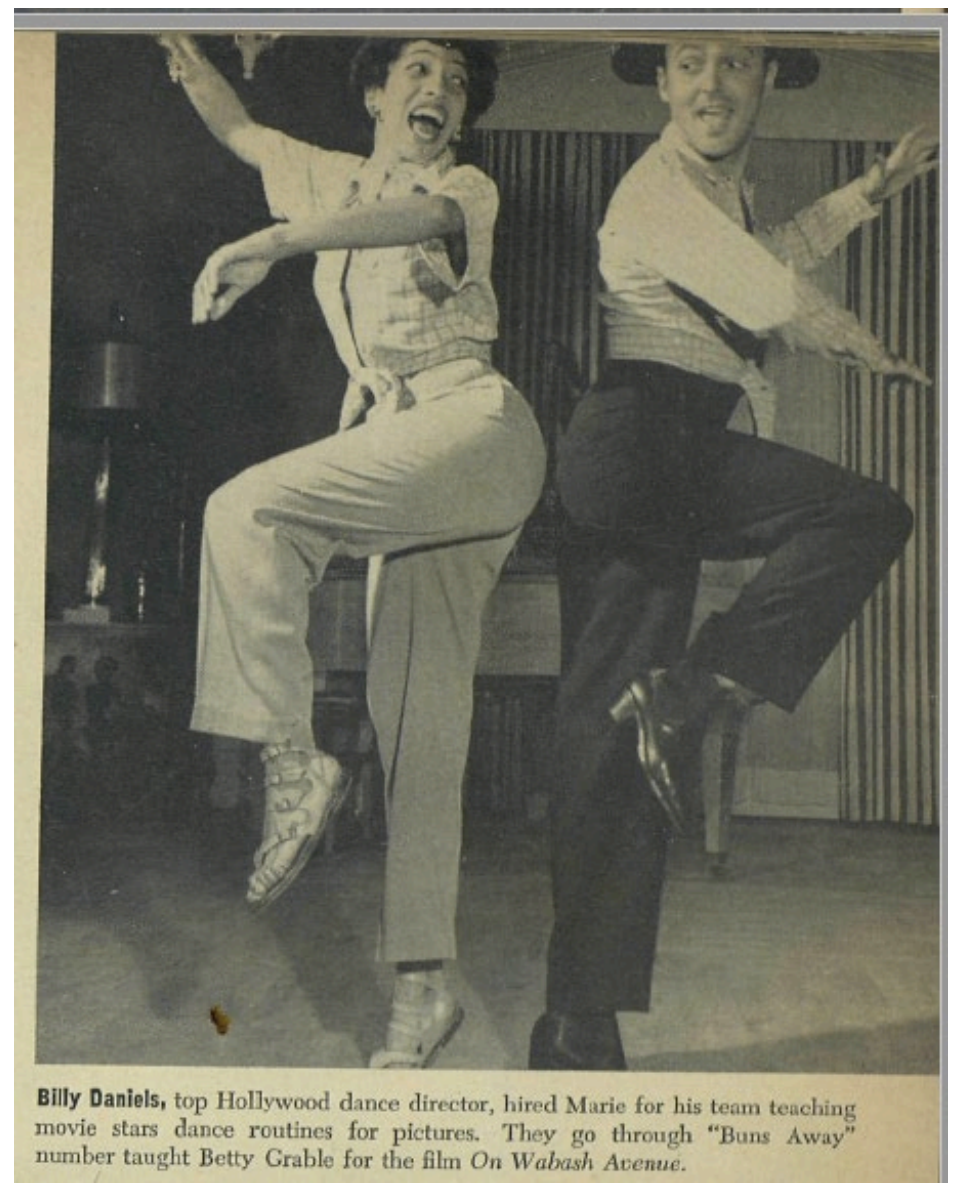

Bryant and Daniel (mis-labeled as Daniels). Credit: Ebony Magazine, Copyright (c) Johnson Publishing Company, Inc.

The third part of the feature in Ebony explains the nature of Bryant's work as assistant to Billy Daniel: "Marie, Daniels[sic] and his other assistant, Frances Grant, report on a picture, create the choreography for the stars. Then the three of them block out the steps, acting in place of the stars, who stand by, watching, then learning the dance routines. ${ }^{81}$ As described here, the relationship between choreographers and stars bears a striking resemblance to that between dance-ins and stars: dance directors perform terpsichorean motions until stars are ready to take their place. For anyone who has ever learned choreography, this description of observation, imitation, and place-swapping may well fall into the category of the obvious. But in spelling it out in this manner, Ebony 
calls attention to the surrogation that choreographic transmission - the act of transferring movement across flesh - entails. Choreographers perform as stars' surrogates; stars insert their bodies into places carved out by choreographers. Put another way, choreographers act as dance-ins, just as, in the case of Blue, dance-ins function as choreographers.

The Ebony spread also includes a series of photos of Bryant and the various stars with whom she worked. Among these are images of Bryant embracing Gene Kelly, in conversation with the actor Bob Hope and choreographer Nick Castle, and in rehearsal with Vera Ellen, Ava Gardner, and Billy Daniel. An additional three shots show white female stars in films on which Bryant coached them. There are also six photos of Bryant teaching a routine to a white burlesque dancer, and one of Bryant alone, demonstrating her "controlled release" technique of warming up the body, which she described as "finding the natural line of each body and the favorite ways it likes to move about - then controlling these movements." ${ }^{12}$

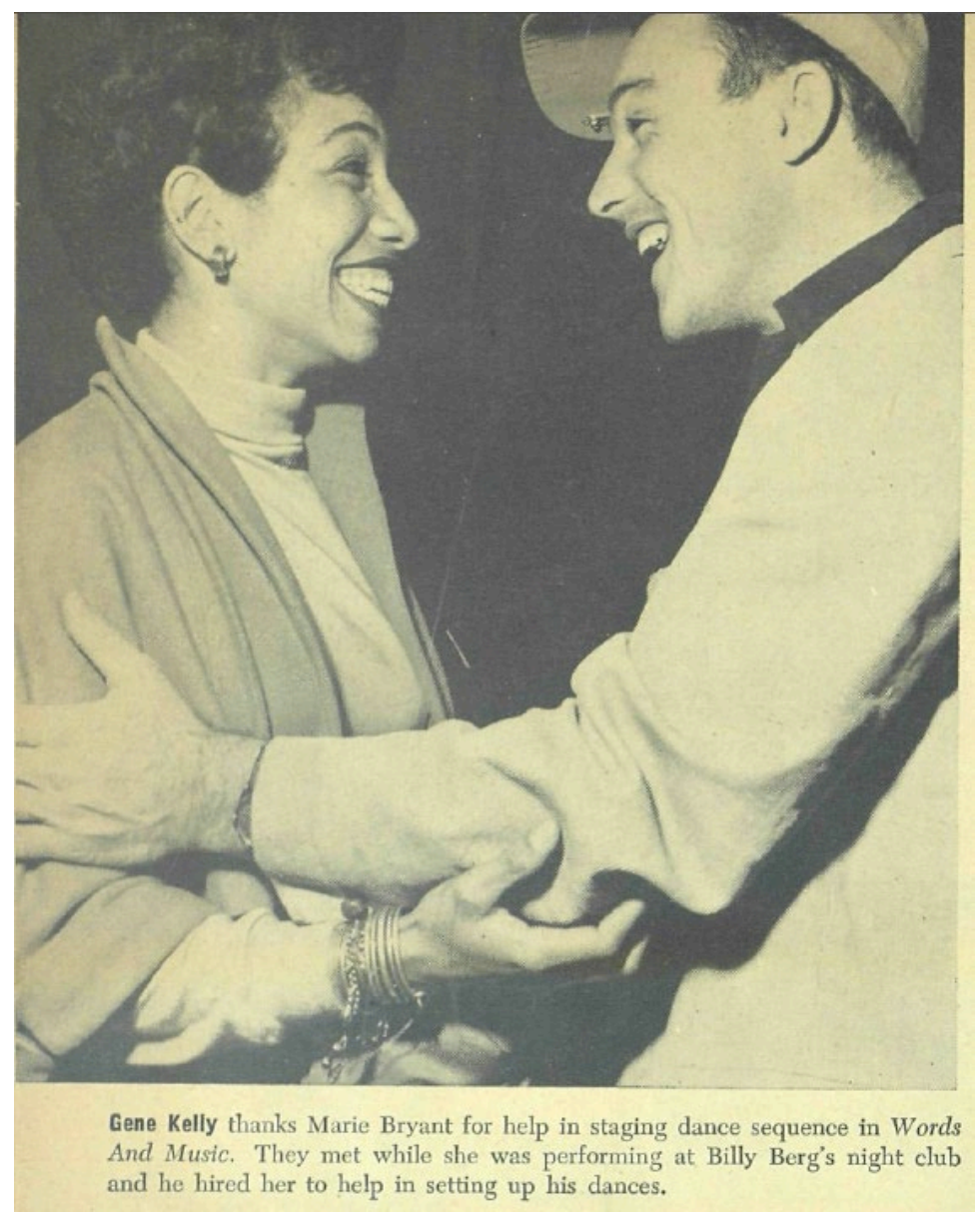

Bryant and Kelly. Credit: Ebony Magazine, Copyright $\odot$ Johnson Publishing Company, Inc. 


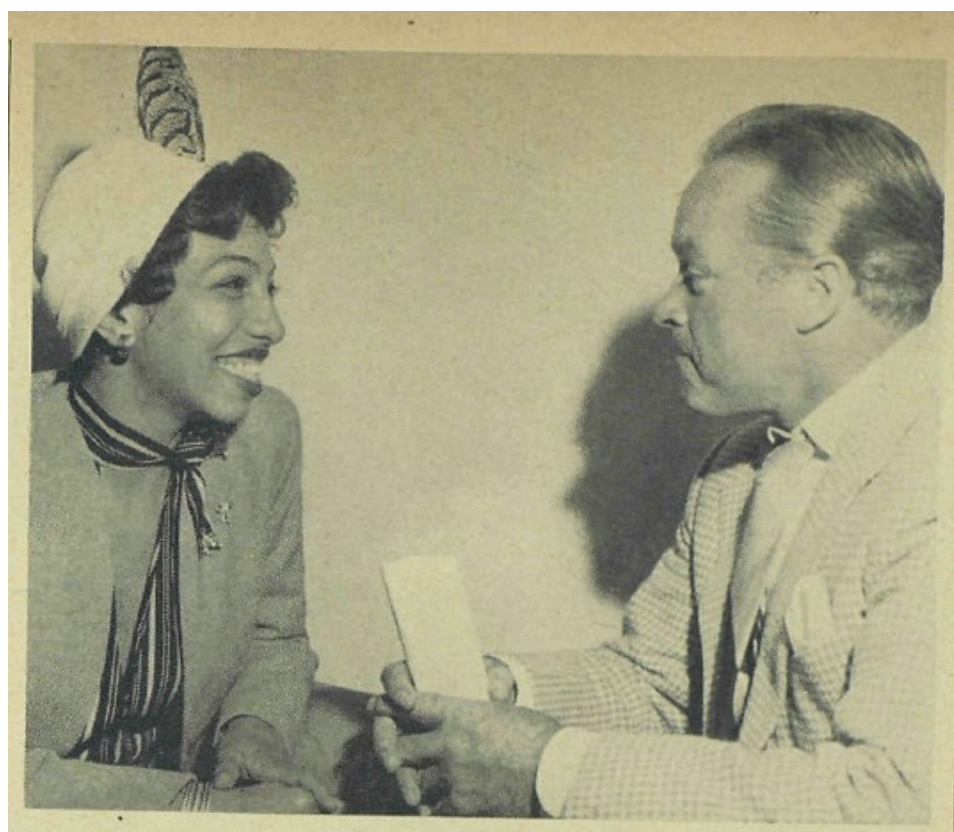

Bob Hope was assisted by Marie in staging Indian-Chinaman sequence in Fancy Pants. He still calls her Pocahontas. She started as dancer in Los Angeles club making $\$ 17$ a week in 1935 , worked with then unknown Lionel Hampton.

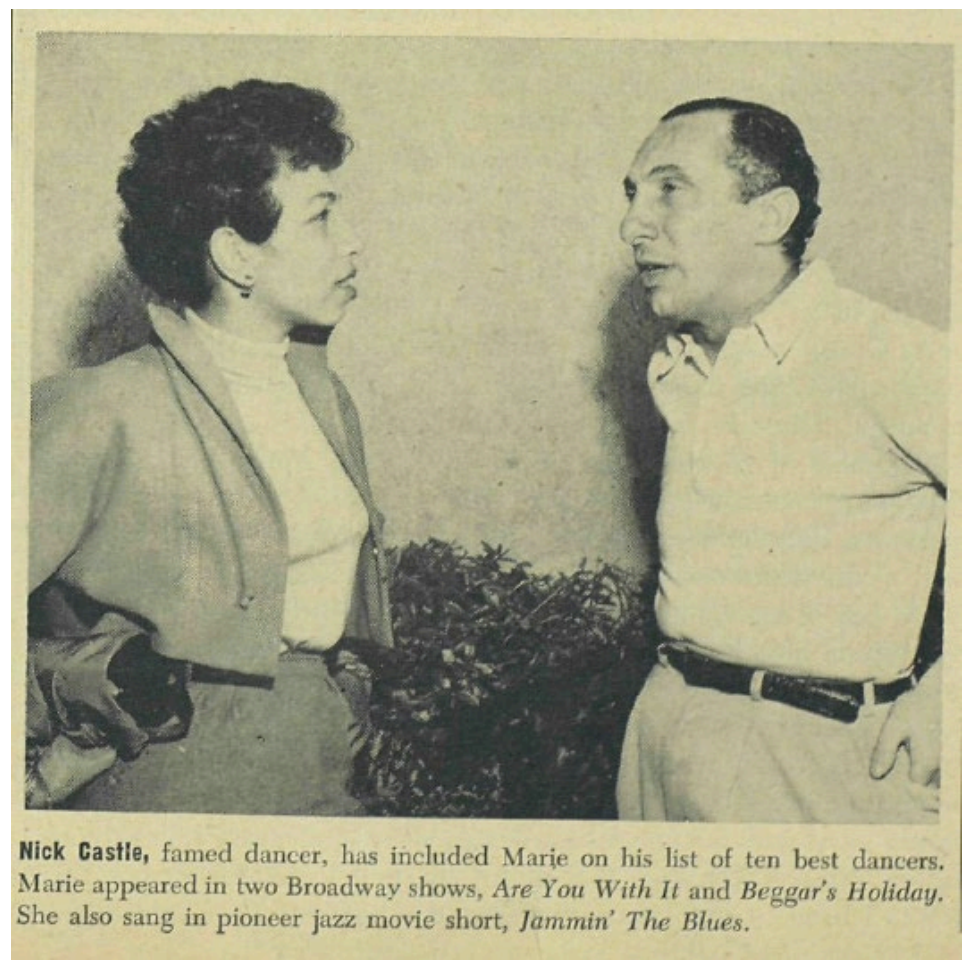

Bryant and Hope. Credit: Ebony Magazine, Copyright (c) Johnson Publishing Company, Inc.
Bryant and Castle. Credit: Ebony Magazine, Copyright (๑) Johnson Publishing Company, Inc. 


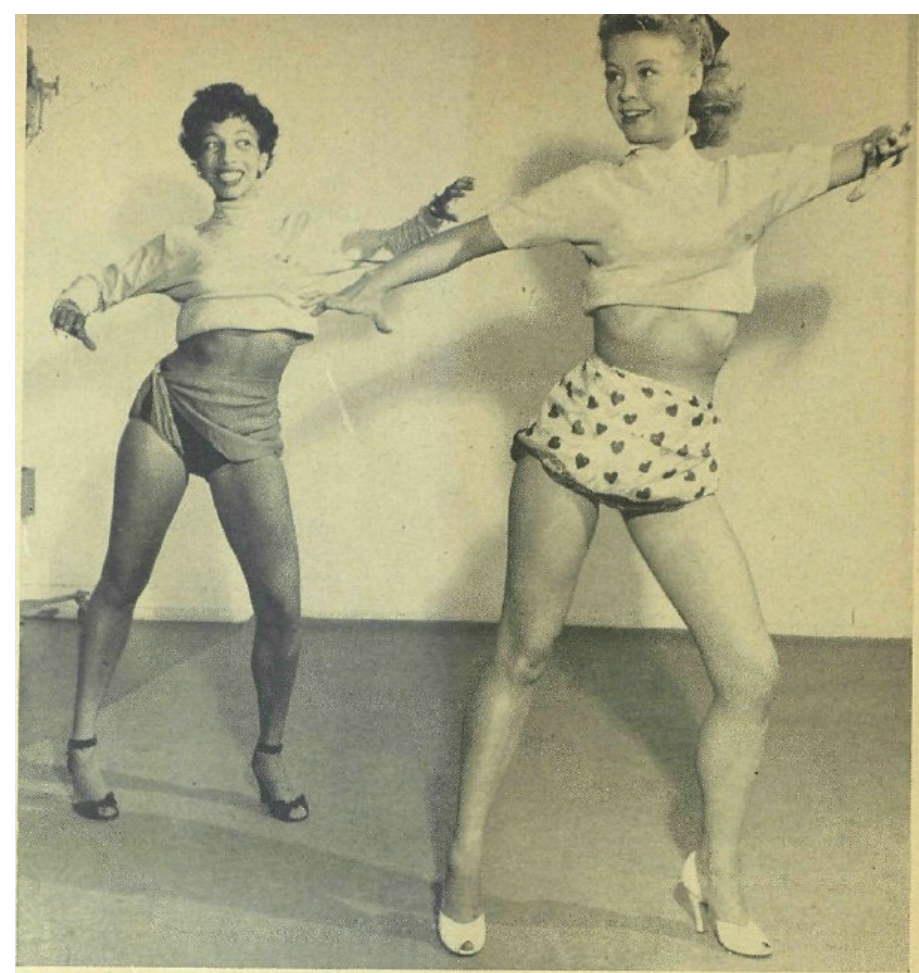

Vera Ellen, MGM star, goes through steps for "Slaughter On Tenth Avenue" number in Words And Music. Marie also did dances for Miss Ellen in Marx Brothers film, Love Happy. She currently has personal dancing and singing role in RKO's They Live By Night.

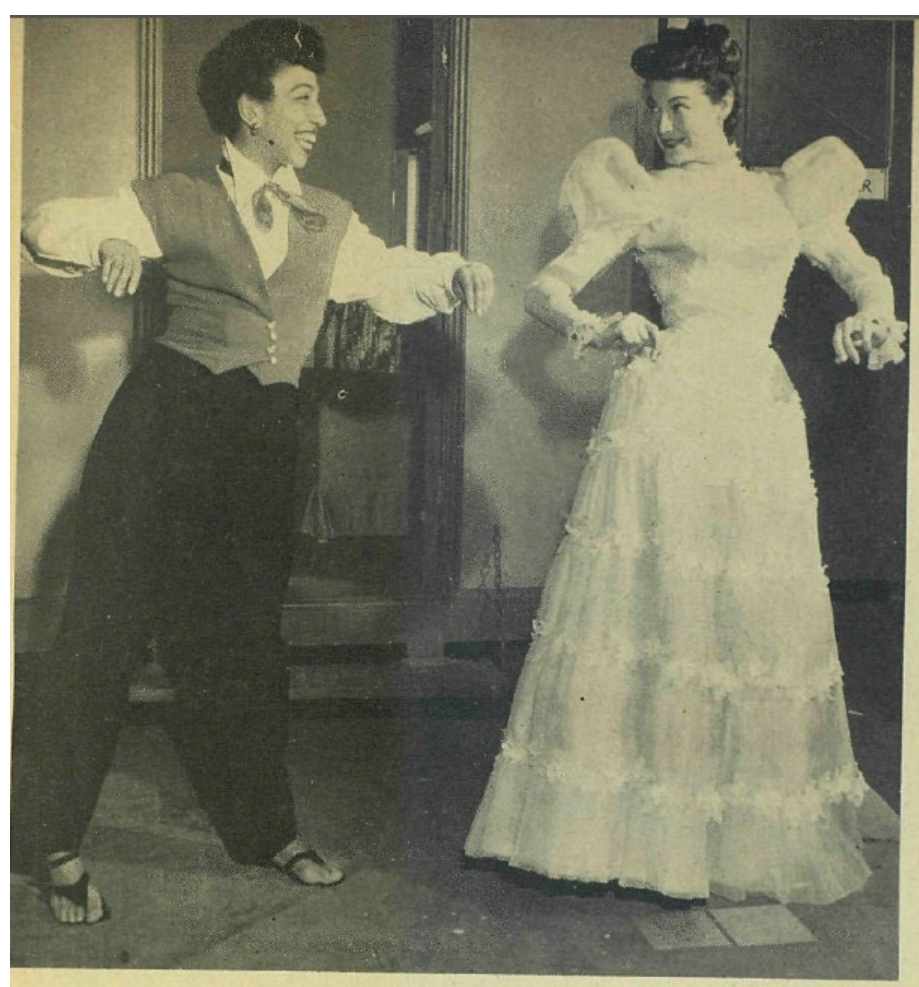

Ava Gardner is regular pupil of Marie's, picked up unusual ease and agility in costume clothes for her part in Carriage Entrance. Marie teaches class of Hollywood wives including Mrs. John Garfield and Mrs. Richard Conte. She charges stars \$15 an hour.
Bryant and Vera Ellen. Credit: Ebony Magazine, Copyright () Johnson Publishing Company, Inc.

Bryant and Gardner. Credit: Ebony Magazine, Copyright @ $\odot$ Johnson Publishing Company, Inc. 


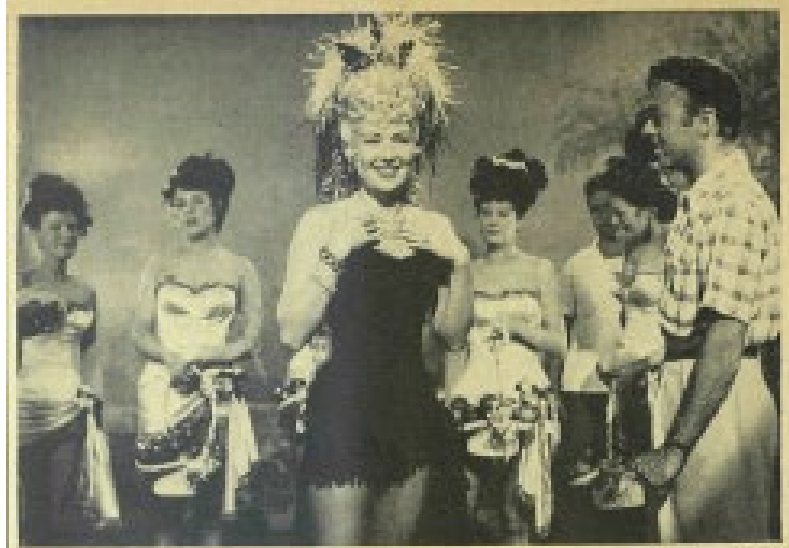

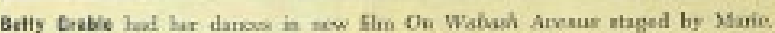

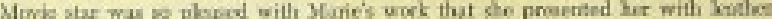

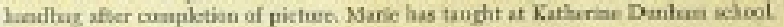

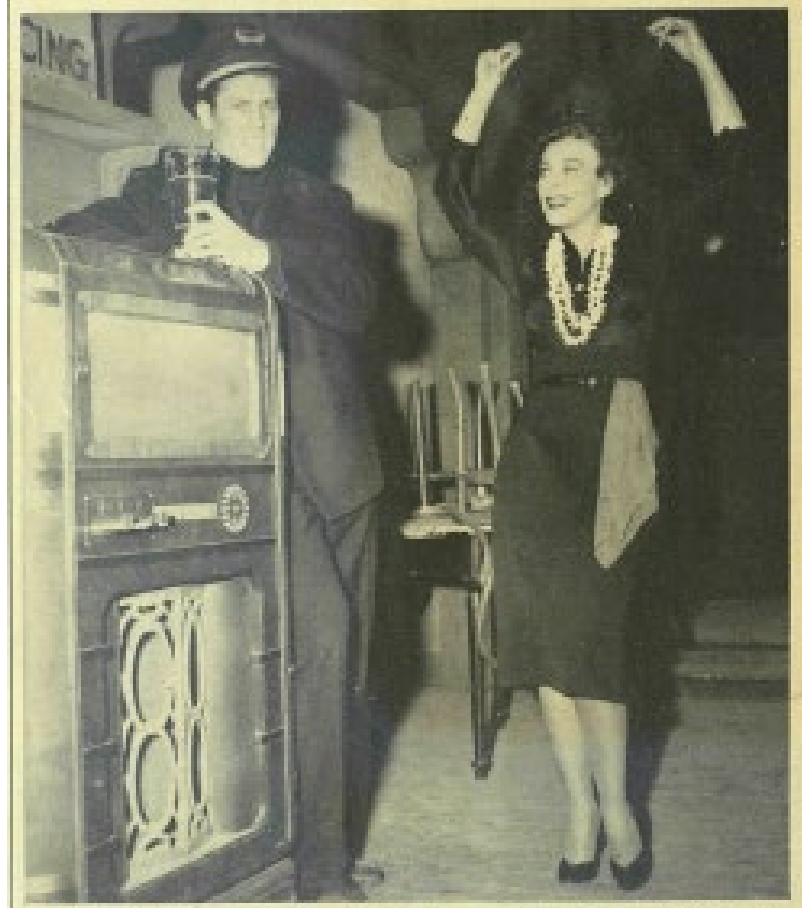

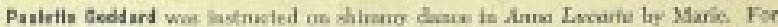

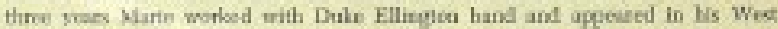

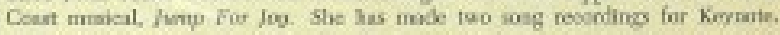

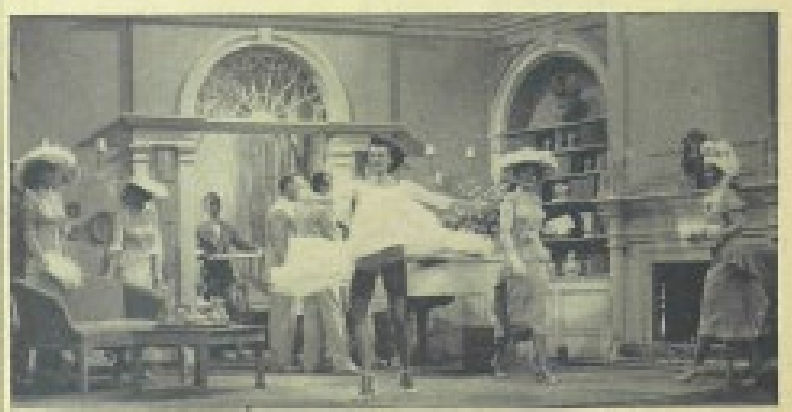

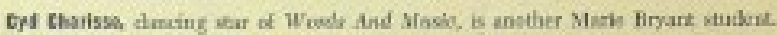

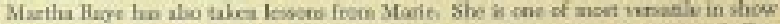
besines-singisg asd actiog besdes dancien evirythity fruen looge to bolles.
Stars Coached by Bryant (Betty Grable, Paulette Goddard, and Cyd Charisse). Credit: Ebony Magazine, Copyright (o) Johnson Publishing Company, Inc. 


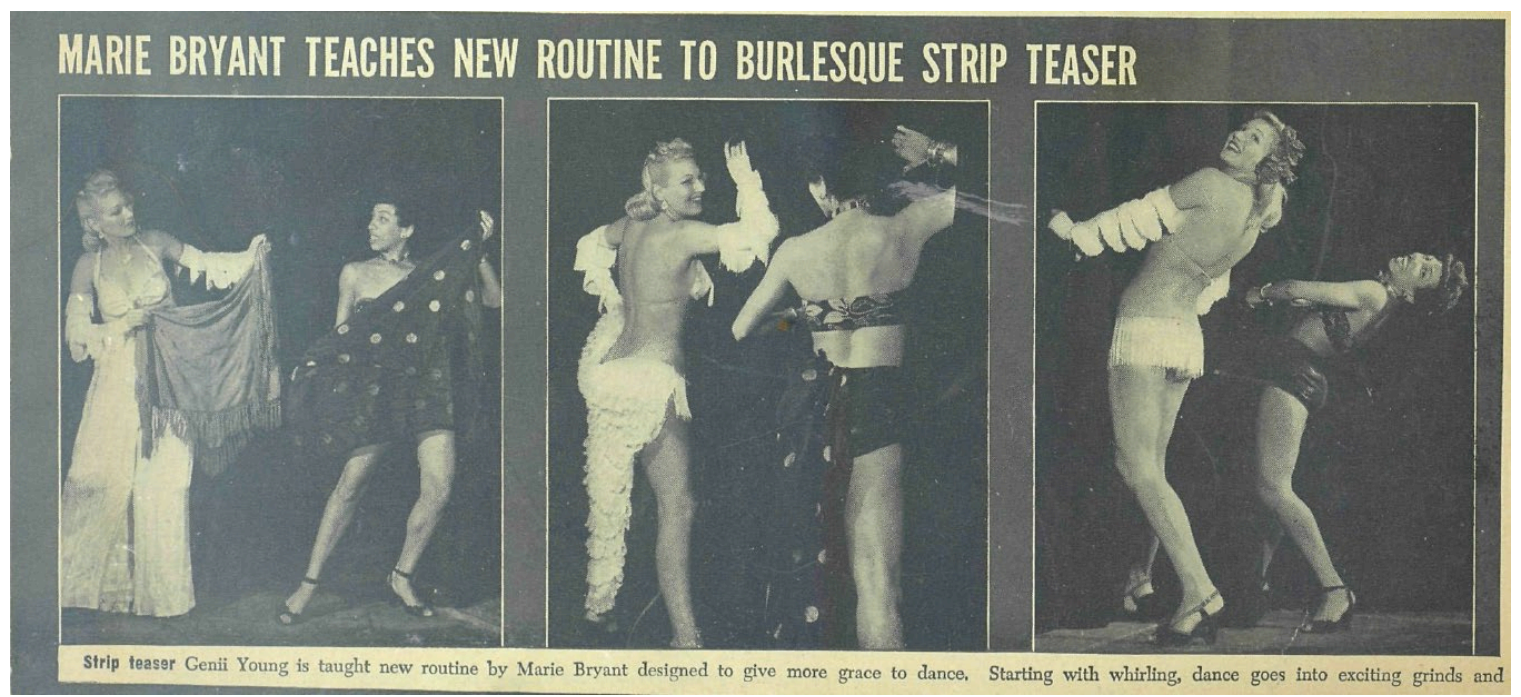

"Bryant Teaches New Routine to Burlesque Strip Teaser." Credit: Ebony Magazine, Copyright @ Johnson Publishing Company, Inc.

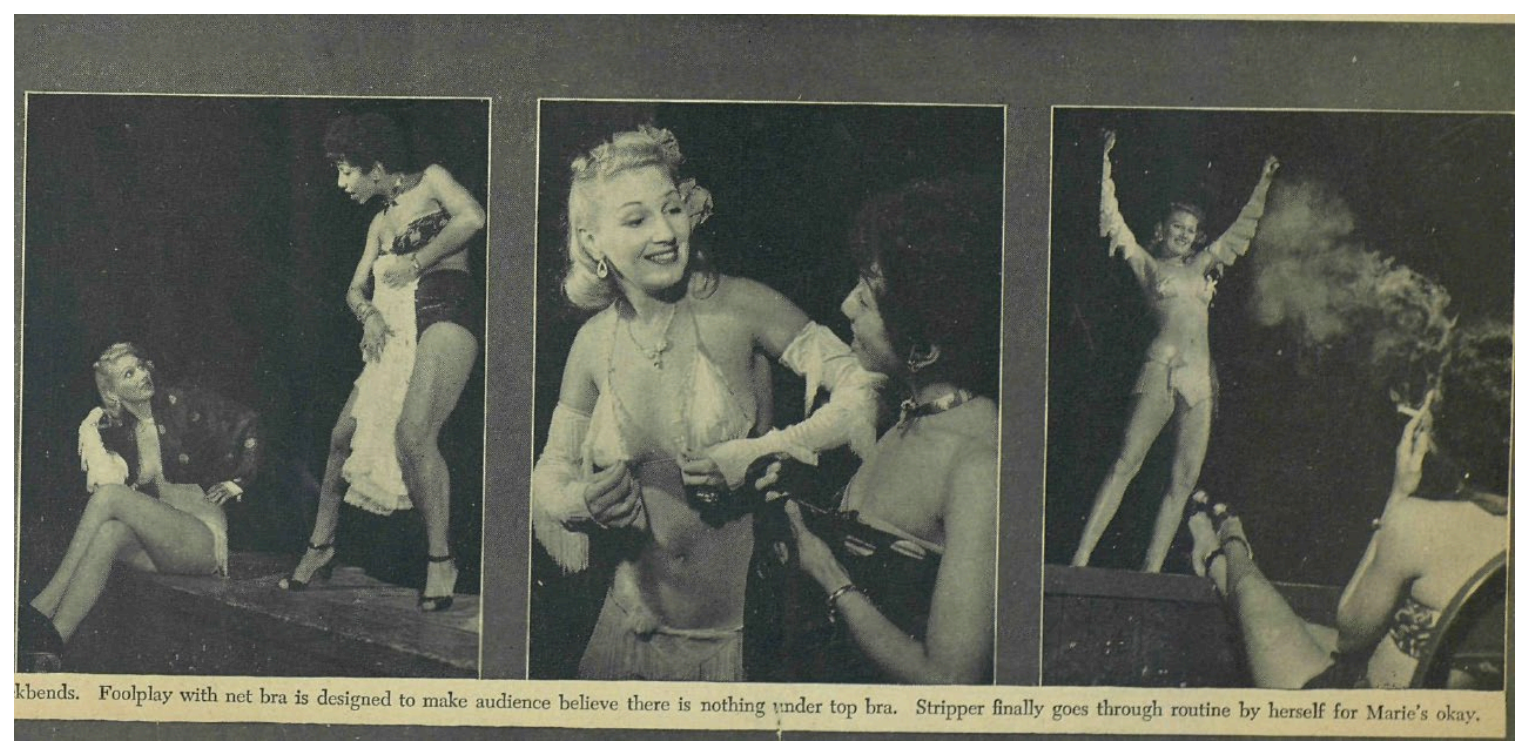

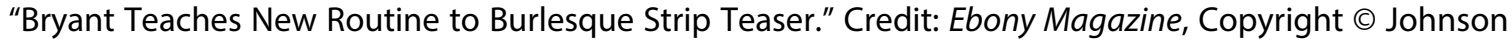
Publishing Company, Inc. 


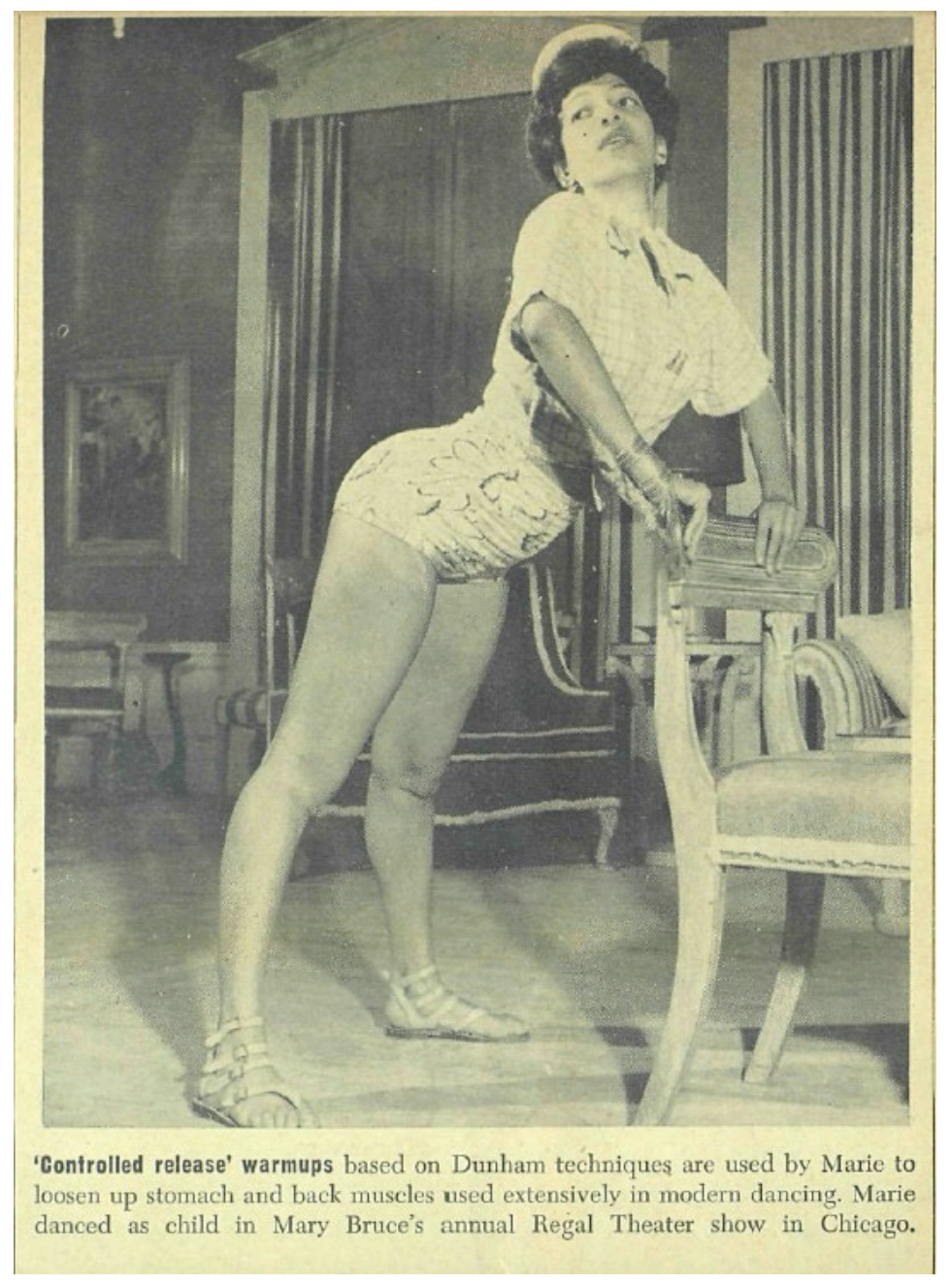

Bryant Demonstrates her "Controlled Release" technique. Credit: Ebony Magazine, Copyright (c) Johnson Publishing Company, Inc.

These images serve as powerful visual evidence of Bryant's position within Hollywood's dance economy. In the sequence with the burlesque dancer, Bryant is clearly the authoritative, "demonstrative body, ${ }^{183}$ giving movement to, instructing, and observing her pupil. The other photos are particularly fascinating because of the ways the black Bryant and the white Hollywood stars double one another. In the action shots, Vera Ellen, Ava Gardner, and Billy Daniel either mirror or echo Bryant's physicality almost exactly, even if they don't quite achieve her angularity. And in the still shots, Bryant's body language is virtually identical to that of Kelly, Hope, and Castle. What all of this doubling registers is transmission: the exchange of smiles, of thoughtful conversation, and, most crucially, of movement, between black body and white. 


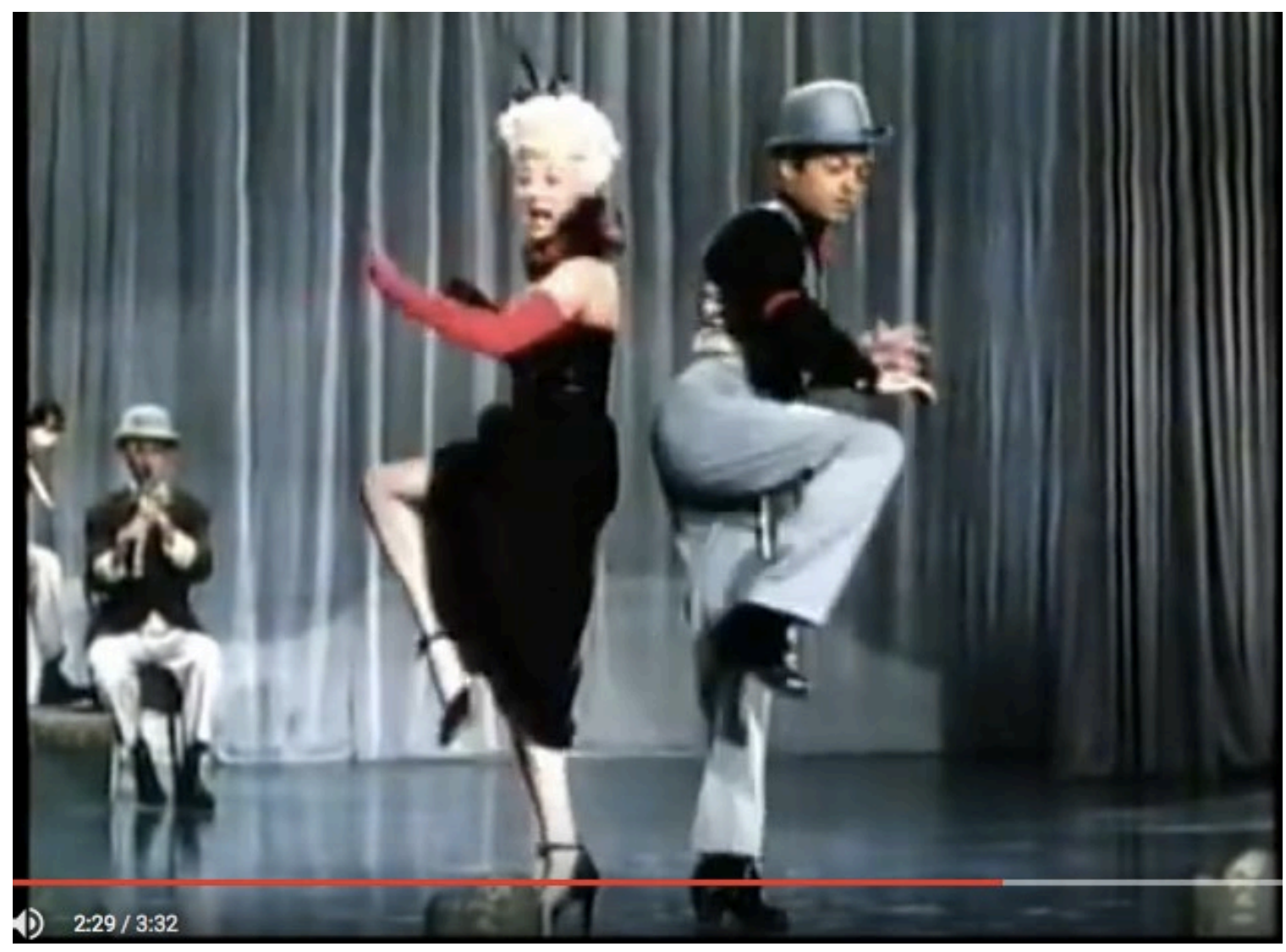

Screencapture of Grable and Daniel in Wabash Avenue. Note the comparison with Bryant and Daniel above.

But these photographs are as much documents of surrogation as of doubling and exchange. That is, they teach us to see Bryant's presence where she is ostensibly absent and, in turn, to read white star bodies not as autonomous and self-contained but as relational, malleable, and indexical of black corporeality. This is especially clear in the image of Bryant partnering Daniel: in the film version of the scene pictured, "Buns Away" from Wabash Avenue, Grable has taken Bryant's place. But it is also true for the images in which Bryant does not (visually) appear at all. Even in the absence of credit or onscreen visibility, the article and photographs suggest, white female stars' dancing bodies refer back to Bryant. Here, again, we may see whiteness as photograph-like insofar as it is a document of absent presences. But what whiteness-as-photograph depicts is not "itself" but an assemblage of physicalities.

According to Daniel in the Ebony feature, one of Grable's body parts in particular bore the traces of Bryant's training efforts. "During work at 20th," he told the magazine, "Marie was teaching Betty Grable a hard routine. After a couple of tries, Betty started to do such a fine dance that Marie suddenly yelled at her, 'That's it, Betty! Those buns are great! Oh those buns!"'"84 At a time when the Arthur Murray Dance School warned (white) ballroom dancers not to emphasize the backside, and amid a legacy of white 
objectification of black female bottoms, Bryant reverses the white gaze as she works to cultivate an explicitly Africanist aesthetic in Grable. ${ }^{85}$ The same flesh that comprised part of Grable's most distinguishable and valuable feature was thus no less inter-corporeal than the rest of her terpsichorean motions.

So, what to make of all this? What are the implications of understanding doubling, surrogation, and recorporealization as part of the technology that produced Grable's on-screen white femininity, and what difference does it make to see her iconic white femininity as indexical of both white and black dance-ins and coaches? To start with, knowledge of these off-screen acts of surrogation can help us read dance on screen differently. Not only can we learn to perceive Grable's dancing body as indexical of something other than "herself," but we can also learn to detect signs of the work required to uphold the façade of the white body's boundedness and singularity. As Roach reminds us, surrogation is an operation that often generates anxiety and a complicated oscillation between remembering and forgetting. One way this anxiety can materialize in performance is in the form of a "momentary self-consciousness," in which an "alien double... appear[s] in memory only to disappear." 86

We should not be surprised, then, that both Blue and Bryant appear fleetingly onscreen with Grable. Blue, of course, was a chorus girl in a number of Grable's films, but it is difficult if not impossible to single her out among the background dancers. In the 1944 film Pin-Up Girl, however, Blue has a featured though uncredited role dancing with choreographer Hermes Pan. In what has been described as an "apache blues number" (although they are not technically dancing an apache dance), Blue, wearing a brunette wig - presumably to distinguish her from Grable - saunters on the stage-within-the-film and begins a seductive dance with Pan, before Grable begins to sing from a balcony, sending Blue off stage left. We might say that the footage momentarily remembers Blue as Grable's surrogate so that we can forget that Grable is also Blue's surrogate insofar as she is "doing Angie." That Grable is less of a dancer than Blue - her performance is competent but somewhat stiff - only highlights the way the surrogate's fit can never "be exact." 88 


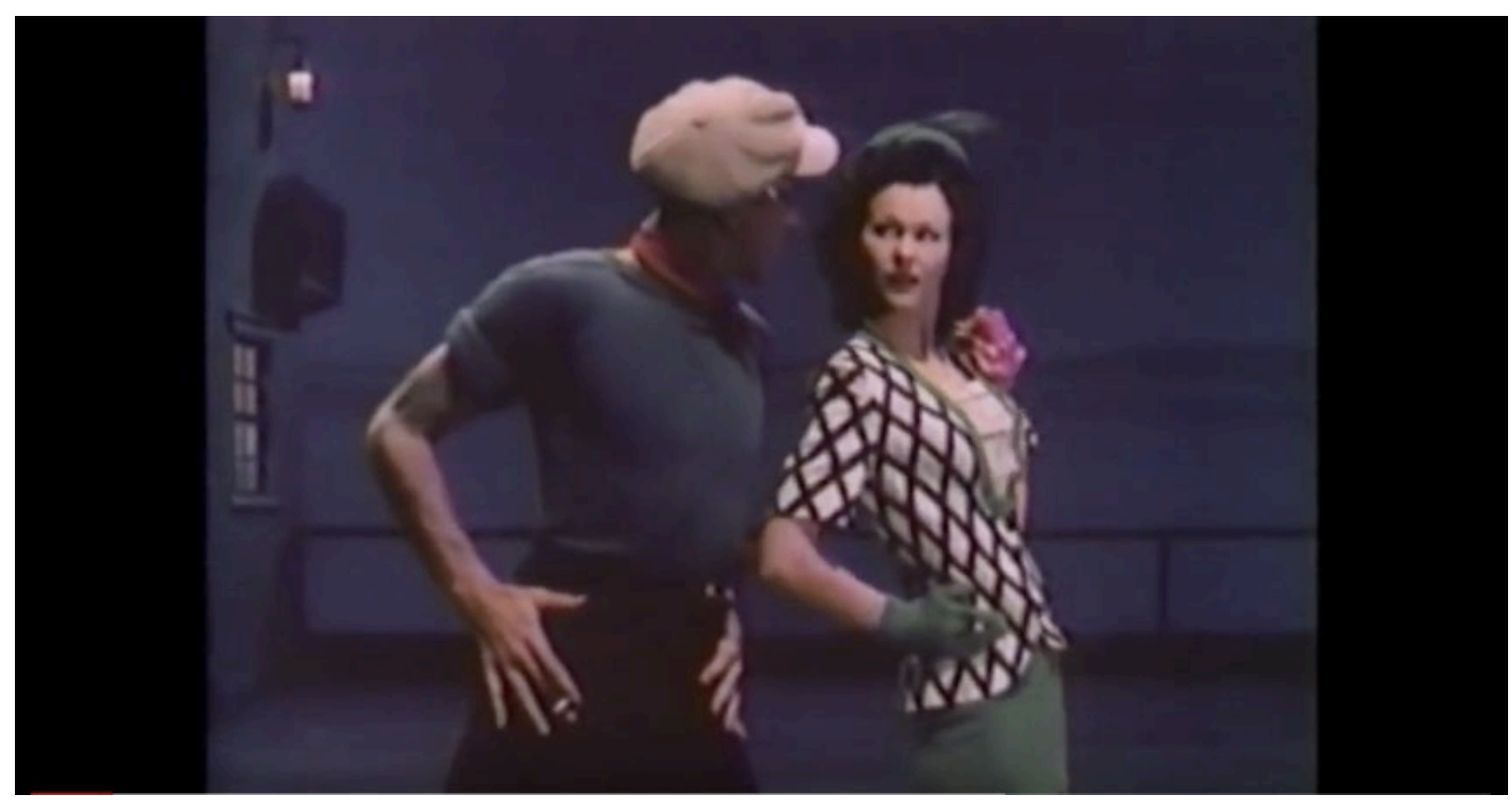

Screenshot, Angie Blue and Hermes Pan in Pin-Up Girl.

Marie Bryant's on-screen performance with Grable, in contrast, establishes that not all surrogates are remembered and forgotten in the same way. In the 1950 film Wabash Avenue, Bryant shares the screen with Grable in a credited but non-dancing role, as Elsa, Grable's character's maid. The star and dancer/choreographer appear together in two scenes: one in Grable's dressing room, and one backstage, just after Grable has finished a musical performance. In the latter, Bryant greets Grable's character with a fawning "Oh, Miss Ruby" as Grable walks off stage, thrusts her bouquet of flowers at Bryant, and walks right past her. Bryant's presence is so brief that it's easily missed. Certainly, Grable hardly sees her. The one-sided transmission captured on screen - the hand-off of flowers from Grable to Bryant, Bryant's unreturned gaze - is almost exactly the converse of the exchanges documented in the Ebony coverage, in which white stars solicit Bryant, eye contact is returned, and white bodies look to and learn from Bryant. There is almost a violence to the way that Bryant is remembered on-screen that intimates an urgency to forgetting that Bryant stood for a time in Grable's place and served as her choreographer and coach on this very film. This violence suggests that, as much as surrogation may have been a necessary pre-condition of the white dancing film star's emergence on screen, it demanded considerable policing. It also reconfirms Keeling's insight about how fraught the issue of indexicality is even in pre-digital film: the image of blackness here completely fails to represent the off-screen relationship between Bryant and Grable, even as that on-screen portrayal serves to uphold the fiction that Grable's image is a faithful representation of her inherent physicality. ${ }^{89}$ The white female body that circulates via the screen smoothes over and erases even as it unwittingly indexes the corporeal exchanges and substitutions that preceded and produced it. 
Under this light, the white incorporation that Cherniavsky theorizes as the privileged form of embodiment is clearly exposed as a myth, a myth that the technology of the dance-in both explodes and preserves. The body of the white female dancing film star is not just at risk of dispersal; it is already dispersed, already an assemblage of others' terpsichorean motions and teachings. The privilege of white corporeality, then, lies simultaneously in the right to reproduce others' motions and the right to conceal those reproductions. It lies simultaneously in the right to occupy the position that others have saved for you and to dis-place those who have stood and danced in your place. It lies in the right to choose when to return your surrogate's gaze and when to refuse to see. It lies in the right to appear autonomous and original when the flesh that your own body indexes is staring you in the face.

\section{Biography}

Anthea Kraut is Professor in the Department of Dance at UC Riverside. She is the author of Choreographing the Folk: The Dance Stagings of Zora Neale Hurston (University of Minnesota Press, 2008) and Choreographing Copyright: Race, Gender, and Intellectual Property Rights in American Dance (Oxford University Press, 2015), as well as essays that have appeared in The Oxford Handbook of Critical Improvisation Studies, The Oxford Handbook of Dance and Reeanctment, The Routledge Dance Studies Reader, and Worlding Dance, Theatre Journal, Dance Research Journal, Women \& Performance: a journal of feminist theory, The Scholar \& Feminist Online, and Theatre Studies.

Email: anthea.kraut@ucr.edu

\section{Notes}


1 "Dance Stand-in." I wish to express my gratitude to two anonymous reviewers, as well as to editor Harmony Bench, whose feedback and encouragement made this essay much stronger than it otherwise would have been. Any and all errors and oversights are completely my own.

2 Jerome Delameter, Dance in the Hollywood Musical.

${ }^{3}$ Anthony Slide, Hollywood Unknowns, 3; Ann Chisholm, "Missing Persons," 124.

${ }^{4}$ Chisholm, 127. Both Chisholm and Slide tell us that stand-ins became commonplace in the 1930s. A 1938 article in Colliers reports that stand-ins originated with Polish silent film actress Pola Negri, who "couldn't stand still long enough for the electricians to spot their lights or the cameramen to focus, so the director, out of sheer necessity, resorted to a dummy for all preliminary work." Grover Jones, "Star Shadows," 46.

${ }^{5}$ Chisholm, 128, 125.

${ }^{6}$ As Chisholm writes, "the pervasiveness of doubling nearly always was shrouded or contained by industry publicity releases" (128).

${ }^{7}$ The use of dance doubles in film evidently preceded the use of dance-ins. A 1925 article in the Los Angeles Daily Times reported that white silent film star Blanche Sweet "never requires the service of a double in scenes where she is called upon to execute difficult solo dances." "Blanche Sweet Never Requires Dance Double."

${ }^{8}$ See, for example, Wendy Perron, "Black Swan Blackout," and Randy Schmeltzer, "'Black Swan' Blasted." In what was no doubt an effort to avoid a similar controversy, Twentieth Century Fox was much more transparent about the dance doubling work that American Ballet Theatre's Isabella Boylston did for Jennifer Lawrence in the 2018 film Red Sparrow. See Pia Catton, "It's Hard Work."

"Slide notes that some stand-ins went on to be performers "in their own right" (119), and, as I will discuss below, some dance-ins did appear on screen as extras and chorus dancers.

${ }^{10}$ My sincere thanks to Yumi Pak for encouraging me in a much earlier presentation of this research to dwell on this ambiguity.

${ }^{11}$ In their "Editors' note" to Volume 5 of this journal, Harmony Bench and Simon Ellis refer to "[s]creendance's development as a hybrid discipline." See also Douglas Rosenberg, Screendance, 2, 11; Selby Wynn Schwartz, "Light, Shadow, Screendance," 205.

${ }^{12}$ Sherril Dodds, Dance on Screen, 29, 170-71, 174.

${ }^{13}$ Rosenberg, Screendance, 55. 
${ }^{14}$ Addie Tsai, "Hybrid Texts."

${ }^{15}$ White stars were not the only ones to rely on "supplementary bodies." Despite African Americans' too-frequent omission from academic discourse on stardom, and despite the massive barriers created by Jim Crow racism, the handful of African Americans who managed to become film stars also depended on stand-ins and doubles to help produce the gendered and racialized representations that appeared on screen. Jeni Le Gon, for example, both choreographed and served as a dance-in for Lena Horne in the number "Sping" in the 1942 film Panama Hattie. LeGon actually received a contract with MGM before Horne but was dropped because she was perceived to be a threat to the white tap dancer Eleanor Powell, also under contract with MGM. See James Gavin, Stormy Weather, 107, and Nadine George-Graves, "Identity Politics and Political Will." In addition, an African American performer named Millie Monroe served as Horne's stand-in for Cabin in the Sky. See "Film Beauty." I have also found evidence that, in one shot in the 1945 film Pillow to Post, the African American actor/dancer Louise Franklin doubled for Dorothy Dandridge when Dandridge was unavailable. "Newcomer Doubles for Dot Dandridge;" Harry Levette, "Dorothy Dandridge Hurt." A 1946 article in Ebony magazine by Avanelle Harris, an aspiring film star who had appeared in uncredited dance roles in films for years and also served as a stand-in for Horne, offers a scathing account of the obstacles African American dancers faced in Hollywood. Alternately deemed too light-skinned and too dark-skinned, losing roles to white women who were artificially darkened to play exotic Others, Harris and her colleagues made the "bitter" discovery that Lena Horne's success did not ultimately translate to more opportunities for them. Avanelle Harris, "I Tried to Crash the Movies." Harris's report is a particularly poignant illustration of scholar Miriam Petty's argument that African American performers had only the most "limited access within Hollywood's economy of power and resources." Petty, Stealing the Show, 5. My argument, then, is not that dance-ins were productive solely of whiteness. Rather, I'm interested in how the acts of substitution between white stars and their dance-ins can help expose the workings of white privilege. By a similar token, although male movie stars, too, relied on dance-ins, my focus here is on how dance-ins supported the production of white femininity.

${ }^{16}$ Sima Belmar, "Behind the Screens."

${ }^{17}$ Rosenberg, Oxford Handbook, 1.

${ }^{18}$ As Beth Genné writes in her recent Dance Me a Song, at its peak in the middle of the twentieth century, the Hollywood studio system possessed "vast and deep human and technical resources," many of whom "remained buried in the opening credits or went entirely uncredited." These included dance assistants "who performed a variety of tasks" and "acted as partners" to choreographers. Genné, 7. 
${ }^{19}$ I refer here to Brenda Dixon Gottschild's pioneering work on the Africanist influences on American dance performance. See Digging the Africanist Presence. For examples of the Africanist influences on celebrated Hollywood choreographers like Gene Kelly, Jack Cole, and Bob Fosse, see Clover, "Dancin' in the Rain;" Hill, "From Bharata Natyam to Bop;" and Gottschild, The Black Dancing Body, 175. I address choreographer Hermes Pan's indebtedness to black dance sources a bit later in this essay.

${ }^{20}$ Toni Morrison, The Bluest Eye; Ann duCille, "The Shirley Temple of my Familiar;" James Snead, "Shirley Temple;" Kristen Hatch, Shirley Temple.

${ }^{21}$ My thanks to an audience member at The Ohio State University, where I gave an earlier version of this paper, for asking how child labor laws may have driven the need for Temple's dancing stand-in. On the degree to which child-labor laws affected Temple, see Anne Edwards, Shirley Temple. Although it was not until 1938 that the Fair Labor Standards Act placed limitations on child labor, in her autobiography, Child Star, Shirley Temple Black writes that stand-ins "made good business sense" for the studios because California state law "limited[her] to four hours work each day, plus the three hours of school." Black, 63.

${ }^{22}$ Theresa De Lauretis, Technologies of Gender, 3, 2.

${ }^{23}$ As Daniel Bernardi acknowledges, "racist practices dominate the industrial, representational, and narrational history of the medium." Bernardi The Birth of Whiteness, 4-5. See also Bernardi, Classic Hollywood, Classic Whiteness, and volume 9 of The International Journal of Screendance, which is devoted to interrogating the "assumed heteronormative, white space of the screen."

${ }^{24}$ Richard Dyer, White, 83, 122-42.

${ }^{25}$ Dan Mainwaring, "Hollywood Nobodies," 137. A 1938 article in Colliers likewise observed that "many stand-ins resemble their stars so much that they can also double for them" (Jones, "Hollywood Nobodies," 44). This has not always been the case for black actors, however. Dyer cites an example of a white woman standing in for Cicely Tyson during production of the 1976 film The Blue Bird with disastrous results. Dyer, 97. Similarly, in the fall of 2014, the Warner Bros. (WB) television show "Gotham" generated controversy when it was discovered that they had employed a white stunt woman to double for an African American guest star. Engaging in a practice known as "painting down," apparently Hollywood's preferred term for blackface, the stuntwoman had "dark makeup applied to the face, in a hair and makeup test, in advance of two days of filming in New York" before public outrage caused the WB to hire a black stunt woman and apologize for their "error." As the Screen Actors GuildAmerican Federation of Television and Radio Artists (SAG-AFTRA) contract governing stunt doubles states, "When the stunt performer doubles for a role which is identifiable as female and/or black, Hispanic, Asian Pacific or Native American, and the 
race and/or sex of the double is also identifiable, stunt coordinator shall endeavor to cast qualified persons of the same sex and/or race involved...."

http://deadline.com/2014/10/gotham-stunt-woman-blackface-warner-bros-848969. Accessed July 8, 2015.

${ }^{26}$ Thus far, I have not discovered Harper's name in any other sources on Temple's career. Biographer Edwards lists Marilyn Granas and Mary Lou Islieb as Temple's standins (77), as do Slide (127) and Black (70). It is possible that the Los Angeles Times mistakenly identified Granas as Harper. In her autobiography, Temple describes Granas as "someone I vaguely recalled from our ranks at Meglin's." Black, 63.

${ }^{27}$ The clip is available here: http://www.historicfilms.com/tapes/53371. Accessed June 26, 2018. According to the Los Angeles Times, when Meglin Kiddies founder Ethel Meglin merged her dance studios with two other organizations in 1936, she "presided over what was believed the largest dance organization in the nation-137 schools." Burt A. Folkart, "E. Meglin, 93." Judy Garland also got her start at the Meglin Dance Studio. For more on the Meglin Studios, see Edwards, 28-30; and Black,1, 5-6.

${ }^{28}$ On the ways African American performers have defined and "stolen" stardom on different terms from the white establishment, see Arthur Knight, "Star Dances," and Petty.

${ }^{29}$ Joseph Roach, Cities of the Dead, 3.

${ }^{30}$ Idem, 80, 2.

${ }^{31}$ Diana Taylor, The Archive and the Repertoire, 46.

${ }^{32}$ Gottschild, Digging the Africanist Presence.

${ }^{33}$ Bench and Ellis. See also Tsai.

${ }^{34}$ Erin Manning, Always More Than One, 16. In a somewhat different manner, José Gil writes that "Thanks to the space of the body, the dancer, while dancing, creates virtual doubles or multiples of his or her body." Gil, "Paradoxical Body," 24.

${ }^{35}$ Hortense Spillers, "Mama's Baby," 67.

${ }^{36}$ Idem, 74, emphasis in original.

${ }^{37}$ Idem, 67.

${ }^{38}$ Ashon Crawley, Blackpentecostal Breath, 59. See also Alexander G. Weheliye, Habeas Viscus for an in-depth engagement with and expansion on Spillers's notion of flesh.

${ }^{39}$ Dance scholars' use of the word "corporeality" (which I use throughout this essay) may be a way of grappling with the simultaneous materiality of flesh and 
discursiveness of the body, although, as I have written elsewhere, there is not exactly consensus on whether the "corporeal" refers to a material and/or a discursive realm. Anthea Kraut, Choreographing Copyright, 14. It is worth noting, too, that the space Spillers opens up between flesh and body shares some similarities with dance scholar Ann Cooper Albright's formulation of the moment of dancing as a "double moment of representation" in which there is slippage between a dancer's "somatic identity (the experience of one's physicality) and a cultural one (how one's body renders meaning in society)." Albright, Choreographing Difference, xxiii. The work of Spillers and other critical race theorists should encourage us to give more thought to how the somatic and the cultural converge and diverge differently across racial lines. Dance scholars have also challenged Western notions of a bounded body from other angles. See, for example, Andrée Grau, "When the Landscape becomes Flesh" and Anurima Banerji, "Dance and the Distributed Body."

${ }^{40}$ In Dyer's influential discussion, one of the central paradoxes of whiteness is that it aspires to "something that is in but not of the body" and involves a "vividly corporeal cosmology that most values transcendence of the body." Dyer, 14, 39.

${ }^{41}$ Eva Cherniavsky, Incorporations, xiv.

${ }^{42}$ Idem, xv, emphasis in original.

${ }^{43}$ Like all racial formations, whiteness is historically contingent. While this essay's examples are drawn from the middle of the twentieth century, I am also interested in how whiteness maintains its corporeal privilege in shifting historical conditions. On "racial formations," see Michael Omi and Howard Winant, Racial Formation in the United States.

${ }^{44}$ My thoughts here are inspired by a talk given at UC Riverside on May 16, 2018 by Kara Keeling, titled "I'm a Man Eating Machine': On Digital Media, Corporate Cannibals, and (Im)Proper Bodies," with a response by Grace Kyungwong Hong. The talk was part of the "Undisciplined Encounters: Experimental Dialogues on Critical Ethnic Studies" series.

${ }^{45}$ Film scholars' concept of indexicality is indebted to the semiotic theory of Charles Sanders Peirce.

${ }^{46}$ Keeling, “Passing for Human," 238.

${ }^{47}$ Idem, 244.

${ }^{48}$ For Cherniavsky, film itself, as a mass medium that converted white stars into "commodity-images," posed a crisis for the status of white women. She argues that the film star's "glow" (in Dyer's terms) served to "(re)mediate... her implication in the commodity form." Cherniavsky, xxv. 
${ }^{49}$ Keeling cites Frantz Fanon's famous discussion of the anxiety he experiences waiting for images of "the Black" to appear on screen, an image that is "radically incommensurate with Fanon's own sense and understanding of" his pre-filmic reality. Keeling, "Passing for Human," 244. See Frantz Fanon, Black Skins, White Masks.

50 Jane Feuer identifies the era spanning "the coming of sound in 1927 to the television era of the mid-1950s" as epitomizing "the golden age of Hollywood's studio era in the popular imagination" (ix).

${ }^{51}$ Erin Brannigan, Dancefilm, 142, 145.

${ }^{52}$ Kraut, "Signature Steps."

53 Jeanine Basinger, The Star Machine, 518.

${ }^{54}$ Robert B. Westbrook, "'I Want a Girl,'" 596; Tom McGee, Betty Grable, 85; George Lipsitz, The Possessive Investment in Whiteness, 76; Basinger, 519.

${ }^{55}$ Westbrook, 599, 600.

${ }^{56}$ As Pan later recalled, the first time he met Blue, "She was wearing a bikini bathing suit and a live marmoset on her shoulder. Her appearance was so outrageous I hired her just because I thought she'd be fun." Quoted in John Franceschina, Hermes Pan, 55.

${ }^{57}$ Svetlana McLee Grody and Dorothy Daniels Lister, Conversations with Choreographers, 8; David Patrick Columbia, "The Man Who Danced," 848.

${ }^{58}$ Grody and Lister, 8.

${ }^{59}$ Franceschina, 106, 110; Pete Martin, "The World's Most Popular Blonde."

${ }^{60}$ Franceschina, 122, 109.

${ }^{61}$ Idem, 122.

62 John Kobal, People Will Talk, 630. Unsurprisingly, McGee's biography of Grable contains a more favorable appraisal of Grable's dancing. McGee writes that Pan recalled Grable as possessing a "'natural and graceful' dancing style" and that Pan considered Grable, along with Rita Hayworth, one of the "two top female dancers on the screen." McGee 47, 84.

${ }^{63}$ Martin, 106; Columbia, 848. On the surface, Grable's own admission of averageness and her treatment like a chorus dancer might seem to compromise the legitimacy of her star status. But film scholar Sean Redmond reminds us that it is the paradoxical simultaneity of extraordinariness and ordinariness, uniqueness and commonness, that lies "at the heart of white stardom." Redmond, 267. See also Dyer.

${ }^{64}$ Columbia, 848. 
${ }^{65}$ Mainwaring, 137.

${ }^{66}$ Redmond, 266. Redmond draws here on the work of theorists John Ellis and Roland Barthes.

${ }^{67}$ According to The Telegraph and Rob Easterlea, the former director of 20th Century Fox's photo archives, the pin-up photograph of Grable was also the product of airbrushing. Easterlea is quoted as saying, "They airbrushed out a garter she was wearing on her left leg, to make her look less slutty, and enhanced the shadows under her left butt, to make it really pop. So you're left with healthy-as-apple-pie sexuality, which Gls went crazy for when the United States entered the war." "Twentieth Century Fox Archives."

68 Jones.

${ }^{69}$ In addition to Pan, the list of choreographers with whom Grable worked includes Jack Cole, Billy Daniel, and Busby Berkeley. See McGee and Larry Billman, Betty Grable.

${ }^{70}$ Columbia, 759.

${ }^{71}$ See Gottschild, Digging the Africanist Presence.

${ }^{72}$ I am indebted to John Franceschina for his extreme generosity in sharing his Pan materials with me, as well as to Micheline Laski, Pan's niece, for granting me permission to publish Pan's personal photos.

${ }^{73}$ Spillers, "Mama's Baby," 65.

${ }^{74}$ Kimberly Wallace-Sanders, Mammy, 3. See also Harryette Mullen's discussion of the "black woman as a conflicted site of the (re)production of whiteness." Mullen, "Optic White," 82.

${ }^{75}$ Franceschina, 17. Elsewhere, Pan described Clark as "a black kid who was our houseboy and drove for us.... He was a little older than I was and he used to teach me all kinds of shuffles, the Black Bottom and the Charleston. From these beginnings, I got my show business start...." Pan traced his show business career back to Clark quite literally. As he reported in an interview, on his first day working with Astaire, when asked if he had any ideas to fill out a solo tap dance, "something clicked in my mind and I remembered a break that Sam Clark had taught me back in Tennessee. I showed it to Fred and he loved it. After that he always called for me...." David Fantle and Tom Johnson, Reel to Real, 87, 89. Franceschina's biography of Pan is full of other anecdotes that document the influence of African American aesthetics on his choreography.

${ }^{76}$ Asymmetry is one of the Africanist aesthetic principles that Gottschild identifies in Digging the Africanist Presence. 
77 Janette Prescod, "Marie Bryant." See also Donald Bogle, Bright Boulevards, 240-43.

${ }^{78}$ Erskine Johnson, "In Hollywood," 4; "Movie Dance Director."

${ }^{79}$ See an online clip of Bryant dancing between the 0:17 and and 0:37 marks here: https://www.youtube.com/watch?v=EFyDd8CFLVw. Accessed July 10, 2018.

${ }^{80}$ Notably, Angie Blue also worked on both of these films as an assistant to Daniel. Billman, "Angie (Angela) Blue (Deshon)," 241; "Behind the Scenes in Hollywood," 5. The extent to which Blue and Bryant interacted on these films is unknown. It was not uncommon for different choreographers and coaches to work with stars on different numbers on a particular film, but the difficulty of finding any documentation of Blue's and Bryant's relationship is a reminder of the ways the archive reflects the interests of the powerful.

81 "Movie Dance Director," 26.

82 Ibid.

${ }^{83}$ Susan Leigh Foster, "Dancing Bodies," 237-38.

84 “Movie Dance Director," 26.

${ }^{85}$ Gottschild, The Black Dancing Body, 148.

${ }^{86}$ Roach, 6.

${ }^{87}$ Franceschina, 130.

${ }^{88}$ Roach, 3.

${ }^{89}$ Dolores Calvin, a reporter for the African American newspaper The California Eagle, took note of the vast incongruity between Bryant's on-screen image and her offscreen role. In an article titled "Marie Bryant Gets No Credit," she expressed grave disappointment that Billy Daniel received sole screen credit for Wabash Avenue's choreography, despite Bryant's "official capacity as assistant dance director, and a great necessity to the department," while being "cast...in a menial maid's role where the average layman, not knowing of her great talent, would chalk up her appearance as 'just another maid.'" Calvin, "Marie Bryant Gets No Credit," 17. 


\section{References}

Albright, Ann Cooper. Choreographing Difference: The Body and Identity in Contemporary Dance. Hanover, NH: Wesleyan University Press, 1997.

Banerji, Anurima. "Dance and the Distributed Body: Odissi, Ritual Practice, and Mahari Performance." About Performance 11 (2012): 7-39.

Basinger, Jeanine. The Star Machine. New York: Random House, 2007.

"Behind the Scenes in Hollywood." The Gaffney Ledger, Feb. 8, 1951, 11.

Belmar, Sima. "Behind the Screens: Race, Space, and Place in Saturday Night Fever." In The Oxford Handbook of Screendance Studies. Ed. Douglas Rosenberg. New York: Oxford University Press, 2016. 461-79.

Bench, Harmony, "Choreographing Bodies in Dance-Media," Dissertation, University of California, Los Angeles, ProQuest Dissertations Publishing, 2009.

Bench, Harmony and Simon Ellis, "Editors' Note: On Community, Collaboration, and Difference." The International Journal of Screendance 5 (2015).

https://doi.org/10.18061/ijsd.v5i0.4866

, ed. "Editorial: Solo/Screen.” The International Journal of Screendance 8 (2017).

https://doi.org/10.18061/ijsd.v8i0.5891

Bernardi, Daniel, ed. The Birth of Whiteness: Race and the Emergence of U.S. Cinema. New Brunswick, NJ: Rutgers University Press, 1996.

, ed. Classic Hollywood, Classic Whiteness. Minneapolis: University of Minnesota

Press, 2001.

Billman, Larry. "Angie (Angela) Blue (Deshon)." In Film Choreographers and Directors: An Illustrated Biographical Encyclopedia, with a History and Filmographies, 1893 through 1995. Jefferson, NC: McFarland \& Company, Inc., 1997, 240-41.

. Betty Grable: A Bio-Bibliography. Westport, CT: Greenwood Press, 1993.

Black, Shirley Temple. Child Star: An Autobiography. New York: Warner Books, 1988.

"Blanche Sweet Never Requires Dance Double," Los Angeles Daily Times, June 11, 1925, 11.

Blanco Borelli, Melissa and Raquel Monroe, "Editorial: Screening the Skin: Issues of Race and Nation in Screendance." The International Journal of Screendance 9 (2018). https://doi.org/10.18061/ijsd.v9i0.6451 
Bogle, Donald. Bright Boulevards, Bold Dreams: The Story of Black Hollywood. New York: One World, 2005.

Brannigan, Erin. Dancefilm: Choreography and the Moving Image. New York: Oxford University Press, 2011. https://doi.org/10.1093/acprof:oso/9780195367232.001.0001

Calvin, Dolores. "Marie Bryant Gets No Credit," The California Eagle, April 20, 1950, 17. Catton, Pia. "It's Hard Work Being Jennifer Lawrence's Body Double, Especially for Jennifer Lawrence," Daily Beast, March 2, 2018, https://www.thedailybeast.com/itshard-work-being-jennifer-lawrences-body-double-especially-for-jennifer-lawrence. Accessed June 22, 2018.

Cherniavsky, Eva. Incorporations: Race, Nation, and the Body Politics of Capital. Minneapolis: University of Minnesota Press, 2006.

Chisholm, Ann. "Missing Persons and Bodies of Evidence," Camera Obscura 43, 15.1 (2000): 123-161.

Clover, Carol. "Dancin' in the Rain," Critical Inquiry 21.4 (Summer 1995): 722-747. https://doi.org/10.1086/448772

Columbia, David Patrick. "The Man Who Danced with Fred Astaire," The Dancing Times (May and June 1991): 759, 848-850.

Crawley, Ashon. Blackpentecostal Breath: The Aesthetics of Possibility. New York: Fordham University Press, 2017.

“Dance Stand-in.” Los Angeles Times, Dec. 15, 1935, p. C9.

De Lauretis, Teresa. Technologies of Gender: Essays on Theory, Film, and Fiction. Bloomington and Indianapolis: Indiana University Press, 1987. https://doi.org/10.1007/978-1-349-19737-8

Delameter, Jerome. Dance in the Hollywood Musical. Ann Arbor, MI: UMI Research Press, 1981.

Doane, Mary Ann. "Indexicality: Trace and Sign: Introduction." differences: A Journal of Feminist Cultural Studies 18.1 (2007): 1-6.

Dodds, Sherril. Dance on Screen: Genres and Media from Hollywood to Experimental Art. London: Palgrave, 2001.

duCille, Ann. "The Shirley Temple of My Familiar," Transition 73 (1997): 10-32. https://doi.org/10.2307/2935441

Dyer, Richard. White. London and New York: Routledge, 1997. 
Edwards, Anne. Shirley Temple: American Princess. Guilford, CT: Lyons Press, 2017.

Fanon, Frantz. Black Skin, White Masks. Translated by Richard Philcox. New York: Grove Press, 2008.

Fantle, David and Tom Johnson. Reel to Real: 25 Years of Celebrity Interviews from Vaudeville to Movies to TV. Oregon, WI: Badger Books, Inc, 2004.

Feuer, Jane. The Hollywood Musical. Bloomington: Indiana University Press, 1993.

"Film Beauty," Pittsburgh Courier, Nov. 14, 1942.

Folkart, Burt A. “E. Meglin, 93; 'Meglin Kiddies' Dance Instructor," Obituary, Los Angeles Times, June 25, 1988, http://articles.latimes.com/1988-06-25/news/mn-

4707_1_meglin-kiddies. Accessed June 25, 2018.

Foster, Susan Leigh. "Dancing Bodies." In Meaning in Motion: New Cultural Studies of Dance. Ed. Jane Desmond. Durham, North Carolina: Duke University Press, 1997. 23558.

Franceschina, John. Hermes Pan: The Man Who Danced with Fred Astaire. New York: Oxford University Press, 2012.

https://doi.org/10.1093/acprof:oso/9780199754298.001.0001

Gavin, James. Stormy Weather: The Life of Lena Horne. New York: Atria Books, 2009.

Genné, Beth. Dance Me a Song: Astaire, Balanchine, Kelly, and the American Film Musical. New York: Oxford University Press, 2018.

George-Graves, Nadine. "Identity Politics and Political Will: Jeni LeGon Living in a Great Big Way." In The Oxford Handbook of Dance and Politics. Ed. Rebekah J. Kowal, Gerald Siegmund, Randy Martin. New York: Oxford University Press, 2017, pp. 511-34.

Gil, José. "Paradoxical Body." TDR: The Drama Review 50:4 (Winter 2006): 21-35. https://doi.org/10.1162/dram.2006.50.4.21

Gottschild, Brenda Dixon. The Black Dancing Body: A Geography from Coon to Cool. New York: Palgrave Macmillan, 2003. https://doi.org/10.1007/978-1-137-03900-2

Digging the Africanist Presence in American Performance: Dance and Other Contexts. Westport, CT: Greenwood Press, 1996.

Grau, Andrée, "When the Landscape becomes Flesh: An Investigation into Body Boundaries with Special Reference to Tiwi Dance and Western Classical Ballet." Body \& Society 11.4 (2005): 141-163. https://doi.org/10.1177/1357034X05058024

Grody, Svetlana McLee and Dorothy Daniels Lister. Conversations with Choreographers. Portsmouth, NH: Heinemann, 1996. 
Harris, Avanelle. "I Tried To Crash the Movies," Ebony, August 1946, 5-10.

Hatch, Kristen. Shirley Temple and the Performance of Girlhood. New Brunswick, NJ: Rutgers University Press, 2015.

Hill, Constance Valis. "From Bharata Natyam to Bop: Jack Cole's 'Modern' Jazz Dance." Dance Research Journal 33.2 (Winter 2001/02): 29-39. https://doi.org/10.2307/1477802

Johnson, Erskine. "In Hollywood," Miami Daily News-Record April 5, 1943, 4.

Jones, Grover. "Star Shadows." Colliers Apr. 30, 1938, 18, 44-46.

Keeling, Kara. "Passing for Human: Bamboozled and Digital Humanism." Women \& Performance: A Journal of Feminist Theory 15:1 (2005): 237-250.

https://doi.org/10.1080/07407700508571495

Knight, Arthur. "Star Dances: African American Constructions of Stardom, 1925-1960." In Classic Hollywood, Classic Whiteness. Ed. Daniel Bernardi. Minneapolis: University of Minnesota Press, 2001. 386-414.

Kobal, John. People Will Talk. New York: Alfred A. Knopf, 1985.

Kraut, Anthea. Choreographing Copyright: Race, Gender, and Intellectual Property Rights in American Dance. New York: Oxford University Press, 2015.

https://doi.org/10.1093/acprof:oso/9780199360369.001.0001

_. "'Stealing Steps' and Signature Moves: Embodied Theories of Dance as Intellectual Property." Theatre Journal 62.2 (May 2010): 173-89.

https://doi.org/10.1353/tj.0.0357

Levette, Harry. "Dorothy Dandridge Hurt So Substitute Continues Work." Chicago Defender, Sept. 16, 1944, 6.

Lipsitz, George. The Possessive Investment in Whiteness: How White People Profit from Identity Politics. Philadelphia: Temple University Press, 2006.

Mainwaring, Dan. "Hollywood Nobodies." Good Housekeeping (April 1938): 40-41+.

Manning, Erin. Always More Than One: Individuation's Dance. Durham, NC: Duke University Press, 2013.

Martin, Pete. "The World's Most Popular Blonde." Saturday Evening Post, April 15, 1950, 26-27+.

McGee, Tom. Betty Grable: The Girl with the Million Dollar Legs. New York: Welcome Rain Publishers, 1995.

“Movie Dance Director." Ebony 5 (April 1950): 22-26. 
Morrison, Toni. The Bluest Eye. New York: Vintage Books, 1970, 2007.

Mullen, Haryette. "Optic White: Blackness and the Production of Whiteness." Diacritics 24.2/3 (Summer - Autumn 1994): 71-89. https://doi.org/10.2307/465165

"Newcomer Doubles for Dot Dandridge in 'Pillar to Post,'" Pittsburgh Courier, Sept. 6, 1944.

Omi, Michael and Howard Winant. Racial Formation in the United States. New York: Routledge, 1986.

Perron, Wendy. "Putting the Black Swan Blackout in Context," Dance Magazine blog, March 11, 2011, https://www.dancemagazine.com/them-performance-space-newyork-2579978597.html. Accessed June 22, 2018.

Petty, Miriam J. Stealing the Show: African American Performers and Audiences in 1930s Hollywood. Oakland: University of California Press, 2016.

Pin-Up Girl. Twentieth Century Fox. Film. 1944.

Prescod, Janette. "Marie Bryant." In Notable Black American Women, Book II. Ed. Jessie Carney Smith. Detroit, MI: Gale Research Inc., 1996. 71-73.

Redmond, Sean. "The Whiteness of Stars: Looking at Kate Winslet's Unruly Body." In Stardom and Celebrity: A Reader. Ed. Sean Redmond and Su Holmes. London: Sage Publications, 2007. 263-274. https://doi.org/10.4135/9781446269534.n25

Roach, Joseph. Cities of the Dead: Circum-Atlantic Performance. New York: Columbia University Press, 1996.

Rogin, Michael. Blackface, White Noise: Jewish Immigrants in the Hollywood Melting Pot. Berkeley and Los Angeles: University of California Press, 1996.

Rosenberg, Douglas, ed. The Oxford Handbook of Screendance Studies. New York: Oxford University Press, 2016.

https://doi.org/10.1093/oxfordhb/9780199981601.001.0001

Rosenberg, Douglas. Screendance: Inscribing the Ephemeral Image. New York: Oxford University Press, 2012. https://doi.org/10.1093/acprof:oso/9780199772612.001.0001

Schmeltzer, Randy. "'Black Swan' Blasted for Ballet Cover-Up." Adweek, March 30, 2011, https://www.adweek.com/digital/black-swan-blasted-for-ballet-cover-up/. Accessed June 22, 2018.

Schwartz, Selby Wynn. "Light, Shadow, Screendance: Catherine Gallaso's Bring on the Lumière!" In The Oxford Handbook of Screendance Studies, ed. Douglas Rosenberg. New York: Oxford University Press, 2016. 205-24. 
Slide, Anthony. Hollywood Unknowns: A History of Extras, Bit Players, and Stand-Ins. Jackson, MI: University of Mississippi Press, 2012.

Snead, James. "Shirley Temple." In White Screens/Black Images: Hollywood from the Dark Side. New York: Routledge, 1994. 47-66.

Spillers, Hortense J. "Mama's Baby, Papa's Maybe: An American Grammar Book." Diacritics 17.2 (Summer, 1987): 64-81. https://doi.org/10.2307/464747

Taylor, Diana. The Archive and the Repertoire: Performing Cultural Memory in the Americas. Durham, NC: Duke University Press, 2003.

https://doi.org/10.1215/9780822385318

Tsai, Addie. "Hybrid Texts, Assembled Bodies: Michel Gondry's Merging of Camera and Dancer in 'Let Forever Be,'" The International Journal of Screendance 6 (2016).

https://doi.org/10.18061/ijsd.v6i0.4892

"Twentieth Century Fox Archives." The Telegraph. https://www.telegraph.co.uk/culture/film/3675305/20th-Century-Fox-Archives.html. Accessed November 30, 2018.

Wallace-Sanders, Kimberly. Mammy: A Century of Race, Gender, and Southern Memory. Ann Arbor: The University of Michigan Press, 2008.

https://doi.org/10.3998/mpub.170676

Wabash Avenue. Twentieth Century Fox. Film. 1950.

Weheliye, Alexander G. Habeas Viscus: Racializing Assemblages, Biopolitics, and Black Feminist Theories of the Human. Duke University Press, 2014.

https://doi.org/10.1215/9780822376491

Westbrook, Robert B. "'I Want a Girl, Just Like the Girl that Married Harry James': American Women and the Problem of Political Obligation in World War II." American Quarterly 42.4 (December 1990): 587-614. https://doi.org/10.2307/2713166 


\title{
Trans-Screens of Gender and Jewishness in Jill Soloway's Transparent: Post-Network TV and the Screendance Scene
}

Hannah Schwadron, Florida State University

\begin{abstract}
This essay analyzes the artful insertion of screendance scenes in Season Two of Jill Soloway's Amazon hit, Transparent (2014- ), highlighting how bodies and camera choreograph affective connections core to the plot in this televisual portrait of a Jewish American family. In doing so, I underscore a layered screenic trans-ness that conjoins circular manipulations of time and bodily action to overlay transgender and transhistorical experiences as co-constitutive themes.
\end{abstract}

Keywords: Trans-Screens, Transgenerational, Transhistorical, Gender, American Jewishness, Post-Network TV

How does the TV portrait of a lovably strained Jewish family endear audiences to transgender narratives, and what do artful screendance aesthetics, such as filming in the round have to do with it? This essay's critical discussion of Jill Soloway's hit series Transparent (Amazon Prime 2014-present) follows this line of questioning. In doing so, I champion the show's contributions to pop cultural representations of ethnic and sexual diversity through highlighting the use of non-verbal communication and camera choreography. In what follows, I offer a close reading of two movement-driven scenes, and draw from that analysis a framework for thinking about the affective integration of screendance aesthetics in the popular televisual realm. In both of the scenes I discuss, dance becomes the expressive mode by which characters access the bodily effects of traumas carried over from past generations, and through which audiences witness characters experiencing their present-day bodies in especially painful ways.

In looking at the aestheticization of Transparent's narrative content through screendance scenes, it becomes clear how the circular compositions of body and camera manifest an emancipatory embrace of the show's Jewish and transgender storylines. I argue that this collaborating bodily and camera choreography works to conjoin ethnic and sexual identities as overlapping circles. My analysis honors the difficult work of rendering marginalized bodies legible in the popular realm while considering the limits of such shared representation for groups in varying stages of mainstream acceptance and assimilation. Finally, I discuss this point in relation to the recent ousting of lead actor, Jeffrey Tambor, after allegations of his harassment of two 
transwomen on set. In analyzing the show in this way, my aim is to underscore the representational stakes of Transparent's movement aesthetics while addressing the minoritarian discourses and experiences they circumscribe on and off set.

First, I situate the emergence of screendance on television as part of a broader postnetwork phenomenon. In broad terms, post-network TV can be defined as the current period of watching television that allows us more individuated control than ever. ${ }^{1}$ This increased access and control has accompanied ever more diversification of programming, which has allowed TV to be edgier and more oppositional in content. As television scholar Nick Marx has pointed out, this has resulted in shows that are more "inviting" in scope, offering possibilities for marginalized cultural identities to be seen on-screen and courted as viewers. ${ }^{2}$ These are edgy and inclusive attributes for which Transparent has been celebrated. For one, Amazon's wildly popular dramatic comedy has more transgender and gender-nonconforming people-thirty-six employees in total -in its cast and crew than any other show in television history. ${ }^{3}$ Moreover, the show is widely heralded for its social justice content, as well as the way it delivers this content through especially artful means. ${ }^{4}$

It is within this context that a screendance look and feel, here referring to a broad array of cinematic techniques and 'dancerly' sensibilities often reserved for galleries and screendance festivals, now makes its way onto narrative TV, where niche viewers can find a growing number of shows that speak to special interest or subcultural topics like Transparent. This assimilation of especially artful cinematic qualities helps a show like Transparent accompany its often darkly funny material with emotional depth and movement-driven metaphor. It also brings high art aesthetics into the popular realm. In this adoption of screendance for TV, Soloway and her creative team deliver powerful social messages through high art dramatizations of social justice themes. The show's huge success in number and scope of awards suggests a wide-spread appreciation of such creative tactics. ${ }^{5}$

Importantly, attention to crafting the movement of the actors was always a priority in Transparent's pre-production creative approach. Soloway and the cast worked with Los Angeles directing coach Joan Scheckel in early iterations of the rehearsal process to explore elements of non-verbal communication. For example, actors were asked to move towards those to whom their characters felt closer, and away from those they felt farther from emotionally. ${ }^{6}$ Such open-ended exploration is known to be fundamental to Soloway's directorial style and is especially exciting for cast members who regularly talk about Soloway's feminist, egalitarian approach and her mode of honoring the artistic choices made by cast members. ${ }^{7}$ Soloway herself joined in these family role plays, enacting encounters no doubt familiar to her as she drew movement inspiration from a show loosely based on her own Jewish father's transgender coming out. It is significant to note that the cast regularly described the dynamics on set through familial terms. For example, Actor Jay Duplass who plays the middle brother Josh described his 
first screen test with co-stars Amy Landecker and Gaby Hoffman "who are not only my sisters on a TV show but my sisters in real life now" as "kind of magic." ${ }^{8}$ No doubt this is why the allegations of Tabor's violence in the fall of 2017 was so personal for the cast, causing Duplass to describe the situation as "traumatic." ${ }^{9}$ In this slide between actor and character dynamics and their enactment through movement and affect on and off camera, it is helpful to foreground the family-style ethos that also link an analysis of screendance scenes to the real-life traumas they encircle.

\section{Ethno-Sexual Inheritance and the Dancing Circles of Jewish Trans-ness}

Within the world of Transparent's Pfefferman family, individual and collective experiences of trauma extend beyond the time and place in which the characters live. A central component of the show is the depiction of intersecting Jewish, gender, and sexual identities that carry across multiple generations to account for past traumas, or what I will call "ethno-sexual inheritance." This ethno-sexual inheritance is manifest for every current-day Pfefferman family member, albeit in different ways. Father Mort is transitioning to "Mapa" Maura, Mother Shelly is finding her voice after early abuse by a school teacher, Eldest daughter Sarah, middle son Josh, and youngest daughter Ali deal with various character crises that dial back to sexual dysmorphias informed by traumatic events they lived, as well as those they inherited. As each pursues their individual journey of self-reconciliation, a larger communal circle of acceptance from current day community and ghostly past figures continually embraces them all.

Transparent yokes transgenerational, transhistorical frames to transgender ones as current-day characters come to know themselves through what they find out about transgender members of their Jewish family's past. It is this central relationship, which I'm calling the "Jewish-trans-ness" of the show, that continues to unfold through transgenerational family inheritances and a growing number of transgender characters and plotlines across four seasons and counting. In the scenes I describe below, dance and camera choreographies physicalize this core relationship between trans subjects. Filmed as movements of memory in Transparent's second season, I argue that these screendance scenes should be seen as "trans-screens" insofar as they interrelate identity, inheritance, and embodiment through dance and a dancing camera, despite the absence of any choreographer or movement director in the credit roll. They offer artful layering of ethno-sexual identities as the show's Venn diagram of Jewish and transgender demographics, and do so through body and camera techniques which both resonate with and help construct the circular themes of the narrative content.

Soloway's trans-screens aestheticize the diachronic blurring of past and present realities to elicit empathetic response around the show's "epigenetic" subject matter. The premise of epigenetics in these scenes and as a field of genetic study is that bodies hold and can access histories beyond their own lifetimes. Similarly, bodily movement carries 
layered meaning beyond what is said, and even beyond what may be consciously intended. Simply put, epigenetics concerns itself with how genetic inheritance influences lived experiences. The understanding is that traumatic events in our family's lives persist in our bodies, blood, and bones, leaving molecular scars that adhere to our DNA. ${ }^{10}$ Leading researchers in epigenetics and dance artists alike suggest that addressing those scars can help us heal at the level of the body. ${ }^{11}$ In Transparent's transscreen scenes, I find this enactment of past trauma through bodily movement and movement of the camera especially significant. Body and camera act as co-constituting elements of the individual and collective subject in need of healing.

In the first example I will analyze from Season 2, Episode 1, the screendance scene is structured as a flashback. The juxtaposition of time periods is made possible by a quick camera cut that moves from a present-day wedding party scene to a festive ball at the historic Institute of Sexuality in Berlin, wherein the action of a central dancing figure encircled by communal joy continues in the foreground of both shots. The second example of a trans-screen scene from Season 2, Episode 9 utilizes a group campfire as a core mechanism through which characters make contact across generations and contexts. A present-day forest gathering morphs into a figment of feelings and imagination. This second trans-screen scene is less a conjoining of dancing scenes as in the first example, and more of an imaginative fantasy, or what we might think of as epigenetic illusion. In this scene, the prospect of past traumas inherited through the body come to life as if they were happening in a time neither past nor present, but one that only exists in the realm of emotions.

Season 2, Episode 1 takes place at the lesbian wedding of eldest daughter Sarah, which is nulled as soon as the party ends. Sarah realizes midway through the reception that she is not ready to leave her ex-husband and life with her kids. The moment hits her hard in the bathroom stall where she forces her siblings to help process what to do while she panics and pees. But before this abrupt confession, the festive event is in full swing. Dressed all in white, the family and friends dance the quintessential wedding Horah to the live accompaniment of singer Ayana Haviv and attending klezmer band. The mood is big-spirited and convincingly human, if also exaggerated to create a sense of the heightened and often frenetic energy that accompanies weddings. ${ }^{12}$ Hands clasped tightly and arms raised overhead, they complete the marriage with a cultural dance that all on set appear to know well. The camera traces the inside of the dancing circle, panning over their faces as characters commune in ritual tradition, straining to talk over the music. 


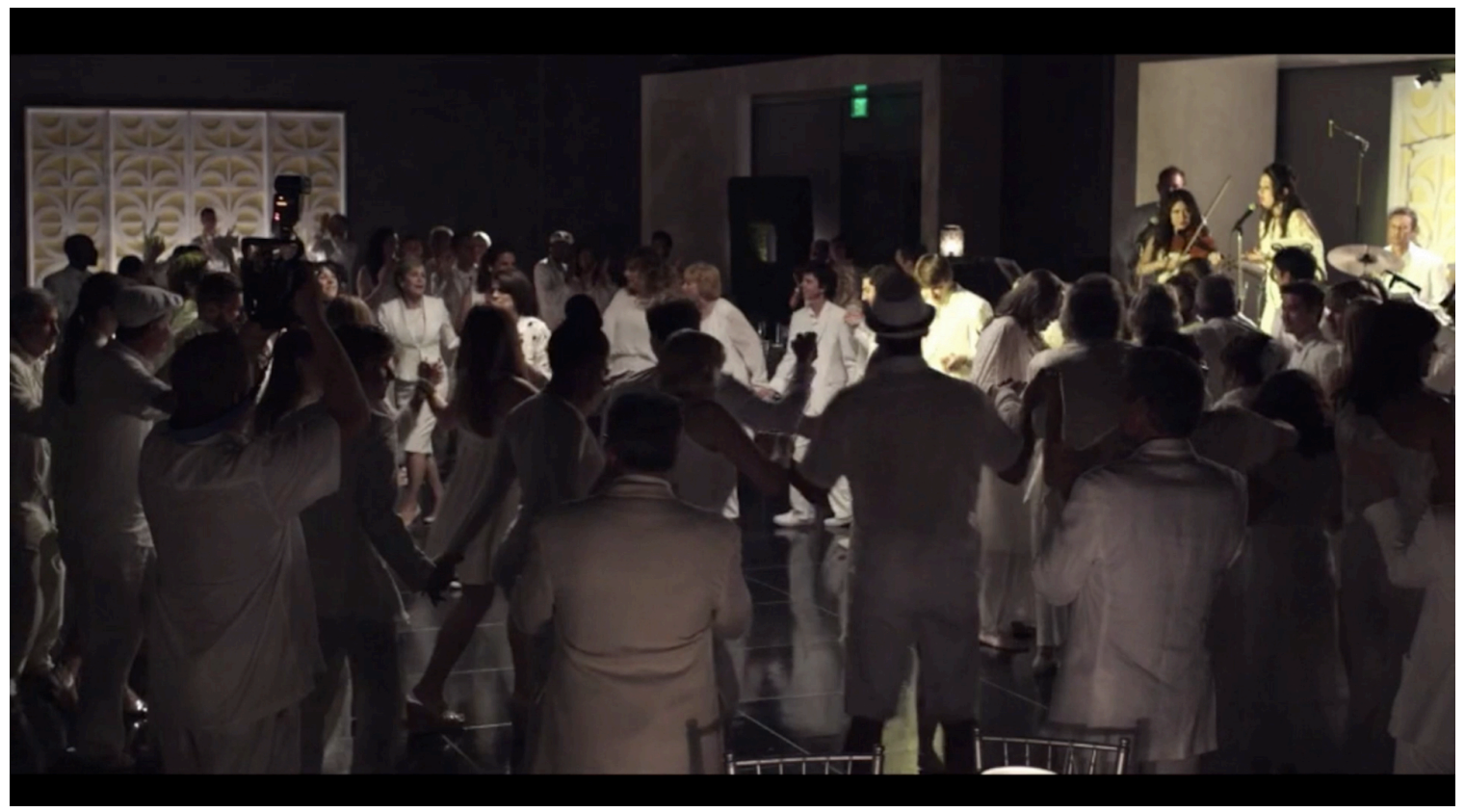

The wedding Horah in full swing. Screenshot taken by the author.

Cousin Simon (Bashir Naim) enters the center of the shot and the symbolic ring, gazing upward. His long steps emphasize the downbeat, and his gait slows against the sustained speed of the crowd. The community bounces their grapevine to the right, holding him in his moment, and his hips sway side-to-side with iconic flamboyance. Closing his eyes, he travels inward, driven into a trance by the immersive energy and sound. He lifts his chest to the sky and tears off his white suit jacket, swinging it in lassoing circles overhead. The rotations of the jacket wind time backwards, a transhistorical move, and a quick cut takes the viewer to a queer costumed ball in Weimar Berlin. A tight shot closes in on a male dancer (while the face is out of focus, it is likely also Naim) who picks up where Cousin Simon left off. The frame moves from his undulating wrist to the full party scene. 


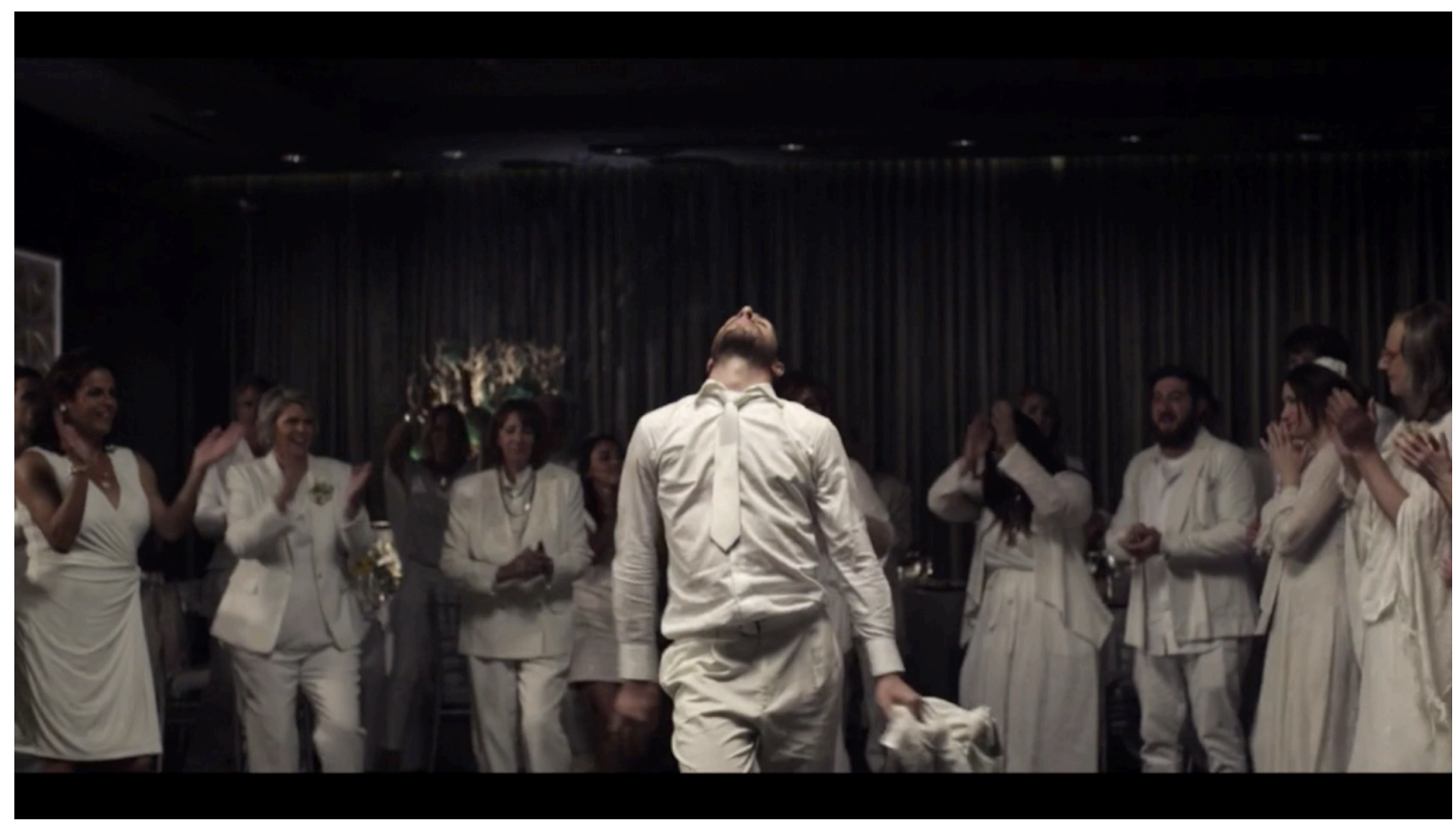

Cousin Simon (Bashir Naim) dances in the middle of the Horah scene. Screenshot taken by the author.

The camera introduces a glitzy mix of dancing bodies and animated faces we haven't yet met; a bare-chested sailor, a flapper pianist, a lounging male femme fanning off. And for the duration of the scene, there is only joy. Costumed people dance alone and in groups, as lavish boas and lingerie accent impromptu high kicks and conga lines. Silk and feathers combine period party dress and draped finery to outfit a full room of individuated style. Transgender actor-model Hari Nef, who we soon learn plays Tante (Aunt) Gittel, appears on camera for the first time as a teenaged beauty, wearing a deep red velvet cape over a low-cut green dress. When we meet her, the regal fabric has just whipped into extravagant rotation to spin the camera with the same circular force. The royal figure greets her dance partner's nipples first as if every dance might start this way, and the infectious smiles filling every frame suggest that somehow they do. 


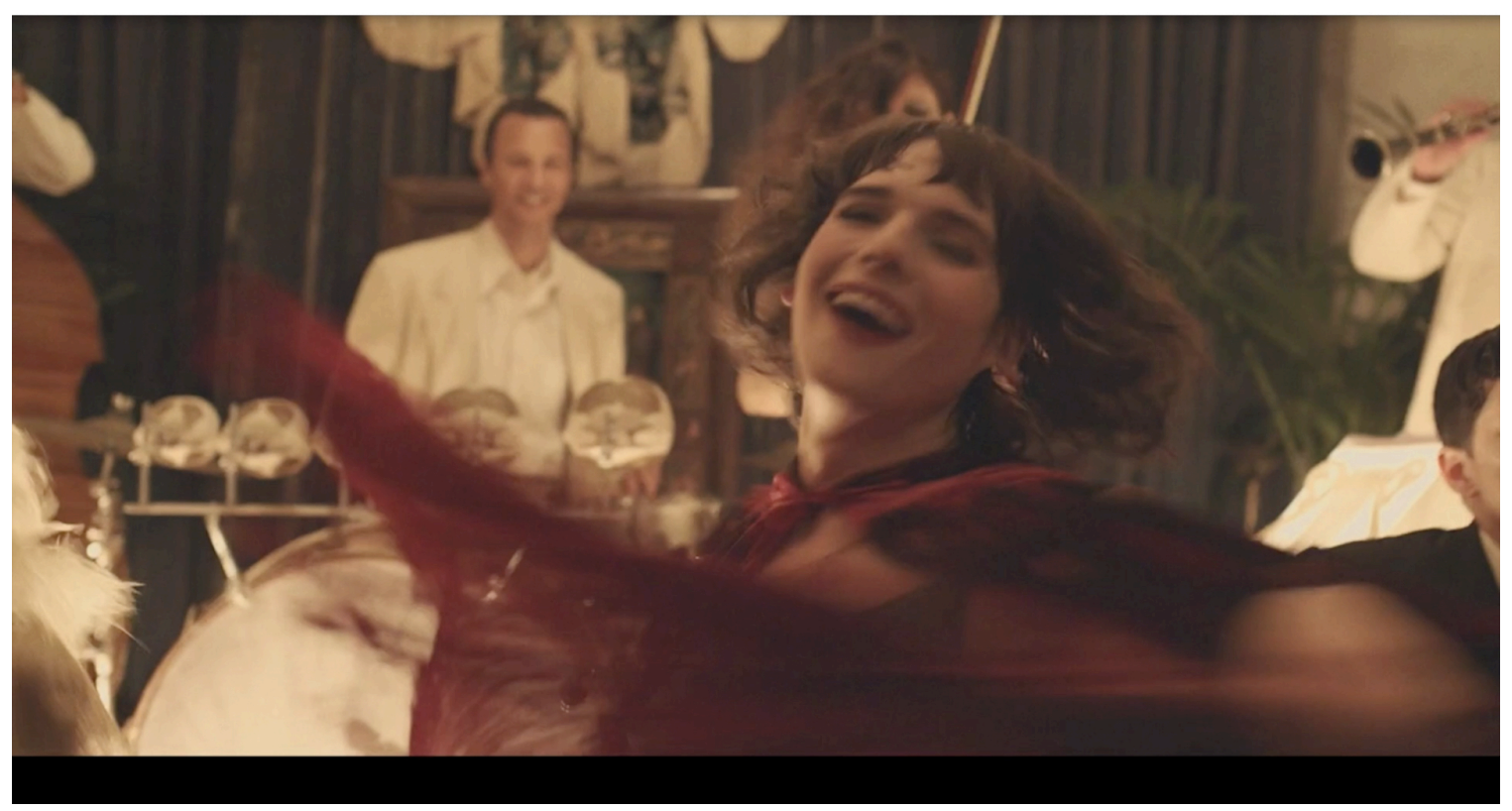

Gittel (Hari Nef) whips her velvet cape in a flashback to 1933 Berlin. Screenshot taken by the author.

The 1933 Berlin flashback shows the cosmopolitan city's flourishing gay subculture before the Nazis destroyed it and the people who populated it. ${ }^{13}$ The scene takes place in a historical reconstruction of the Institute on Sexual Science, an elaborate villa of gender non-conforming people who lived and worked alongside Magnus Hirschfeld, founding researcher known as the "Freud of transvestite understanding" during the Weimar period. ${ }^{14}$ The party scene sparkles with bohemian decadence and glamorous abandon and the bodily and camera action create an atmosphere that is free and unabashed, consistent with historical images and accounts of the period. This fairly unfamiliar depiction of German life before the Holocaust connects Jewish and transgender subjects and experiences for the first time on American television, and its screendance depiction brings the safe circle of the Institute into the foreground.

When, in Episode 9, Nazi-era soldiers drag Gittel violently into the woods at a presentday campfire turned transhistorical book burning, the festive circles of Jewish lesbian wedding dances and queer balls are broken by a terrorizing raid that also makes use of the circular theme. Like in Episode 1, this second screendance scene also results from an emotional trigger, this time just after a horrible moment for Maura and Ali at the Idyllwild Wimmin's Festival. Despite going to the festival to join cadres of liberated women (in theory, a protective circle of acceptance), Maura and Ali deal with the discriminatory and exclusionary ethos of feminist purists who reject Maura on the basis of her having been born male. They force her to leave by screaming the episode's title: "Man on the Land!" The intense moment of rejection recalls the violent past, where Hirschfeld's institute was sieged and his papers and library collection burned. 
The scene starts as youngest daughter Ali (Gaby Hoffman) enters from out of frame. Her eyes are bloodshot from crying and still outlined in the dotted faux tribal decoration from an earlier visit to Shaman Crying Bear's Intention Circle, where a white New Yorker feigns connection to indigenous rituals. Despite the humorous juxtaposition of Ali's face makeup against her evident emotional fatigue, the tone has shifted drastically from such sardonic parodies of the festival feel to a flashback sequence that she imagines. Nazi horns blow and a violinist still dressed from the party plays in time with the instrumentation of Alice Boeman's tender ballad "Waiting," but the sound is from elsewhere, imposed upon the scene. A repeating soundtrack from the end of Season 2, Episode 1, the song carries a circular tie back to the previously described scene, as if a theme song for Ali's newfound access to Gittel. Aching variations of bound tension and release present duets of aggression and affect that punctuate the melancholic female voice, which is neither Ali's nor Gittel's, but somehow both. Teenaged Gittel stands by, face and body hung heavy as she watches a friend get pulled from behind by a figure in white button-down shirt and black tie, the same clothing worn by Hitler Youth in the Institute raid.

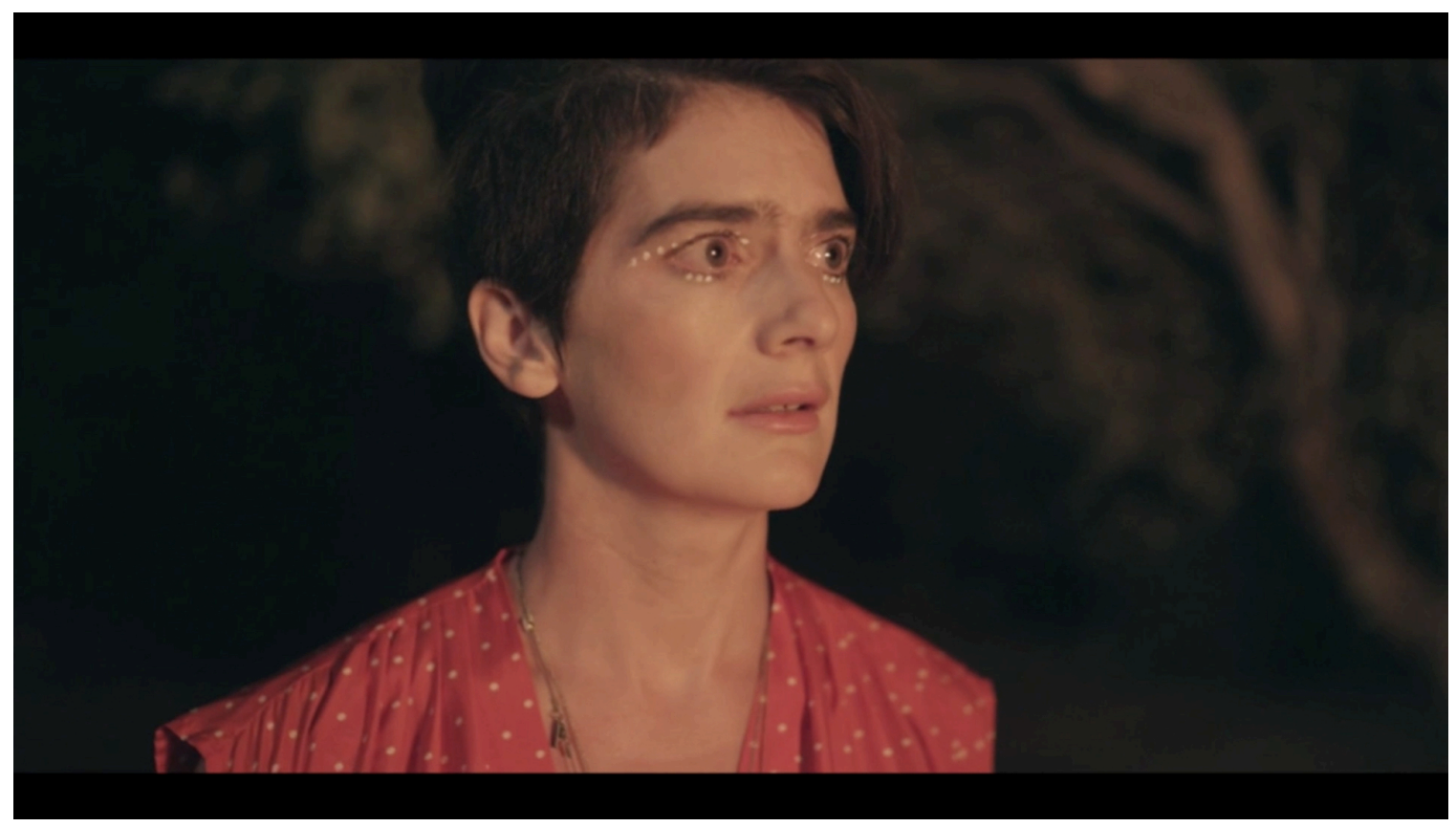

Ali (Gaby Hoffman) enters the fire scene, eyes bloodshot and adorned with white paint. Screenshot taken by the author.

The next image re-costumes these men in full Nazi uniforms, as two yank the necks of more friends from the earlier party scene away from the fire. The camera then comes from behind one such duet, framing their failed struggle to muscle free from the state's stronghold. The moving lens lets us look around the fire at the pained expressions of Institute musicians and dancers alongside unknown men in suits who people the fire's perimeter with eerily hardened facial expressions. Consecutive figures are strangled 
from the back, fighting to loosen limbs from death's grip, which the camera mostly shoots from below, catching the action from a vantage point very close to the center fire pit.

This theater in-the-round continues as the camera partners Ali's solemn transhistorical walk along the circle's edge. She finds her grandmother as a young girl (played by actress Emily Robinson who doubles as Ali's younger self in a previous episode), and the two stand in the flickering light cast by the center flame, holding hands. When the camera moves back to Gittel, crying, two soldiers restrain her arms from the back. A handheld camera then follows her as she falls, traveling down the length of her legs and beige character heels to a pile of strewn books littering the dirt floor. Gittel wrestles against the control until she is carried out of view.

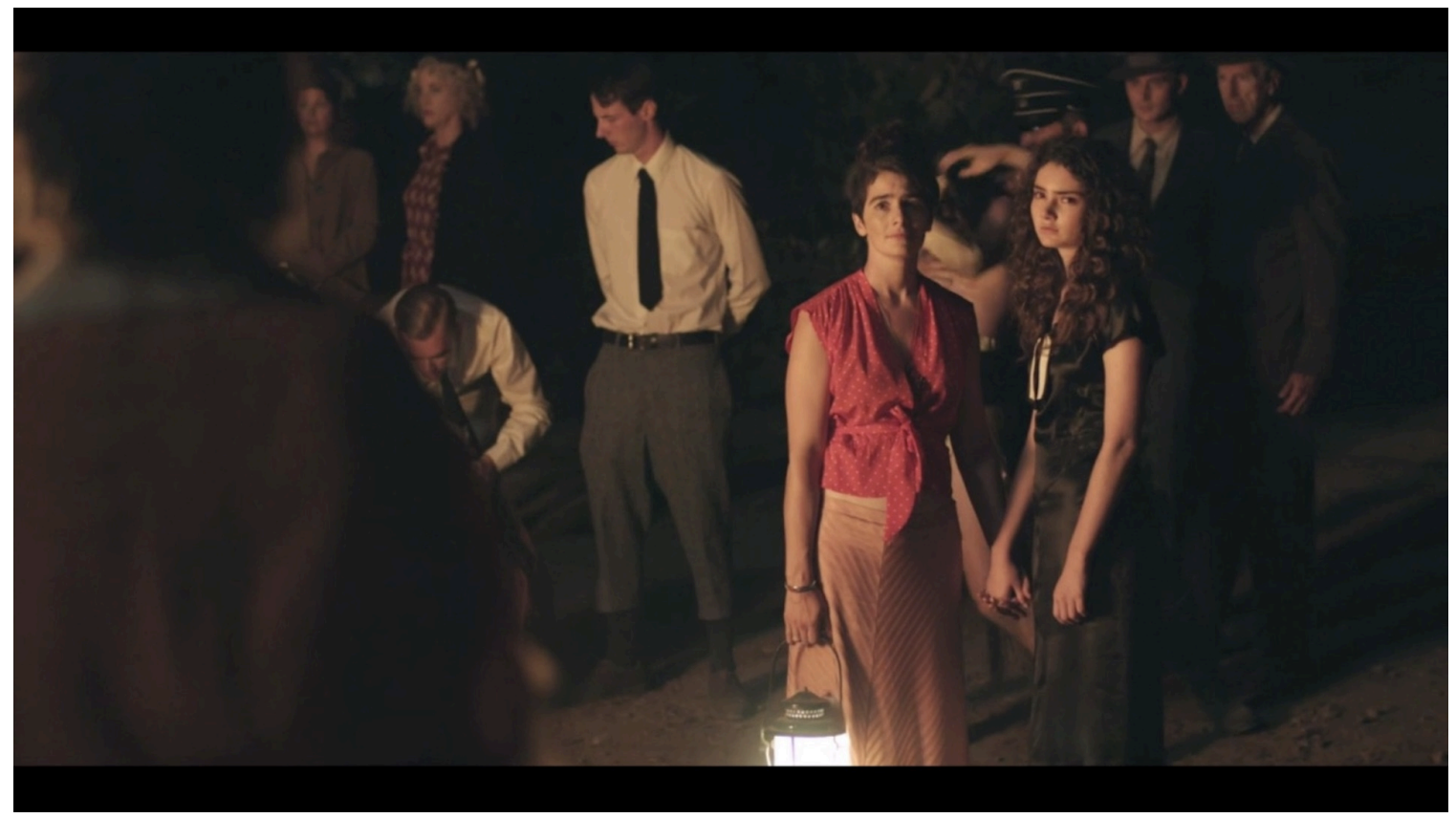

Ali and young Grandma Rose hold hands as they look toward Gittel. Screenshot taken by the author.

The scene's collapse of temporal boundaries around then and now imagines transgenerational bodily trauma as an epigenetic inheritance and choreographic movement sequence of terror and loss. As Ali's anguished expression lingers on-screen at the end of scene, the possibility of self-identification beyond her lived experience is, for these non-verbal moments on camera, both felt and seen. Like the extra-diegetic soundtrack's deafening effect, the scene instills a dizzying sense of characters that can't speak to each other. A waking dream of isolation and despair in the midst of a purportedly pro-women festival, the broken circle of the fireside scene frames the visceral experience of exclusion that drives the episode. 
In both Episodes 1 and 9, screendance scenes appear as filmic reveries, deploying dance and camera techniques to create trance-like states for individual figures and trans-like states for larger compositions of screenic bodies. Conjuring the past to explicate the present, both scenes use circular placements of bodies and camera pathways to deliver intense joy or pain. The first example does the former, flashing from a joyful Jewish wedding dance to a liberated queer Berlin in the 1930s. The second scene is a chimeric choreography of painful present-day harassment and harm, where the embodied encounter between characters and the ghosts of family members is a haunting return; not of monsters, but of the monstrous ways they were mistreated.

The work of the camera in these scenes choreographs rather than merely captures the affective connections unfolding in the plotline. ${ }^{15}$ And it does so through the blending of screendance modes with iconic Jewish ones. Micro-choreographies of the face and hands show feeling in ways that invoke screendance techniques of intimacy and expressivity. ${ }^{16}$ These tight shots also highlight the depth of ethnic connection animated in Jewish circular folk dances, where images of interlocked hands, shared smiles, and cross-circle gazing upon one another, exemplify the spirited nature of dancing together. Moreover, tight shots of the legs and feet convey details of the dancing that anchor the viewer in a literal and figurative understanding of weight. Heavy heels strike the floor with a rhythmic bounce as all on-camera dance the Horah's grapevine pattern. The focus on the step orients the viewer to the gravity of the movement, while also offering a choreographic metaphor of the collective weight of group identity.

Taken together, the bodily positioning of the characters and cameraperson establish circularity from the inside, allowing viewers to witness the action of bodies moving toward the center or pulled beyond the periphery. In other moments, the camera mimics the rotational action of body parts such as a wrist movement or the swirl of costumed fabrics, like Cousin Simon's cape that whipped through the air and into the past. In all cases, both body and camera traverse the space, which viewers take in from 360-degree views. The approach invites the audience to experience the dancing figures as if they were dancing along rather than watching a proscenium-styled documentation oriented towards a frontal plane. Furthermore, tight shots on faces, body parts, and contact points in which bodies across the circle are in view encourage a sense of being present in the space and the experience, which work with the especially festive or sorrowful soundscape to enhance the probability of kinesthetic empathy in the viewer. ${ }^{17}$

While circles are a repeating motif, the dancing bodies and dancing camera operate differently in each of these scenes. Deploying unique techniques of transhistorical juxtaposition, these scenes make symbolic use of circular themes that break with linear time and progression. Though proceeding in clear seasonal and episode sequence, these trans-screens extend the storyline while interrupting any chronological view of events. In this sense, the scenes offer important echoes of each other. As paired dances 
that rely on their cumulative power, they act as both narrative and affective devices that help drive the plot forward only to circle back and around. This circular theme informs the staging of bodies on screen as well as the camera techniques deployed to depict them. This compositional strategy represents and aestheticizes the biological and chosen family circle, the relationship to Jewish tradition through actual circle dances, the rounded relationship to time that suggests the cyclical movement of memory, the transitory aspects of identities in motion, and the epigenetics of trauma that return again and again with each new generation.

\section{Trans-face Embodiments and the Limits of Representation}

Transparent's huge success among U.S audiences exemplifies the ever-expanding embrace of niche programming on post-network TV that continues to stretch the boundaries of what and who can appear on screen. The show has won major gains for its representational politics, and the ways it showcases the humanity of transgender subjects either excluded from televisual subject matter or too often depicted as sex workers without a history worth remembering and without family support. ${ }^{18}$ Important too is the show's extension of the more familiar Jewish family portrait to include transgender subjects and experiences, which offers much needed revisions to the typical scripts of a heteronormative family whose aim is acculturation. ${ }^{19}$

Still, this well-intentioned circle drawn around Jewish and transgender identities deserves more critical attention. In depicting a layered "trans" frame that draws together themes of Jewish identity, family inheritance, and gender and sexual liberation, the show takes liberties to partner oppressed groups and histories with unequal histories; that is, as if they were equivalent, when they are not. Transparent's Second Season does so primarily through the inspiration of Magnus Hirschfeld, who was targeted by the Nazi party as a Jewish transsexual rights advocate. This is significant to note when understanding the ways that Season Two's screendance scenes reference especially legible Jewish American material, that is, the Jewish wedding and the Holocaust. Decades of popular media portrayals (think Fiddler on the Roof and Schindler's List) have created a broad audience familiarity with these Jewish contexts. In what I am arguing here, the visceral intensity of feeling that accompanies both Jewish wedding and Holocaust representations works to make it possible for audiences less familiar with transgender experiences and storylines to see and accept transgender identities on TV. In doing so, these screendance scenes create the affective conditions for viewers who understand Jewishness as always already abject, to also understand Jewish family trauma as a way to embrace other marginal identities less represented in the mainstream.

In addition to winning audiences across liberal post-network niches, Jewish insideroutsider tropes humanize abject experiences that the Jewish body has come to 
represent. In turn, transgender tropes reaffirm the openness of Jewish progressive discourse. When it comes to the history of Jewish pop cultural presentations, however, transgender subjects extend and revise a legacy of Jewish American corporeal representation that centers on the effeminate Jewish male. The most beloved Jewish figures in American television have been Woody Allen-esque schlemiels and viewed as such. In Transparent's cast of characters, however, many are women by birth or by choice, and a core aspect of the show appears to be the celebratory destabilization and reconfiguration of this longstanding masculine femme trope for both male and female Jewish characters. Refreshingly, transgender characters appear the most self-actualized of all. And yet, the show revolves around its featured lead, Maura, played by cisgendered Jewish male actor, Jeffrey Tambor.

Even as the performance of abject Jewishness arguably paves a humanizing way for transgender acceptance on post-network TV, the specific gendered history of Jewish bodies on-screen (always already effeminate), as well as the transgender impersonation of the lead actor, risks alienating the transgender subjects the show means to celebrate. ${ }^{20}$ As for this latter premise, it is easy enough to see Transparent's casting of its central character as troublingly appropriative, wherein "trans-face" may offer the next addition to a history of Jewish minstrel traditions (i.e. blackface, yellowface, redface, and self-othering Jewface). These performance impersonations, most popular for Jewish stage and screen performers of the early 20th century but arguably sustained ever since $^{21}$ were known to be as sympathetic in their intention as they are exploitative in practice. ${ }^{22}$ Such plays with otherness entailed the application of face make up, accompanying physical gestures, and vocal accents that often took on gender-bending characterizations for female performers. From vaudeville to minstrel circuits, the performance tradition established Jewish entertainers as comic chameleons that could play anything, anywhere. Putting on and taking off masks of more marginal figures meant performers could effectively distance themselves from the personages they parodied, however sympathetically or not. The casting of Tambor in the lead role begs this question of "trans-face" as the next of Jewish impersonations that appear especially harmful in light of his harassment. ${ }^{23}$

It is less clear, however, how Transparent works with longstanding representational tropes of Jewish men as always already womanish, and Jewish women as necessarily then more mannish (unattractive and unfeminine, and either sexually promiscuous or not available). If Jews on-screen are forever gender benders in this sense, or at the least, seen as gender non-binary and not by choice, how does a show about celebrating the possibility of actual gender diversity recuperate, reconfigure, or replace this representational script? And how does this history of Jewish male effeminacy on screen complicate the issue of Tambor's transgender impersonation as always already facilitated by the actor's Jewishness? 
Unfortunately, Tambor's actions off-camera interfered in the favorable possibilities of playing out these questions on screen. After receiving multiple prestigious awards for his performance as Maura, Tambor's trans-face role was abruptly interrupted when he was accused of sexually harassing two transwomen on set in December 2017. After the accusations against Tambor were confirmed by investigators in early 2018, Soloway fired her leading actor, issuing the public statement to The Hollwood Reporter saying she respected and admired Van Barnes and Trace Lysette for speaking out. ${ }^{24}$ As of summer 2018, Season Five has been delayed, but is proceeding without Tambor. ${ }^{25}$ I call this out to further complicate the show's altruistic efforts to draw parallels between Jewish and transgender suffering, and also to highlight Soloway's important lack of tolerance for his behavior, however difficult it must have been to proceed without the show's protagonist.

One productive takeaway of Tambor's failed trans-face is the light it sheds on the show's less than transparent conflation of ethnic and gender identity discourses, where perhaps too much is taken for granted. The casting choice of a non-transgender person in a transgender role might have remained okay for media-watch groups like GLAAD in the context of a show with record numbers of transgender actors and crew members were it not for Tambor's misconduct. However, what representational slides happen in the show's narrative conflation of Jewish and transgender stories? To what extent does this flatten discourses that are not the same, and not in the same stage of acceptance within the contemporary moment? This murky middle ground raises more questions about the ways the Season Two screendance scenes use devices of juxtaposition and circularity to depict the transgender, transgenerational possibility as a shared ring perhaps too naively.

There is no doubt that Tambor's actions break the protective circle of the Transparent family on-set and on-screen. Still, there is something else here, for me, left unresolved about the bad behavior of a Jewish father-mother figure and the question of transparency around representational stakes. In a show about loyalty no matter what and an understanding of pathologies dredged forward from the past, I can't help but wonder and worry about how Tambor's misogynist aggression comes from an ethnosexual inheritance, too, where the unchecked power abuses of Hollywood and Amazon celebrity status are mixed in with unaddressed effects of ethnic trauma. To what degree does Tambor's Jewishness, its histories of abjection in the US and also his particular experience growing up with alcoholic parents, account for but certainly not excuse some kind of transgenerational abused-to-abuser affliction? And what might it mean to posit an epigenetic scarring at the level of the body for Jewish men in strained (and trained) cycles of violence?

It is clear enough that Tambor's chauvinism off-camera fails to help the transgender liberation cause or the reparative transgenerational one, either for the Pfeffermans or the rest of us. As described by Seth Abramovitch in Hollywood Reporter, Tambor went 
"from LGBTQ folk hero to fugitive." ${ }^{26}$ And yet, I look back at the ways I experienced the celebrity's harassment like a shame on my own home and wonder what else there may be to say about Tambor's violence in the context of Jewish representation in popular culture during the age of the \#metoo movement.

I count the rising number of ousted celebrity men in Hollywood with Jewish names and ask them here at least for more transparency. Why the shmucky abuses of power? I am not alone in this critique. Writer Joseph Aaron of Chicago Jewish News wrote in the wake of Harvey Weinstein's expulsion from the Academy of Motion Picture Arts and Sciences and the slew of high-profile Jewish men that followed in fall of 2017 that "The last couple of weeks have been nothing short of a shandahfest, a shandapalooza for the Jewish people. Shandah being that great Yiddish word meaning intense shame."27 Adding emphasis, he argued, "It might be simpler for me to list all the Jewish men who have not been accused of sexual harassment than it would be to list all those Jewish men who have been." I find myself equally emphatic as Aaron then writes, "What in the hell is going on with us? Why have so many Jewish men been at the center of all this?" ${ }^{28}$

As I write, I know the consequences of my words. In a moment when Jews the world over face a dangerous resurgence of anti-Semitism, my challenge to Jewish men negotiating their own celebrity power may provoke fears in readers wondering if such a critique is "good for the Jews." ${ }^{29}$ The question lingers like an unanswered adage in cultural commentaries of American Jewishness not wanting unfavorable actions to be seen as broader ethnic phenomena. But in a show that so blatantly asks its Jewish viewers to question our own behavior in the context of generations past as a process of coming out and into more liberated versions of ourselves, Tambor's on- and off-camera character begs us to ask: What is the full range of cultural inheritances that encode our actions and experiences into scarred DNA, and how can our depictions of transgenerational memory help both access and re-pattern the fullest dimension of inherited trauma and cycles of abuse?

A different analysis of the show might focus on the slew of inappropriate and even aggressive decisions that each of the Pfefferman family member makes in excess throughout the show's four seasons. From predatory sex requests to any number of other self-serving tactics, the nuclear family appears prone to present-day manipulations played out in ways justified by the very transgenerational traumas (aka the Holocaust) underscored here. But in this essay's focus on screendance scenes, and the co-choreography of the bodily action and camera to invoke visceral instances of inclusion and exclusion, this final take on Tambor's misconduct necessarily muck up the copacetic, co-constitutive premise of the show's artful conjoining of transgender, transhistorical frames in ways that point to particular issues of internal versus external abuses. The sympathetic joys and pains aestheticized through the show's screendance scenes ultimately stand out most for their admittedly uncomplicated depictions of the family either working well together or pulled apart by external forces. Tambor's 
harassments move him from the former family bonds into the latter limitations on them, as he becomes the aggressive figure pulling the circle apart.

\section{Conclusion}

As I have tried to show, Transparent frames its central transgender coming out and all that it throws in question for the Pfefferman family through a transhistorical, transgenerational portrayal of their collective ethno-sexual past. It does so most potently through screendance sequences that emphasize a circularity of time and context, wherein dialogue stops and movement (plus costume, sound, and lighting design) takes over. It is this layered trans context that moves around and within, as opposed to merely across historical and gender boundaries that is matched by the circular movement of dancing bodies and camera. Framing this circular depiction of trans-ness as the show's key contribution to screendance scholarship, I have argued for a naming of Soloway's screendance scenes as "trans-screens" that deploy body and camera action to encircle and embrace bodies and identities in healing motion, whether through the joy of collective dancing, or the pain of lived and inherited trauma, that in a process of communal grieving, can begin to heal for present-day characters.

As the communal body moves in harmonious happiness or sadness together, the circle stays intact as choreographic motif, its characters belonging to the inside group. It is this feature of the screendance-styled scene for post-network TV that aestheticizes "edgy" and "oppositional" material to make it more digestible, and in turn more pardonable, operating on our senses in ways that engender kinesthetic empathy with the family and friends we come to know. It is this artful insertion of dance in the midst of the show's more controversial storylines that best helps viewers repeatedly embrace this family, their problems, and their transitions within the circle frame. In that transgender, transhistorical view of a Jewish family's collective coming out, however, questions remain about the ethics of representation or even impersonation, when actors are less generous, and less transparent, than their roles.

\section{Biography}

Hannah Schwadron writes and dances on Jewish themes, and is author of The Case of the Sexy Jewess: Dance, Gender, and Jewish Joke-work in US Pop Culture (OUP, 2018). Other essays appear in Liminalities, PARtake, Choreographic Practices, The Oxford Handbooks on Dance and Politics and Dance and Music, and the Dancer-Citizen. Her dance film Klasse 
(Germany, 2015), made with director Malia Bruker and a cast of middle school students, won Dance Film Association's Production Grant, and has shown at Washington Jewish Film Festival, American Dance Festival, Antimatter [Media Art], Tiny Dance Film Fest, Israelitische Töchterschule, Third Coast Dance Film Festival (Spirit of the Festival award), and ScreenDance Miami (Audience Choice award). Her second screendance Between I and Thou (Germany, 2017), has shown at Little Mexico Film Festival, Docs Wthout Borders, and Toronto Short Film Festival, and Richmond International Film Festival. She is Assistant Professor of Dance at Florida State University.

Email: HSchwadron@fsu.edu

\section{Notes}

${ }^{1}$ Post-network TV is that matrix of broadcast networks, cable channels, web outlets, and streaming media we access by now without much thought, but which is always thinking about us as it programs ever-edgier content its numbers show we want to see. After corporate firms like Viacom and Time Warner raced to catch up with the pace of cultural change in the 1980s and 90s, twenty-odd years of post-network television has evolved single-channel shows to infinite iterations made for nicheviewer devotees; smaller market segments with bigger gains. The term "post-network" was coined by Amanda D. Lotz, The Television Will Be Revolutionized.

${ }^{2}$ Nick Marx, "Expanding the Brand," 275.

${ }^{3}$ Ann Friedman, "TV's New Revolutionary."

${ }^{4}$ Ibid. According to Friedman's interview with Zackary Druker, who, along with her partner, Rhys Ernst, was hired by Soloway as a consultant to ensure the show was portraying transgender lives authentically, "There is absolutely a social-justice mission to what we do in addition to creating art...Jill's really shown herself to be such a huge ally to the community."

${ }^{5}$ Since Transparent aired in 2014, the show has won countless awards, including the 2015 Golden Globes Best Television Series and Best Performance by an Actor in a Television Series; 2015 and 2016 Primetime Emmy Awards in Outstanding Lead Actor in a Comedy Series for Jeffrey Tambor's role as Maura, Outstanding Director of a 
Comedy Series for Jill Soloway, among others; 2016 BAFTA TV award for Best International program; 2016 Screen Actors Guild Awards for Outstanding awards by a Male Actor in a Comedy Series; 2015 AFI award for TV Program of the Year; Casting Society of America award in 2016 and 2017 for Outstanding Achievement in Casting; Critics Choice Television Awards in 2015 and 2016 for Best Actor in a Comedy Series, and many more.

"Soloway's cinematographer, Jim Frohna told Indiewire that "Jill asked me to join her and the cast at rehearsals with indie filmmaking guru and consulting producer Joan Scheckel. The time spent was not about running scenes, but about exploring character, relationship and emotion - all with music and through movement. Jill or Joan would call out specific actions: 'Go to the person who you feel most connected to, or least connected to,' for example. And while I had my still camera there to document moments for possible reference, I was participating as fully as the actors were. That's a treasure for a DP. And it was fantastic." See Valentina I. Valentini, "Shooting 'Transparent."'

${ }^{7}$ lbid.

${ }^{8}$ Matt Wilstein, "Jay Duplass on 'Transparent' Without Jeffrey Tambor and His Most Devastating Role Yet."

${ }^{9}$ lbid.

${ }^{10}$ Dan Hurley, "Grandma's Experiences Leave a Mark on Your Genes."

${ }^{11}$ Rosy Simas, "We Wait in the Darkness."

${ }^{12}$ For New York Times TV critic Rachel Syme, Soloway's "exaggerated lens" mirrors Sarah's unease in marrying Tammy (Melora Hardin) through "a kind of glitterbomb of nauseating excess: the overlined lips of the chanteuse, the bouncing of the dancing crowd, the kind of sickly yellow light cast over the whole party." Such techniques help foment the feeling of "commitment-phobia" which Syme says plagues the family. Syme, "Transparent' Season 2 Premiere."

${ }^{13}$ Kyla Bills, "A Guide to Transparent Season Two's LBGT plotline." In February 1933, the Nazi Party launched an LBGT purge in Berlin. The books of the Institute were destroyed and the Institute itself closed, ending the golden era of Berlin LGBT life. Between 1933 and 1945, over 100,000 men were arrested for being homosexual. Many were sent to concentration camps, although the exact number is unknown.

${ }^{14}$ See Robert Beachy, Gay Berlin.

${ }^{15}$ Douglas Rosenberg, "Introduction," 6.

${ }^{16}$ See Erin Brannigan, "Micro-Choreographies." 
${ }^{17}$ Karen Wood, "Kinesthetic Empathy," 247. According to Wood's explication of kinesthetic empathy in screendance, the viewer's mirror neurons fire not only because of identification with the characters and content, but also because of the unique work of dance on camera. While she bemoans the lack of research on the kinesthetic experience of watching screendance, Wood confirms the rich body of scholarship on emotion elicitation in film studies, which is implicitly linked to kinesthetic empathy.

${ }^{18}$ For more on this, see John Phillips, Transgender on Screen; Joyelle Ruby Ryan, Reel Gender; and Theresa Carilli and Jane Campell, Queer Media Images.

${ }^{19}$ Such filmic representation of Jewish acculturation started arguably with the first "talkie" The Jazz Singer and has reiterated across a century of Jewish representation in Hollywood films such as Funny Girl (1968), Portnoy's Complaint (1970), and Annie Hall (1977) as serious and humorous content.

${ }^{20}$ See for instance Daniel Boyarin, Unheroic Conduct.

${ }^{21}$ See Hannah Schwadron, The Case of the Sexy Jewess.

${ }^{22}$ As Jews navigated positions of alterity, scholarship on the subject disagrees over the extent to which these race and gender impersonations engendered empathetic allegiances to other Others even as such performance practices assisted the process of assimilation. For helpful histories of this debate regarding Jewish race impersonation in live and screen performance as well as literature, see Eric Lott, Love and Theft; Michael Rogin, Blackface, White Noise; Lori Harrison-Kahan, The White Negress; and Schwadron.

${ }^{23}$ See Stacey Wilson Hunt's interview for Vulture Magazine with actress Alexandra Billings ("Davina"); producer Zackary Drucker; producer Rhys Ernst; actress Alexandra Grey ("Elizah Edwards"); director Silas Howard; writer Ali Liebegott; actress Trace Lysette ("Shea"); and writer Our Lady J, on how the series has changed the way television tells trans stories, the hopefulness they now feel for trans children, and why they disagree on how important it is to cast trans people in transgender roles. Stacey Wilson Hunt, "How TV is Breaking Into Us."

${ }^{24}$ See Lesley Goldberg, "Jeffrey Tambor Officially Dropped." In her official statement Soloway said, "We are grateful to the many trans people who have supported our vision for Transparent since its inception and remain heartbroken about the pain and mistrust their experience has generated in our community. We are taking definitive action to ensure our workplace respects the safety and dignity of every individual, and are taking steps to heal as a family."

${ }^{25}$ Clarisse Loughrey, "Transparent season 5 delayed." 
${ }^{26}$ Seth Abramovitch, "'Lines Got Blurred.'”

27 Joseph Aaron, "Anti-Bris Jewish Men." Aaron bemoans a growing list as of fall 2017 of Jewish men in Hollywood called out for sexual abuse. He writes, "TV commentator Mark Halperin and magazine writer Leon Wieseltier and director James Toback and producer Brett Ratner and head of Amazon studios Roy Price and actors Dustin Hoffman and Richard Dreyfuss and Jeremy Piven and Jeffrey Tambor, who plays the head of a Jewish family in his series 'Transparent,' which last season was largely set in Israel, and NPR news chief Michael Oreskes and comedian Louis CK, whose grandfather was born Jewish and whose father converted to Orthodox Judaism. I could name another ten. Indeed, even though Jews are a minority, they are a majority of those recently accused of being sexual harassers."

${ }^{28}$ Ibid.

${ }^{29}$ See the same line of questioning in Grace Overbeke, "The Case of The Sexy Jewess," a review of my book of the same title.

\section{References}

Aaron, Joseph. “Anti-Bris Jewish Men." Chicago Jewish News. Posted 16 Nov 2017. https://www.chicagojewishnews.com/2017/11/anti-bris-jewish-men/

Abramovitch, Seth. "'Lines Got Blurred': Jeffrey Tambor and an Up-Close Look at Harassment Claims on 'Transparent.'" Hollywood Reporter. Posted on 7 May 2018. https://www.hollywoodreporter.com/features/lines-got-blurred-jeffrey-tambor-an-upclose-look-at-harassment-claims-transparent-1108939

Annie Hall. Directed by Woody Allen. Los Angeles: Jack Rollins \& Charles H. Joffe Productions, 1977.

Beachy, Robert. Gay Berlin: Birthplace of Modern Identity. New York City: Vintage Books, 2014.

Bench, Harmony. "Screendance: Inscribing the Ephemeral Image by Douglas Rosenberg, and Dancefilm: Choreography and the Moving Image by Erin Brannigan." Dance Research Journal 45.2 (2013): 132-138. https://doi.org/10.1017/S0149767713000053

Bills, Kyla. "A Guide to Transparent Season Two's LGBT plotline" Posted 12 December 2015. https://milk.xyz/articles/a-guide-to-transparent-season-twos-historical-lgbtplotline/ 
Boyarin, Daniel. Unheroic Conduct: The Rise of Heterosexuality and the Invention of the Jewish Man. Berkeley: University of Califonia Press, 1997.

Brannigan, Erin. "Micro-Choreographies: The Close-Up in Dancefilm." International Journal of Performance Arts and Digital Media 5.2-3 (2009): 121-139.

https://doi.org/10.1386/padm.5.2-3.121/1

Carilli, Theresa and Jane Campell, eds. Queer Media Images: LGBT Perspectives. Maryland: Lexington Books, 2013.

Fiddler on the Roof. Directed by Norman Jewison. Los Angeles: The Mirisch Production Company, 1971.

Friedman, Ann. "TV's New Revolutionary: How Jill Soloway Is Singlehandedly Changing the Game." Posted on 27 Oct 2015. https://www.marieclaire.com/culture/a16338/jillsoloway-profile/

Funny Girl. Directed by William Wyler. Los Angeles: Columbia Pictures Corporation, 1968.

Goldberg, Lesley. "Jeffrey Tambor Officially Dropped From 'Transparent' in Wake of Harassment Claims." The Hollywood Reporter. Posted 15 February, 2018.

https://www.hollywoodreporter.com/live-feed/jeffrey-tambor-officially-firedtransparent-wake-harassment-claims-1085236

Hager, Jenna Bush. "Jeffrey Tambor \& 'Transparent' Cast: The World Has Changed." TODAY. Posted 25 June, 2015. https://www.youtube.com/watch?v=DPXU8TIM9_U

Harrison-Kahan, Lori. The White Negress: Literature, Minstrelsy, and the Black-Jewish Imaginary. Piscataway: Rutgers University Press, 2011.

Hunt, Stacey Wilson. "How TV is Breaking Into Us." Vulture Magazine. Posted 28 September 2016.

Hurley, Dan. "Grandma's Experiences Leave a Mark on Your Genes." Discover Magazine. Posted 25 June 2015. http://discovermagazine.com/2013/may/13-grandmasexperiences-leave-epigenetic-mark-on-your-genes

The Jazz Singer. Directed by Alan Crosland. Los Angeles: Warner Brothers, 1927. Lott, Eric. Love and Theft: Blackface Minstrelsy and the American Working Class. New York City: Oxford University Press, 1993.

Lotz, Amanda D. The Television Will Be Revolutionized. New York City: New York University Press, 2007. 
Loughrey, Clarisse. "Transparent Season 5 Delayed in Wake of Jeffrey Tambor allegations" Independent. Posted 8 March 2018. https://www.independent.co.uk/artsentertainment/tv/news/transparent-season-5-delayed-2019-jeffrey-tambor-quitssexual-harassment-allegations-a8245481.html

Marx, Nick. "Expanding the Brand: Race, Gender, and the Post-Politics of Representation on Comedy Central." Television \& New Media 17. 3 (2016): 275.

Overbeke, Grace Kessler. "The Case of The Sexy Jewess: Dance, Gender, and Joke-Work in U.S. Pop Culture by Hannah Schwadron (review)." Theater Journal 70.2 (2018): 265267. https://doi.org/10.1353/tj.2018.0046

Phillips, John. Transgender on Screen. London: Palgrave Macmillian, 2006. https://doi.org/10.1057/9780230596337

Portnoys Complaint. Directed by Ernest Lehman. Los Angeles: Chenault Productions, 1972.

Rogin, Michael. Blackface, White Noise: Jewish Immigrants in the Hollywood Melting Pot. Berkeley: University of California Press, 1998.

Rosenberg, Douglas. "Introduction." In The Oxford Handbook of Screendance Studies. Ed. Douglas Rosenberg. New York City: Oxford University Press, 2016. 1-22.

https://doi.org/10.1093/oxfordhb/9780199981601.013.37

Ryan, Joelle Ruby. Reel Gender: Examining the Politics of Trans Images In Film And Media. Ohio: Bowling Green State University Popular Press, 2009.

Schwadron, Hannah. The Case of the Sexy Jewess: Dance, Gender, and Jewish Joke-work in US Pop Culture. Oxford University Press, 2018.

Schindler's List. Directed by Steven Spielberg, Los Angeles: Universal Pictures, 1993.

Simas, Rosy. "My Making of We Wait in the Darkness." Dance Research Journal 48.1 (2016): 29-32. https://doi.org/10.1017/S0149767716000073

Syme, Rachel. "Transparent' Season 2 Premiere: Hava Nagila and Kina Hora." The New York Times. Posted 11 Dec 2015.

https://www.nytimes.com/2015/12/10/arts/television/transparent-season-2-premierereview.html

"Transparent: Cast Members Talk Season 4, Character Dynamics \& Much More." Entertainment Weekly. Posted on 24 Oct 2016.

https://www.youtube.com/watch?v=h0ixqGJlvTY

Valentini, Valentina I. "Shooting 'Transparent': From Rehearsal to Lenses to Intimate Family Drama." IndieWire. Posted on 7 Oct 2014. 
https://www.indiewire.com/2014/10/shooting-transparent-from-rehearsal-to-lensesto-intimate-family-drama-69326/

Wilstein, Matt. "Jay Duplass on 'Transparent' Without Jeffrey Tambor and His Most Devastating Role Yet." Posted on 23 March 2018. https://www.thedailybeast.com/jayduplass-on-transparent-without-jeffrey-tambor-and-his-most-devastating-role-yet

Wood, Karen. "Kinesthetic Empathy: Conditions for Viewing." In The Oxford Handbook of Screendance Studies. Ed. Douglas Rosenberg. New York City: Oxford University Press, 2016. 245-262. 


\title{
Mr. Gaga: Embodying the Exceptionalism of Ohad Naharin
}

\author{
Dr. Meghan Quinlan, Independent Scholar
}

\begin{abstract}
The life and work of Israeli choreographer Ohad Naharin are documented in the 2015 film by Tomer Heymann, Mr. Gaga. With nearly a decade of footage from following Naharin's work with the Batsheva Dance Company, the documentary celebrates Naharin's life with abundant footage from his choreographic successes. This article explores the ways in which this film, like many dance documentaries, uses dance footage in strategic ways to present dance artists as exceptional. In Mr.Gaga in particular, the national and cultural specificity of the story and footage portrayed in the film require critical analysis to better understand subtle political undertones and bias embedded in the film's otherwise primarily aesthetic focus.
\end{abstract}

Keywords: Gaga, Naharin, Israel, documentary, politics

Mr. Gaga, subtitled "A True Story of Love and Dance," is a documentary consisting of family archives, interviews, and raw footage filmed by Tomer Heymann over an eightyear period of observing Israeli choreographer Ohad Naharin and his work. First released to the public in October 2015, the film has won multiple awards and laudatory reviews at international film festivals, and as of 2017 was publicly released on DVD and streaming via platforms such as Netflix. Described on the official Mr. Gaga website as the "story of an artistic genius who redefined the language of modern dance,"1 the film tells the story of how Naharin - the creator of the dance practice known as Gaga and the former Artistic Director of Israel's Batsheva Dance Company ${ }^{2}$ - became the worldrenowned choreographer he is today. Between performance vignettes of the company, Heymann weaves a loose narrative from interviews with Naharin, as well as his former teachers, company dancers, family members, and friends. The story, told somewhat chronologically, follows Naharin's childhood in a kibbutz in Israel to his service in the Israeli army, to New York and his early experiments with choreography, and back to Israel to his current success with Gaga and the Batsheva Dance Company. True to the subtitle the film focuses on love and dance. Yet, I suggest that it represents a fetishization of Naharin's dancing career in addition to a loosely structured narrative about Naharin's romantic loves or love for dance. Tomer Heymann's filmmaking style creates an undeniable favoritism of Naharin. While not uncommon in documentaries of choreographers, this preferentialism is amplified by his methodology of becoming personally attached to his documentary subjects. At nearly every turn, Naharin is 
presented as exceptional: as a dancer, a choreographer, and a person. What this version of his life story emphasizes is highly subjective perspectives and praise, bolstered by substantial footage of a world-famous dance company, which often overlooks the larger frameworks in which his work and words circulate. In what follows I offer a critical reading of the work that unpacks the ways in which Mr. Gaga presents Naharin in line with other dance documentaries or challenges the genre at times, and a consideration of the ways in which Naharin and his work are fetishized as exceptional in a manner that largely ignores cultural and political frameworks that shape the production and reception of his work. Ultimately, I argue that the dance sequences used in this film are strategically placed to highlight connections to Israeli culture and politics as well as the success of his aesthetic point of view. In this way, Heymann presents a view of Naharin and his work that is directly tied to issues that Naharin often denies in interviews, thus giving his exceptionalism political as well as aesthetic significance.

\section{Dance Sequences and the Genius Figure}

Over the past decade, a great number of documentaries about extraordinary contemporary dance artists have been released alongside the production of more performance-oriented dancefilms. Many of these films have even surpassed the usual dance audiences to earn widespread appeal, such as Wim Wender's Pina (2011) and Mr. Gaga. There are still many others that may not have gathered as much interest, at least by mainstream English-speaking cultural consumers, but are now available via streaming platforms such as Netflix and Amazon Prime. Not unlike early written dance histories, the focus of the majority of these films are standalone choreographers with a depth of works to explore: examples of the artistic genius. As Douglas Rosenberg notes in his introduction to the Oxford Handbook of Screendance Studies,

For a significant number of artists, screendance in practice is a small part of a larger engagement with the arts. For some, a relationship with screendance per se only occurs when a project seems to situate itself within an exhibition opportunity or funding stream or simply out of an interest in the field. ${ }^{3}$

Similarly, it is rarely the artists that seek out documentaries on their own work - they are often drawn into it by the interest of a filmmaker intrigued with their work or life. In Mr. Gaga, which is structured somewhere between a dancefilm and a non-fictionalized biopic, ${ }^{4}$ there are sequences of dance scenes cut together with interviews and other life background. The way in which they are spliced together attempt to draw in viewers unfamiliar with dance by exploiting the most sensational moments of a choreographer's oeuvre. At times, such scenes are used to change the mood of the stories told in interview segments, or to illustrate a point being made verbally. Yet, frustratingly enough for those unfamiliar with dance styles and conventions, there is 
rarely much analysis or unpacking of these dance scenes which are ostensibly supposed to contribute to the narrative structure and meaning of documentary films rather than serve as sheer sensationalism.

The performance footage in Mr. Gaga constitutes an attention-grabbing utilization of dance in the documentary of Naharin's life and work. Whereas scenes of Naharin in the studio with dancers often includes speech that helps viewers contextualize his thought process or vision behind his actions, performances by Batsheva are often set apart with little explanation to the audience, seemingly to amuse and entertain rather than illustrate a particular idea or concept. Take, for instance, the first scene of the film. The camera focuses on a single female dancer, Maya Tamir, who slowly raises her left leg through a passé to an inwardly rotated extension just above hip height with her torso leaning to the right. As she releases her control slightly to begin the leg's descent, a deep male voice is heard. "Beautiful." On the left side of the screen, a dark blur comes into clearer focus, revealing itself as the back of Ohad Naharin's head. We continue to watch Naharin watching Tamir as she brings her leg back to the ground and slowly undulates her body in a slightly contracted position. The camera cuts to show Naharin observing the rehearsal before cutting back to Tamir. She is now arched backward, forcefully shaking her entire body before collapsing backwards onto the ground. "Let's stop," Naharin announces, before chastising Tamir about the way she is performing the fall. With his coaching she performs the movement three more times before he stands up to demonstrate. "Instead of going back, just let it happen," he explains from the floor, echoing concepts often heard in Gaga classes about letting yourself be moved by outside forces. The screen cuts to several short clips of her practicing the fall again in quick repetition, emphasizing the demanding process she is being put through. She begins with the quake-a fairly common Gaga movement idea-and collapses more quickly, presumably to Naharin's satisfaction, and the film cuts to a dynamic rhythm and footage of Naharin's choreography "Echad Mi Yodea" ${ }^{5}$ to begin a series of opening credits.

The drum pounds as a large group of dancers enter the stage to join the semi-circle of dancers standing in front of wooden chairs, wearing uniform black suits and hats that contrast from the dusty colored costumes for Mamootot (2003) shown in the opening scene. The title of the film, Mr Gaga: A True Story of Love and Dance, is displayed in black and white above the dancers getting into position. Although normally performed with the company in a semi-circle, what is shown seems to be a reunion of dancers performing the work en masse facing the audience in lines. As the Hebrew words of the Passover song are heard, "Shivah mi yodea?" then "Shivah ani yodea" and finally "Shivah y'mei shabta..." (Seven, who knows? Seven, I know seven. Seven are the days of the week until Shabbat...) Director Tomer Heymann's name appears and the dancers stand up and begin the repetitive dance as the song counts down through a series of common Jewish motifs and teachings, unintelligible to nonHebrew speaking audiences. The singing pauses for a rhythmic slowdown 
preceding the next repetition including the number eight as the dancers once again sit slowly in their chairs, and the screen fades to footage of a young Naharin dancing in a garden in 1969, indicated by on-screen text. While the scene is aesthetically gripping - this is, indeed, one of Naharin's most famous and staged works-the dancing is contextualized only by the demanding nature of Naharin's direction seen in the previous studio scene, then followed by a familiar trope in documentaries of genius figures to delve into the choreographer's past. The significance of this work and its Jewish references-which later contributed to the infamous 1998 "gatkes incident" 6 -is not explored until over halfway through the film, leaving the significance of this particular footage used as an introduction to be more aesthetically driving than narratively or politically relevant.

The motif of varied selections of striking performance footage from throughout Naharin's career repeats during the film, alongside more thoroughly integrated archival footage and performances by Naharin or his contemporaries in New York in the 1980s that illustrate his journey. Though we learn more about Naharin, Batsheva, and his choreographic process as a whole throughout the film, the particularity of the short dance sequences by Batsheva highlighted during interview voice-overs are rarely integrated into the narrative arc of the film. At times the footage illustrates the mood, such as a clip of several dancers lying on the ground as if dead in Mamootot's drab costumes while Naharin discusses witnessing atrocities during military service, followed soon after by a clip from Sadeh21 (2011) that features a group of men stomping and chanting in rhythm as if soldiers. The connections found between Naharin's early life and these later choreographies implies that his upbringing has deeply influenced his current work, though in interviews outside of the film Naharin often rejects any sort of Israeli reading or specificity for his choreographies. Interestingly, the dance sequences highlighted during the story of his childhood are the most obviously aesthetically evocative of the ideas introduced in the narratives, though the statement that Naharin's Israeli-ness deeply influences his work is never explicitly said. Throughout the majority of the rest of the film, the dance sequences directly relate to the era or work in Naharin's past being discussed in the voiceover, eventually becoming more about illustrating his successes in artistry than any specific mood or idea.

It is only in rare moments that the dance scenes seem to effectively imply a deeper analysis of a situation than is portrayed in the interviews and voiceovers, without investigating it further. One such instance is when Naharin's first wife, Mari Kajiwara, is introduced in the film. The transition into this love affair is voiced over a scene from Sadeh21, where dancers are falling off of a back wall on the stage into an unseen abyss. The trope of "falling" for someone is quickly let go, however, in favor of more literal footage of their early years dancing together. Though the documentary mentions some of their many differences - initially their nationality and training backgrounds, and later Kajiwara's discomfort with the Hebrew language and living in Israel_-it also uses subtle 
cues from dance scenes to suggest differences not deeply explored in the film. When introducing Kajiwara'a work as a famed Alvin Ailey dancer, for instance, Heymann selected a moving duet from Revelations (1960) that highlighted her fluidity and grace. While the voiceover talked about her technical prowess, however, the imagery of a crucifix created by her male partner holding up her limp body and the crooning of a singer exclaiming "fix me, Jesus" introduces the question of religious and cultural difference between the two artists that is not explored explicitly in the film. As with much of Mr.Gaga, these short cuts of performances that call out for deeper investigation into Naharin's life and work are quickly edited to thrilling clips of his contemporary choreographic success, failing to engage with deeper narratives.

The success of these dance scenes-which are often referenced in positive reviews of the film-are a testament to the phenomenal filming of these more contemporary clips and the accessibility of Naharin's choreography to audiences largely unfamiliar with concert dance histories and conventions, as noted by several authors of reviews. The range of angles, the high quality of the footage, the driving music, and of course the dynamism of the movement itself marks a sharp contrast to much of the archival footage which appears grainy, washed out, and arguably stuffy in comparison to the more recent footage.

Dance sequences - tied to the narrative or not-are fundamental to the concept of a dancefilm. The mood and appeal of the film depends deeply on the type of dancing portrayed. Many "biopics" that introduce famous choreographers, both past and present, have similar narrative trajectories: coming of age, introduction to dance, some sort of barrier or setback to success such as injury or limited resources, and examples of their most popular works combined with insight into their choreographic process. The aesthetics of the dances produced by "genius" figures contributes to each film's appeal. It is perhaps for this reason, then, that films documenting the "greats" are generally better-received than portraits of emerging artists. For instance, one of Naharin's former company members, Bobbi Jene Smith, was the subject of an intimate documentary released in 2017, at nearly the same time that Mr. Gaga was finally coming to Netflix and DVD in the US after a successful round of showings at festivals and art houses across the world. Rather than an overview of her successes, the film Bobbi Jene documented the dancer's process of leaving Batsheva and navigating both personal relationships and goals with her emerging independent artistry. The critical response to the film paled in comparison to Mr.Gaga. In a particularly scathing review, critic Sheila O'Malley complains that the story told is too banal and does not sufficiently illustrate the artist apart from her life. Yet, is her problem with the subject of the work, or the aesthetics of the dancing produced by Smith? The importance of aesthetics can be seen in her closing paragraph:

Earlier this year, Tomer Heymann's documentary "Mr. Gaga," profiled Ohad Naharin and his work with Batsheva. Naharin is intimidating, handsome and 
intense, and he makes a compelling central figure. But "Mr. Gaga" was also a riveting dance film, its camera work and visual style carefully designed to capture Naharin's choreography in such a visceral way that watching the film was the next best thing to being there in the theatre. "Bobbi Jene" suffers by comparison, although the problem goes deeper than that. Lind has not found a way to show us what she finds so interesting in Smith. ${ }^{7}$

Describing Mr. Gaga as a "riveting dance film" in a review of Bobbi Jene implies that Bobbi Jene is dull, raising the question of whether this is due to the dancing, the subject of the film, or both. Though critics commonly refer to Naharin as an enticing subject because of his intensity and good looks, I argue that the dancing itself is what drives the mainstream popularity of Mr. Gaga. In spite of some criticism of the narrative structure of the film, nearly every review comments on the "strong vignettes," 8 and how it is "an intense pleasure: the extensive footage of Naharin's choreography in performances over the years, beautifully captured by Ital Rziel, gives an intimate and thrilling glimpse of what he is all about." ${ }^{\prime 9}$ While such comments speak to the popularity of the filmparticularly among Naharin's existing fanbase-a critical scholarly view of the film requires further analysis of filmmaker Tomer Heymann's approach to putting the story and the dance scenes together to understand subtle and perhaps subconscious messages about Naharin's value or status as an artistic figure both internationally and specifically within Israel.

\section{A Sabra's Story}

The story of Naharin's artistic growth and current success, of course framed and largely determined by the quality of the footage of his choreographic works, is also deeply informed by the perspective of filmmaker Tomer Heymann and their shared interests and backgrounds. Not only is Heymann well known for his personal connection with his documentary subjects, but the work of Naharin in particular appeals closely to themes commonly explored in Heymann's films: love, Israel, and gender/sexuality. Several other films created by Tomer Heymann focus on issues of sex and gender in Israeli society, such as Who's Gonna Love Me Now? (2016) which focuses on a queer man who left Israel after being kicked out of a kibbutz and I Shot My Love (2009), a telling of Tomer Heymann's love affair with a German man and their relationship to Heymann's Israeli mother. Mr. Gaga, too, focuses on issues of sexuality and romantic love as a theme to bind together Naharin's history and the variety of dance footage. In a Kickstarter video requesting funding for the making of the film, Heymann explains how he has known "Ohad Naharin more than 20 years" and "always wanted to make a film about him, but he never agreed." ${ }^{10}$ Later in the clip, he showcases his friendship with Naharin as they

collectively ask for help funding the final editing process. After shaking his head and resting it on Tomer Heymann's arm, Naharin laughs and states: "No, seriously, seriously, give him the money and let him finish the movie. Really. It's enough, enough, seven 
years..."11 They continue to joke about Naharin wanting him to be done with his years of filming before ending the statement with a warm handshake and a short kiss on the lips. Unsurprisingly, the editing of the film portrays Naharin in an extremely laudatory light, as do the majority of dance documentaries. In the pursuit of one artist, a filmmaker, documenting the life and work of another artist, a choreographer, one might expect a great deal of creative interpretation. Yet scholars of creativity and screen studies Susan Kerrigan and Phillip Mclntyre suggest that:

...it is possible to map a documentary film-maker's processes using the framework of the creative system's model ... it also emphasizes how significant it is for a documentary film-maker to have internalized those domain rules, conventions and knowledges contained in film and video production skills, as well as the way the field's opinions are formed (Csikszentmihalyi 1995: online), which makes their creative process appear to others as being implicit, tacit and seamless. ${ }^{12}$

In Mr. Gaga, Heymann uses such documentary conventions to portray an obvious adoration of Naharin and his work. This love, combined with their shared backgrounds as Israeli artists, requires a critical perspective on the cultural and political framing that influences the work and how it may be perceived as it is shown internationally, especially by non-Israeli audiences unfamiliar with their national narratives and norms.

In this particular film, there are a series of life events that lay the foundation for the subjective editing of interviews, choreographic excerpts, and other voiceovers: an overview of Ohad Naharin's history, with an emphasis on his Israeli identity. He was born on Kibbutz Mizra in Israel in 1952. Growing up on a kibbutz he experienced a great deal of play and freedom, but he had no official dance training during this time. When called to his mandatory military service, he was allowed to serve in the entertainment division rather than in combat because of an ankle injury. In this role he often choreographed little numbers, excerpts of which are shown in Mr. Gaga featuring a young, fit, and tan Naharin singing and dancing with a group of men and women wearing well-fitting Israeli Defense Force uniforms. Upon completion of military service, he was encouraged by his mother to audition for the Batsheva Dance Company in Tel Aviv, then led by Martha Graham, where he was immediately accepted into the company. In the film, both Naharin and former teachers and peers recount Graham's affection for him, and his ability to jump right into compelling dancing without prior experience - all evidence of his future path to become an artistic "genius." He soon moved to New York City to further his training in ballet and modern dance forms, all of which he rejected in favor of his personal movement research and choreographic endeavors. Although he had success in New York and fell in love with Alvin Ailey dancer Mari Kajiwara, he is represented as largely unhappy while living abroad through scenes such as Naharin solemnly singing "Nobody Knows the Trouble I've Seen" naked in the bathtub. When he was invited in 1990 to return to Israel and lead the then-failing Batsheva Dance 
Company, he leapt at the opportunity to return home. From there, the legend is well documented. He quickly turned the company around, introduced his personal movement research and named the practice Gaga by 2003, and provoked controversy in Israel over artistic censorship during the infamous 'gatkes incident' in Jerusalem at what presenters called a "jubilee program" celebrating Israel's 50th anniversary as an independent nation-state. Since then, his consistent production of choreographic works and success with Batsheva have helped him become a celebrated choreographer not only in Israel but internationally in the contemporary dance community. ${ }^{13}$

Throughout this history, Naharin's identity as a native-born Sabra is integrated to promote popular Zionist tropes throughout the film such as a specific form of Israeli masculinity that allows him to be both a heterosexual and homosexual object of desire, and an empowered man who can wear a long red dress to great applause as shown in some of the film's archival footage. The film also presents, at times, what I consider to be aggressive behavior from Naharin, especially as recounted by his previous dancers. The Sabra - a cactus with a prickly exterior and a sweet inside-has become a symbol and name for Jews born in the State of Israel (or, before 1948, Palestine), and represents important shifts in public perception of Jewish people as a result of Zionist politics that emerged throughout the twentieth century. The ways in which Naharin's body is consistently objectified throughout the film as both himself and others refer to his sexiness or attractiveness and interviews with former dancers that laughingly reminisce about his harsh demeanor all play into Zionist tropes of new conceptions of Jewish corporeality and identity. Similar connections between Israeli histories such as kibbutz upbringings and horrifying moments in military service are made in the film by editing such references with contemporary choreographic works that visually illustrate the passion, animalism, terror, and other feelings brought up in the verbal telling of Naharin's - and Israel's - historical background.

Central to the Zionist project during its early stages in the late nineteenth and early twentieth centuries was the concept of a strong "new Jew" to counteract the antiSemitic representations of Jewish bodies and people circulating widely in Europe during that time. The focus of this new vision was on physicality, though there was also an interest in other identifying markers of this body such as language and cultural interests and norms. This new Jew was the model for the Jewish pioneers that would emigrate to the land of Palestine and create a new society. Portraying a Jewish body as strong during this time period was a bold claim, predicated on an internalization of the Christian understanding of the body and masculinity as the ideal bodily form. ${ }^{14}$ Meanwhile, the dominant stereotype presented in the Christian-dominated news, caricatures, and plays portrayed Jews-men in particular-as weak, sickly, and grotesque. ${ }^{15}$ Doctor and politician Max Nordau, a high-ranking official of the Zionist movement during this era, championed the idea of the new Jew. Also referred to as the Muscle-Jew, this conception of the body directly contradicted anti-Semitic stereotypes 
and embraced Christian understandings of the body and masculinity. Nordau first introduced this idea at an 1898 speech at the Second Zionist Congress in Basel, calling for a warrior-like and healthy Jewish body. Nina Spiegel, a dance and Jewish studies scholar, writes:

Nordau believed that in order for Jews to fully recreate themselves, they needed to become physically strong. This notion was influenced by both European national movements that aimed to create a "new man" based on ancient Greek ideals and the German Physical Culture Movement that began in the early nineteenth century. ${ }^{16}$

Following the trends of the European culture that denied Jewish integration, Nordau created a vision of a strong pioneer that could carry out the Zionist project. Physical health was tied to spiritual, mental, and most importantly national health. Thus, urging Jews to desire a strong body was an important strategic move towards establishing a Jewish nation state. In his view, the new homeland would need strong bodies able to do physical labor and defend themselves; once out of the ghettos of Europe, Jewish society would diversify and the image of the working Jewish man would become the primary representation of Jewishness. ${ }^{17}$ The image of the 'new Jew' functioned as a rejection of anti-Semitic representations of feminized Jewish men, and praised as the ideal citizen for the future Jewish homeland. This ideal would eventually be defined by those in military service in Israel, although I would argue that the ideal has recently been expanded to include artistically inclined strong figures such as Naharin, who are also shaping dominant images of the Israeli body as well as the actual bodies of average Israeli citizens through popular open classes in Tel Aviv, Jerusalem, and other smaller towns and kibbutzim throughout Israel.

Historians such as Sander Gilman and Daniel Boyarin have carefully outlined the importance of masculinity to Zionist conceptions of the body, and how this developed as a reaction to the assumed effeminacy of Jewish men in Europe at the time of Zionism's rise to popularity in the early 1900s. Each author notes in particular the relationship between circumcision and the Jewish male 'lack' of foreskin as feminizing, often citing Freud's paranoia about this lack and how this can be argued to have driven his work on psychoanalysis predicated on penis envy and fears of castration. Although Boyarin in his text Unheroic Conduct argues for the value in the 'femminized' Jewish male bodies as continuing in a traditional Talmudic tradition that challenges heteronormative Western gender models, all of these scholars show that nevertheless the masculine 'new Jew' became the ideal Zionist body, or Sabra. The same can be said of contemporary Jewish masculine identity; even though the Israeli army and the city of Tel Aviv have become well known for promoting queer tourism and acceptanceespecially of gay men-these military bodies are still often portrayed as stereotypically heteronormative in terms of aesthetic norms and physical capabilities that align with European masculinity such as the men often seen on stage performing with Batsheva. 
In contemporary Israel, the figure of the masculine IDF soldier continues to play a role in the formation of national identity. Jewish studies scholar Yehuda Sharim writes about the strong role the military plays in both the physical and ideological constructions of contemporary strong Jewish bodies. He quotes from The Israel Army Physical Fitness Book (1967) to illustrate the importance of physical strength for the military: "...continuous physical fitness is an absolute necessity; on dramatically short notice a boy or girl of 18 or a man of 50 might be called to battle. Physical training, therefore, becomes an important part of the life of every potential soldier, male or female, young or old." ${ }^{\prime 18}$ Physical strength is tied to military victory, and thus a powerful and safe nation-state. Yet these bodies are not inherently muscular, as the early figures of the new Jew were. Rather, these are alert and fit bodies that can easily maneuver between civilian life and the call of military duty. The prevalence of military style training in civilian life and the embodiment of the combative, aggressive side of the Sabra can be seen in the rise of popularity of Krav Maga, a contact-combat technique developed by the IDF in the 1950s and brought to popular culture in the 1980s and 1990s for selfdefense. ${ }^{19}$

Alertness and fitness are also crucial for a successful Gaga dancer, thus creating the groundwork for Naharin's work and the practice of Gaga as potentially in line with Zionist or Sabra ideals for bodily development. In spite of recent attempts to trouble this stereotype in both scholarship and practice, dance in most Western contexts has been understood as a largely feminine endeavor. Yet Naharin challenges this by emphasizing the importance of "working out" in Gaga and exploring the contrasts of delicacy and strength in movement. The emphasis on bodily strength and working out through dance mimics a similar appeal to the masculinity of physical exertion by early twentieth century men in America, such as Ted Shawn who created dancers and choreographers focused on masculine strength to counteract feminine stereotypes associated with the practice of dancing. ${ }^{20}$ Many Gaga teachers use similar phrases such as finding pleasure in effort to encourage participants to push to their physical limits in addition to their artistic edges. Although Naharin arguably challenges a conventional idea of masculinity in his own dancing and choreography by allowing for a wide range of softness and delicacy by all dancers regardless of gender, and not just the rote masculinity shown by early 20th century American male choreographers such as Ted Shawn, Naharin and his dancers are still unequivocally seen as strong, able to be aggressive, and always ready for action. In this way, both Naharin and his dancers-and the training system of Gaga-are able to embody the alert fitness required of Israeli masculinity ideals embodied by IDF soldiers albeit in an artistic rather than military capacity. It is also seen as an element in Naharin's own dancing success even though he started at a young age. In the film, footage of Naharin taking an advanced ballet class in New York City plays as he narrates how he was in class with famous people such as Rudolf Nureyev and Peter Martins, and that even though he hardly knew the basics of ballet, he "could somehow imitate it. I don't think they've met someone who at such a 
late time in his life can become a dancer." ${ }^{21}$ This comment, which hints at Naharin's own sense of exceptionalism, also celebrates the ideas of readiness and alertness rather than skill as key to success in new movements, while simultaneously downplaying the fact that many male dancers start successful dance careers later in life. His strong male body is also highlighted in the middle of the film as a voiceover describes the femininity required of dancers which is contradicted by a visual of Naharin's shirtless young body performing vigorous movement.

The bodily capacity of Naharin and his dancers is not the only overlap with the masculine Sabra figure. Just as the movements of Gaga require challenging oneself and breaking habits, Naharin's instruction in classes and rehearsals push his dancers emotionally, psychologically, and mentally as well as physically. Similar to the prickly exterior of the Sabra cactus, throughout the film there is ample evidence of Naharin's often harsh demeanor. Perhaps the most striking example is a short but powerful sequence of interviews with some of his former dancers in New York. Carl House, for instance, recalled how Naharin would yell from the sidelines during a performance: "YOU'RE BORING ME!!" Though he laughed during the interview, he also noted that this is not something that is done in the dance community. He continues to recount the pressure put on performers, talking about how Naharin would intimidate dancers before performances by occasionally saying, "don't fuck with me, my life depends on you." Many other of his former dancers are present in the documentary supporting this view of Naharin's strict and at times aggressive working style. New York-based dancer and current director of the Fist and Heel Performance Group Reggie Wilson, for instance, commented that Naharin usually said "NO" and made his dancers repeat movements constantly with no instruction to help them get to a positive response. Rather than positive encouragement, Naharin was described as clear with vocal cues that indicated his frequent displeasure with his dancers' ability to interpret his movement. Dancer Ani Udovicki similarly recalls rehearsals where dancers would tell him that he had to be clearer about what he wanted, to which he would respond that he just wanted them all to read his mind. Udovicki recounted that only Mari Kajiwara, Naharin's future wife, was able to push back and force Naharin to explain himself or deal with his momentary wraths.22

This type of behavior of expecting others to read his mind can be interpreted as demonstrative of Naharin's perceived dominance, which could stem from a variety of sources. As the New York Times review of Mr. Gaga notes, "The filmmakers' disinclination to contextualize Mr. Naharin's sometimes prickly personality is also bothersome." ${ }^{23}$ In a gendered and raced reading of his personality and actions, one can understand it as an unacceptable but expected symptom of white male privilege and the assumption of his way of thinking as the norm. This behavior is often seen in the Western ballet world, exemplified by the recent case of Peter Martins at the New York City Ballet resigning after allegations of sexual and physical abuse. ${ }^{24}$ Culturally, the Sabra figure is also 
expected to be more brash and demanding. Not only is Israel politically positioned as always under attack, which justifies the ongoing military ventures that support the Sabra ideal of masculine dominance, but the very way of speaking is often more blunt and forward. Though I had witnessed bluntness in the speaking styles of many Israeli artists in previous fieldwork, it was not until my first week at a Hebrew language intensive at Middlebury College in 2014 that I was taught about the cultural norm of bluntness. One of the first utterances I was taught by my Israeli level 1 Hebrew teacher was the Yiddishism "nu" (I), which is commonly muttered in Israel to hurry people along or show displeasure. Although these influences do not justify Naharin's often brusque behavior-he is even cited in a New York Times article as saying that "he has spent years working to become less severe, ${ }^{\prime \prime 2}$ indicating his own awareness that his actions are not acceptable, especially in international contexts - they add another layer of justification to dancers accepting his behavior. The dominance of choreographic geniuses, Naharin's mentor Martha Graham included, is commonly accepted as a byproduct of their passion and pursuit of artistic perfection. Yet putting his actions in cultural context is perhaps relevant for understanding why such behavior is not criticized or explored any deeper than a few stories from dancers in this particular film, which even ends with a justification of the process as a means to a laudable end. After a series of interviews recounting this type of demeaning behavior from Naharin, the film cuts back to Reggie Wilson stating that although someone left the studio either yelling or crying almost every day, "it was really, really tough. But everybody came back into the situation. Because twisted or not, they felt that the work was worth it." ${ }^{26}$ Naharin's overbearingly masculine and aggressive Israeli Sabra prickly exterior is thus justified as integral to his artistic process, and acceptable because of his culture as well as his artistic exceptionalism, though the true root of this behavior is never uncovered in the film.

Naharin's exceptionalism is also due in part to the sexiness of the Sabra figure, which is frequently referenced by both Naharin himself and others. Much media representation of the "sexy Sabra" figure is of female IDF soldiers. Dance scholar Hannah Schwadron analyzes the figure of this sexy Israeli female as it is represented in magazines, racy calendars, and even pornography as an exotic and patriotic alternative to the unsexy, "funny girl" Jews of America. ${ }^{27}$ She goes on to clarify that there are differences in the representations of these Israeli women in Hebrew language and English language media, suggesting that this overly sexualized representation of Israeli femininity is geared towards American consumption while more masculine and strong representations of the women are presented in Israeli media and official IDF materials. The number of scandals of young Israeli soldiers-often, but not always, femaleposing in their underwear or naked with their guns on social media, however, suggests that the overt sexuality of these physically fit youth is also present within Israeli society.

Just as Israeli women have differing relationships to masculinity when presented in Israel or the United States, Israeli men have to contend with regional stereotypes and 
assumptions about both their masculinity and sexuality. For Naharin, the combination of the Sabra masculinity and Orientalist stereotypes of Middle Eastern dance as embodying feminine qualities ${ }^{28}$ resulted in a unique ability to draw on both masculine and feminine tropes during his choreographic emergence in New York. He was muscular, strong, and could dance aggressively, just as the ideal new Jew figure should. Yet he was also celebrated for having a movement style that was "very unusual for a man" in the New York dance scene during the 1970s/80s by dancers such as Gina Buntz, in part because of his "Mediterranean spine" movement that was "serpentine, and sinewy, and flowy, and yet articulate. It's not just a wet noodle of a movement. So Ohad, in this country, in this city, even in the dance Mecca, was a rarity as a male dancer. Very womanly." ${ }^{\prime 2}$ Dance scholars such as Stavros Stavrou Karayanni have explored the histories of Orientalist dance practices, such as how belly dance was the primary dance representative of the Middle East to Western societies throughout the twentieth century. His work suggests that any male dancing by Middle Eastern men in the West is always already compared to the practice and framework of the sultry, fluid sensuality of belly dancing regardless of the genre being performed. ${ }^{30}$ In the case of Naharin, he avoids the effeminate stereotypes of the sickly or queer Jew described earlier by Sander and Boyarin in spite of his appeal to stereotypically feminine characteristics such as fluid spine movement because of his masculine appearance and demeanor. This normalization of Naharin's attractiveness throughout the film can thus be understood as part of the nationalist Zionist project of creating a new, positive identity of Jewishness and Jewish people, as celebrated by the Israeli filmmaker.

Still, Naharin is presented as straight, with the film documenting his passionate marriage to the late Mari Kajiwara and his current relationship with partner Eri Nakamura and their daughter Noga. Yet he cryptically explains in a voiceover that his love with Nakamura is not the first or last time he has fallen in love with one of his dancers-gender unspecified-rather, what is unique about their relationship is his commitment to her. Naharin's playfulness with gender and sexuality is frequently highlighted, as is his sexiness. For instance, Naharin tells the story of how he got into Maurice Béjart's company with delight: though he was quickly cut from the audition, he soon ran into Béjart on the street. He remembers: "I'm a young and handsome man, which he likes, and I smile and say: I'm just coming from your audition. I wasn't accepted. ${ }^{\prime \prime 1}$ He then continues the story, telling how Béjart took him into a studio to improvise for just a few minutes before offering him a job. Naharin is fully aware of his sexual appeal in this story and is not beyond utilizing it as a tool to get ahead in his career regardless of his personal sexual interests.

Other references to Naharin's sensuality and sexiness are common throughout Mr. Gaga, ranging from his recollection of running around naked on a kibbutz as a child to his flirtatious performances during military service and others' descriptions of him passionately kissing his wife like they were wild animals. This evocation of sensation and 
playful hints of sexual undertones are not entirely created by the film's editing, however. In the practice of Gaga beyond the context of the film there are still frequently allusions to sexiness and sensuality, such as Naharin's comments about how movement turns him on or the use of the word "available" on T-shirts for Gaga workshops participants which-although intended as a reference to the common directive of being available for movement in your body-can also be taken as descriptors of one's sexual availability when walking down the street. Whether it is a marketing strategy or a true representation of Naharin's feelings about the relationship between sex, gender, and dancing, it is clear that for Gaga and Naharin, sex sells.

\section{Except...ionalism?}

As such, in this article I challenge the uncritical presentation of Naharin's exceptionalism seen in Mr. Gaga by pointing to the cultural and political contexts in which his actions are entrenched. I refer to the term exceptionalism here as evoked by Lucy Mae San Pablo Burns in Puro Arte, where she explores how "spectacular accomplishments tend to blind us, serving often to mystify rather than open up historical conditions." ${ }^{\text {22 }}$

In Mr. Gaga and its disjointed narrative, it becomes incumbent upon viewers to place the work in context, and to think for themselves about what truth(s) are portrayed about Naharin and his career in the film. This point is made abundantly clear early on in the film, when Naharin narrates the story of how he discovered his passion to move at a young age. His solemn face covers the screen as he begins telling a touching story of his twin brother, who was nearly mute and communicated through dancing with their grandmother. Footage of a young boy dancing with other children and then an older woman in a field is displayed on the screen as his narrative continues with Naharin explaining how, after their grandmother died, he learned to dance to communicate with his twin. The story is assumed by the audience to be true as Naharin questions whether or not this ignited his passion for dance: maybe he would have found it regardless. It is not until the end of the film that Naharin reveals that this story is completely false. He casually announces that he once made it up when a reporter asked where his love for dance came from and has repeated it many times since, suggesting that there is no singular truth and perhaps hinting at the fetishization reporters have with sensationalizing the role of dance in his life. In spite of this adept intellectual justification given for the lies, particularly interesting in this seemingly post-truth era, the story is more manipulative than playful. Though lying about oneself is a common strategy for controlling how you are narrativized, an entirely fictionalized backstory about the inspiration for your passion that touches on issues of death and illness that would likely connect with many viewers' lives takes a step toward intentionally manipulating others rather than just making a point. 
This embrace of alternate "truths" mirrors Naharin's relationship to his own choreography, which he similarly views as unstable and constantly available for revision. The film openly acknowledges this intentional lie, letting the audience in on Naharin's idea of lying as a playful approach to truth at the end of the film. This editing choice of offering a detailed false narrative and letting it stand as fact for an extended time is peculiar, saying more about the willingness of Naharin and the filmmakers to manipulate audiences' emotions than it does about the idea of truth or objectivity in documentary filmmaking. Even as the documentary attempts to unravel the mysteries that surround Naharin and his work, it appears that the film is too closely tied to adhering to Naharin's self-narrative and his intentional mockery of the idea of himself as a celebrity figure to truly "dispel the mystery" ${ }^{\prime 33}$ of this choreographer and his work. As Gaga, Naharin, and their image(s) continue to circulate internationally via films, dance studios, and mass media, it is imperative that viewers and participants dive beneath the surface of the practice's public perception. Interrogating the cultural, social, and political context of (Mr.) Gaga can deepen our understanding of both Naharin as an artist and the practice of Gaga by dancers today. Doing so will help us move beyond familiar limits and understandings, just as the very practice of Gaga requires of its students, and open up a wider understanding of the significance of the ways in which Naharin and his work are represented and experienced across cultures and contexts.

Moving beyond the laudatory and vague presentation of information seen in Mr. Gaga, I offer this culturally specific reading of Naharin's masculinity as a Sabra, or native-born Israeli, to question the widespread fetishization of Naharin's artistic vision. I argue that the exceptional figure of the genius artist figure, which the editing of Mr. Gaga presents Naharin to be, must be read in light of the cultural, political, and social contexts that create the possibility for his artistic vision to reach international fame. As such, this article is intended to elucidate some of the cultural and political contexts that are overlooked in dominant media representations and reviews that contribute to the uneasy reactions to the film evidenced by many of my interlocutors. Such recognition also challenges the common desire to create clear narratives or understandings of stories, especially in film. Dance, with performances that are more often abstract than narrative in structure and meaning, does not fit neatly into the conventions of documentary filmmaking. Rather than attempting to tell audiences the true story of someone's life or the definitive meaning of a dance work, these documentaries expose the viewers to a wide range of works and background information that requires viewers to critically interrogate how they put the story together for themselves and understand these artists. 


\section{Biography}

Meghan Quinlan is an independent scholar with a PhD in Critical Dance Studies from the University of California, Riverside and a BA in Dance and English from Marymount Manhattan College. Her work, which focuses on political analysis of the practice of Gaga from a range of perspectives such as queer, nationalist, and historical theory, has been presented at conferences throughout the United States, Greece, and Germany, and published in TDR: The Drama Review, Dance Research Journal, Oxford Handbook of Dance and Competition, and anthologies coming out of both the US and Germany. This research is based on years of ethnographic study in Gaga classes taking place throughout the United States, Israel, and Germany as well as interviews with students, teachers, and administrators.

Email: meghanruthquinlan@gmail.com

Website: https://www.meghanquinlan.com

\section{Notes}

1 "Story."

${ }^{2}$ Naharin stepped down in 2018, after joining the Batsheva Dance Company as Artist Director in 1990, but continues to remain actively involved with the company and Gaga.

${ }^{3}$ Douglas Rosenberg, Oxford Handbook of Screendance Studies, 12

${ }^{4} \mathrm{~A}$ biopic, or fiction film that is underpinned by reenactment, "deals with a figure whose existence is documented in history, and whose claims to fame or notoriety warrant the uniqueness of his or her story." Belén Vidal, "Introduction," 3. Although archival footage is used instead of re-enactments, and the subjects themselves are usually present in the films, these dance documentaries of great choreographers follow similar conventions to dramatize and draw viewers into the personal lives of these artists as well as showcase their choreographic works.

5 "Echad Mi Yodea" is a short piece that is normally performed within the broader framework of evening length works such as Decadance (2000).

${ }^{6}$ The 1998 'gatkes incident' refers to a disagreement between Ohad Naharin and the Israeli government regarding artistic control of costuming. Batsheva was set to perform at a festival in Jerusalem celebrating Israel's 50th anniversary as a nation- 
state. Part of the dance, entitled "Echad Mi Yodea," features the company systematically stripping to their underwear to the tune of a Passover song. Government officials urged Naharin to "let them wear gatkes" (Yiddish for long underwear) in order to maintain decorum and propriety as laid out by the more conservative government officials that would be in attendance. This attempt at censorship was not well received, and resulted in a temporary shutdown of the company as Naharin resigned and the company refused to perform at the festival. Amends have since been made, and Naharin was quickly reinstated as Artistic Director with full artistic control. In this fully Israeli debate, no reference or issue was made of the appropriateness of celebration during the Palestinian Nakba, or remembrance of their removal from lands in what is now the State of Israel.

7 Sheila O'Malley, "Bobbi Jene."

${ }^{8}$ Glenn Kenny, "Review"

${ }^{9}$ O'Malley, "Mr. Gaga."

${ }^{10}$ Heymann Brothers, "Mr. Gaga."

${ }^{11}$ Ibid.

${ }^{12}$ Susan Kerrigan and Phillip Mclntyre, "The 'creative treatment of actuality'," 122.

${ }^{13}$ See Deborah Friedes Galili, “Moving Beyond Technique.” See also Mr. Gaga.

${ }^{14}$ See Daniel Boyarin, Unheroic Conduct and Sander Gilman, The Jew's Body.

${ }^{15}$ Ibid. See also Rebecca Rossen, Dancing Jewish.

${ }^{16}$ Nina Spiegel, Embodying Hebrew Culture, 9.

${ }^{17}$ Michael Berkowitz, Zionist Culture, 99-118.

${ }^{18}$ Yehuda Sharim, "Choreographing Masculinity," 137.

${ }^{19}$ Ibid.

${ }^{20}$ See Mary Louise Adams, "Death to the Prancing Prince."

${ }^{21}$ Mr. Gaga.

${ }^{22}$ All quotations in this paragraph are from Mr. Gaga.

${ }^{23}$ Kenny, "Review."

${ }^{24}$ Gia Kourlas and Siobhan Burke, "Two Critics Reflect on Ballet's \#MeToo Moment."

${ }^{25}$ Kourlas, "'Mr. Gaga' Comes to Town." 
${ }^{26}$ Mr. Gaga.

${ }^{27}$ Hannah Schwadron, "White Nose," 255.

${ }^{28}$ See Anthony Shay and Barbara Sellars-Young, "Belly Dance."

${ }^{29}$ Mr. Gaga.

${ }^{30}$ See Stavros Stavrou Karayanni, "Native Motion and Imperial Emotion."

${ }^{31}$ Mr. Gaga.

${ }^{32}$ Lucy Mae San Pablo Burns, Puro Arte, 15.

${ }^{33}$ Heymann Brothers, "Mr. Gaga."

\section{References}

Adams, Mary Louise. "'Death to the Prancing Prince': Effeminacy, Sport Discourses and the Salvation of Men's Dancing." Body \& Society 11.4 (2005): 63-68.

https://doi.org/10.1177/1357034X05058020

Ahmed, Sara. Queer Phenomenology: Orientations, Objects, Others. Durham and London: Duke University Press, 2006. https://doi.org/10.1215/9780822388074

Azoulay, Ariella. "Declaring the State of Israel: Declaring a State of War." Critical Inquiry 37.2 (2011): 265-285. https://doi.org/10.1086/657293

Berkowitz, Michael. Zionist Culture and West European Jewry Before the First World War. Cambridge: Cambridge University Press, 1993.

Bobbi Jene. Dir. Elvira Lind. 2017.

Boyarin, Daniel. Unheroic Conduct: The Rise of Heterosexuality and the Invention of the Jewish Man. Berkeley: University of California Press, 1997.

Burns, Lucy Mae San Pablo. Puro Arte: Filipinos on the Stages of Empire. New York and London: New York University Press, 2013.

DecaDance. Chor. Ohad Naharin. 2000.

Galili, Deborah Friedes. "Moving Beyond Technique with Ohad Naharin in the TwentyFirst Century." Dance Chronicle 32.3 (2015): 360-392.

https://doi.org/10.1080/01472526.2015.1085759 
Gilman, Sander. The Jew's Body. New York and London: Routledge, 1991.

Heymann Brothers. "Mr. Gaga: Film about Ohad Naharin and Batsheva Dance Company." Kickstarter. Accessed July 19, 2018.

https://www.kickstarter.com/projects/heymannbrothers/mr-gaga-a-documentary-

film-about-ohad-naharin/description

I Shot My Love. Dir. Tomer Heymann. 2009.

Karayanni, Stavros Stavrou. "Native Motion and Imperial Emotion: Male Performers of the 'Orient' and the Politics of the Imperial Gaze." In When Men Dance: Choreographing Masculinities Across Borders. Ed. Jennifer Fisher and Anthony Shay. New York: Oxford University Press, 2009. 314-348.

https://doi.org/10.1093/acprof:oso/9780195386691.003.011

Kenny, Glenn. “Review: 'Mr. Gaga' Doesn't Sing But Has His Own (Dance) Language." The New York Times. Posted 31 Jan. 2017. Accessed 29 July 2018.

https://www.nytimes.com/2017/01/31/movies/mr-gaga-review-ohad-naharin.html

Kerrigan, Susan and Phillip McIntyre. "The 'creative treatment of actuality':

Rationalizing and reconceptualizing the notion of creativity for documentary practice." Journal of Media Practice 11.2 (2010): 111-130. https://doi.org/10.1386/jmpr.11.2.111_1

Kourlas, Gia. "'Mr. Gaga' Comes to Town." The New York Times. Posted 27 Jan. 2017. Accessed 29 July 2018. https://www.nytimes.com/2017/01/27/arts/dance/mr-gagaohad-naharin-batsheva-dance-company-comes-to-town.html

Kourlas, Gia and Siobhan Burke. "Two Critics Reflect on Ballet's \#MeToo Moment." The New York Times. Posted 18 Oct. 2018. Accessed 10 March 2019.

https://www.nytimes.com/2018/10/18/arts/dance/new-york-city-ballet-me-too.html

Mamootot. Chor. Ohad Naharin. 2003.

Massad, Joseph. "The 'Post-Colonial' Colony: Time, Space, and Bodies in Palestine/Israel." In The Pre-Occupation of Postcolonial Studies. Ed. F. Afzal-Khan and K. Seshadri-Crooks. Durham and London: Duke University Press, 2000. 311-46.

Mr. Gaga: A True Story of Love and Dance. Dir. Heymann Brothers Films. Abramorama (USA). 2017. DVD.

O'Malley, Sheila. "Bobbi Jene." RogerEbert.com. Posted February 1, 2017. Accessed December 18, 2018. https://www.rogerebert.com/reviews/bobbi-jene-2017

. "Mr. Gaga." RogerEbert.com. Posted September 22, 2017. Accessed December 18, 2018. https://www.rogerebert.com/reviews/mr-gaga-2017

Pina. Dir. Wim Wenders. 2011. 
Revelations. Chor. Alvin Ailey. 1960.

Rossen, Rebecca. Dancing Jewish: Jewish Identity in American Modern and Postmodern Dance. New York: Oxford University Press, 2014.

https://doi.org/10.1093/acprof:oso/9780199791767.001.0001

Sadeh21. Chor. Ohad Naharin. 2011.

Schulman, Sarah. Israel/Palestine and the Queer International. Durham and London: Duke University Press, 2012. https://doi.org/10.1215/9780822396536

Schwadron, Hannah. "White Nose, (Post) Bawdy Bodies, and the Un/dancing Sexy Jewess." PhD diss., University of California, Riverside. 2013.

Sharim, Yehuda. "Choreographing Masculinity in Contemporary Israeli Culture." In Choreographies of 21st Century Wars. Ed. G. Morris and J. Giersdorf. London and New York: Oxford University Press, 2016. 133-156.

https://doi.org/10.1093/acprof:oso/9780190201661.003.0007

Shay, Anthony and Barbara Sellers-Young. "Belly Dance: Orientalism, Exoticism, SelfExoticism." Dance Research Journal 35.1 (Summer 20003): 13-37.

Spiegel, Nina. Embodying Hebrew Culture: Aesthetics, Athletics, and Dance in the Jewish Community of Mandate Palestine. Detroit: Wayne State University Press, 2013.

"Story." Mr. Gaga the Film. Accessed 29 July 2018.

http://www.mrgagathefilm.com/story

Vidal, Belén. "Introduction: the biopic and its critical contents." In The Biopic in Contemporary Film Culture. Ed. Tom Brown and Belén Vidal. New York and London: Routledge, 2014.

Who's Gonna Love Me Now? Dir. Tomer Hermann. 2016.

Yosef, Raz. Beyond Flesh: Queer Masculinities and Nationalism in Israeli Cinema. New Brunswick, NJ: Rutgers University Press, 2004. 


\title{
Digital ${ }^{1}$ Dance Criticism: Screens as Choreographic Apparatus
}

\author{
Kate Mattingly, University of Utah
}

\begin{abstract}
Prior to the introduction of websites and social media, professional dance criticism circulated through print publications: newspapers, magazines, and journals. This article examines the current proliferation of screens as platforms for criticism and how theymobile devices, laptops, televisions, and computers-shift the frameworks that writers and readerships use to engage with dance. I use the concept of a choreographic apparatus to show how digital technologies generate symbiotic relationships between online contexts and contemporary performance. By focusing on three sitesthINKingDANCE, On the Boards TV, and Amara Tabor-Smith's House/Full of Black Women-I analyze how these platforms challenge widespread assumptions about the disappearance of dance critics.
\end{abstract}

Keywords: dance criticism, digital technologies, choreographic apparatus, tactical media, contemporary performance

When The Atlantic published "The Death of the American Dance Critic" in 2015, Madison Mainwaring wrote that dance coverage in the mainstream press has been "decimated" over the last 20 years. Mainwaring cited the fact that there are "only two full-time dance critics in the country" as evidence of this crisis. ${ }^{2}$ A closer look at the history of dance criticism in the United States reveals that the 21st century has seen a proliferation of awareness and discourses about dance through websites, television shows, social media platforms, and programming events that necessitate a more thoughtful examination of what constitutes criticism today, who 'counts' as a critic, and the venues through which dance criticism is accessed. In the wake of concerns expressed about how digital technologies are eroding the profession of dance criticism, this article takes a critical look at such claims and their contexts.

Setting aside momentarily the oversights in Mainwaring's article-she refers to John Martin as the United States' first dance critic, calls New York the "dance capital" of the United States, and dismisses the role of websites as platforms for dance criticism in the 21 st century - the focus of her analysis seems to be two-fold: not only is dance criticism dead, but there is a surge of articles about dancers by those she deems unqualified to be dance writers. Mainwaring's opening paragraphs describe how Misty Copeland has become a "household name," yet "hardly any of the countless stories published about Copeland have been written by dance critics-a dying breed of writers uniquely The International Journal of Screendance 10 (2019).

https://doi.org/10.18061/ijsd.v10i0.6524

(c) 2019 Mattingly. This article is published under a Creative Commons Attribution 4.0 International License (https://creativecommons.org/licenses/by/4.0/) 
capable of offering informed commentary on the singular talents she brings to the stage." $^{3}$ In this single sentence, Mainwaring adopts a limiting definition of dance criticism as commentary on individual events or artists and is unable to see the regeneration of dance writing in digital spaces due to her commitment to a "dying breed" of writers.

The significance of Mainwaring's article lies in these foreclosures: it is symptomatic of a putative split between dance criticism in print publications and digital modes of engagement. Screens-not printed pages-are the dominant forms of access and circulation for dance commentary in the 21st century. Mining these distinctions between dance writing on printed pages and screens, as well as dancing on stages and dancing on screens, exposes other hierarchies: dancing on stage is privileged by a dance canon and history textbooks, and dancing on screen is often relegated beyond the purview of dance criticism with such descriptors as "popular dance" or "commercial dance." ${ }^{4}$ As digital technologies have amplified access to dance on screens, flows of movement and aesthetics between screens and stages, as well as forms of criticism by well-known critics, bloggers, and fans, become increasingly blurred in the 21 st century. ${ }^{5}$ Mainwaring's article perpetuates a definition of criticism as an act of reporting on performances, a system of evaluation practiced by "an expert pair of eyes" and focused on a performer's "technical, lyrical, and theatrical abilities." ${ }^{6}$ She is not alone in lamenting the loss of these 'experts' or describing dance criticism as an endangered species.

In 2009, Elizabeth Zimmer published "The Crisis in Criticism: The Economy, the Internet and the Death of Dance Writing" in the Bay Area publication In Dance. In this essay, Zimmer announces, "The current collapse of print media is disastrous for the arts, especially experimental, low-budget work." ${ }^{17}$ Zimmer is a longtime critic, and her views have been echoed and repeated elsewhere. However, given that most analyses of dance criticism have focused anecdotally on isolated decades of dance writing or on the work of a single writer, it is hard to evaluate what has, in fact, collapsed. ${ }^{8}$

In this article, I place these pronouncements of doom and demise alongside three projects that redirect dance discourse, allowing us to see the generative role of dance criticism in the 21st century, and effectively challenging binaries that have been perpetuated by the gatekeepers of the aforementioned dance canon and what former dance critic Ann Daly calls "canon criticism." ${ }^{9}$ In other words, this article challenges the hierarchical arrangements between stage and screen, which have propelled the criteria we use to engage with dance. The examples I analyze highlight how screens operate as sites through which practitioners, writers, and audiences are changing the priorities of dance criticism. They also offer ways of rethinking the edges of a screendance community. As the editors of the International Journal of Screendance, Harmony Bench and Simon Ellis, stated in the sixth volume, "[O]ur community (however narrowly or broadly that might be defined) needs artists to continually challenge and question the 
means by which their work is made, framed, and presented." ${ }^{10}$ Attending to the multiple ways screens are redefining approaches to dance criticism highlights the ways digital circulations are also changing the frameworks through which audiences engage with dance. Since these frameworks are imbricated in the cultural, social, and political value systems of certain times and places, I have bracketed this analysis to examine the functions of critics in the United States. ${ }^{11}$ Rather than theorize all dance criticism, this article examines a finite geography and time period to address the modicum of analysis that has been brought to dance criticism in the United States and to assess the ways that digital dance criticism redistributes access, authority, and regimes of value. ${ }^{12}$

\section{Theoretical Framework: Dance Criticism as Choreographic Apparatus}

The role of the critic is not only to respond to artists' work, but also to set in motion the criteria through which audiences evaluate their performances. In the history of dance criticism in the United States, there are alignments between a critic's set of aesthetic preferences and the work of canonical choreographers-John Martin and Martha Graham, Edwin Denby and George Balanchine, Joan Acocella and Mark Morris-and writers have occupied different roles at different historical junctures. For example, John Martin served as both a microphone and gatekeeper for modern dance, and such positionings have afforded certain outcomes. Between 1965 and 1975, Yvonne Rainer occupied a variety of roles (artist, writer, reviewer, essayist, and event organizer), and her fluctuating positions and movement between these spaces could be described as a form of choreography that made possible the placement and visibility of certain projects.

Defining choreography as an arrangement of movement in space as well as the notation of these arrangements, I use "choreographic" in "choreographic apparatus" to describe ways in which writers constructed concepts and redirected discourse that surrounded artistic projects. ${ }^{13}$ In other words, a choreographic understanding of space and time, movement and interaction, plan and documentation provides a lens through which to examine written projects. The word apparatus signals a method for framing and capturing. As André Lepecki writes, an apparatus is "a mechanism that simultaneously distributes and organizes." ${ }^{14}$ Lepecki continues:

...the concept of apparatus is one that foregrounds perception as always tied to modes of power that distribute and assign to things visibility or invisibility, significance or insignificance. According to Deleuze, Foucault's discovery is that 'each apparatus has its regimen of light, the way it falls, softens and spreads, distributing the visible and the invisible, generating or eliminating an object, which cannot exist without it.. ${ }^{15}$

I introduce the idea of criticism functioning as a choreographic apparatus to highlight the influence of critics' work on readerships' values systems and artists' networks of 
support. A choreographic apparatus is a malleable system that makes visible these interdependencies, arranging and structuring relations among people, organizations, and publications.

In the concept of a choreographic apparatus, that I explore here, the framing function of the word "apparatus" is essential because it highlights how the frames generated by critics have set in motion the value systems deployed by communities of discourse. "Community" is used here to mean social configurations in which enterprises are defined as worthwhile. Value systems are tethered to communities and the mechanisms through which they designate some artists and creative processes as more valuable than others. By extension, dance criticism participates in the injustices of recognition that have constituted some social actors as less than full members of a community and prevents them from participating as peers. ${ }^{16}$ What's important about this apparatus is that if we expand the study of criticism from a decade or an individual critic's body of work to a century encompassing many voices, we see how the apparatus is rechoreographed over time.

The concept has been useful to my study of dance criticism because there are few examples of pieces that reveal a critic's methods or evaluative criteria. ${ }^{17}$ This is one of many reasons why dance studies' scholars have sometimes presented their work as remedy to critics' and historians' lack of theoretical engagement. For example, Randy Martin noted that the "critic's authority resides in an appeal to a system of classification that values dance in terms of where it places choreographers and dancers in that system," ${ }^{18}$ and Susan Foster introduced her 1986 book, Reading Dancing, as a corrective to criticism's shortcomings: "At best, criticism is able to provide a historical perspective or aesthetic judgment."19 André Lepecki uses critics-Anna Kisselgoff in the "Introduction" and Marcia Siegel in the "Conclusion"—as perspectives to challenge and oppose in his book Exhausting Dance. He quotes their writing to emphasize their shortsightedness, then introduces his own theories as remedy and more substantive analysis. If criticism in print publications is lacking substance or relevance, where does this leave today's artists who seek engagement with critics' platforms? More and more frequently I find the answer to be online contexts and social media.

Conversations about criticism today are inflected by the presence of digital technologies, and awareness of the types of participation digital platforms elicit is essential for conversations about discourse and its circulations. ${ }^{20}$ In a 2015 interview, communication scholar Zizi Papacharissi stated:

There are events, and there are stories that are told about events. Most events we are not able to experience directly, so we have always relied on the storytelling oralities and technologies of an era to learn about them. What happens when we become contributors to these narratives, or stories, rather than simple consumers, is that we become involved in the developing 
story about an event; how it is presented, how it is framed, how it is internalized, and how it is potentially historicized. ${ }^{21}$

In the 1920s and 1930s these "stories" about dance performances were recorded by John Martin in his articles, and circulated in newspapers and lectures, the dominant "technologies" available to dance criticism of the era. In the 1960s, Yvonne Rainer contributed her own "stories" as articles that shifted frameworks through which her performances could be seen.

Current digital technologies make it possible to accelerate the speed and expand the scope of writers' communications, as well as to mitigate barriers to broad participation in dance discourse. In the first years of the 21st century, as print publications decreased their page space for dance coverage, ${ }^{22}$ websites and theaters introduced alternate platforms for documenting and discussing performances. ${ }^{23}$ These technologies also influence the types of performances that are being recorded and circulated. As new media scholar Abigail De Kosnik writes in Rogue Archives: "a society's technologies for storing and retrieving its memories influence and inform how and what individuals recollect." ${ }^{24}$ In both contemporary performance and 21 st century writing, there's an emphasis on discourse and dialogue, spoken and embodied. Events merge performance and theory, calling attention to our systems for organizing ideas, as seen vividly in Untitled Feminist Show (2011) by Young Jean Lee with choreographer Faye Driscoll, and the performative lectures by Deborah Hay and Alva Noë called Reorganizing Ourselves (2014). These performances share a symbiotic relationship with digital dance criticism. Relevant to this research, Noë emphasizes the role of choreography in reorganizing worldviews, comparing choreography to philosophy:

Both philosophy and choreography take their start from the fact that we are organized but we are not authors of our organization... They are practices (not activities) - methods of research-aiming at illuminating the ways we find ourselves organized, and so, also, the ways we might organize ourselves... they expose the concealed ways we are organized by the things we do. ${ }^{25}$

Noë seems to be describing a choreographic apparatus, a shifting system that sheds light and exposes criteria we use to engage and analyze our relationships with the world.

When we trace the ways critics have framed and promoted the aesthetics and performances of certain artists, we are using the concept of a choreographic apparatus to notice how canonical choreographers have been nurtured by specific writers and publications. For example, Martin's retirement in 1962 was coterminous with the first evening of Judson Dance Theater, a movement that ushered in its own writers and a different choreographic apparatus. This reframing of artists' projects through the choreographic apparatus makes visible how concepts such as "institution" and "form" 
intersect with one another, as well as how the apparatus is mutable and can be redesigned or re-choreographed. Rainer activated a choreographic apparatus by writing about her practices thereby elucidating her priorities, and generating a type of discursive agency that challenged mainstream critics who dismissed her performances and the work of other Judson artists.

Yet artists in the first decades of the 21st century rarely find the kind of discourse in nonacademic publications that existed in the last century. In fact many dance critics willingly profess an aversion to the critical theory that permeates academic environments, as seen in Claudia Bauer review of Gerald Casel's work: "Casel's dancers make Splinters worth watching, independent of the critical theories at hand." ${ }^{26}$ Theory or analysis confuses these critics' definition of dance as athletic display. Critic Allan Ulrich's response is even more revealing. He describes Casel's performance as "hopelessly uncommunicative" because it's "so devoid of sensual allure." ${ }^{27}$ Ulrich exposes his anti-academic bias paternalistically observing, "the dancing resembles something cooked up in a graduate dance seminar," ${ }^{28}$ after which he rejects basic tenets of critical and postcolonial theory motivating Casel's work: "In a wild flight of conceptualizing, [Casel] suggests that choreography amounts to colonizing the body of another person. It's a wacky notion, born of one too many late-night college bull sessions." ${ }^{29}$ As Rebecca Chaleff, a dance scholar and performer in Splinters, pointed out when she read this, "Ulrich employs anti-intellectualism to paint Gerald as a college student even though he is a Professor at UCSC." ${ }^{30}$ Ulrich's writing exemplifies the misrepresentations of an artist's work through a critic's lenses, and also makes explicit the vital need for different voices and different approaches to dance criticism.

In the three examples - or sites - that follow, I foreground the affordances that screens bring to dancing and writing, and how these digital intersections of dancing and writing inform definitions of dance, dance criticism, and screendance. The three sites are distinct yet foreground three themes: first, the dialogic capacities of technologies, meaning abilities to see, engage, and respond, that motivate a rethinking of the authoritarian role of a critic. Second, each site exists in spaces between performance and documentation, between what Diana Taylor has theorized as "repertoire," meaning "all those acts usually thought of as ephemeral, nonreproducible knowledge," and "archive," as in the "supposedly enduring materials." ${ }^{31}$ Third, if a function of dance criticism in the 20th century was to document, assess, and "record" events that took place in theaters, these projects foreground other purposes in relation to other types of performance. Against a notion of a critic's words and dancer's performance existing in a "unidirectional relationship," with the critic having the "last word," 32 these digital platforms expand the roles of criticism, artists' access to self-determination, and flows of discourse.

Studies of dance criticism have primarily focused on artists and critics based in New York $\mathrm{City}^{33}$ but the three sites I analyze, thINKingDANCE, On the Boards TV, and Amara Tabor- 
Smith's House/Full of BlackWomen, bring attention to other cities: Philadelphia, Seattle, and Oakland, respectively. By highlighting the priorities and modes of each platform, I aim to reframe conversations about what dance writing values, and to diminish the power of critics whose writing perpetuates systems of exclusion. As Linda Smith advocates in Decolonizing Methodologies, it's important to keep "struggling to make sense of our own world while also attempting to transform what counts as important in the world of the powerful." ${ }^{\prime 4}$ The concept of the choreographic apparatus provides a way of "making sense" of the influence of critics on artists' careers and readerships' criteria. As the analysis of each site in this article reveals, dance criticism not only documents, contextualizes, and describes, but also organizes, nurtures, and promotes creative work, and in the digital sphere the affordances of online platforms share a symbiotic relationship with contemporary performance.

\section{Site 1: thINKingDANCE: Dialogic capacities of dance criticism}

On November 20, 2014, thINKingDANCE (hereafter TD) published Lisa Kraus's article about Steve Paxton's work at Dia:Beacon. Paxton posted his response one the site in December, which was followed by Kraus's reply. This exchange highlights the dialogic affordances of digital platforms, meaning critics' words set in motion conversations and ideas, today as in the 1920s. "Letters to the Editor" have been replaced by "Comments," "Likes," and "Tweets." Articles and manifestos circulate in the digital sphere with speeds that were inconceivable when reviews were assembled in "composing rooms," as they were in the 1920s and 1930s, then printed and published on paper.

Created in 2011 by Kraus and Anna Drozdowski, TD shifts practices of criticism from commentary on individual events to engagement with structures, issues, and voices that serve Philadelphia's artists and readers. The current project description for TD states: "thINKingDANCE members have a wealth of experience in the dance field and elsewhere, as dancers, choreographers, university academics, or other professionals. They are deeply knowledgeable, passionate, and are invested in improving both the quantity and quality of discourse in the dance field." ${ }^{35}$ TD is both a response to older critical practices and catalyst for engaging new forms of performance with new forms of discourse.

Rather than separate academic scholarship from dance criticism, TD publishes writing by dance scholars. Lynn Matluck Brooks, a frequent contributor to the site, has headed the Dance Program at Franklin \& Marshall College in Lancaster, Pennsylvania since 1984. On January 1,2019, Brooks became editor-in-chief of TD. One of her posts, an interview of dance scholar Brenda Dixon Gottschild, interweaves priorities in dance both within and outside of higher education, expanding the very notion of what constitutes dance writing. During the interview, Gottschild reflects on the racial stratification in the American dance landscape, "When I started out, to even say 'Africanist aesthetic' in the 
same breath as 'Balanchine' was taboo. People are now reading those chapters from my books; that is a sea change in how dance departments are visioning dance research." ${ }^{36}$ By calling attention to exclusionary practices that have historically separated canonical and non-canonical artists, or that made "concert dance" the purview of white artists, TD intervenes in discourses of both disciplinary formation and dance criticism. In the interview, Gottschild calls attention to a shift away from a "modern" or "postmodern" aesthetic and notes the importance of Philadelphia as a city that is conducive to dancers and experimentation. Gottschild says there is "a basic change in the ways dances are constructed, which is definitely not according to a 'modern dance model'—Graham, Wigman, Cunningham, or whoever. There's a basic conceptual and even kinesthetic difference to how dance is perceived now, and Philadelphia is part of that movement." ${ }^{37}$ The posting is significant for two reasons: first, it moves Gottschild's scholarship from academic audiences to an online format that is accessed by both academic and nonacademic readerships, and second, because it highlights the importance of recognizing geographic centers for dance beyond New York City, namely Philadelphia. TD is both providing a platform for educating dance audiences as well as highlighting the significance of local aesthetics.

In both direct and indirect ways, these three sites displace the dominance of New York critics and New York mastheads in the evaluations of dancers and performances. As another example, TD provides a forum to challenge and reconsider critics' points of view, and has explicitly responded to missteps by mainstream critics. In a December 2015 posting, Jane Goldberg analyzes Joan Acocella's New Yorker review of Brian Siebert's book, What the Eye Hears: A History of Tap Dancing. ${ }^{38}$ Goldberg notes the multiple misrepresentations in Acocella's writing as well as a blatant conflict of interest (Acocella was Siebert's mentor and served as his reference for jobs) that Acocella does not mention in her review. Goldberg's post inspired 25 comments, written by professors, dancers, and audience members, about the importance of ethics, research, and contextualization in criticism. If publications like the New Yorker and the New York Times were determining forces in the success of certain choreographers during the 20th century, TD presents often unheard and under-represented perspectives that nurture artists and artistic criteria of the 21 st century. ${ }^{39}$

A choreographic apparatus that positions contemporary performance, digital technologies, and dance critics in relation to one another makes visible the ways that artistic processes and critical responses share a constitutive interaction. While audience response has always been a part of the choreographic apparatus through such mechanisms as letters to the editor and post-show conversations, social media technologies make this component of the apparatus more visible, and potentially part of the performance itself. An earlier version of TD's mission stated that they sought authors of a variety of critical formats, "including reviews, features, interviews, think pieces and, hopefully, as-yet-undiscovered forms." TD emerged as artists presented 
performances that could also be described as "as-yet-undiscovered forms," events that focused more on process than product, more on states of being than steps, and more on theories integrated with practice than displays of physical virtuosity.

Another method for involving audiences in contemporary performances happens when artists dismantle walls like a proscenium divide or choreographers use perambulatory formats rather than auditorium seating. These interventions, often adopted to increase performer-audience intimacy or co-present connections, find a parallel in dance criticism that emphasizes audiences' response and offers ways for readers to comment. Recent shows that have adopted these installation-like formats include David Zambrano's Soul Project, made in 2006 and presented in 2012 at San Francisco's Yerba Buena Center for the Arts. Zambrano, born in Venezuela and now based in Europe, said about his performers after the show: "We are a social-centric society. The whole group is the leader. A dancer takes any center and the audience has to come to them." ${ }^{40}$ Because the experience of wandering through performance-installations is personal and volitional, these events make explicit the heterogeneity of audience responses to performance and the impossibilities of one writer capturing, describing, or analyzing its activities.

When Soul Project was presented in Philadelphia in 2015, TD writers reconfigured the "unidirectional" flow of criticism by expanding voices in conversations about the performance. In a format called "Write Back Atcha" TD hosts writing events postperformance and gives audiences prompts that elicit descriptions and "letters" to the performance. In the "Write Back Atcha" that followed Zambrano's Soul Project, writers posted the following:

Karl Surkan: "Experiencing David Zambrano's Soul Project is a bit like going to church-the kind of church where something rapturous, sweeping, transformative, and spiritual is happening..." ${ }^{41}$

Anonymous: "Dear Soul Project, I find you exhausting. Your flailing, thrashing, grinding, grimacing, pumping, primping, and peacocking just makes me want to look away. To escape. To find something softer. I love your music, sure... who doesn't? But I need more from you. Your overwhelming energy, rather than enticing me, ends up pushing me away and I just end up feeling uncared for. I really tried to love you..." ${ }^{42}$

This format dismantles a traditional role of criticism, from an authoritative voice or expert opinion to a gathering of differing perspectives placed side by side. Contemporary performance itself is often an exchange that is indeterminate and variable from site to site, so a format like "Write Back Atcha" reflects this multivalent work by engaging multiple voices and perspectives. 
This conversational relationship between authors and readers highlights multidirectional flows and disrupts the notion of a critic as sole authority. As the mainstream press competes with websites and blogs for readers' attention, newspaper critics gravitate towards slick, assessment-based styles designed to capture readers with short attention spans. This tone is evident in the dance criticism of Sarah Kaufman in The Washington Post. Kaufman covered Voices of Strength, a program presented at The Kennedy Center in October of 2012, wherein female artists broke down walls between performers and audiences. Performers addressed the audience directly and literally sat in the house seats as Nadia Beugré, an Ivory Coast-based dancer and choreographer, did at the beginning of her solo, "Quartiers Libres." Similarly, in "Correspondences" by Haitian Kettly Noel and South African Nelisiwe Xaba, the dancers spoke with, walked through, and interacted with people seated in the theater. Their creations were hybrids of voices, movements, and architectural designs. In The Washington Post, Kaufman responded by writing, "In both pieces, the emotional tension was only fitfully maintained, and they cried out for a director's discerning eye." ${ }^{43}$ Kaufman uses her review to exert her influence as an evaluator, and judges the artists' work according to the tenets of modern dance. ${ }^{44}$ As contemporary artists present work that defies this rubric, advocating for moments that are challenging and creating durational performances, a new choreographic apparatus emerges that brings together websites, audiences, and frameworks for engaging with their performances. Contemporary performance is congruent with a digital sphere that engages with ideas, philosophies, and aesthetics from a broad range of critics, theorists, and practitioners.

In other words, previous critical models were coincident with the rise of forms like modern dance, while the digital sphere is coincident with the rise of contemporary performance aesthetics. Maurice Berger writes in his 1998 introduction to The Crisis in Criticism, "If earlier in this century, critics-journalistic, specialized, or academic-have frequently played a vital, even public, role in influencing the shape, texture and direction of American culture, their value and relevance is growing increasingly tenuous in many sectors of mainstream American cultural life." 45 When online platforms call attention to the irrelevance of critics' methods or foreground how theory and history inform a performance, they merge these varied journalistic, expert, and academic roles of critics and offer different frameworks for readers to engage with dance. While TD presents a format that expands approaches to criticism-as well as voices and aesthetics promoted by writers - it still centers writing as the material of criticism. In the following sections I call attention to recordings and images as forms of criticism made possible by digital technologies and that reconfigure dance criticism in the 21 st century.

\section{Site 2: On the Boards TV (OtB TV) — In-between archive and repertoire}

OtB TV, created by the Seattle-based presenting organization On the Boards, invests in theatrical productions by contemporary artists by offering a distinct design: it brings 
full-length performances to a wide public by filming with high-definition cameras, editing collaboratively with the artists, and delivering performances online. Proceeds from the site's subscriptions are split between On the Boards and the artists. As of 2017, over 92 higher education institutions in the United States, Europe, and Australia have purchased content for their campuses, and the site has reached audiences in over 152 countries. ${ }^{46}$ OtB TV describes successes of the project in terms of pedagogical value, audience engagement, and archival purposes. ${ }^{47} \mathrm{I}$ add to this list of outcomes the proposition that OtB TV reconfigures dance criticism by supplanting criticism's role in description and documentation, ${ }^{48}$ and by introducing a format that merges presentation and circulation. It is different from Vimeo or YouTube because it is a curated platform for contemporary performance. Additionally, OtB TV makes evident the imbrications of performance with new modes of discourse because it highlights the importance of creating access to work by contemporary artists when there is a dearth of professional critics available to write about their projects.

OtB TV focuses on contemporary performance, and these performances shape both the form and contents of the site. Contemporary artists featured on OtB TV investigate the slippages between images and impressions, between what is felt and what is remembered. When artists edit their performances for online circulation through OtB TV, they consider a viewer's kinesthetic response as important as the event's documentation. For example, Zoe Scofield, one of the Seattle artists who has performed at On the Boards and created a film of her performance A Crack in Everything, said that the use of close-up became an important tool for giving viewers contact or closeness with the experience of the performance. She distinguished close-up in dance as different from theater because it involves a full-body but close range shot, different from theater's close-up on a facial expression or hand gesture. She said a question that was present in the process was creating a film that was not about showing "This is what happened," but rather giving the viewer a kinesthetic impression described as, "This is what I felt." ${ }^{49}$ This is a fundamental difference between OtB TV and archival footage of a dance performance. It also shifts the role of criticism from describing in words what a performance looked like to communicating through film, edited in collaboration with the artists. In this way OtB TV occupies a liminal place between embodied experience and circulating document.

Diana Taylor's The Archive and the Repertoire examines the characteristics of sensory experiences - "this is what I felt" - as embodied practices or repertoire, and contrasts these experiences with archival materials that can be stored and circulated-articles, books, videotapes, and DVDs, for instance. Taylor posits the need for methodologies that account for interrelationships of these practices and materials. In her article "Save As... Knowledge and Transmission in the Age of Digital Technologies," Taylor states:

The shift from the archive to the digital has moved us away from the institutional, the confined, the long-term of Foucault's disciplinary society to 
the controlled society outlined by Deleuze: free floating, short term, rapidly shifting... the politics of the archive are not the politics of the digital. What counts as embodied knowledge has also morphed. ${ }^{50}$

Taylor exposes the ways that digital technologies disrupt hegemonic discourses: if archival memory was the purview of the dominant- "Those who controlled writing... gained an inordinate amount of power" ${ }^{51}$ — digital circulations challenge both access to discourse and the authority of writers. With OtB TV, artists work with a professional film company to design and edit the recording of their live event, thereby replacing the critic who described or documented, and by extension controlled, the circulation of their performance.

Taylor's theorization of the digital, as existing in relationship to both the repertoire and the archive, is useful for situating OtB TV in between documentation and performance. OtB TV is a platform for discourse and discussion, as evidenced by the numerous higher education institutions that use its films. I see OtB TV as an approach that expands the boundaries of both dance criticism and screendance, as part of a new choreographic apparatus. It creates, to use Douglas Rosenberg's definition, "an entirely new hybrid form, a dismantling of tradition that rejects and challenges the mainstream." ${ }^{52}$ By giving access to full-length performances, recorded in a theater and edited by the artists, OtB TV dismantles traditional modes of documentation and generates access to contemporary artists. Further, OtB TV calls attention to the ways in which screens usher in a different approach to dance criticism at a time when contemporary artists seek platforms that support their processes.

One example of the ways critics in print publications have dismissed work of contemporary artists comes from New York Times critic Alastair Macaulay, who is known for dictating what choreographers should do. In a review of Tere O'Connor's performance in 2012, Macaulay writes: "How do the movements add up as theatrical experience? Here's where Mr. O'Connor's choreography is least sure... how does one sequence connect to another? How do the very appealing ideas cohere in memory?" 53

For Macaulay, O'Connor's work falls short of being a "theatrical experience" because it lacks necessary connections between sequences and a unifying coherence, attributes that Macaulay admires in choreographers like Mark Morris (included in this review as "a great choreographer"). ${ }^{54}$ There's no mention of the fact that $\mathrm{O}^{\prime}$ Connor is not interested in pursuing or displaying such characteristics, thus the yardstick by which Macaulay evaluates O'Connor is irrelevant to his own artistic investigation. A description of O'Connor's film on OtB TV, Bleed, more accurately captures O'Connor's aesthetic project, noting his "lifelong obsession with the vast possibilities of human movement to create a brand-new choreographic language." ${ }^{55}$ His works are playful, meticulous, and unexpected, and as a platform dedicated to contemporary performance, OtB TV engages with criteria and rubrics that acknowledge O'Connor's intentions, and that are 
different from those espoused by critics in the New York Times or Washington Post. In other words, access to more voices enables a dance criticism that is reflective of artists' priorities. Similar to the framing of artists' work in Philadelphia on TD, OtB TV reworks the choreographic apparatus to call attention to frameworks that align with artists' methods in the 21 st century.

Many artists outside of New York are featured on OtB TV, in particular artists from Europe, Canada, and Central America, and the site includes performances filmed in Portland (at the Portland Institute for Contemporary Art), in Austin (at Fusebox Festival), and New York (at PS 122). Techniques used in filming these events aspire to situate online audiences within the theater audiences. For example, watching Crystal Pite's Dark Matters on OtB TV, I first notice that heads of audience members are included in the frame so that I feel as if I am sitting in the auditorium with these spectators. The rustling of programs, bursts of laughter, and applause coming from the theatre's audience are clearly audible in the recording. Such details enhance the feeling of live performance as autopoietic feedback loop, a self-producing exchange that is occurring between distinct watchers and performers, rather than an event that can be captured or translated by a single critic's writing.

If OtB TV provides some of the vital elements of dance criticism, such as growing potential audiences for dance and deepening discourse that surrounds artistic work, ${ }^{56}$ the platform also gives tremendous power to the curator or director who selects which performances are recorded. In other words, if we recognize that, historically, critics wielded authority in terms of documenting performances and promoting certain artists, is the role of a critic now being replaced by that of digital curator? How does digital technology and a platform like OtB TV turn its creator-Lane Czaplinski-into a force determining the trajectory of dance history? Further, if there is an element of indeterminacy in the performances, or as choreographer Jan Fabre says his performances change as much as 30\% between shows and "the performance is finished when I do the last performance, the last show," ${ }^{57}$ how does one film become representative of a piece that is in continual process? The PBS television series Alive From Off Center grappled with similar questions between 1985 and 1996, and dance documentation as a genre continually investigates how one recording can stand in for multiple performances of a piece. Analyzing OtB TV as a form of dance criticism, the website distinguishes itself by providing access to multiple approaches to contemporary performance. Similar to a magazine that focuses on one genre of dance, like Pointe magazine for ballet, OtB TV offers access to more than 40 artists, giving viewers opportunities to engage with similarities and differences between their creations, rather than foregrounding one artist or one performance as representative of all contemporary work. 
OtB TV encourages audiences to adopt the practices of Internet archive users, who are different from traditional collector cultures, as Henry Jenkins explains in Spreadable Media:

While traditional collector cultures have been governed by preservationist impulses, these new retro subcultures are often more generative, more imaginative, and more playful in the ways that they recontextualize and reimagine the residual. ${ }^{58}$

"Traditional collector cultures" suggest Taylor's notion of archival practices that store and preserve "enduring" material and require special access. As Abigail De Kosnik writes in Rogue Archives, "users of an Internet archive may 'activate' whichever of the materials they wish, constructing their own personal canons based on the materials that they use... The definitions of 'canon' and 'archive' so firmly established in the era of print have changed dramatically in a digital regime." ${ }^{59}$ Such a reorganization of objects, archival material, and critical frameworks is the working of a choreographic apparatus, shifting audience perspectives and acknowledging interdependent ecologies of performance and writing, repertoire and archive, a dance canon and dance criticism. While OtB TV presents a collaboration between film companies and artists' performances, a different approach is introduced by artist Amara Tabor-Smith. By controlling the documentation and circulation of images of her work, Tabor-Smith calls attention to systems of exclusion that have made her work invisible to canon critics and draws on the affordances of social media to distribute her ideas and photographs of Conjure Art.

\section{Site 3: Amara Tabor-Smith: Dance criticism as tactical media}

An essential aspect of Tabor-Smith's House/ Full of BlackWomen (November 2015December 2020) is its location: Oakland, California is a national hub for human trafficking, specifically minors, and specifically exploited children. ${ }^{60}$ Tabor-Smith creates a series of processions to call attention to the environments in which children are exploited. The lived and communal focus of the work is vital to its presentation and circulation. In other words, the processions are created by, for, and with a community, and held without announcement or invitations for critics to attend. As a result, Tabor-Smith dismantles a power relationship where critics are invited to write about artists' work, as if they have the tools necessary to engage the creation. Instead of having one critic's writing stand in for a performance that is multi-modal and motivates multiple responses, Tabor-Smith handles the documentation and circulation of images of her work.

Using the concept of a choreographic apparatus, I situate Tabor-Smith's circulation of images as a kind of dance criticism that introduces different perspectives and platforms to highlight artists' projects. Tabor-Smith's control of the House/Full's circulation 
generates a form of tactical media since the traces of the event are crucial to its dissemination. As Tabor-Smith says, "The whole point of this ritual work is to leave a trace, to leave a stain, to leave an echo. I'm less interested in talking about the issues, per se, than I am in changing the vibrations." ${ }^{61}$ Photography by Robbie Sweeny becomes a form of criticism for House/Full that bypassed words or language, and that bypassed critics who "name," "capture," or, in the case of Ulrich's and Macaulay's reviews, dismissed an artist's investigation. Sweeny's photos were selected and posted on Facebook by Tabor-Smith, and offered access to an event that was visual, kinetic, and kinesthetic. Instead of relinquishing control to a critic, the artist decided what circulated from/about/for the ritual. This act of self-determination makes visible the theories of Patricia Hill Collins who writes, "When Black women define themselves, they clearly reject the taken-for-granted assumptions that those in positions granting them the authority to describe and analyze reality are entitled to do so. Regardless of the actual content of Black women's self-definitions, the act of insisting on Black female selfdefinition validates Black women's power as human subjects." ${ }^{62}$ By selecting photographs to post on social media, Tabor-Smith curates and defines. Collins continues:

Black women's insistence on self-definition, self-valuation, and the necessity for a Black female-centered analysis is significant for two reasons. First, defining and valuing one's consciousness of one's own self-defined standpoint in the face of images that foster a self-definition as the objectified "other" is an important way of resisting the dehumanization essential to systems of domination. The status of being the "other" implies being "other than" or different from the assumed norm of white male behavior. In this model, powerful white males define themselves as subjects, the true actors, and classify people of color and women in terms of their position vis-a-vis this white male hub. Since Black women have been denied the authority to challenge these definitions, this model consists of images that define Black women as a negative other, the virtual antithesis of positive white male images. ${ }^{63}$

Dance criticism in the United States has been-and is - written predominantly by white critics, and my analysis of Tabor-Smith's work foregrounds the significance of who is given authority to represent another person's performances. It's important to note that Tabor-Smith's acts of self-definition and self-valuation emerged before House/Full.

In 2015 Amara Tabor-Smith named and defined her creative practice "conjure art." ${ }^{164}$ By identifying what she valued, she implicitly pointed out what has been made invisible by modern dance aesthetics:

The work of the conjure artist explores traditional spiritual myths, images and/or practices from a contemporary or experimental art perspective. 
Conjure artists believe in the forces of nature such as ancestor spirits, gods and/or deities found in indigenous cultures and recognize these energies as the guiding forces in their art practice. ${ }^{65}$

This definition, with its emphasis on collective creations, traditions, and "ancestor spirits," exposes and resists the "individual innovation" and "autonomy" that modern dancers (and critics) prioritized. Brenda Dixon Gottschild, for instance, speaks of combating racism by acknowledging historical precedents and cultural sources, and especially acknowledging work by artists of color. In contrast, Roger Copeland's essay "The Death of the Choreographer" bemoans the attention given to "collectively created" works at the expense of "dances whose 'authorship' can be attributed to unique Western individuals." 66 Copeland continues, "[T]he growing emphasis on traditional and popular cultures evolves into a zero-sum game that is played at the expense of individual Western choreographic 'authors."'67 In contrast to Copeland's assessment that indigenous cultures and epistemologies do not belong with great "individual" artists, Tabor-Smith highlights the value of interdependence and interconnection. Her artistic works, which draw from her spiritual practice as a priest in the Yoruba/Lukumi tradition known as Ifa, disrupt a teleological ordering of dance history as the purview of individual, white artists' perpetual innovation or inventing.

In her project description for House/Full Tabor-Smith states:

House/Full of Black Women is a site-specific ritual performance project that addresses issues of displacement, well being, and sex trafficking of Black women and girls in Oakland. Set in various public sites throughout Oakland over a two-year period, this community engaged project is performed as a series of "Episodes" that are driven by the core question, "How can we, as Black women and girls find space to breathe, and be well within a stable home?"68

In our conversation in 2017, Tabor-Smith emphasized that "well being" must be at the center of her description because "it's important that the well being of Black women is affirmed... What often happens is we are encouraged (or we make the choice willingly) to make work that focuses on the struggle and our oppression. When we do that we are reinforcing the struggle. We are affirming and thereby normalizing the issue." ${ }^{69}$ Through this description, three themes emerge: the first is the irrelevance of a critic who serves as an evaluator or judge for this type of work. The intent of House/Full is tactical: TaborSmith is interested in the "ways people's perceptions can be shifted." ${ }^{\circ}$

As Rita Raley theorizes in Tactical Media, "These projects are not oriented toward the grand, sweeping revolutionary event; rather they engage in a micropolitics of disruption, intervention, and education." ${ }^{71}$ Tabor-Smith's work operates within the realm of tactical media and calls for someone who recognizes the importance of sensorial engagement, vibration, dissent and resistance, more than shape, effort, or line, 
which continue to be indicators of value for prominent dance critics (see criticism cited in this article by Ulrich and Macaulay). In Raley's words, "disturbance" is the critical element in tactical media. Raley continues, "Tactical media signifies the intervention and disruption of a dominant semiotic regime, the temporary creation of a situation in which signs, messages, and narratives are set into play and critical thinking becomes possible." ${ }^{72}$

A type of writing that "describes" or "captures"-words commonly used by critics to define their approaches-is part of a system that prioritizes efficiency and operationalism. ${ }^{73}$ These are not Tabor-Smith's priorities, but they motivate many critics' writing, especially those who define their role as that of a "distant observer." In a speech to the Dance Critics Association in 1989, Sally Banes said, "Ethnographers are moving toward a dialogic construction of cultural texts, but as critics we remain-and I would argue should remain-distant observers. Who wants to coauthor their review with the choreographer?"74 As current performances makes clear, an artist's knowledge and insights are not always visible to a "distant observer," yet Banes's definition of criticism as "description, evaluation, interpretation, and contextual explanation" continues to propel much of today's dance writing. ${ }^{75}$ In order to investigate this value of "distance" proposed by Banes, it is important to differentiate between objectivity, neutrality, impartiality, and distance, and to notice how such concepts intersect with dance criticism.

Canon criticism extends a genre defined by Matthew Arnold, who viewed criticism as a "disinterested endeavor" and emphasized an "impartial distance" from which a critic could offer evaluation of an artist's aesthetic. ${ }^{76}$ These critics sought out the "universal" and "transcendent" qualities of dance, drawing a border between performance and context. As Randy Martin writes in Critical Moves: "Criticism is an authority that can police the boundary between the aesthetic and the political economy of art, often coded as the divide between art and life." ${ }^{17}$ This act of critical policing depends on distance. Sima Belmar examines this assumed dependence when she writes, "The dance critic is granted authority predicated on distance (mostly by lay people who value journalistic objectivity and merciless judgment)." ${ }^{78}$ John Rockwell, former editor of Arts \& Leisure at the New York Times, affirms this view: "[T] he very nature of the perception of artwork places one at a distance from the creator, or indeed anybody else watching the artwork. To pretend otherwise is kind of futile." 79 This framing of a critic's role as evaluator or distant observer implies an ability to judge and discern objectively, hence the anxiety about distance as a form of impartiality.

When critics like John Martin published in the New York Times, they were embedded within institutions that prioritized unbiased commentary and avoided conflicts of interest. A closer examination of critics' relationships with artists—such as John Martin and Martha Graham-reveals that they were not only in conversation about artistic processes but also critics' writing influenced the choices and directions of artists' 
practices. Nevertheless dance critics adopted a tone that prioritized distance and objectivity, reporting on performances as if they were neutral observers. They did this to promote their own authority, as well as the "universality" of dance performances, and the value of dance as an art form that could be analyzed with an almost scientific rigor. ${ }^{80}$

In the early 1990s, and simultaneous with the growing popularity of cultural studies in academic settings, artists like Jawole Willa Jo Zollar began to question writers' "objectivity." Zollar's "Listen, Our History is Shouting at us: A choreographer confronts racism in dance" is an essay that includes an 8-point checklist for critics with some of the key points being:

- I will confront the issue of linguistic racism and be willing to examine my writing from that point of view;

- As a world citizen, I will recognize that I embrace many aesthetics and though I may intensely identify with one, I will not hold that aesthetic in a superior position;

- I will not confuse the ways in which American culture has been influenced by nonwhite cultures with an assumption that those cultures have had equal access to the stage;

- I will be willing to examine language patterns and ideas that generalize a group while, at the same time, figuring out what truth there may be in the generalities that are made about a particular culture. ${ }^{81}$

Online platforms encourage a greater sense of polyvocality in criticism by making visible reader responses through comments that are easily posted and accessible. They also offer opportunities to add different or opposing perspectives, and then circulate these ideas through social media platforms. Such interactions refuse the ability of the critic to speak for everyone or to go unanswered. ${ }^{82}$

For Amara Tabor-Smith, photographic images are relevant to her project, even though photography may not be the solution to the ways critics have misrepresented and overlooked aspects of artists' work. As dance scholar Tria Blu Wakpa has said, "Images can also be interpreted in ways that reify dominant representations of Black peoplewhat's more important is engagement with and accountability to artists of color and indigenous artists. Another thing is that the meaning of the visual realm is fluid, so Amara's photos can still be 'misunderstood' by critics or used to reify stereotypes of Black women and girls." ${ }^{83}$ Indeed, photographs do not surpass or supplant a written form of criticism, rather they shed light on modes of engagement-images instead of words - that have been overlooked in earlier approaches. As RoseLee Goldberg says, "I think photographs have an extraordinary capacity to bring us closer to the work, to give us an experience of the work, and to allow us to build a reference bank of images and ideas." ${ }^{84}$ 
This "capacity to bring us closer" connects with Tabor-Smith's priorities for the project as well as with her choice to circulate Sweeny's photography:

We wanted to create ritual and the impact of ritual necessitates that people who happen upon it have a different experience. There's a way they are "caught." There's a moment when their curiosity takes over or they get destabilized. When they go, 'Oh what's this?' That questioning is an opening in and of itself. Even if it's momentary, it's enough for us to seep in. ${ }^{85}$

House/Full operates through moments of destabilization, and Sweeny's images, which are characterized by poetry, mystery, and evocations, use similar tactics. There is a constitutive relationship between the modes of engagement in Tabor-Smith's project and those used in its criticism, meaning the traces that emanate from these events.

\section{Conclusion}

As important as dance criticism has been to dance as an art form, serving as documentation, validation, and promotion, there are few scholarly analyses of dance criticism that account for its constitutive properties, for the changing functions of critics and formats of platforms, as well as its relation to digital technologies. The three sites analyzed here illustrate how digital circulations are methods of re-distributing the voices and modalities engaged in criticism. Within this digital sphere there are shifts away from criticism as evaluation and assessment and towards more dialogic and inclusive forms of discourse. Questions remain: historically and currently there are relatively few women of color writing dance criticism. What does this do to the perspectives and priorities of artists like Tabor-Smith? How is this work valued and documented, outside of her circulation of images? For dancers, scholars, and audience members, I find the digital sphere is essential to countering the dismissals and hierarchies that privilege certain forms of assessment that have become embedded in canonical definitions of dance, especially those events which occur on proscenium stages, choreographed by predominantly white, male artists, and feature codified techniques that perpetuate systems of racism, ableism, sexism, and classism. The images and articles that circulate through websites offer counterpoint to these exclusions, and assert artists' agency in the representations of their work. Just as print journalism was constitutive with earlier genres of dance-modern and postmodern dance, specifically-digital technologies share symbiotic relationships with contemporary performances. A choreographic apparatus clarifies these interconnections among artists, audiences, and critics, and the digital sphere, specifically online platforms and social media, is generating frameworks for us to consider more capacious definitions of criticism.

Acknowledgements: Special thanks to Harmony Bench for her invaluable feedback and edits that improved this article immensely. 


\section{Biography}

Kate Mattingly is an Assistant Professor in the School of Dance at the University of Utah. Her research focuses on dance criticism and the transfer of experiences that are felt, embodied, and kinesthetic into formats that are written, spoken, and recorded. Her articles have been published in the New York Times, the Village Voice, Dance Research Journal, Dance magazine, Pointe magazine, The Washington Post, and many other journals and publications. She received her undergraduate degree in Architecture: History and Theory from Princeton University in 1993 and graduated with high honors. Her Master's of Fine Arts degree is from New York University's Tisch School of the Arts where she worked closely with Professor Deborah Jowitt and performed choreographic works by William Forsythe and Amanda Miller. Her doctoral degree from the University of California, Berkeley is in Performance Studies with a Designated Emphasis in New Media.

Email: kate.mattingly@utah.edu

\section{Notes}

"I am intentionally using "digital" and not "online" here because digital encompasses a greater number of formats and processes that intersect with certain modes of communication and behaviors, including online platforms. "Digital" additionally signals formats for storing and transmitting material that differ from print modalities.

${ }^{2}$ Madison Mainwaring, "Death of American Dance Critic."

${ }^{3}$ Ibid.

${ }^{4}$ When Oxford University Press published its Handbook to Dance and the Popular Screen in 2014, the book was marketed as "a powerful corrective to the lack of accessible scholarship on dance in the popular screen." In dance history textbooks often used in higher education, such as No Fixed Points by Nancy Reynolds and Malcolm McCormick, concert dance artists occupy most of the chapters while dance on screen is given one chapter or minimal mention. See also Sherill Dodds, Dancing on the Canon. Dodds emphasizes how a dance's circulation influences its validation, and vice versa: a canonical history in dance is verified and perpetuated by excluding forms that are "popular." 
${ }^{5}$ This blurring is exemplified by press departments that previously used wellestablished critics for pull-quotes in brochure marketing and now use websites and bloggers as sources for material. Shows like "So You Think You Can Dance" and "Dancing with the Stars" turn audiences into "critics" who select the "best" performers. My analysis departs slightly from important arguments put forward by Harmony Bench in "Digital Research in Dance Studies" by emphasizing the ways that dance criticism has been treated as a document of dancing, and why this is problematic, instead of seeing "[t]he absence of documentation" as the "greater barrier to the legitimacy of dance as an academic field of study." Continuing this approach, I find dance critics have superseded other forms of accounting for dance and would place more emphasis on their role than on "anthropologists and creative practitioners themselves" as determining forces in dance scholarship. I think the archives listed"the Jerome Robbins Dance Division of the New York Public Library, Jacob's Pillow, the Smithsonian, and the Library of Congress"- perpetuate an investment in canonical dance that is different from online platforms I analyze in this article.

${ }^{6}$ Mainwaring.

${ }^{7}$ Elizabeth Zimmer, "The Crisis in Criticism."

${ }^{8}$ Scholars who have written about dance criticism include Lynne Conner, who explores constitutive relationships between performances and writing from 1850 to 1934, noting how dance as an art form was established at a time when both choreographers and critics searched for recognition, in Spreading the Gospel of the Modern Dance: Newspaper Dance Criticism; Gay Morris, who analyzes relationships between criticism and artists' approaches in the mid-20th century in A Game for Dancers: Performing Modernism in the Postwar Years, 1945-1960; Diane Theodores, who selects four American writers-Arlene Croce, Nancy Goldner, Marcia Siegel, and Deborah Jowitt—-to establish a "New York School" of dance criticism in her book First We Take Manhattan; Ann Daly, who created a collection of her writing, called Critical Gestures, and Sally Banes who describes the role of the critic by collecting her own essays and reviews in Writing Dancing in the Age of Postmodernism. In this article I show how digital platforms reconfigure definitions of criticism as well as the "appropriate" role for a dance critic described by these scholars.

${ }^{9}$ Daly defines canon criticism as "an approach that centers around the ideology and practice of connoisseurship." See Critical Gestures, xxxiii. Today, canon criticism is most visible in the writing of Alistair Macaulay (New York Times), Sarah Kaufman (Washington Post), and Allan Ulrich (San Francisco Chronicle) who see their roles as guardians or gatekeepers for a distinct definition of "dance" that is predicated on systemic exclusions and biases such as sexism, racism, ableism, and classism. In this article I argue that digital dance criticism acknowledges both the subjectivity of such "connoisseurship" and the positionality of dance critics. As analyzed in this article, all 
three critics emphasize evaluation and judgment over a disclosing of their own subjective preferences or a performance's context. For example, Ulrich comments on Alvin Ailey American Dance Theater choreographer Jamar Roberts, "His first work for the company, 'Members Don't Get Weary,' received its West Coast premiere Tuesday, and it seemed more than slightly promising."

${ }^{10}$ Harmony Bench and Simon Ellis, "Editorial: Field Perceptions," 8.

${ }^{11}$ Research by Ananya Chatterjea examines how criticism perpetuates inequities that intersect with location and politics in Butting Out. Chatterjea writes, "Though they are both important figures in the international circuit of touring companies, and though the reception of their performance obviously differs in different locations, I am framing much of my argument about the work of Chandralekha and Zollar in the dominant terms of the field as I see it from here, in the United States. This is because their workas is the work of most artists, certainly those of color-tends to be categorized in terms of descriptors generated from and in terms of Euro-American culture and it is against and in relation to these formulations that I make my argument." Chatterjea, 11-12.

${ }^{12}$ In her writing on theatre criticism, Diana Damian Martin states: "Performance itself offers a site in which the sensible can be re-distributed, that is, in which certain conflicts, ideas and sensibilities can be challenged and the terms of the conflict reordered. Criticism holds a responsibility towards the articulation of this re-distribution; in its relationship to a wider cultural and political context, criticism holds the ability to engage in a process of re-distribution of the sensible that operates discursively and aesthetically." In "Criticism as a Political Event," 223.

${ }^{13}$ For examples, see Yvonne Rainer in TDR, "Parts of Some Sextets," in particular the excerpt of this article that became known as Rainer's "No Manifesto."

${ }^{14}$ André Lepecki, "Choreography as Apparatus of Capture," 120.

${ }^{15}$ Quoted in Lepecki, 120.

${ }^{16}$ Nancy Fraser, "Rethinking Recognition." Examples in the writing of critics are numerous. For instance, John Martin misrepresented the work of artists of color such as Katherine Dunham, Talley Beatty, and Archie Savage. As Joanna Dee Das writes, "Martin expressed 'distress' that Talley Beatty and Archie Savage, two male dancers in Dunham's company, had a 'tendency to introduce the technique of the academic ballet."' Das, Katherine Dunham, 70.

${ }^{17}$ One example that resonates with this study is Miguel Gutierrez's "The Perfect Dance Critic."

${ }^{18}$ Randy Martin, Critical Moves, 83. 
${ }^{19}$ Susan Foster explains that her Reading Dancing was written to "get to the workings of dance," a task that critics have failed to do. Foster, xvi.

${ }^{20}$ This speaks to a broader conversation about roles of print and digital platforms summarized here: "In 2005, according to the Newspaper Association of America, US newspapers generated $\$ 47.4$ billion in print revenue. That number has dropped every year since, and, in many, precipitously. By 2014, US print revenue had declined to $\$ 16.4$ billion, marking a 66 percent drop over nine years. In that same time period, digital revenue for US newspapers increased only from \$2 billion to \$3.5 billion." From: http://www.cjr.org/analysis/local_news_newspaper_print_business_model.php

${ }^{21}$ In Henry Jenkins, "Affective Publics and Social Media."

${ }^{22}$ Village Voice, San Francisco Examiner, and Time Out are examples.

${ }^{23}$ Brenda Dixon Gottschild cites pre-performance discussions as sites of discourse: "I've been invited to hold pre-performance conversations with Liz Santoro, Gus Solomons and Valda Setterfield, and Jaamil Kosoko and [Honji] Wang/[Sébastien] Ramirez at Tanz im August this summer in Berlin." In Lynn Matluck Brooks, "Arrows at Racism."

${ }^{24}$ Abigail De Kosnik, Rogue Archives, 28.

${ }^{25}$ Alva Noë, “Reorganizing Ourselves," 17-18.

${ }^{26}$ Claudia Bauer, "GERALDCASELDANCE."

${ }^{27}$ Allan Ulrich, "Casel's Splinters fractures at ODC."

${ }^{28}$ Ibid.

${ }^{29}$ Ibid.

${ }^{30}$ Rebecca Chaleff, personal communication, June 2018.

${ }^{31}$ Diana Taylor, The Archive and the Repertoire, 20, 19.

32 See Wendy Perron, "Beware the ego of critics."

${ }^{33}$ Collections by Arlene Croce (Writing in the Dark, Dancing in the New Yorker), Deborah Jowitt (The Dance in Mind), and Marcia Siegel (At the Vanishing Point). Scholarship by Lynne Conner (Spreading the Gospel of Modern Dance), Gay Morris (A Game for Dancers: Performing Modernism in the Postwar Years), and Diane Theodores (First We Take Manhattan).

${ }^{34}$ Linda Tuhiwai Smith, Decolonizing Methodologies.

35 "Our history and what we do..." 
${ }^{36}$ Brenda Dixon Gottschild quoted in Lynn Matluck Brooks, "Arrows at Racism."

${ }^{37}$ Ibid.

${ }^{38}$ Jane Goldberg, "Credit Where Credit is Due."

${ }^{39}$ For a recent example of a point of view not often heard, read "I don't need to see Jessica Lang Dance," review by Kat J. Sullivan and comments.

${ }^{40}$ David Zambrano, spoken during post-performance discussion at YBCA, April 28, 2012.

41 "Letter to the Whirl."

${ }^{42}$ Ibid.

${ }^{43}$ Sarah Kaufman, "Voices of Strength."

${ }^{44}$ Doris Humphrey's Art of Making Dances presents statements that align with Kaufman's priorities: "All dances are too long" (159), "Monotony is fatal; look for contrasts" (159), "Perhaps the only thing everyone agrees on is that there should be music with dance" (164), "Communication in terms of nonintellectualized movement seems to me the desirable goal" (165), "Critics have some influence on public opinion but the average theatergoer cannot be coerced into going to see something which does not reach him[sic], no matter how the connoisseur may rave" (172), and "One other kind of theme to try to avoid is the too-complex scenario" (39). Humphrey was one of the "Big Four" artists of modern dance, a genre that prioritized simplicity, efficiency, drama, and idealism.

${ }^{45}$ Maurice Berger, The Crisis of Criticism, 4.

${ }^{46}$ Data from "About" at OntheBoards.tv.

${ }^{47}$ lbid.

${ }^{48}$ On the role of dance criticism as documentation, see, for example, Julie Van Camp, "Dance Criticism."

${ }^{49}$ Zoe Scofield, personal conversation, November 3, 2012.

${ }^{50}$ Diana Taylor, "Save As..."

${ }^{51}$ Taylor, The Archive and the Repertoire, 18.

${ }^{52}$ Douglas Rosenberg, Screendance, 12.

${ }^{53}$ Alastair Macaulay, "Seeking Answers."

${ }^{54}$ Ibid. 
55 "Tere O'Connor: Bleed, poem \& Secret Mary."

${ }^{56}$ Dance critics play an essential role in circulating ideas about artists and performances and growing audiences for dance. In 2016 the decrease in audiences for dance was attributed to dance critics being cut from publications. See Pia Catton, "Dance Audiences are Down."

${ }^{57}$ Jan Fabre in conversation with Lane Czaplinski. "On the Boards Journal." See 4:004:45.

${ }^{58}$ Henry Jenkins, Sam Ford, and Joshua Green, Spreadable Media, 101.

${ }^{59}$ De Kosnik, 66-71.

${ }^{60}$ Trafficking involves the use of force, fraud or coercion to exploit a person for labor or commercial sex, and there have been steadily increasing cases of youth sex trafficking in California: from 352 documented cases in 2012 to 1,052 cases in 2016. Statistics come from National Human Trafficking Hotline quoted in Lisa Hornak, "When Love Never Fails."

${ }^{61}$ Amara Tabor-Smith, phone conversation with the author, November 2017.

${ }^{62}$ Patricia Hill Collins, "Learning from the Outsider Within," S17.

${ }^{63}$ Idem, S18.

${ }^{64}$ Tabor-Smith, "The Practice of Conjure Art."

${ }^{65} \mathrm{Ibid}$. I use this example because it is one of the few labels for dance that is not about being in the present or current time but rather speaks to aesthetic priorities the way "Impressionism" or "Surrealism" does in art history. I think the scarcity of terms and confusion about categories for dance-artists is evidence of a lack of sustained, substantive writing about dance compared to other disciplines.

${ }^{66}$ Roger Copeland, "The Death of the Choreographer," 40.

${ }^{67}$ Idem, 55. Original emphasis.

${ }^{68}$ Tabor-Smith, "Creative Capital."

${ }^{69}$ Tabor-Smith, phone conversation with the author, November 2017.

${ }^{70}$ Ibid.

${ }^{71}$ Rita Raley, Tactical Media, 4.

${ }^{72}$ Ibid.

${ }^{73}$ Ibid. 
${ }^{74}$ Sally Banes, Writing Dancing.

${ }^{75}$ Banes's Writing Dancing continues to be used as a textbook for criticism courses.

${ }^{76}$ The full quote is: "Criticism is a disinterested endeavor to learn and propagate the best that is known and thought in the world." Matthew Arnold, The Function of Criticism, 77.

${ }^{77}$ Randy Martin, 79.

${ }^{78}$ Sima Belmar, "Out of Order."

${ }^{79}$ John Rockwell quoted in Deborah Jowitt, "Getting it."

${ }^{80}$ For an analysis of how dance critics shored up support for the art form by applying formalist and New Critical methods of writing, see Mattingly, "Set in Motion: Dance Criticism and the Choreographic Apparatus."

${ }^{81}$ Jawole Willa Jo Zollar, "Listen, Our History is Shouting at Us," keynote address at the Dance Critics Association Conference in Los Angeles, 1990. Reprinted in Looking Out.

${ }^{82}$ Scholars Jacqueline Shea Murphy (The People Have Never Stopped Dancing), Thomas DeFrantz (Dancing Many Drums), and Ananya Chatterjea (Butting Out) have brought important attention to the ways in which writing by critics and historians has excluded and misrepresented Indigenous peoples and artists of color. Another excellent example is provided by scholar Joanna Dee Das (Katherine Dunham) when she examines how John Martin's writing perpetuated and circulated racist assumptions about Katherine Dunham's work.

${ }^{83}$ Tria Blu Wakpa, personal communication, June 2018.

84 "On Record: RoseLee Goldberg and Roxana Marcoci in Conversation."

${ }^{85}$ Amara Tabor-Smith, personal communication, November 2017.

\section{References}

"About." OntheBoards.tv. https://www.ontheboards.tv/about

Arnold, Matthew. The Function of Criticism at the Present Time. New York: Macmillan Company, 1900. 
Banes, Sally. Writing Dancing in the Age of Postmodernism. Wesleyan University Press, 1994.

Bauer, Claudia. "GERALDCASELDANCE: Splinters in our Ankles." Dance Tabs. Dec. 20, 2015. http://dancetabs77.rssing.com/browser.php?ind $x=41757196 \&$ item $=26$

Belmar, Sima. "Out of Order: Disobedient Dance Criticism." In Dance October 1, 2009. https://dancersgroup.org/2009/10/out-of-order-disobedient-dance-criticism/.

Bench, Harmony. "Digital Research in Dance Studies: Emerging Trends in a StillEmerging Field." Humanities Futures. Duke University, March 25, 2015. https://humanitiesfutures.org/papers/digital-research-in-dance-studies-emergingtrends-in-a-still-emerging-field-2/.

Bench, Harmony and Simon Ellis. "Editorial: Field Perceptions." International Journal of Screendance 6 (2016). 1-13. https://doi.org/10.18061/ijsd.v6i0.5250

Berger, Maurice. The Crisis of Criticism. New York: The New Press, 1998.

Blanco Borelli, Melissa, ed. The Oxford Handbook of Dance and the Popular Screen. New York: Oxford University Press, 2014.

Brady, Jim. "Local news isn't dead. We just need to stop killing it." Columbia Journalism Review June 17, 2016.

http://www.cjr.org/analysis/local_news_newspaper_print_business_model.php

Brooks, Lynn Matluck. "Arrows at Racism in Dance and Beyond." June 25, 2016. http://thinkingdance.net/articles/2016/06/25/Arrows-at-Racism-in-Dance-andBeyond-Brenda-Dixon-Gottschild-

Catton, Pia. “Dance Audiences are Down." Wall Street Journal Oct. 20, 2016. https://www.wsj.com/articles/dance-audiences-are-down-in-nyc-study-finds1477009338

Chatterjea, Ananya. Butting Out: Reading Resistive Choreographies Through Works by Jawole Willa Jo Zollar and Chandralekha. Middletown: Wesleyan University Press, 2004.

Collins, Patricia Hill. "Learning from the Outsider Within: the Sociological Significance of Black Feminist Thought," Social Problems 33.6 (December 1986): S14-S32. https://doi.org/10.2307/800672

Conner, Lynne. Spreading the Gospel of the Modern Dance: Newspaper Dance Criticism. Pittsburgh: Pittsburgh University Press, 1997.

Copeland, Roger. "The Death of the Choreographer." In Dance and Politics. Ed. Alexandra Kolb. Oxford: Peter Lang, 2010. 39-65. 
Correspondences. Kettly Noël and Nelisiwe Xaba. Part of the Voices of Strength program, The Kennedy Center, October 2012.

A Crack in Everything. zoe|juniper. Premiered at Jacob's Pillow June 2011.

Croce, Arlene. Writing in the Dark, Dancing in the New Yorker. New York: Farrar, Straus and Giroux, 2000.

Daly, Ann. Critical Gestures: Writings on Dance and Culture. Middletown, CT: Wesleyan University Press, 2002.

Dark Matters. Kidd Pivot. Premiered at the National Arts Centre, Ottawa, Canada, April 2009.

Das, Joanna Dee. Katherine Dunham: Dance and the African Diaspora. Oxford: Oxford University Press, 2017. https://doi.org/10.1093/acprof:oso/9780190264871.001.0001

De Kosnik, Abigail. Rogue Archives: Digital Cultural Memory and Media Fandom. Cambridge, MA: MIT Press, 2016.

DeFrantz, Thomas. Dancing Many Drums: Excavations in African American Dance. Madison: University of Wisconsin, 2001.

Dodds, Sherill. Dancing on the Canon: Embodiments of Value in Popular Dance. Basingstoke, UK: Palgrave Macmillan, 2011. https://doi.org/10.1057/9780230305656

Fabre, Jan. "On the Boards Journal: Late Night TV." May 4, 2009. http://wpc.162d.edgecastcdn.net/00162D/audio/20090413_fabre.mp3

Foster, Susan. Reading Dancing: Bodies and Subjects in Contemporary American Dance. Berkeley: University of California Press, 1986.

Fraser, Nancy. “Rethinking Recognition.” New Left Review 3, May-June 2000. 107-120.

Goldberg, Jane. "Credit Where Credit is Due." thINKingDANCE December 18, 2015. http://thinkingdance.net/articles/2015/12/18/Credit-Where-Credit-is-Due-a-Letter-tothe-Editor-of-The-New-Yorker/

Gutierrez, Miguel. "The Perfect Dance Critic." In "What Makes a Good Dance Critic?" Movement Research Journal 25 (Fall 2002): 8-9.

Hornak, Lisa. "When Love Never Fails." Oakland North December 14, 2017. https://oaklandnorth.net/2017/12/14/with-love-never-fails-vanessa-russell-reachesout-to-sex-trafficking-survivors/

House/Full of BlackWomen. Amara Tabor-Smith/Deep Water Dance Theater. Performed in public sites throughout Oakland, CA between November 2015-Fall 2018. 
Humphrey, Doris. Art of Making Dances. New York: Grove Press, 1959.

Jenkins, Henry. "Affective Publics and Social Media: An Interview with Zizi Papacharissi (Part One)." Confessions of an Aca-Fan, January 19, 2015.

http://henryjenkins.org/2015/01/affective-publics-and-social-media-an-interviewwith-zizi-papacharissi-part-one.html

Jenkins, Henry, Sam Ford, and Joshua Green. Spreadable Media: Creating Value and Meaning in a Networked Culture. New York: New York University Press, 2013.

Jowitt, Deborah. "Getting it." Village Voice February 21, 2006.

http://www.villagevoice.com/arts/getting_it_7136449

. The Dance in Mind. Boston: David R. Godine Publisher Inc. 1985.

Kaufman, Sarah. "Voices of Strength." The Washington Post October 5, 2012. http://www.washingtonpost.com/entertainment/theater_dance/voices-of-strengthallows-african-women-to-express-themselves-in-movement/2012/10/05/b3115e92of20-11e2-bd1a-b868e65d57eb_story.html

Lepecki, André. Exhausting Dance: Performance and the Politics of Movement. New York: Routledge, 2006.

. "Choreography as Apparatus of Capture." TDR: The Drama Review 51.2 (Summer 2007): 119-123. https://doi.org/10.1162/dram.2007.51.2.119

"Letter to the Whirl." thINKingDANCE September 22, 2015. http://thinkingdance.net/articles/2015/09/22/Letter-to-the-Whirl-The-Crowd-CirclesRound

Macaulay, Alastair. "Seeking Answers Among the Etudes: Tere O'Connor Dance at New York Live Arts." New York Times November 28, 2012.

https://www.nytimes.com/2012/11/29/arts/dance/tere-oconnor-dance-at-new-yorklive-arts.html

Mainwaring, Madison. “Death of American Dance Critic." The Atlantic, August 2015. http://www.theatlantic.com/entertainment/archive/2015/08/american-dancecritic/399908/

Martin, Diana Damian. "Criticism as a Political Event." In Theatre Criticism: Changing Landscapes. Ed. Duska Radosavlijevic. London: Bloomsbury, 2016. 219-235.

Martin, Randy. Critical Moves: Dance Studies in Theory and Politics. Durham: Duke University Press, 1998.

Mattingly, Kate. Discussion with Tria Blu Wakpa. June 2018. 
. Discussion with Rebecca Chaleff. June 2018.

. Discussion with Lane Czaplinski. October 2012.

. Discussion with Amara Tabor-Smith. November 2017.

. "Set in Motion: Dance Criticism and the Choreographic Apparatus." University of California, Berkeley. Dissertation 2017.

Morris, Gay. A Game for Dancers: Performing Modernism in the Postwar Years, 1945-1960. Middletown: Wesleyan University Press, 2006.

Noë, Alva. Strange Tools: Art and Human Nature. New York: Hill \& Wang, 2015.

On the Boards TV. https://www.ontheboards.tv

On The Boards: Tere O'Connor's Bleed, poem \& Secret Mary.

https://www.ontheboards.org/performances/bleed-poem-secret-mary

"On Record: RoseLee Goldberg and Roxana Marcoci in Conversation." Aperture 221 (Winter 2015): 43-49.

"Our history and what we do..." thINKingDANCE.

http://thinkingdance.net/about/what-were-doing

Perron, Wendy. "Beware the ego of critics." Village Voice April 9, 1991. Reprinted in Wendy Perron, Through the Eyes of a Dancer. Middletown: Wesleyan University Press, 2013. 101-104.

Quartiers Libres. Nadia Beugré. Part of the Voices of Strength program, The Kennedy Center, October 2012.

Rainer, Yvonne. "Some Retrospective Notes on a Dance for 10 people and 12 mattresses called Parts of Some Sextets performed at Wadsworth Atheneum, Hartford, Connecticut, and Judson Memorial Church, New York in March 1965." TDR Winter 1965. Republished in Happenings and Other Acts, ed. Mariellen R. Sandford. New York: Routledge, 1995. 160-167.

Raley, Rita. Tactical Media. Minneapolis: University of Minnesota Press, 2009.

Rosenberg, Douglas. Screendance: Inscribing the Ephemeral Image. New York: Oxford University Press, 2012. https://doi.org/10.1093/acprof:oso/9780199772612.001.0001

Shea Murphy, Jacqueline. The People Have Never Stopped Dancing. Minneapolis: University of Minnesota Press, 2007.

Siegel, Marcia. At the Vanishing Point: A Critic Looks at Dance. New York: Saturday Review Press, 1973. 
Soul Project. David Zambrano. First tour to United States, April-May 2012.

Smith, Linda Tuhiwai. Decolonizing Methodologies: Research and Indigenous Peoples. London: Zed Books 1999.

Sullivan, Kat J. "I don't need to see Jessica Lang Dance."

http://thinkingdance.net/articles/2018/12/14/43/I-dont-need-to-see-Jessica-Lang-

Dance/

Tabor-Smith, Amara. "The Practice of Conjure Art." Dance. September 1, 2015.

http://dancersgroup.org/2015/09/speak-practice-conjure-art-makingearthbodyhome/

. "Creative Capital." https://www.creative-capital.org/projects/view/868

Taylor, Diana. The Archive and the Repertoire: Performing Cultural Memory in the Americas. Durham: Duke University Press, 2003.

https://doi.org/10.1215/9780822385318

. "Save As... Memory and the Archive in the Age of Digital Technologies." Lecture. University of California, Berkeley, September 30, 2010.

https://www.youtube.com/watch?v=xGurF1RfjoU

Theodores, Diane. First We Take Manhattan: Four American Women and the New York School of Dance Criticism. Amsterdam: Harwood Academic Publishers GmBH, 1996.

thINKingDANCE. Website. http://thinkingdance.net

Ulrich, Allan. "Ailey dancers strike gold in annual UC visit." San Francisco Chronicle Apr. 11, 2018. https://www.sfchronicle.com/movies/article/Ailey-dancers-strike-goldin-annual-UC-visit-12825912.php

. "Casel's Splinters fractures at ODC." SFGate Dec. 20, 2015.

https://www.sfgate.com/performance/article/Casel-s-Splinters-fractures-at-ODC6709481.php

Van Camp, Julie. "Dance Criticism by Croce, Denby, and Siegel." Dance Research Journal 24.2 (Fall 1992): 41-44.

Zambrano, David. Soul Project Post-performance Discussion. Yerba Buena Center for the Arts, 2012.

Zimmer, Elizabeth. "The Crisis in Criticism." In Dance. June 2019, http://dancersgroup.org/2009/06/the-crisis-in-criticism-the-economy-the-internetand-the-death-of-dance-writing/ 
Zollar, Jawole Willa Jo. "Listen, Our History is Shouting at Us: A Choreographer Confronts Racism in Dance." Looking Out: Perspectives on Dance and Criticism in a Multicultural World. New York: Schirmer Books, 1995. 


\section{PROVOCATIONS AND VIEWPOINTS}




\title{
How Screendance Was Invented While We Were Busy Claiming It Wasn't ${ }^{1}$
}

Katja Vaghi, Independent Scholar

\begin{abstract}
Many screendance authors seem to worry about the marginalized state of the practice and its lack of a solid scholarly discourse. This leitmotif goes against my perception of screendance as one of the fastest growing fields in dance, both in practice and theory. This short provocation considers some reasons for this feeling of lack and, by juxtaposing them with reflections on the advent of new institutionalized courses in screendance, invites us to revise our perception of the field. Screendance has finally reached a critical mass of works and research to 'stand by itself.'
\end{abstract}

Keywords: essence, history, institutionalization, scholarly discourse

While reading about screendance I cannot but notice a constant preoccupation. Many authors deplore the marginalized state of the practice and its lack of a solid scholarly discourse. If in early texts the complaints were vaguely formulated as a lack of outlets, works and artists, in later texts, they become very precise such as the necessity to define genres in moving-picture dance expressed by Nöel Carroll in 2000, to Douglas Rosenberg's 2010 advocacy for excavating screendance genres closely or, also Rosenberg in 2016, the need for more cohesion in a diasporic and globally spread likeminded community. ${ }^{2}$ This leitmotif, this feeling of lack, goes against my perception of screendance as one of the fastest growing fields in dance, both in practice and theory. On the practical side, there is a growing artists population, an ever increasing number of screendance festivals with associated competitions, platforms inside dance festivals but also outside the dance field, commissions, and last autumn the first MA solely dedicated to screendance started at the London School for Contemporary Dance. ${ }^{3}$ On the theoretical side, there are several publications such as a dedicated journal, several articles in other academic journals and a growing number of conferences. With all of this, how can screendance still be lacking something?

The reply to this question is in fact complex and entails answering the implicit question behind the French film critic André Bazin's argument, exposed in a 1967 article, that "cinema has not been invented yet" concerning the essence of cinema. A variation on the theme ("Screendance has yet to be invented") is also at the origins of a box in a box game with the titles of several screendance articles, alongside IJSD's very first issue that 
was explicitly "dedicated to the proposal that Screendance has not yet been invented." ${ }^{\text {" }}$ In his 1967 article, Bazin tried to trace the ideas that inspired the early initiators of film at the end of the nineteen-century and concluded that cinema's invention was due to their obsession with reproducing reality. Thus, the ideal of cinema, its essence, should be the perfect rendition of reality, or total cinema. ${ }^{5}$ Bazin's speculations about early filmmaking have been challenged by, among others, the Latvian film critic Yuri Tsivian. Tsivian's main argument against Bazin is, based on a reflection by Yuri Lotman, that early film was associated, at least for its early viewers, with theatre conventions. The early film enthusiasts might have chased an ideal of realism and of the total event, but the audience's perception was another, namely that of assisting to a new kind of theatre performance. ${ }^{6}$ Transposing this discourse to screendance: no one in the field would argue that their works strive for a mimetic reproduction of reality. Thus, questioning screendance's invention, as in the first issue of IJSD, rather indicates the general sensation by those involved that the field has yet to exhaust practical and theoretical possibilities (besides the question relating to its essence and origin). It is possible to argue that up until now screendance needed to reach a critical mass of works and research to 'stand by itself'. My feeling is that a hypothetical confirmation of screendance's invention would mean having found an answer to the question (or rather a host of questions) on screendance's essence and origin, such as "when was screendance earliest instance and how would this knowledge influence our sense of what a dance film is?." Possibly, as Rosenberg argues in "Excavating genres" (2010), authorial intention is an important element in determining the genre of a work, and thereby its historic lineages. So, in this light, doesn't the existence of an MA dedicated to screendance point to the field's independence? ${ }^{8}$ But also, that some of these questions about screendance's essence and origin have been at least partially answered?

The MA hosted at the London School of Contemporary Dance and validated by Kent University, advertises to be 'a place' for students to delve into screendance. This course and program is to be celebrated - we are finally able to have such a dedicated spacebut it is also invites a slightly uneasy reflection. My intuitive reaction, especially having read so many voices pointing to lacks in the screendance panorama, was: do we finally know enough of what screendance is in order to teach it? Teaching surely does not requires a complete understanding of a field, which is by definition an impossible task, but rather the feeling to have reached Rosenberg's envisioned critical mass of "literature framing screendance as a practice." ${ }^{\prime 9}$ Has this critical mass been reached? We all have the impression it finally has, at least in the English speaking countries. However, I worry that there is a risk of institutionalizing the field and an aesthetic. In fact, Rosenberg cautions about a premature historicization and institutionalization of screendance as possibly "curtailing its forward motion," that the creative exploration of a field that might be too difficult to do once in an academic setting. ${ }^{10}$ What consequences might this have on the economy of screendance as it is known? Will there still be places for 
Chirstinn Whyte's 'amateurs'; those artists who despite no professional training in digital media have greatly contributed to the development of experimental films and screendance? ${ }^{11}$ Or will people in the far or near future need such a qualification to work in the field (i.e. to participate in festivals and in the theoretical discourse)? Whyte rightly points to the great hybridity of today's "contemporary professional identities" that often are "translated into a mixture of highly specialist professional dance training and experience, combined with self-taught experimentation in the field of digitized moving images," and Rosenberg rightly underlines the fact that screendance is "for many a small part of a larger engagement in the arts." 12

Today, there is no question about the importance of technologies or of the analysis of the mediated body (or recorporealised body). As Melissa Blanco Borrelli states, media have become so pervasive that for many the screen substitutes the stage as a first encounter with dance. ${ }^{13}$ For several artists, media have also become the tool of choice to express what cannot be expressed through movement and choreography on stage. Screendance might no longer be in the uncharted territory of the early days described by Whyte and others, but there are still plenty of possibilities for new research and practices. Bit by bit, screendance has been invented while we were busy claiming it hadn't.

\section{Biography}

With a background in modern dance and ballet (Ballet Arts, NYC) and in Literature and Linguistics (MA English Studies, Zurich University), Katja Vaghi is a Swiss dancer, choreographer, dance researcher and somatic technique teacher, who alternates theoretical reflections in written form to practical musing in the rehearsal space. She holds a PhD from the University of Roehampton in dance philosophy with a dissertation on intermedial and intertextual references to the Baroque in Jiří Kylián's works. Her areas of interest are the relation between theories developed for language and dance, with particular attention to the role of embodiment in understanding, and humour in dance. She works as a freelance dancer and choreographer, and is guest lecturer at the Rambert School for Ballet and Contemporary Dance. She was the recipient of the Selma Jeanne Cohen Award 2014 offered by SHDS for the best postgraduate article.

Email:kvaghi@yahoo.com 


\section{Notes}

${ }^{1}$ This is a shorter version of a provocation given at the Screendance Landscape symposium hold at the Università IUAV of Venice in $16^{\text {th }}-17^{\text {th }}$ April 2018. The title refers to the first issue of The International Screendance Journal- "Screendance has not yet been invented" - published in the spring of 2010 which is a variation on the title of a lecture given by Professor lan Christie at Brighton University, in September 2009 for the Screendance Network (2009 - 2011). This last variation is an adaptation of a lecture Christie gave 2006 for the Slade Lecture Series at the University of Cambridge. Christie's presentation in turn refers to the French film theorist André Bazin's famous article "The Myth of Total Cinema" published in 1967.

${ }^{2}$ A reprint of Carroll's article can be found in the first edition of The International Screendance Journal, which also contains Rosenberg's article "Excavating genres" on the importance of genres in screendance appreciation, where he describes screendance as a "nascent academic form" (63). The last part is paraphrased from Rosenberg's introduction to The Oxford Handbook of Screendance Studies. However more examples can be found in the editorial comment of the first edition of The International Journal of Screeendance where Rosenberg and Claudia Kappenberg conclude that "This expansion in both exhibition and conference opportunities for screendance has not, however, been matched by an equivalent growth in written theorization, and there has been no dedicated forum for ongoing publication and dissemination of critical texts" (2). Carroll's letter, (also in the first volume), follows in the same tone "Although motion-picture dance is a thriving and exciting art form, it does not garner the respect it deserves. The reasons for this are primarily institutional. [...] it has not yet had its great critical voice [...]" (5), and Ann Cooper Albright concludes "Ideally, I would be able to point to a recent screendance that realized a vision of falling that was both suspended and grounded. But that screendance has not yet been invented" (26). In his following 2012 publication, Screendance: Inscribing the Ephemeral Image, Rosenberg argues "The twin trends of festival screenings and streaming video sites tend to operate within social spaces that avoid critical analysis, and as such have helped to defer the possibilities of an emergence from prolonged adolescence into 'adulthood,' as well as the kind of deep reflection that comes with such and evolution" (154). He also paints an unfavorable academic situation by saying "In order to consider the place of screendance in the academy, institutions must first clarify their rationale for its inclusion" (172). Lastly, in The Oxford Handbook of Screendance Studies edited by Rosenberg and published in 2016, Christinn Whyte argues for "the emergence of screendance as a recognised form (63) and Roger Copeland argues "Despite the fact that we live in an age of theory, screendance remains relatively undertheorized" (230). I have found similar arguments previous to 2010 — such as Sherill Dodds in the introduction to Dance on Screen: Genre and Media 
from Hollywood to Experimental Art who claims, "Unfortunately, at the present there is a lack of scholarly writing on the subject" (xi), or Claudia Rosiny, who wishes for a more in depth analysis of screendance works so to develop dance research (184) - but I feel these earlier comments are justified by the historical context.

${ }^{3}$ Other universities in the UK also offer screendance modules in their graduate and postgraduate programmes. These are generally single modules that the students have to complete along other theoretical and/or practical modules. The MA offered by the London School for Contemporary Dance is solely about screendance theory and practice.

${ }^{4}$ Rosenberg and Kappenberg, "Screendance: The Practice in Print," 3.

${ }^{5}$ A similar argument is brought forward by Nicolas Salazar Sutil and Sebastian Melo in their article "Exposed to Time: Cross-histories of human motion visualization from Chrono- to Dynamophotography" in Rosenberg's The Oxford Handbook of Screendance Studies. They connect the development of photography and film (as we know it today), to ideas about movement expressed in ancient Greece, and more precisely in Zeno of Elea and Aristotle. These ideas have put a framework to the way of thinking about and subsequently capturing movement-where movement is seen as sequences of stills.

${ }^{6}$ The audience found it startling that the background moved rather than the object in the front.

${ }^{7}$ In his article, Christie seems to want to detach the history of film from that of technical inventions when he argues discarding the mechanical and digital eye that Cambodian shadow theatre, as an example of projected entertainment, can be also considered as a precursor to film. Following this logic, the works containing dances such as the Tayungan or Bima's victorius dance, or Cakil's dance before the battle, or punakawan (clown) dances could also be seen as early instances of screendance. I find this argument particularly appealing as pointing to a history of ideas, of a specific way of seeing and perceiving the world. Seeing screendance in this broader light, helps to take distance almost bypassing Ann Dills' question "Am I slave to technology, or is it liberating?" Considering Cambodian shadow theatre as antecedent to screendance would surely include works that now are not necessarily considered screendance.

${ }^{8}$ Single modules at BA and MA level, even if very comprehensive, can only cover a reduced and condensed amount of material and are limited in scope. A PhD, on the other hand, specializes on one aspect of a field, analyzing it in depth and usually does not offer a general bird's eye view. My understanding is that the MA at The Place focuses solely on dance and screens.

${ }^{9}$ Rosenberg, Screendance, 176.

${ }^{10}$ Idem, 175. 
${ }^{11}$ Two early figures Whyte indicates as 'amateurs' are Maya Deren and Stan Brakhage. Whyte's discourse rotates around the dissolution of the notions of "amateur practiceundertaken as a pastime or hobby, and set apart from notions of commercial gain or career advancement" and that of professional practice "set apart by specialist knowledge, and financially recompensed for labor" (7).

${ }^{12}$ Idem 10, and Rosenberg, The Oxford Handbook of Screendance Studies, 12.

${ }^{13}$ Blanco Borelli, The Oxford Handbook of Dance and the Popular Screen.

\section{References}

Bazin, André. "The Myth of Total Cinema." What is Cinema. Berkley, Los Angeles: University of California Press, 1967. 23-7.

Bench, Harmony. "Anticipation and Securitization: Dance Video Games and Choreographies of Wartime." Metabody conference 2013. Available at https://www.youtube.com/watch?v=orgUE54q5wM. Accessed 1 August 2018.

Blanco Borelli, Melissa, ed. The Oxford Handbook of Dance and the Popular Screen. New York: Oxford University Press, 2014.

https://doi.org/10.1093/oxfordhb/9780199897827.001.0001

Brum, Leonel. "Brazilian Videodance: A Possible Mapping." In The Oxford Handbook of Screendance Studies. Ed. Douglas Rosenberg. New York: Oxford University Press, 2016. 105-24. https://doi.org/10.1093/oxfordhb/9780199981601.001.0001

Carroll, Nöel. "Toward a Definition of Moving-Picture Dance." The International Journal of Screendance 1 (Spring 2010): 111-25. https://doi.org/10.18061/ijsd.v1 i0.6154

Cooper Albright, Ann. "Falling ... on Screen." The International Journal of Screendance 1 (Spring 2010): 21-6. https://doi.org/10.18061/ijsd.v1i0.6139

Copeland, Roger. "The Best Dance Is the Way People Die in Movies (or Gestures Toward a New Definition of 'Screendance')." In The Oxford Handbook of Screendance Studies. Ed. Douglas Rosenberg. New York: Oxford University Press, 2016. 225-42. https://doi.org/10.1093/oxfordhb/9780199981601.001.0001

Dils, Ann. "Moving Across Time with Words: Toward a Etymology of Screendance." The International Journal of Screendance 2 (Spring 2012): 24-6.

https://doi.org/10.18061/ijsd.v2i0 
Dodds, Sherrill. Dance on Screen: Genre and Media from Hollywood to Experimental Art. Basingstoke: Palgrave, 2001.

Kappenberg, Claudia. "Cinema Has Not Yet Been Invented: Lecture by lan Cristie." The International Journal of Screendance 2 (Spring 2012): 4-20.

https://doi.org/10.18061/ijsd.v2i0

Lotman, Yuri (1973) "Semiotka kino i problem kinoesetiki" [Semiotics of Film and the Problems of Film Aesthetics] in Tsivian, Yuri "'What is cinema?' an Agnostic Answer." Critical Inquiry 34. 4 (Summer 2008): 754-776. https://doi.org/10.1086/592543

Rosenberg, Douglas. "Excavating Genres." The International Journal of Screendance 1 (Spring 2010): 63-73. https://doi.org/10.18061/ijsd.v1 i0.6167

. Screendance: Inscribing the Ephemeral Image. New York: Oxford University Press, 2012.

ed. The Oxford Handbook of Screendance Studies. New York: Oxford University

Press, 2016. https://doi.org/10.1093/oxfordhb/9780199981601.001.0001

Rosenberg, Douglas and Claudia Kappenberg. "Screendance: The Practice in Print," The International Journal of Screendance 1 (Spring 2010): 1-4.

https://doi.org/10.18061/ijsd.v1i0.6380

Rosiny, Claudia. "Videotanz-Ansätze" in Klein, Gabriele Tanz, Bild, Medien. Münster: Literatur Verlag, 2000. 167-86.

Salazar Sutil, Nicolas and Sebastian Melo. “Exposed to Time: Cross-histories of human motion visualization from Chrono- to Dynamophotography." In The Oxford Handbook of Screendance Studies. Ed. Douglas Rosenberg. New York: Oxford University Press, 2016. 143-65. https://doi.org/10.1093/oxfordhb/9780199981601.001.0001

Temperley, Susana. "Perplexed Writing: Towards a Possible Encounter between Criticism and Videodance." The International Journal of Screendance 1 (Spring 2010): 83-90. https://doi.org/10.18061/ijsd.v1i0.6142

Tsivian, Yuri "'What is cinema?' an Agnostic Answer." Critical Inquiry 34. 4 (Summer 2008): 754-776. https://doi.org/10.1086/592543

Whyte, Chirstinn. "Selective Histories: Moving Image from the Late Nineteenth Century to the Early Twenty-First." In The Oxford Handbook of Screendance Studies. Ed. Douglas Rosenberg. New York: Oxford University Press, 2016. 63-77. https://doi.org/10.1093/oxfordhb/9780199981601.001.0001 


\title{
A Note Towards
}

Claudia Kappenberg, University of Brighton

\begin{abstract}
Some reflections on the development of screendance since the launch of the International Journal of Screendance almost 10 years ago, taking the long view with regards to the relation between innovation, knowledge, history and teaching.
\end{abstract}

Keywords: invention, knowledge, non-knowledge, knowledge maps, Georges Bataille

The provocation in this issue by Katja Vaghi ${ }^{1}$ led me to think about invention now and in the future of screendance. As Vaghi notes, inventiveness was at the heart of the International Journal of Screendance launch in 2010; so was the desire to be provocative, to invite debate, reflection, and challenges, whilst showcasing new work and new writing.

Vaghi makes a positive assessment of the field since 2010, but questions the sense of deficiency that continues to permeate some of the writing. She asks, "How can we still be lacking something?"2 I propose that we turn this impatience into a creative impulse, and posit that screendance will always be incomplete and in the making, invented over and over and over again.

As suggested in the provocation, we can safely argue that screendance has reached a critical mass, and is proliferating in many ways and many places. In 2019 we have quite a good sense of the 20th century artists who contributed to what we now call screendance, and the dynamics that shaped the field. We have many discursive threads becoming refined over time on representation, mediation, intermediality, and criticality. We will not, however, have a definitive account, neither should there be one. Does an artwork not need to challenge what went before and shouldn't a curatorial project rethink the histories it works with, and imagine new pathways?

History can always be rewritten, and knowledge is not a pillow we can rest on. The French philosopher Georges Bataille challenged our concept of knowledge and the limits of reasoning. He proposed 'non-knowledge' as another kind of knowing, distinct from knowledge gained through rational enquiry. ${ }^{3}$ In Inner Experience, Bataille plunged deep into experience and subjectivity, challenging the conventional notion of seeing as a path to knowledge, and arguing that knowledge hides and makes us blind. He rejected the kind of mastery promised by knowledge, claiming that it was limiting, and 
not enough. But what is the relation between the rational mind and the non-rational, and how do they interact? Bataille wrote:

Non-knowledge lays bare, therefore I see what knowledge was hiding up to that point, but if I see, I know. Indeed I know, but non-knowledge again lays bare what I have known. ${ }^{4}$

Bataille used the notions of 'non-knowledge' and 'laying bare' to describe a different kind of seeing or knowing, which is perhaps more like sense recognition from an embodied, intuitive point of view. Bataille described this also as "half-blind movements" and as "movement from the heart." screendance, and these metaphors may speak to those who are trying to make sense of the art of screendance and what it portrays. They are however metaphors for fleeting modes of understanding and we may need to accept that non-knowledge cannot be explained. However, the term serves to challenge what we understand by 'knowledge' and to point to its limits. As Bataille argued, knowledge is not only grasping something which we can therefore categorise and order, but knowledge also hides and masks the fugitive aspects of experience. Furthermore Bataille highlighted a circularity of this process, whereby knowledge is unmasked by a sense of non-knowledge, sense recognition or experience, which inevitably turns into knowledge as we reflect on that experience, until it is challenged again by a sense of the limitations of what is knowable, and so ad infinitum.

The work each of us does is marked by these cycles; through the work we navigate the unknown and shape our knowledge, sometimes through sound and image, and sometimes through words. Everyone has to find their own way, not unlike squirrels who are, apparently, not taught how to crack nuts but have to work it out themselves. Over time each artist and maker refines her or his approach, sometimes developing a recognisable body of work.

And where does this leave the teaching of the Masters Course in screendance, or, as Vaghi asks, "do we finally know what screendance is in order to teach it?" A teaching space that concerns itself with an artform is perhaps mainly a space for research and experimentation, which is why Schools and Universities are so vital. Teaching and learning in this context mean developing and sharing tools with which to formulate questions and with which to test ideas and explore possibilities. There are knowledge maps of various kinds of course, but these are not written in stone. Knowledge is at best the little crumbs which helped Gretel map her way into the dense forest, and find her way back out. ${ }^{7}$

What I suspect is that future debates in screendance will be less concerned with form or history-although we will occasionally undo what we have done. Instead, screendances will continue to engage with the politics of space and place and the experience of time, 
and envisage and represent multiplicities and diversities-as well as our relatedness, interdependence, strengths and fragilities - in order to investigate our lives inside an extraordinarily complex biosphere. Screendances will always be a chance to protest, to provoke and to dream, and to make new futures from the images and fragments of the past. In the first issue of the IJSD I referred to Rachel Moore's insightful comment, that "the pleasure of the spectator resides not in the pure fantasy of illusion, but in providing a screen on which to exercise the 'ebb and flow' between the real and the copy." ${ }^{8}$ In the 21 st century screens have very much become part of our lives, and our real and screenic worlds are forever intertwined. How screendance curates and exercises this ebb and flow, between who or how we are and who or how we might imagine to be, is its project and its challenge.

\section{Biography}

Dr Claudia Kappenberg is a performance and media artist and Principal Lecturer at the University of Brighton, UK. She is a founder of The International Journal of Screendance. Recent writing has been published in Art in Motion: Current Research in Screendance (2015), The Oxford Handbook of Screendance Studies (2016), Syncope in Performing and Visual Arts (2017), Repères, cahier de danse (2017) and Performing Process: Sharing Dance and Choreographic Practice (2018). Her performance and screen-based work consists of minimal choreographies which examine patterns of the everyday. At the heart of the practice is an interrogation into that which makes us human.

Email: c.kappenberg@gmail.com

Website: http://www.ckappenberg.info

\section{Notes}

${ }^{1}$ Katja Vaghi, “How Screendance Was Invented While We Were Busy Claiming It Wasn't."

${ }^{2}$ Ibid.

${ }^{3}$ Georges Batille, Inner Experience, 45-55.

${ }^{4}$ Idem, 52. 
${ }^{5}$ Idem, 51.

${ }^{6}$ Vaghi, 127.

${ }^{7}$ Peggy Phelan, Mourning Sex, 153.

${ }^{8}$ Rachel Moore, Savage Theory, 87; cited in Claudia Kappenberg, "The Logic of the Copy," 39-40.

\section{References}

Bataille, Georges. Inner Experience. New York: State University of New York Press, 1988. Original publication, Expérience Intérieure. Paris: Editions Gallimard, 1954.

Kappenberg, Claudia. "The Logic of the Copy, From Appropriation to Choreography." The International Journal of Screendance 1 (2010).

https://doi.org/10.18061/ijsd.v1i0.6140

Moore, Rachel. Savage Theory, Cinema as Modern Magic. Durham and London: Duke University 2000.

Phelan, Peggy. Mourning Sex. London and New York: Routledge 1997. https://doi.org/10.4324/9781315004969

Vaghi, Katja. "How Screendance Was Invented While We Were Busy Claiming It Wasn't." The International Journal of Screendance 10 (2019).

https://doi.org/10.18061/ijsd.v10i0.6528 


\section{Red Shoes}

Erin Brannigan, University of New South Wales

Keywords: dance, screen, festivals, musicals, curation

My mother watched the musicals that came on television in the middle of the day in Australia in the 1970s. So we did too. She knew all the songs and sang along.

In 1999 at Monaco Dance Forum we were like the United Nations. I knew practically every dance screen curator in the world and we talked about how much we paid artists to screen their films. Nerdy dancefilm spotters. Alla Kovgan (Russia), Christiana Galanopoulou (Greece), Steve Jackman (UK), Katherine Smith (Canada), Nicolas Villodre (France), Douglas Rosenberg (USA), Deirdre Towers (USA), Janine Dykmeyer (The Netherlands), Silvina Szperling (Argentina), Lynette Kessler (USA) Hélène Lesterlin (USA), Fabio Bruschi (Italy), Marilena Riccio (Italy), Nuria Font (Spain), Eduardo Bonito (Brazil), Franz Patay (Austria), Pascale Moyse (UK), Virve Sutinen (Finland), Michel Bargues (France), Birgit Hauska and Rita Kramp (Germany), Chendra Effendy (Indonesia), Avi Feldman (Israel), Mariana Arteaga Vazquez (Mexico), Magne Antonsen (Norway), Ellen Bromberg (USA), and many, many more who conjured programs and events from very little ... some of them still do. And many of them were also filmmakers.

It's such a shame that Olivia Newton John couldn't dance.

I saw Chantal Akerman's One Day Pina Asked ... (1983) in Film Studies at Sydney University with Laleen Jayamanne. That was the start of something.

Someone moves self-consciously, or suspends a gesture. It's begun.

In 2010 the Australian dancescreen festival ReelDance, begun in 2000, folded and the Australia Council for the Arts put three years of their funding out to tender. The organization that won, blew it all on one exhibition. Nobody presents dancescreen in Australia anymore, except art galleries.

William Kentridge and Nick Cave make beautiful dance animations for galleries.

Jan Verbeek, Pascal Magnin, Philippe Decouflé, Pascal Baes, Anna Di Maninor, Miriam King, Cordelia Beresford, David Hinton, Thierry De Mey, Laura Taler, Shelley Love, Wim Vandekeybus, Miranda Pennell, Tracie Mitchell, Nic Sandiland, Katrina McPherson, Simon Ellis, Sue Healey, Antonin De Bemels, Clara van Gool, Annick Vroom, Sean O'Brien, Margie Medlin, Daniel Belton, Magali Charrier, Lutz Gregor, Walter Verdin, Gina Czarnecki, Christinn Whyte...

The International Journal of Screendance 10 (2019).

https://doi.org/10.18061/ijsd.v10i0.6822

(c) 2019 Brannigan. This article is published under a Creative Commons Attribution 4.0 International License (https://creativecommons.org/licenses/by/4.0/) 
When I walked out of the screening room after viewing Rize (2005), my internal body was in knots.

The move from film festivals to exhibitions was the right one-you have to follow the artists.

My dance teacher, Dorothy Cowie, was an old hoofer from the Tivoli in Sydney. We had to yell out songs from the top of our lungs while holding paper rainbows around our heads. We sang all the same songs my mother sang.

Claire Denis, Angelica Mesiti, David Rosetzky, Tacita Dean, Raul Ruiz, Robert Bresson, Chantal Akerman, Isaac Julien, Bill Viola, Daniel Crooks, Shaun Gladwell ...

We learnt how to dance from music videos. Pointy shoes, spikey hair, and step touch side-to-side.

Amazing people convinced broadcasters to commission short dancefilms in the 1990s to screen on television. That doesn't happen anymore.

Bob Lockyer ...

I went to the Sydney Film Festival in 2018 and saw ten films of varying genres and lengths. Nine of them had dancing in them.

Choreography has expanded and circulates liberated from dancing. Cinema was an early site for this adventure.

\section{Biography}

Dr. Erin Brannigan is Senior Lecturer in Theatre and Performance at the University of New South Wales and works as a writer, academic and curator. Her academic publications include Moving Across Disciplines: Dance in the Twenty-First Century (Sydney: Currency House, 2010), Dancefilm: Choreography and the Moving Image (New York: Oxford University Press, 2011) and Bodies of Thought: 12 Australian Choreographers, co-edited with Virginia Baxter (Kent Town: Wakefield Press, 2014). She has published various chapters and articles in film, performance and dance journals and anthologies. Her current research projects are The Persistence of Dance: Choreography, Art and Experimental Composition (a monograph), New Paradigms for Performance Pedagogies (UNSW T\&L Grant with Bryoni Trezise) and Dancing Sydney : Mapping Movement : Performing Histories (Linkage project with Julie-Anne Long and Amanda Card).

Email: e.brannigan@unsw.edu.au

Website: cargocollective.com/Erinbrannigan 


\section{References}

One Day Pina Asked .... Dir. Chantel Akerman. Film. 1983. Icarus.

Rize. Dir. David LaChapelle. Film. 2005. Lionsgate. 


\title{
On Watching Screendance
}

Sherril Dodds, Temple University

\begin{abstract}
In this provocation, I ask what is it to watch screendance, what is at stake, and what comes into play? I suggest that in identifying works as examples of "dance on screen", we enter into a complex history of aesthetic innovations, marketing criteria, funding systems, and intellectual debates. I compare the viewing practices of film, television and the internet, and consider how different screen formats shape experiences of teaching and research. I reflect upon the ethics of participation in online debates, and suggest that the modes and stakes of watching are as important as the dance itself.
\end{abstract}

Keywords: watching, research, teaching, consumption, participation

What is it to watch?

What is at stake?

What comes into play?

To say that we are watching screendance assumes that we can identify the very character of screendance. Operational categories certainly exist that organize screendance into generic groupings: dance documentary, film musical, pop music video, dance commercial, reality television show, dance for camera, Bollywood film, television adaptation, experimental dance film, TV dance competition, Hollywood dance film, dance animation, and so on. Yet the borders of these typologies fail to hold as tropes and techniques slip from one category to another. Boundaries become fluid and genres resist easy definition. And while the term "screendance" might serve as a useful placeholder that gently and inclusively holds together a multitude of screen works that feature "dance," it may also include representations that complicate common conceptions of dance. Such screen works do not necessarily employ explicit images of dancing people, but instead are attentive to the choreographic sensibilities of film-making (the movement of the camera and rhythm of the cut) and the quality of movement per se (the motion of inanimate objects or non-human mobile subjects). Therefore in naming our viewing choice as screendance, we enter into a complex history of aesthetic innovations, marketing criteria, funding systems, and intellectual debates. For artists and scholars, the naming and claiming of screendance gives visibility to that which we hold dear both aesthetically and politically. 
Opportunities to watch screendance differ considerably from when and how I watched it as a young viewer to how I watch it now. As a child I walked to our local cinema to witness the spectacle of dance in the movies, often returning at a later date for a repeat viewing of my favorite dance films. Alternatively, I scoured through the entertainment sections of the newspaper to catch television programs that featured dance. In my teens, the luxury of home video allowed the opportunity to sit by the VHS player all set to press "record" seconds before the television show started, and then watch these scratchy images many times over. While a graduate student, in my mid-twenties, I needed to employ social and economic capital to study the screendance to which I would otherwise have limited or no access. A friend who worked in advertising managed to find out which agency had produced a Hellmann's mayonnaise commercial that featured dance. I called the agency, tracked down the person who negotiated the "spot times" during which the ads would run, and then dutifully set my video machine to record them, keeping my fingers crossed that the information was accurate. I rang several travel agencies to find the cheapest return airfare to Monaco so that I could attend the annual IMZ Dancescreen festival, spending almost the entire three days isolated in small viewing cubicles so that I could watch as many of the entries as possible, the majority of which would never be screened on British television. I made extensive notes trying to imprint the style and content of punchy little dance films onto my mind's eye. And through a wonderful connection, brokered by my dissertation adviser, to BBC television producer Bob Lockyer, I gained a day's access to the BBC archives where I watched grainy black and white recordings of dance films from the mid-twentieth century. On the bus home, I read through more reams of notes and carefully held on to a VHS copy of Houseparty (1964), an early example of dance designed for television, that the BBC archivist had kindly run off for me. The magic of those one-off viewings and the satisfaction of watching poor quality video recordings many times over characterized my early research life.

As I entered university teaching in the late 1990s, the technical paraphernalia of how to enable my students to watch screendance proved equally challenging. I would prepare for lectures by sitting in a large closet that served as the dance department video library diligently compiling video clips onto a single VHS tape as someone had managed to hook up two recorders that enabled tape-to-tape recording. I spent hours fastforwarding, rewinding and recording in private, but at least this saved the awkward time in a class fumbling around with multiple tapes or holding down the fast-forward button to cycle through different sections of a dance. Even as DVDs became commercially available, the temperamental university machines would not always play them or allow me to cue a certain point in a dance. And although I had built up a huge personal video library neatly catalogued through a numerical system that tallied with hand-written index cards that detailed the title, dance company, director, choreographer, creation date, and other pertinent information, I ditched the entire collection when I relocated to the United States. The loss of my precious video archive still gives me shivers, 
however most universities no longer provide video players in their classrooms, and my British PAL tapes were not compatible with the American NTSC machines. While I had been slowly transferring some of my most beloved recordings onto DVD in the year or so prior to my departure, most of these now sit in the bottom of my office filing cabinet as the US region 1 players at my university will not accommodate my European region 2 discs. Although I am a little sad about this, and want to recognize the emotional relationship that we invest in the physical artifacts that facilitate our teaching and research, the development of digital technologies and the internet have utterly transformed what we watch and how we watch screendance.

On arriving in the United States in 2011, I decided at that point that I would no longer mess around with tapes and discs, but would only use teaching materials that I could access online. The sheer quantity of screendance available online, through free video platforms such as YouTube and Vimeo and curated subscription sites such as Alexander Street, proves almost overwhelming. Indeed the shift from scanning the newspapers for rare glimpses of screendance to the deluge of dance through digital means is staggering. While this greater level of access to watching, making, and learning dance has sometimes been couched within a rhetoric of democratization, this needs to be accompanied with caution. Some sections of the population either remain without access to, or elect not to engage with, the internet, although it is widely available in schools, universities, and public libraries. And though many sites are open access, some require membership fees, thus excluding those with limited economic means.

In addition to increased availability of screendance, greater opportunities to engage in its production have come about through low-cost digital recording devices that we can carry around in our pockets. Again, not everyone has access to smartphones or GoPros; however, a substantial proportion of the population has the capacity to capture dance images on screen whether simply pointing and shooting dance at a family wedding or using playful production techniques to curate and manipulate moving bodies. Consequently, greater access to the means of production enables voices and bodies to be seen and heard that may have otherwise been overlooked through the taste and value structures of a limited pool of commissioning editors responsible for screendance within public broadcasting networks. A similar sense of diversification comes about through the ways in which we might learn dance through screen tutorials. Whereas throughout the 1980s and 90s, a limited number of commercially available dance instruction videos benefited from mass circulation through those with concomitant social and economic capital (although dances were also transmitted within grassroots communities through DIY video-making), we can now access tutorials on just about any topic imaginable through amateur teaching on YouTube. Though we always need to check the authority and expertise of dance teaching, the abundance of online videos affords us plenty of opportunity for cross checking and validating the reliability of sources. 
Yet the excess, the overload, and the seemingly infinite leave me unsettled. I am no longer left hungry for more, but instead feel utterly saturated. This endless quantity clearly re-shapes how I watch. While the big screen continues to thrive, the option to 'watch again' through Netflix or Hulu leaves me spoilt for choice and struggling to decide what to watch. I see people watching feature films on tablets, laptops and phones in bright and bustling public environments far removed from the quiet intimacy of a blacked-out movie theater. While I want to avoid the simplistic binary that cinema spectatorship always ensures a focused and complete viewing experience whereas watching television or the digital screen is distracted and fragmented in comparison, the range of options regarding what and where we watch makes me think twice about contemporary viewing habits. I fear my capacity to sit and watch carefully is usurped by the need to scan quickly and keep moving through the virtual viewing landscape. I worry that my patience and tolerance are constantly tested and that, unless a film can hold my attention through novelty, brevity, and spectacle then I will move on to the next piece of click bait. Of course I need to remind myself that as a dance researcher with my own values and interests, I might attentively watch a long passage of screendance (such as a poor resolution and fixed camera recording of an entire hip-hop battle) that would be of little interest to those outside this taste community. The point is that it is available. Furthermore, I can easily locate all manner of dance commercials, music videos, and experimental dance films that were extremely difficult to track down twenty-five years ago. Although I keep returning to the caveat that not all dance is accessible online and not all people have online access, exponentially more screendance exists in the digital realm than in the analog days of my early research. The research process might be less exciting, but the research findings remain so.

Excitement aside, I also think about the ethics of our engagement with screendance online. Unlike cinema and television, online spectatorship frequently offers space for feedback and commentary. A quick glance through the viewer comments posted below video clips reveals all kinds of wonderful and wacky responses that range from truly enlightened to horribly toxic, depending upon one's position and politics. This prompts me to question whether watching should be an end in itself or whether we should frame our response in dialogue with other spectators. When dance clips are taken out of context or comments reveal naïve assumptions or dangerous perceptions about dance on screen, do we have an ethical responsibility to intervene? In a digital landscape in which images and words, spectatorship and interpretation, are placed in such close relationship, do we simply approach this material as valuable research data or do we take on the role of expert interlocutors willing to inform and take a stand? This might depend on whether our emotional and intellectual investments are resilient enough to withstand all kinds of voices and perceptions, which can speak loudly and forcibly in the digital realm. Yet another option asks us to wait patiently until new screendance work begins to circulate that speaks back to us through the artistry and motion of its own visual and kinetic language. The work itself then enters into conversation with what has 
come before. Whether we speak our politics blatantly or live them quietly through how we move in the world, we take a position on the screendance that surrounds us: we choose what, how, where, when and why we watch.

The screen clearly orients us to watch dance under specific historical, technological, and social conditions, which in turn shape how we invest in and value screendance, our practices of spectatorship, and how we might learn from it or share it with others. Through understanding these frameworks of consumption, reception, and participation, we then have the option to choose how we engage with screendance and to what end. Often students joke that I have killed any pleasure in watching as I redirect their attention to the technical and aesthetic apparatus that construct images of dance on screen, thus bringing into focus the politics of representation. While I try to reassure them that they can still indulge in scopic pleasures and spectacular desires, film studies tells us that visual pleasure is itself a social construction. Contemporary audiences are fortunate to have an excess of screendance from different historical eras, national contexts, and of diverse artistic styles that satisfy a wide spectrum of tastes and interests. For screendance studies, however, thinking about the modes and stakes of watching is perhaps as important as the dance itself.

\section{Biography}

Sherril Dodds is a Professor of Dance at Temple University. Her books include Dance on Screen (2001), Dancing on the Canon (2011), Bodies of Sound (co-edited with Susan C. Cook, 2014), The Oxford Handbook of Dance and Competition (2019) and The Bloomsbury Companion to Dance Studies (2019). She has been a visiting scholar at Trondheim University in Norway, Griffith University in Australia, Stanford University in the USA, and Blaise-Pascal University in France. She was awarded the 2015 Gertrude Lippincott prize for her article, 'The Choreographic Interface: Dancing Facial Expression in Hip Hop and Neo-burlesque striptease'.

Email: sherril.dodds@temple.edu

\section{Reference}

Houseparty (1944). Dir. Margaret Dale. TV movie. 1964. BFI. 


\title{
Digital Spaces, Analogue Thinking: Some Thoughts on Screendance
}

Marisa Zanotti, University of Chichester

\begin{abstract}
With the rapid development of camera technologies and screening platforms over the past 10 years comes an expanded screendance field that opens itself up to new screen bodies, sites, and audiences. Are there new considerations and indeed less-positive effects in this potential? This writing reflects on process, production, and durationnow and in the past-in screendance, performance, and artists' films, to address the question, 'where are we now?'
\end{abstract}

Keywords: democratization, Lisa Nelson, duration, perception, analogue

I'm going to begin with a negative: this writing cannot possibly address the complexity of screendance over the past ten years in all its new and developing manifestations. However, departing from a brief overview of a parallel evolution in film technologies, I'm going to take you on a journey through time, space, and screendance practices and perhaps turn this limitation into a positive.

In the past ten years recording and screening technologies have been getting lighter, smaller, and more affordable and this has had the effect of democratization in many areas of filmmaking and especially in the field of screendance production and distribution. For artists in the field who, either by choice or necessity work outside of a commissioning or funding system and/or had previously found it difficult to access and indeed use technologies, this has been a good thing. Developing screen choreographies is a complex, time-consuming proposition. Now, it's possible to choose to easily move lightweight cameras, rehearse, and perfect camera movement through instant playback, use pre-programmed settings, and shoot immediately in light conditions that until relatively recently would have needed costly equipment and considerable expertise. We can go into locations with smaller, in fact almost invisible, devices with amazing recording capabilities.

\section{Online spaces}

Further to this, the ability to post films online means that screendance festivals, whose entry fees all too often discouraged people of limited means from entering, or people who did not want to participate in festivals for any number of reasons, are no longer the The International Journal of Screendance 10 (2019).

https://doi.org/10.18061/ijsd.v10i0.6569 
only way to show films. Of course screening online is not without its complexities. I am sure I'm not alone in feeling uneasy sharing/creating work on some social media platforms; ${ }^{1}$ online space, like any space, is defined by a set of relations including to capital, to wider questions of politics, censorship, and the information economy and those that trade in it. Nevertheless, the capacity to show online does enable the field to be relevant to a broader spectrum of communities. This continues on from Cara Hagan's eloquent writing in Volume 9 of this journal about creative strategies and affirmative action in curation and dissemination in screendance, and the potential of moving toward "a culture that is a departure from the norms and narratives found in dance, cinema, and museum". ${ }^{2}$

\section{Expanded screen dance practices}

In 2019 screendance artists' practices might include original choreographies developed for the screen, adaptations of existing choreographies, choreographies created in the edit using software programs, and/or all of these artistic choices combined. Alongside the other work that the majority of screendance artists are asked to do, a practice is often a mixture of self-funded, commissioned, and funded work, and a project will often simultaneously include all of these aspects in varying proportions through its development. It's not always possible or desirable to collaborate with cinematographers, editors, designers and sound artists; you might be choosing a more auteurial route or sometimes it's both important and enjoyable to find out about technologies yourself and open up an understanding about the relationships between the tools you can work with and the creative decisions you want to make.

Are there new considerations and indeed less-positive effects in this expanded field of potential? Let's begin by considering bodies and screens: These screen bodies might be dancing bodies, but we might also be thinking about the headless torsos on many dating apps, cyborg bodies with digital tattooing, interfaces in medicine, or the movement activated hoardings of urban spaces where otherworldly entities entice us to join them through a simple, pure act of purchase. How is the field responding creatively and critically to the cultural significance of ways bodies are presented on screens when the phrase 'bodies on screen' now points to any number of signifiers and sites?

There is a strong argument that the most exciting and radical work in dance on screen embodying social critique and evolving technologies is taking place in hip hop and rap: Natty Kasambala's analysis of Donald Glover's This is America (2018) reveals the complexity of the intertextual choreographic language. We might also look to an ongoing exploration of idiosyncratic glitch physicalities in Missy Elliot's collaborations with choreographers such as Sean Bankhead ${ }^{3}$ and Hi-Hat. ${ }^{4}$ In the ecology of this technological landscape, distinctive choreographic bodies are also being produced in 
dances from screens. By this I mean works which are performed live but where screen technologies are embedded in a creative process, integral to the fabric of often longstanding choreographic enquiries. ${ }^{5}$ For example the extreme corporealities of UK choreographer Simon Vincenzi in works like The Surface $(2018)^{6}$ are the result of a film, Alain Resnais' Last Year at Marienbad (1961), being investigated as a closed score in both rehearsal and performance. In The Surface and Vincenzi's earlier work Operation Infinity $(2007-2015)^{7}$ screens and screen languages are present but made visible on stage only through the bodies of performers. Visual exchanges in screen languages between camera, performer, and viewers are also considered as a choreographic strategy in Lea Anderson's Edits (2015), where a queer gaze meets audiences through what appears to be a direct address to the audience but is derived from the queer gaze of director Rainer Werner Fassbinder's The Bitter Tears of Petra Von Kant (1972). Chicago's AToM-R developed yet another way of exploring embodiment and screens in Field Anatomy $(2013)^{8}$ when they created interfaces where dancers' bodies could be physically read by the audience through bespoke QR codes.

Whether dances from screens or dances on screens, what unites these projects is a critical examination of relationships between bodies and technologies that has resulted in radical corporealities; this bodes well for screendance being relevant to broader audiences. Unfortunately, what is more usual in the field is that-unless the work is an adaptation of an existing choreography-it's difficult outside of the commercial sector to get the time to develop the movement element of a screendance in any depth beyond initial research and development. While technologies are definitely cheaper, dancers still need to be paid, and perhaps as a result screendances often have small casts. Additionally screendance can still be marked by a tendency to fall into what the screen-artist and choreographer Mary Wycherly describes as "a trap of beautifying the body." ${ }^{\prime \prime}$ It's possible to work with dancers with what feels like limitless technical capabilities or dancers who are skilled improvisers, and perhaps as a result it can be easy to quickly generate a kind of screendance mirage whose glossy surface and unthreatening content could easily be at home in the rhetoric of advertising, seducing viewers with a spectacle of silent dancing bodies. ${ }^{10}$

\section{Time, speed and ease?}

All of these questions and thoughts lead me to consider what might have been left to the side in my own filmmaking. I have noticed something in my own practice, and that of peers, that speaks to an expression of economics of time and spaces and an experience of labor. I'm questioning the speed at which I'm working, the amount I'm shooting on digital formats either alone or with a crew, the increasing pace within my edits, and the pressures I'm putting myself under in order to produce more and more 'product.' Have ideas of speed and ease become interpolated as desirable values in the experience of production, process, and viewing of screendance as much as in the film 
industry outside of screendance? And if so, do we as a community really want that to be the case? As an artist who moved from working with analogue film and video technologies to a digital screen practice, I have been reflecting on the connection between technologies and process, and what I might bring to my own practice from my previous 'analogue thinking' where I shot less, planned more, made fewer images, and edited on paper. I'm going to consider time in both process and outcome, and in order to do this I will begin outside of screendance with a work made on film that deals with duration ... and see where this path takes me.

\section{Time, attention, and rhythm}

In 1967 the Canadian artist Michael Snow made Wavelength. He shot it in one week having prepared the shoot for a year. The film is 45 minutes and appears to be a single unbroken zoom shot to the far wall of a loft space. The key sound is a sine wave that increases in intensity as the film develops through what Snow describes as "four human events". ${ }^{11}$ Snow plays with perception through work with sound and vision, narrative, and simple action. Wavelength does initially feel challenging, so unfamiliar is its duration. Snow asks us to invest time and a willingness to surrender his desire to take you somewhere uncertain. I emerged from watching Wavelength altered, my internal rhythm slowed down in the space it produced. My return to the rhythms of an everyday world felt clumsy, like I imagine an astronaut would feel coming back from space. A similar effect took place when I watched Jonathan Glazer's Under The Skin (2014: 108 mins) or most recently The Fits (2015: 71 minutes) written about in this journal in Volume 9. ${ }^{12}$ The films I have cited are not screendances although they are open for readings in relation to choreographic mise-en-scéne: their narrative structures resonate with the vertical narratives of screendance, ${ }^{13}$ and at their centre are ideas of corporealities; for example alien bodies (Under The Skin) and bodies that may or may not be possessed (The Fits). These filmmakers ask an audience to be willing to put aside not only normative ways of watching a film, but also that we attend to the world outside the film differently; think again about how we look. In my screen work they invite me to consider the development of unique structures for perception.

\section{Perception and Lisa Nelson}

\section{I'll begin with looking}

The filmmaker and historian Mark Cousins' recent book The Story of Looking ${ }^{14}$ explores looking as a cultural practice, and might be read alongside similar enquiries by John Berger on seeing in visual art, Laura Marks' work on intercultural experience and perception in film, or Maurice Merleau-Ponty's philosophy investigating vision and perception. ${ }^{15}$ As a filmmaker, Cousins' thinking on different ways filmmakers look-the gestures of looking we make-took me back to an idea in relation to dance practice. For 
dance artists, looking occupies a particular role in perceptual experience as a whole and perhaps a heightened awareness that the gesture of looking, like all gestures, does not happen independently of other gestures and actions. The work of American pyschologist J. J. Gibson is relevant here. He posited that perception is not a passive reception of information through a sense organ but an active process undertaken by the perceiver in response to their internal (sensory/kinaesthetic) and external environments, and further that perception is made up of the interactions between the senses. For example, vision is a stream of information actively gathered through the eye, but in response to feedback from all the senses. ${ }^{16}$ Artist-researcher and videographer Lisa Nelson has a long-term project on perception drawn from Gibson's writing. One idea she explores is the role of embodiment in looking, she says of her initial experiments with video:

When I put a camera to my head, I wasn't doing it like a robot, where my brain was on a tripod. I put it to my head and I was struck with how I moved my head following my interest through this frame. It reflected my way of relating to my body and the environment. I work with the medium of video through my kinesthetic sense. In dancing, working without the camera, I find that when I shift into vision, just looking at light and form, I don't have any desire to move. ${ }^{17}$

Rather than immediately thinking about what you might be seeing through the viewfinder, Nelson's approach suggests a different way of thinking about making moving-image work. Her project defines a specific kind of screen production process, one of studio explorations, aligning the making of screendance with performancemaking processe. ${ }^{18}$ In a further investigation of perception Nelson also uses exploratory viewing strategies in her research. One of her techniques shared in workshops includes developing an awareness of the kind of looking we do when we watch the same thing twice. A second viewing of a film often reveals something that was not visible first time around. These exercises demand a discipline that's often to do with taking longer to decide what we have seen than we are used to. Nelson's work highlights the kinds of habits we might have as viewers and invites me to ask how spectatorial experiences and viewing 'habits' might be produced in screendance.

For example, when Hamish McPherson wrote that screendance to his outsider eye seemed to be defined by "established forms and boundaries and requirements"19 one of those forms relates to time. The call for papers for this volume ${ }^{20}$ asked where do we find ourselves as a field? It is of course difficult to say where screendance is right now but wherever we might want to go, we probably need to arrive there in 7 - 12 minutes. ${ }^{21}$ We might also want to consider getting there in 30 seconds on Instagram, under 45 seconds on Twitter, under 1 minute if we are screening on Facebook, or a leisurely 2 minutes on YouTube; that is if we want an online audience to remain with $\mathrm{us}^{22}$ as anyone knows from the sometimes heartbreaking statistics for finished plays for work 
you've screened online. ${ }^{23}$ In the case of social media, duration is all about keeping us interested enough to stay on a platform; but of course it's also in the interest of the platform and its sponsors that we are not so interested in what we are currently watching that we don't pay attention to the many other things simultaneously available. Shorter time frames are not necessarily a barrier to creating affecting new durations. As quantum physics tells us, time is relative, time in the edit is malleable and there are some fine examples in our field of short-form work. ${ }^{24}$ There is also an argument that the short form model of screendance work speaks to current practice in the dance field in how dance is shared online in a culture that encourages artists to make both performance and process visible as product through social media networks and other public platforms. As McPherson comments:

... I only have to look around at my peers and see they are already making short films and putting them online, and these are part of their practice and their work as much as dancing and writing and talking and all kinds of things. ${ }^{25}$

In theory this wave of screen activity could expand the audience for screendance and open up new paradigms such as the way that Hagan uses Instagram strategically at ADF. ${ }^{26}$ It can be argued that the data flow of social media is not unlike the short form programs of a screendance festival. Although, after reflecting on Lisa Nelson's double viewing practice, I'm wondering now if I can re-calibrate the way that I deal with festival programs. I'm thinking about whether there might be possibilities of going back to watch a program again, and what that would do to my experience of the work. Of course, this takes time.

So short form is not all bad, but might it now be time for a serious discussion about longer form screendance works: Who gets to make them? What challenges do they present? What viewing contexts frame them best? The field is probably ready for looking at what creative innovations and technical and dramaturgical solutions have been developed by screendance artists such as Stanley Wong with Dance Goes On (2017) in the development of long form works with vertical narratives. Might it be worth looking to duration in Dash's Daughters of The Dust (1991) or mise-en-scéne in Lucrecia Martel's Zama (2017) or in cinematographer Babette Mangolte's significant collaborations with both Chantal Akerman and Yvonne Rainer? ${ }^{27}$

Returning to where are we now and where might we go next, there are exciting projects strategically developing a more diverse community of young screen artists; for example the UK's Random Acts with Channel $4,{ }^{28}$ and in the US Marcus White and Carlos Funn's Moving $24 p s .{ }^{29}$ Screendance and choreographic artists are bringing knowledges and conceptual frameworks from the dance studio into aspects of filmmaking in different ways, but much of this work remains undocumented. I would be interested to hear in depth about how this is taking place, particularly in cinematography by dance-trained 
camera operators and in sound recording and mixing; areas which remain underresearched in screendance. The field now encompasses augmented reality, gallery work, streaming on dedicated dance channels, curated online screenings, pay per view, playlists, work on social media, work by subscription, transmedia projects, hyperchoreographies and content that is crowd sourced and opensource. These contexts all operate differently through the ways they suggest relationships between bodies, spaces, and screens, and invite different artistic propositions and problems in how we locate viewers and ourselves as makers. How will the evolution of screendance account for the bodies and gestures these complex corporeal mise-en-scènes ${ }^{30}$ invite? Which screenic ${ }^{31}$ languages will respond to, resist, belong to, or lead the continuing evolution of our mediated bodily experiences? The opportunity for screendance to evolve significantly is full of potential and in more immediate reach than ever before.

\section{Biography}

Marisa Zanotti is an award-winning filmmaker who has been exploring ideas around bodies, screens and perception through analogue and digital technologies since the 1990 s in different kinds of projects. Her work is informed by her background in performance, choreography, theatre and installation practices. She has a long-term collaboration with the editor lan Ballantyne and has created screen dance projects with choreographers including Ben Wright (2012) and Lea Anderson (The Pan's People Papers (2015), Edits Film (2014). Recent projects include the VR installation project We Are All Made of Stars, a collaboration with classical composer Matthew Whiteside, a Magnetic North commission with funding from Arts Council England. In 2018 her video projection commissioned by Whiteside for his string quartet Entangled opened the Northern Ireland Science Festival (2018) and won the Light Moves award for Innovative Use of Sound. Current research interests include the parallel development of spiritualism and technologies and embodied cognition and the role of choreographic knowledges in the development of Mixed Reality (MR) experiences. She is currently writing a monograph based on her practice-led doctoral research that explores adapting dance to screens. Marisa is a Reader in Digital Technologies and Choreography at University of Chichester.

Email:m.zanotti@chi.ac.uk

Website: www.marisazanotti.net 


\section{Notes}

${ }^{1}$ Disclosure: I made a Transmedia work, The Pan's People Papers on Facebook and Twitter in 2015 http://panspeoplepapers.com.

${ }^{2}$ Cara Hagan, Curatorial Practices for Intersectional Programming.

${ }^{3}$ https://www.YouTube.com/watch?v=TwyPsUd9LAk.

${ }^{4}$ https://www.YouTube.com/watch?v=Q33ujOhLV-E.

${ }^{5}$ See also Harmony Bench's investigation into other iterations of dances from screens in relation to feedback loops and sites of experimentation in what she terms 'social dance-media'. Harmony Bench Screendance 2.0: Social Dance-Media 183-214.

${ }^{6}$ https://www.simonvincenzi.com/the-surface-video.

${ }^{7}$ http://operationinfinity.org.

${ }^{8}$ https://vimeo.com/67282359.

${ }^{9}$ Mary Martha Wogan, Interview: Mary Wycherly Dance artist and choreographer

${ }^{10}$ This is not to say that advertising has not produced some memorable choreographic moments centred in dance: recent examples include space opening up to FKA Twigs in Spike Jonze's work for Apple (2018) YouTube https://youtu.be/305ryPvU6A8, Mikhail Baryshnikov's sinister cool set against Lil'Buck's speed ramped jookin' in Rag and Bone's 2015 men's project https://youtu.be/2rFRTyfwBH8 and the creepy possession of Gene Kelly's body by breakdancers for Volkswagen (2005)

https://vimeo.com/7775155.

${ }^{11}$ Gloria Moure, Michael Snow: Sequences - A History of His Art, 123.

${ }^{12}$ Elena Benthaus, Dis/Orientation: Rhythmic Bodies and Corporeal Orature in The Fits

${ }^{13}$ Chirstinn Whyte, A Choreographic Sensibility,

${ }^{14}$ Mark Cousins, The Story of Looking.

15 John Berger, Ways of Seeing, Laura Marks, The Skin of The Film, Maurice MerleauPonty, The Phenomenology of Perception.

${ }^{16}$ Melinda Buckwalter, Composing While Dancing, 144.

${ }^{17}$ Lisa Nelson, The Sensation is the Image. 
${ }^{18}$ Nelson's teaching laboratories reveal perception as a whole and that for a dancer, corporeal perception, that is sensing space and action through the whole body often supplements, or indeed takes the place, of vision. Employing corporeal perception often features in different ways in the processes of screen artists.

${ }^{19}$ Hamish McPherson, What Are Screendance Competitions Even For?

${ }^{20}$ Harmony Bench and Simon Ellis, International Journal of Screendance Volume 10: "Screendance Now" Open Call For Papers.

${ }^{21}$ While some screendance festivals will invite proposals for longer works, the majority continue to specify a duration of under 15 minutes and usually shorter works will have a significantly higher chance of being selected for inclusion in a programme.

${ }^{22}$ Chi Clifford, https://blog.hubspot.com/marketing/how-long-should-videos-be-oninstagram-twitter-facebook-YouTube

${ }^{23}$ The need to keep us in a flow of information online operates in a similar way to the need to keep us from changing television channels in the days before streaming. The reality is that this requirement affects both duration and content and in the screen dances of the late 1980s and 1990s in the UK was one factor that led to not just short form but also narrative being the dominant form in screendance. Jordan and Allen's anthology Parallel Lines (1993) offers an important insight into the history of dance on television in the UK.

${ }^{24}$ Filomena Rusiciano: Liquid Path https://vimeo.com/74490969, Evan Seibens, Time Reversal Symmetry: http://evannsiebens.com/time-reversal-symmetry.

${ }^{25}$ Hamish McPherson, idem.

${ }^{26}$ https://www.instagram.com/adfsmoviesby.

${ }^{27}$ Chantal Akerman. Un Jour Pina A Demandé, Yvonne Rainer. Lives of The Performers

${ }^{28}$ https://randomacts.channel4.com/tagged/featured-collection.

${ }^{29}$ http://moving24fps.com/creatives/ see also Marcus White Narrative Shifts: Race, Culture and the production of Screendance, http://screendancejournal.org/article/view/6049.

${ }^{30}$ Erin Brannigan, Dancefilm: Choreography and The Moving Image, 183.

${ }^{31}$ Douglas Rosenberg, Screendance: Inscribing the Ephemeral Image, 45. 


\section{References}

Adams Sitney, Paul. Visionary Film. New York: Oxford University Press, 1974.

Bench, Harmony. "Screendance 2.0: Social Dance-Media." Participations: Journal of Audience and Reception Studies 7.2 (November 2010): 183-214.

Bench, Harmony and Ellis, Simon. "International Journal of Screendance Volume 10: 'Screendance Now' Open Call For Papers" 21 May 2018.

https://screendance.wordpress.com/2018/05/21/international-journal-ofscreendance-volume-10-screendance-now-open-call-for-papers.

Benthaus, Elena. "Dis/Orientation: Rhythmic Bodies and Corporeal Orature in The Fits." The International Journal of Screendance 9 (2018).

https://doi.org/10.18061/ijsd.v9i0.6220

Berger, John. Ways of Seeing. London: Penguin, 2008.

Brakhage, Stan. Stan Brakhage: Metaphors on Vision. USA: McPherson and Co., 2001.

Brannigan, Erin. Dancefilm: Choreography and the Moving Image. New York: Oxford University Press, 2011. https://doi.org/10.1093/acprof:oso/9780195367232.001.0001

Buckwalter, Melinda. Composing While Dancing: An Improviser's Companion. Madison, WI: University of Wisconsin Press, 2010.

Cousins, Mark. The Story of Looking. Edinburgh: Canongate, 2017.

Chi, Clifford. "How long should videos be on instagram twitter facebook YouTube?" 22 April 2018. Accessed 12 September 2018 https://blog.hubspot.com/marketing/howlong-should-videos-be-on-instagram-twitter-facebook-YouTube.

Ching-A- Ling. Dir. Dave Myers and Missy Elliot. Choreography: Hi-Hat. 2008. YouTube. https://youtu.be/Q33ujOhLV-E.

Dance Goes On. Dir. Stanley Wong, Choreographer Hugh Cho. Film. Vimeo. https://vimeo.com/239810326.

Daughters of The Dust. Dir. Julie Dash. 1991. Netflix.

Field Anatomy. AToM-R. Performance. 2014. Vimeo. https://vimeo.com/67282359.

Hagan, Cara. "Curatorial Practices for Intersectional Programming" International Journal of Screendance 9 (2018). https://doi.org/10.18061/ijsd.v9i0.6046

Homepod: The new sound of home. Dir. Spike Jonze. 2018. YouTube. https://youtu.be/305ryPvU6A8. 
I'm Better. Dir. Dave Myers ad Missy Elliot. Choreography: Sean Bankhead and Missy Elliot. 2018. YouTube. https://youtu.be/TwyPsUd9LAk.

Jordan, Stephanie. and Allen, David. eds. Parallel Lines. London: John Libbey and Company Ltd, 1993.

Kasambala, Natty. "Unpacking all the references in Childish Gambino's phenomenal new video." 7 May 2018. Accessed 11 September 2018. http://www.dazeddigital.com/music/article/39966/1/childish-gambino-this-isamerica-meaning-jim-crow-dancing-liberty.

Marks, Laura. The Skin of The Film: Intercultural Cinema, Embodiment and The Senses. Durham and London: Duke University Press, 2000.

McPherson, Hamish. "What Are Screendance Competitions Even For? A Response to the 2015 Leeds International Film Festival Screendance Competition." International Journal of Screendance 6 (2016). https://doi.org/10.18061/ijsd.v6i0.5063

Merleau Ponty, Maurice. The Phenomenology of Perception. London, Routledge, 2002 Moure, Gloria. Michael Snow: Sequences - A History of His Art. Barcelona, Ediciones Poligrafia, 2015.

Moving 24fps Screendance Projects. Accessed 24 February 2019. http://moving24fps.com/creatives.

Nelson, Lisa. The Sensation is the Image: Writings on Dance No. 14 (Summer 1995-96). Accessed 9 September 2018 http://sarma.be/docs/3248.

Rag and Bone: Men's Fall Winter 2015. Dir. Georgie Greville. Advert. 2015. YouTube https://youtu.be/2rFRTyfwBH8.

Last Year at Marienbaad. Dir. Alain Resnais. Film. 1961. Cocinor.

Liquid Path. Dir. Filomena Rusiciano. Film. 2014. Vimeo https://vimeo.com/74490969.

Lives of The Performers. Dir. Yvonne Rainer. Film. 1972. Zeitgeist Films.

Operation Infinity. Dir/Choreographer. Simon Vincenzi. Web Artefact. 2007-2015 http://operationinfinity.org Accessed 9 September 2018.

Random Acts. https://randomacts.channel4.com/tagged/featured-collection Channel 4 UK.

Rosenberg, Douglas. Screendance: Inscribing the Ephemeral Image. New York: Oxford University Press, 2007. https://doi.org/10.1093/acprof:oso/9780199772612.001.0001

The Fits. Dir. Anna Rose Holmer. Film. 2015. Netflix. 
This is America. Dir. Hiro Murai. 2018. YouTube. https://youtu.be/ddJqNY_9U8.

The Pan's People Papers. Dir. Marisa Zanotti, Choreographer Lea Anderson Transmedia. 2015. http://panspeoplepapers.com.

Time Reversal Symmetry. Dir. Evan Siemens. Film. 2018. http://evannsiebens.com/timereversal-symmetry.

Tuffnell, Miranda and Crickmay, Chris. Body, Space, Image: Dance Books: Hampshire, 1990.

Under the Skin. Dir. Jonathan Glazer. Film. 2014. Netflix.

Un Jour Pina A Demandé. Dir. Chantal Akerman. Film. 1986, RAI.

Vincenzi, Simon. https://www.simonvincenzi.com/the-surface-video. Accessed 29 January 2019.

VW Golf GTI Singin' In The Rain. Dir. NEO. Advert. 2010. Vimeo https://vimeo.com/7775155.

Wogan, Mary Martha. Interview: Mary Wycherly Dance artist and choreographer: Accessed 4 February 2019. https://marywycherley.com/invisible-histories.

Wavelength. Dir. Michael Snow. Film. 1967. YouTube https://www.YouTube.com/watch?v=aBOzOVLxbCE.

White, Marcus. "Narrative Shifts: Race, Culture and the production of Screendance." The International Journal of Screendance 9 (2018). https://doi.org/10.18061/ijsd.v9i0.6049

Whyte, Chirstinn. A Choreographic Sensibility (Unpublished PhD thesis) University of Middlesex, 2007. Available at http://www.shiftwork.org.uk/unspooled_site/thesis.

Zama. Dir. Lucrecia Martel. Film. 2017. Walt Disney Studios. 


\section{INTERVIEWS}




\section{What Are We Doing?}

Douglas Rosenberg, University of Wisconsin-Madison

Simon Ellis, Centre for Dance Research (C-DaRE), Coventry University

Simon Ellis spoke with Doug Rosenberg via Skype on 20 December 2018.

SE: You and Claudia Kappenberg were the first editors of The International Journal of Screendance. Could you talk about some things you remember about getting IJSD started?

DR: I remember from the earliest days of these gatherings, all the way back to 2000 or so, what seemed to come up over and over again was the need for literacy. The word 'journal' came up a lot-something that put screendance in a similar territory to other art forms; a repository or something where people could write about the work, and think out loud. That came up really strongly at the first Opensource in 2006, ${ }^{1}$ but it wasn't until the second Opensource in $2007^{2}$ that it really got some traction. Then Claudia Kappenberg and Katrina McPherson put together an AHRC Network grant to create the Screendance Network. When that came through, it gave us the opportunity to meet over the course of two or three years in a number of different places, and we really started thinking in earnest about what a journal would look like and how we might go about creating it.

SE: You said these conversations about a place for writing and thinking about screendance were going on from about the early 2000s; was there any sense that this place was or should be a scholarly place?

DR: Certainly. That's a tricky word and the longer I've been involved in this sort of stuff the more I feel push back on that word because it does have a very narrow meaning in academia especially.

SE: If that's not the right word then what do you feel is more accurate or representative of the kind of writing that, at least initially, went on for the Journal?

DR: In my teaching experience and through going to conferences, the way that scholarly information and knowledge is conveyed always felt very middle-of-the-road ... very equivocal.

SE: Do you mean safe?

DR: Yes. What I've come to understand about scholarship is that most often it did the following when talking about a subject: "Well it could be this or it could be that. Either The International Journal of Screendance 10 (2019).

https://doi.org/10.18061/ijsd.v10i0.6823

(c) 2019 Rosenberg and Ellis. This article is published under a Creative Commons Attribution 4.0 International License (https://creativecommons.org/licenses/by/4.0/) 
are valuable but I'm going to tell you about both sides." And that was very frustrating to me, especially since what excited me, and what still excites me more than anything, are manifesto-driven movements. And out of one of the gatherings at Findhorn came a manifesto, and the entire first part of the 20th century all of the stuff that I would say screendance really flows from-Dada, futurism, surrealism - all those movements that were about interdisciplinary artists coming together for new utopian visions; those were all manifesto-driven, and so nobody would confuse that writing with scholarship the way we are talking about it right now. From my experience it isn't until the late 20th century when we start to get this thing that we talk about now as scholarship. Even at mid-century, Clement Greenberg's writing was more manifesto than scholarship.

SE: It was highly opinionated, that's for sure.

DR: Exactly, and that was always my model; and so that's a long response to what I think about when I think about the word scholarship, and we haven't even gotten into the word research which is another can of worms, right?

SE: Did you envisage initially that the journal was a place for Greenbergian-type writing: highly opinionated and more "This is the way things are"?

DR: Actually I think maybe more like October; that was more like what I was thinking about-interdisciplinary and contemporary writing. Or film journals like Millennium Film Journal, but Greenberg certainly was always in my head.

SE: I'm wondering about the people who write for IJSD, and I know it's hard to know the agendas of people when they submit to IJSD, but do you have a sense that those agendas might have changed since the beginning of the journal?

DR: I think that scholarship and research in an academic institution has this kind of magnetic pull, and once there is a space that opens up, then who has the drive to write for them? And it seems that people who are in Masters or PhD programs are compelled to write because of their programs, so ultimately those pages get filled up with the kind of scholarship that we were just talking about: somewhat equivocal and I don't mean that in a negative way ... a kind of professional scholarship. That idea does extend a little bit to publishing. For example, you may have an idea for searing utopian manifesto-like vision, but then in order to get that published it has to go through a number of hands and readers, and it's difficult to sustain that kind of intensity in an academic publication.

SE: There are certainly a number of filters that are applied in the process of publication. So what would you have done differently in terms of the development of IJSD?

DR: The only thing I wished could have endured was the paper copy. I'm still mourning the deaths of paper copies. I can't even imagine that IJSD has lasted for 10 issues. 
SE: How do you think the field of screendance has changed in the last ten or even 20 years?

DR: Well, I think that when films are made that are not mainstream, and not highly produced, and not heteronormative, and not fill-in-the-blank, the gravitational pull of screendance draws the field back into order. For every film that is 'outside the bubble' or moves the needle in a really aggressive way, there are a hundred films that pull that film back into orbit; that pull it back into maintaining the status quo. And I think that's true with the way that screendance is still presented; it's still presented in these one-off festivals. We still aren't seeing career retrospectives, or multiple works grouped together by single artist or by genre. Except in certain places, I mean Light Moves ${ }^{3}$ is doing an extraordinary job. I think the field-no matter how much we want it to change-somehow snaps back to its original forms.

SE: Are you saying that the field hasn't really changed in the last 10 years? That the kinds of films, the particular production values of films, but also the way in which they're presented, hasn't really changed?

DR: I think there are a number of artists in screendance who have made a lot of films, but there isn't a way that those films are grouped or put together. The festival model still persists, and we are still seeing a lot of first or second films in festivals. I think this is about getting older but I still see a misunderstanding —or lack of understanding - of the history of the medium. There are still some gaps in people's understanding of where things came from and how they got where they are. The flip side of that is that there have been a number of screendance publications in the last 10 years or so since the journal started; there's five or six books now that really focus on screendance; there's literature in the field. There are a lot of positive things about where the field is right now.

SE: I sense your frustration with the stasis in the field, about the kinds of films that are made, and how they are presented. What would your alternatives be in how films are presented?

DR: Well, MOMA in New York recently presented an extraordinary example; they held an exhibition (or perhaps retrospective) called "The Work is Never Done" about the Judson Church Group. It was fantastic. There were a lot of still images, there were films projected throughout the space that you could stand and watch in the company of all this other ephemera. There were reconstructions of work from that time period. So screendance or film dance was integrated into this museum exhibition in a lovely way. A lot of these films I'd only seen stills of, but the films themselves were extraordinary, and so contemporary looking.

SE: Are you suggesting that the presentation of screendance-even though it wouldn't have been called that then-in the context of something else, the placement of those 
films in something bigger is an ideal situation? Is that what you mean, or is it the sense of the retrospective itself?

DR: A little of both, but the context piece is really big. I've always proposed that screendance is an interdisciplinary art form, but ultimately when we're sitting in a theater at a screendance festival what we're seeing is a film-a monodisciplinary work. But screendance in the context of a more multidisciplinary space is really exciting. There's a lot of resonance when you see work like that. To a certain extent Light Moves has done this. They've shown screen work or installation work in the context of the festival, so there are a lot of things bouncing off each other, and the central theme is the body or movement, but site to site to site. It starts to have a different kind of resonance.

SE: It seems like what is driving your interest is interdisciplinary practices; that there are many ways to experience the world or how are senses are provoked or nourished.

DR: I've been inspired by the people involved in the genesis of the journal. For me part of making work or even not making work is about who I'm around. And so those gatherings-like in Findhorn in 2006 and 2007-were incredibly important. The journal came out of the friction and the tensions that happened when that group came together by accident. In the same way I think that manifestos are born; the way that movements come together.

SE: What else seems critical for you at this point in time?

DR: As we age, we have two choices. One is that we can pretend we are not ageing and that we can do everything we used to do. The other is to be with those changes, and the difference in your body, and the differences in everything about your life. Every age has a different sort of reality. I don't see very many bodies on screen that represent the age that people are at. We seem to be working with a very narrow bandwidth of virtuosity. What moves me very much is that there is gorgeousness about older bodies moving in space, or not moving but just being in space. I think that's a real hole in the field.

SE: Do you think that is a virus that has been passed on by dance's obsession with young bodies, of bodies aged say 16-30?

DR: I teach this art history course, and there's this spectrum of behaviour around actual bodies, that goes from the early 20th century-a modernist fetishization of exotic bodies (usually women, usually of color, usually from some other place that isn't Europe or America)-to a lot of work in which we see older ageing bodies, that also fetishizes those bodies. I think it's hard to work with ageing bodies, or lived bodies, without turning them into some kind of other, or without fetishizing those bodies. Mass media does that all the time.

SE: You mean mass media does that fetishization for us? 
DR: I think it does it really well.

SE: I'm paraphrasing you, but what I hear you saying is, "Who is that we are seeing in these films? What kinds of bodies? What kinds of people?"

DR: And what are they doing?

\section{Biographies}

Douglas Rosenberg is an interdisciplinary artist and theorist working with performance and media whose screendance projects have beed exhibited internationally for over 25 years. He is the author of Screendance: Inscribing the Ephemeral Image, and the editor of The Oxford Handbook of Screendance Studies, which was recently awarded the 2018 Oscar G. Brockett Book Prize for Dance Research, from the Dance Studies Association. He was, along with Claudia Kappenberg, a founding editor of the International Screendance Journal, and is currently a professor and Chair of the Department Art at University of Wisconsin-Madison.

\section{Email: rosend@education.wisc.edu}

Simon Ellis is a choreographer, dancer and film-maker interested in practices and ideas to do with (not necessarily at the same time) power, responsibility, memory, dialogue and screens. He is an Associate Professor at the Centre for Dance Research (C-DaRE) at Coventry University, and co-edits IJSD with Harmony Bench.

Email: simon.ellis@coventry.ac.uk

Website: www.skellis.info

\section{Notes}

${ }^{1}$ Opensource \{Videodance\}: Symposium 15th - 19th June 2006 Findhorn, Scotland

${ }^{2}$ Opensource \{Videodance\}: Symposium 21st - 24th November 2007 Findhorn, Scotland

${ }^{3}$ www.lightmoves.ie 


\section{Pathways, Histories, and ScreenDance Diaries: Sarah Elgart in Conversation}

Sarah Elgart, Choreographer \& Director, Sarah Elgart |Arrogant Elbow

Harmony Bench, The Ohio State University

HB: I was very excited to discover your Cultural Weekly column ScreenDance Diaries, which I've been following for a couple of years now. Could you talk about your background in screendance and how you navigated your own path in relation to the form?

SE: Thank you! Well, I was raised here in Los Angeles, spent a lot of time in New York, as well as in Germany at Folkwang Hochschule - Pina Bausch's school - training as a girl, and that impacted me greatly. But I came back to LA because I felt like I really needed to be home to do my own work as a choreographer. I wanted to look into using alternative space for dance performances, other than traditional theater space, I felt like this paradigm in New York was something that hadn't really been explored in Los Angeles, and I started doing that. In the mid ' 80 s, I fell into working at a women's prison, teaching maximum-security inmates, and eventually that led to me being underwritten by the now-defunct Arts in Correction aspect of the CA Department of Corrections. I wrote for and received grants from them with the California Arts Council to create choreography with inmates and started working in the prisons about 20 hours a week. A piece I created with the inmates entitled "Marrying the Hangman" won an award for choreographic innovation and ended up in the 1984 Olympic Arts Festival. During the creative process, I really wanted to capture what the inmates were doing. I got permission from the prison system to go in with a camera. How I did this, I don't know, because it's very difficult to go in and film in prisons. I wrangled a friend who was a professional cinematographer, and we shot rehearsals and a run of the performance. I was working with very, notorious maximum-security inmates, two of whom were from the Manson Family. My company had come in and seen a performance of the work by the inmates, and asked me to re-set it on them and I filmed that as well. I took to the form and the medium of film, and I was really interested in how you could manipulate movement and time, going back and forth from the prison to the company, etc. That was my first introduction to exploring the mediums of film and dance together and I really loved it.

I am the daughter of two artists, and growing up in LA I saw of experimental work. Both my parents were amazing painters, my father was an art professor at UCLA, and my mother taught art at various schools around the city. I grew up amidst a community of The International Journal of Screendance 10 (2019).

https://doi.org/10.18061/ijsd.v10i0.6831

(C) 2019 Elgart and Bench. This article is published under a Creative Commons Attribution 4.0 International License (https://creativecommons.org/licenses/by/4.0/) 
arts professionals who ranged in experience from visual arts to music to film, all of greater and lesser renown. My parents took me to see a lot of dance, theater, and foreign films - classic films by directors like Truffaut, and Fellini, Godard, and Cocteau - really amazing films with movement elements that were inexplicably like dance. The cinematic elements, and images from these films lodged themselves in my brain, and really stayed with me. They are kind of formative, archetypal images for me, and I find that I'm still constantly pursuing them, or elements of them, in my own work. The way that these films could defy gravity with movement, or go into super slow motion and so forth, and contain these magical little moments that aren't necessarily easily re-created on a stage. I think that played a lot into my interest in dance film.

And then in the mid ' 80 s, purely by accident, I fell into creating choreography for music videos, films, etc., and found that I was able to make a great living doing that, and I could support my dance company. At that time, it was not an acceptable path for an artist. I was lambasted by critics. I was creating choreography for music videos and films and showing my own work at mainstream institutions - and that just wasn't okay. Critics commented on superficialities like how me and my dancers looked, and they said things like my "growing success in commercial music video choreography paralleled the coarsening of my powers as an artist."

In the ' 80 s and '90s things started to blow up. I was accepted into Sundance twice in a row as one of four nationally selected choreographers (all concert choreographers I should add) for the Sundance Dance/Film Lab. I was working with incredible mentors there, like Michael Kidd, and Stanley Donen. And for three weeks we would explore how the intersection of dance and film worked, and how to manipulate it, and we were given all these resources - camera, DP, edit bay and editors, as well as dancers... It was paradise. I brought two of my own dancers and I also had access to an entire company to create with. That really was formative. A couple years later, I was accepted into the Directing Workshop for Women at AFI [American Film Institute], still a very prestigious program. It was a very interesting year because Karole Armitage and I were both accepted, and I don't think there's ever been two choreographers there at the same time since!

All of that really laid the groundwork for my interest in film, and simultaneously I was working regularly as a choreographer in these commercial projects, and I was fascinated by the intersection of dance and film and participating in an active inquiry about how it could be used. I really was interested in exploding the sort of traditional model that existed then of, in a music video for example, 5, 6, 7, 8, the shoulders start rolling and the dance number begins. I was working with one director in particular by the name of David Hogan and we must have done 25 or 30 projects together, and he really relied on my eye. I was working very intuitively on site, so he would bring me onto a location and say, "Sarah, what would you do here?" And he entrusted me to it. I would set up a shot, or an idea, and I was of course looking from behind the camera and creating the 
choreography, and it was very exciting for me. And then he would wait for me when he started editing, because he really liked the exchange. We had a very good working dynamic, and it was very interesting and exciting. It was a new medium. It was 1984 . I was very young and very wide-eyed and eager, and really excited by the possibilities. I was exploring what could happen and where to go with it all.

Shortly after my time at AFI's Directing Workshop for Women and the two Sundance Dance/Film Labs, I was hired by The Disney Channel to become a Music Producer for the New Mickey Mouse Club - a fact I speak little about in part because of all the commercial vs. art backlash I have received. Working there for four years until the show wrapped, I was responsible for conceiving, casting, and overseeing all aspects of three weekly music and dance numbers and two music videos a month. And yes, I worked with all those super stars as kids. I frequently co-choreographed with the show's choreographer Myles Thoroughgood, and after one year was directing music/dance numbers and music videos as well. As such I also became a DGA [Directors Guild of America] director member and learned a tremendous amount about the craft of directing.

As part of the job I would relocate for approximately half to two-thirds of the year to Orlando, coming back to LA when we were not in production, at which time I was working on my own non-commercial choreography projects within marginalized communities. One year upon returning to LA, I accepted an offer to teach an afterschool dance program in a very downtrodden, inner city school. My first day there I walked in with a stack of VHS tapes (those were the days!) - my own work and a couple from the show. Two of the kids read the labels of the tapes - they were of the show's musical numbers - and right in front of me, they IMMEDIATELY began dancing the choreography that I had worked on only weeks before. It blew me away and really hit home the power and reach of the media and I thought, if dance on film can do that, wow. After that, I took my job there even more seriously because I realized that the music and dance numbers, in their aesthetic choices of songs, production design, movement, etc. had the power to coalesce and elevate these young people to appreciate aesthetics and choices they might not otherwise be exposed to.

This is a very specific example and of course my own films and the films I write about on ScreenDance Diaries are nothing like those I did for Disney, but it relates directly to the relationship of dance and film, and what is possible at their intersection.

HB: Could you talk about why you decided to start ScreenDance Diaries as an online column, and the conversations you're trying to provoke or engage with it?

SE: I had just left Dance Camera West after about six years, and I was talking with Adam Leipzig, who's the founder of Cultural Weekly, which is the online magazine that ScreenDance Diaries is featured on. He was asking me a bunch of questions about all the dance films I had seen, and did I have a database? How many were there? Where would 
I find them? etc. And then he just pitched the idea of me writing a column. I said yes and named it ScreenDance Diaries. Dance is ephemeral, right? You know, it's only there when it's there. You can't pick it up and take it home with you. And I'm just as fascinated with live dance as I am with dance on film. But the reach of media is just undeniable... Over the past 20 plus years, since my own involvement with music videos, films, working on my own dance films, viewing so many from all over the world I really saw that film as a medium could extend the life of dance. I don't know if you ever watch music videos, but if there's a song that you are particularly fond of, and you've seen the music video and it's well done, it's hard to forget. Take for example [Childish Gambino's] recent "This Is America." It becomes difficult to listen to that song without having what I call the ghost imprint of that video in your head. Such an incredible piece of work, with a powerful and important statement, one of the best music videos I've seen in a long time. And I think that's very profound and important. Screendance becomes a very visceral way of preserving dance so that it has a life in our collective consciousness, and it promotes dialogue. I see dance on film not as a way to replace the experience of seeing dance live, which is completely different, but as a supplement, and a way of prolonging it.

HB: One of the things I really enjoy about ScreenDance Diaries is there's not a fidelity to a certain aesthetic, or a certain style of dance. When you look at work, what strikes you? Are you looking for something in particular? What do you respond to?

SE: I respond to a myriad of different things, and of course it's so subjective. It's hard to characterize what I respond to because dance is an art form - and dance film is an art form - and both are changing all the time. But now with the Web, we are, in a way, all speaking to each other as people, culturally. There are cross-pollinations happening in all art forms constantly, and I'm really excited by that. I think it's what has to happen to make the world more strongly inter-woven. We are in a time where we've got the leader of the so-called Free World focusing only on the divisions that exist between us. And the arts and dance in particular, including dance on film, have the ability to reach a large number of people and speak many languages without saying a single word. I'm interested in work that is technically well done, but I also really like stuff that is shot from the hip and not necessarily pre-planned, films that are of the moment and a form of pure expression. I'm moved by work that is original. I'm moved by work that is honest, that is unpretentious, that has great movement, that has great cutting, that has great color, that has sensitivity. Work that is human.

I did notice, particularly when I was involved with Dance Camera West, and seeing the lineup of films at other film festivals, say in New York or elsewhere, that there was a specific aesthetic, a predisposition that happened in Los Angeles that was different and singular. We were trying to promote and ignite a conversation between directors, producers, and dance film makers. There's this kind of gap between the commercial and the arts worlds, and I'm really interested in bridging that gap. I think we have tremendous amounts to learn from one another. I don't think for example that you 
necessarily have to characterize a beautifully done music video that features dance as only that, I think it can be considered a viable piece of screendance as well.

HB: I really appreciate the work that you're doing with ScreenDance Diaries, not only because I have been introduced to new films via your column, but also because you are opening screendance to a bigger audience than artists and academics. When you are curating and writing about these videos, who do you envision as your audience?

SE: I don't know, I really don't. I actually see what I'm doing as a public service. I think it's a way of educating people, about dance, and dance on film, about film, about art, about what's going on in the world in general, and the power and possibilities within the mediums. I think the possibilities are unlimited, and as a genre, it's just beginning to emerge. I think screendance will explode sometime soon in much more marketable ways. When somebody is online and encounters a piece of work that they never would've imagined existed, and it opens up doors, channels, and ideas for them - that's exciting. All those aspects play into the column, and I hope that it will open people's minds to the possibilities of what can be done in dance and film, both independently and together, and in the arts in general. There's hardly a day where I'm not viewing, and I try to really stay on top of the medium.

HB: What's next for you?

SE: I'm starting to teach annual Screen Dance Intensives, which I really enjoy. What I'm seeing now is that there are increasing possibilities for screendance, not only as a genre but in terms of marketing and using it as a promotional tool for choreographers, directors, and dancers. I've got two dance films of my own that I'm jonzing to make right now, one is more 'shot from the hip,' the other that will require some dollars. I'm getting close to launching Round 3 of Dare to Dance in Public Film Festival, an online dance film festival that I started a couple of years ago. Last year we had submissions from 11 countries all over the globe, which was super exciting. I'm being asked to curate dance film showings for venues like The Music Center, and my own live work is ongoing. I had an amazing East Coast tour this past summer premiering new work at Jacob's Pillow and Insitu Site-Specific Dance Festival in NY, and I was accepted with it into American Dance Abroad's PITCHBOOK so I'm intent on getting my stage and site work to Europe again. All that and more!

\section{Biographies}

Under the auspice Sarah Elgart | Arrogant Elbow, choreographer/director Sarah Elgart has been creating dance for stage, screen, and site-specific venues for many years. Her 
large-scale site works engage audiences by transforming and catalyzing non-traditional sites and has been presented at venues including Jacob's Pillow, INSITU Site-Specific Festival (NYC), Dance Place (D.C.), MASS MoCA, LACMA, European Culture Capitol (Belgium), and Los Angeles International Airport (LAX).

In film, Elgart has created choreography for directors including JJ Abrams, David Lynch, and Catherine Hardwicke, and her own films have received numerous awards and accolades. Elgart's critically acclaimed dance film "Ghost Story" continues to tour film festivals internationally. An alum of the Sundance Institute Dance Film Lab and AFI's Directing Women's Workshop, Elgart worked with Dance Camera West Film Festival in various capacities for nearly seven years, and currently writes a regular column on the intersections of dance and film called ScreenDance Diaries for the online magazine Cultural Weekly, where she also Executive Produces Dare to Dance in Public Film Festival. Her work in Social Justice has extended to communities including transitional homeless women and maximum-security inmates. Elgart continues to be active in "democratizing dance," challenging the notion of what is and is not a stage, and placing dance in the foreground of community and commerce.

\section{Websites: sarahelgart.com; culturalweekly.com/author/sarah}

Harmony Bench is Associate Professor in the Department of Dance at The Ohio State University. From 2014-2019, she has been co-editor of The International Journal of Screendance with Simon Ellis. She is currently at work on a collaborative research project with Kate Elswit, funded by the Arts and Humanities Research Council, which brings data visualization and computational tools of analysis to bear on dance history in the study of mid-century African American choreographer Katherine Dunham. https://dunhamsdata.org/.

Email: bench.9@osu.edu

Website: http://www.harmonybench.com 


\section{REVIEWS}




\title{
Reflecting on Light Moves Festival of Screendance 2018
}

\author{
Katrina McPherson, Independent Artist
}

Keywords: Light Moves, themes, editing, grief, community

In a hotel lift in Limerick recently, I found myself standing next to a man carrying a small wooden box by its handle. It is clearly a homemade receptacle, and I am intrigued to know what it contains. In response to my query, the man opens the front panel of the box and inside there are three shelves, each one populated by crowds of miniature model soldiers. "I'm here for a national gaming convention," the man explains with a flush of anticipation. I recognise his excitement as being similar to my own on this first morning of the latest edition of the Light Moves Festival of Screendance. ${ }^{1}$ Two nerds in an elevator, off to satisfy their different personal obsessions.

Founded five years ago by Irish artist-curators Mary Wycherley and Jürgen Simpson, and produced by Jenny Traynor and Dance Limerick, Light Moves Festival of Screendance has in a very short time become the 'must-go' event on the international dance film calendar. Combining presentations and papers, labs, special events and films, the 2018 Light Moves line-up was as richly thought-provoking as ever. The backbone of the event is a series of screenings of works selected from an open call for submissions, curated into themed programmes which this year included Timings, Remembering, and Journeys. For me, these themes, or sub-categories, seemed to flow into wider ideas around grief and loss that emerged in many of the presentations and conversations over the three days of the festival.

"Editing is grief," said visual artist Annie Pfingst on the first morning of the festival. She was being interviewed about In Memoriam (2016), ${ }^{2}$ an environmental dance film that she made with movement artist Helen Poynor. The synthesis of a shared practice of 20 years, In Memoriam was filmed over three seasons in an ancient mossy grove in South West England, close to where the artists live. In it, Pfingst's camera bears witness to Poynor's process of working-in movement and stillness-through the pain and desolation of grief, as located in her body and the landscape she inhabits. The result is an evocative and meditative screendance work in which framing and editing mimics the grieving process. That there is a profound sense of loss attached to choosing one shot over many others when piecing together the film, suggests that the artists' relationship to the moving image material they have created has intense personal significance. 
This slippage between the deeply personal and a more forensic attention to formal processes feels appropriate and timely. I sensed among the artists, producers, commentators, and presenters at Light Moves a shared desire to reassess the value and role of what we do; to question existing structures and biases, to re-order what has been before, and yet also to look back to a time when things were perhaps less complicated.

Ancestral loss, and the melancholia surrounding it, is the starting point for This is How I'd Like to Die (2018), a talk by Canadian filmmaker Laura Taler. Here Taler presented her latest film work, which she both directs and performs in, although in truth we saw few actual moving images. She instead shared the research, questions, and concerns-both personal and artistic - which occupy her in what she calls her "performing mourning" practice. ${ }^{3}$ Taler recalled the moment in the process when she realized that, in looking to articulate something about absence and grieving, she needed to return to the village in Romania that her mother had left many years before; to re-insert her own theatrical persona-complete with long wig and peasant skirt-into this familial environment. Along with her attempt to transform private questions and personal emotions into screen-based images, Taler also questioned how these might be shared and understood by an audience. She described her desire to "give feelings shape so that people can share them." ${ }^{4}$ However, as Taler herself pointed out, whose are these feelings in the first place and has she the right to be feeling them, let alone tell them as her story? This raises questions about the nature of autobiographical work, of what and whose stories artists may tell, and - with her particular set of circumstances-Taler highlights a tension in the spatial and temporal distance/proximity which results from "being where you don't feel that you belong, ${ }^{15}$ whether that is today, or in the past.

Different kinds of loss also ran through Simon Ellis's presentation-performance Between Faces. ${ }^{6}$ He began by telling us about a survivor of the 2018 tsunami in Indonesia who, describing the experience of having lost everything, said: "I have my body ... and my phone." ${ }^{\prime \prime}$ This anecdotal framing suggests the essential-and existential-role that these digital devices have assumed in our everyday lives. In the context of screendance, Ellis used the dubious centrality of the smartphone as a means of "drawing attention to the movements, timings and spaces that characterize our interfaces with screens, ${ }^{\prime \prime}$ and in doing so, he critiques our assumptions about how we engage with ideas, culture and, most specifically, dance. One of the questions Ellis's talk brought up for me was what is lost and what is gained by filming dance? It is not necessarily a new question, but one which can usefully be revisited as technologies and their contexts evolve. If nowadays everything can - and often is - captured for posterity, what does it mean to edit? Taking the 'real' time to place images into an order to be played back to an audience in analogue seems laborious, clunky, and perhaps too definitive today. Instead, Ellis suggested a more fleeting, ephemeral relationship to images might take place, one that "involves a different set of eyes ... (which) Kim Louise Walden describes as peering as opposed to the "glance" with television, and the "gaze at the cinema screen." 
As I reflected on Ellis's paper, I returned to the image of editing as grief. Is editing a grieving process precisely because our embodiment is now extended to our smartphones? We have reframed the interface between us and the world that surrounds us, and as a result live and film our lives-and dances-relatively indiscriminately. How does this tendency to record everything-eschewing predetermined, consciously choreographed and framed shots in favor of long, fluid, unarticulated captures - affect our approach to editing? If the structure of a work has typically become the result of omitting rather than constructing moments, perhaps it is inevitable that the emotion of editing has become one of loss, a feeling of absence. In that sense, the edit of a dance film becomes less an imagined reality and more a fragmented memory of moments, rendered separate from the present primarily by the passage of time.

Mourning is also about time, and temporal (as well as spatial) distance, which expand and contract within the emotional field of the mourner, often without warning, meaning, or logic. In Marisa Zanotti's film Entangled (2018), perceptions of time emerge as a concern in which loops of archive, shapes, and screen configurations phase and dance in relation to the different sections of composer Matthew Whiteside's score. The only human presence discernible on screen is a short clip of a couple dancing a social dance-archival footage, possibly from the time of the early cinema. Like particles of dust, they spin, step apart, come together, fade away and fade in again. Through Zanotti's editing, they become fleeting glimpses of a moment that is never explained, at which none of us were present, but which etches itself into the viewer's consciousness as memory. The programme note tells us that the theory of quantum entanglement and specifically the work of the late Northern Irish physicist John Stewart Bell provided the sound and image inspiration for Entangled.

Another film in the same programme that stems from scientific research is Evann Sieben's Time Reversal Symmetry (2018). This work was developed as part of a project bringing together artists and scientists at TRIUMF: Canada's national laboratory for particle and nuclear physics. In her response, Sieben puts herself (with her dog Pina Bausch) in the frame, as she carries out everyday activities such as walking, circling, and sweeping. Filmed on a $16 \mathrm{~mm}$ camera, the work uses in-camera split-screen and shot reversal to represent the oscillating dance between matter and antimatter. Its formal structure, relaxed aesthetic, and the pedestrian quality of the physical actions are also a nod to experimental cinema and the post-modern dance tradition.

Perhaps it is indicative of this century's altered world-view, melancholic weariness, or absence of hope, that the oldest film to be screened at the festival was for me the most uplifting. Sitting amongst the Light Moves audience for a screening of Dziga Vertov's film classic, Man With A Movie Camera (1929), with a newly commissioned accompanying score, I experienced editing as optimism. 
The film is hugely influential in the development of cinema, and at Light Moves, the images and the edit still resonate ninety years later. The highly textured, shifting electronic soundtrack was performed live by composers Neil O'Connor and Dunk Murphy. The sound accompanied the audience through the different qualities of the film, sometimes highlighting tiny details - the glance to camera by a smart woman seated in the back of a carriage, the scrunched face of a tightly swaddled new-born-at other times, sweeping up the viewer in the frantic, joyful momentum of the emerging modernity of city life.

Dance Goes On (2017) is the first feature-length film by the Hong Kong artist, designer and photographer Stanley Wong (aka anothermountainman). In his stylish work, Wong presents ideas of life, ageing, and the intense vibrancy of his home city through an exquisitely observed group portrait of his long-term friends, three veteran dance makers, Xing Liang, Mui Cheuk-yin and Yuri $\mathrm{Ng}$. This is a finely intimate film, which has at its heart a spacious timelessness that belies the frenetic onward momentum of the city and its culture. If there is a sense of loss to be identified here, it is in the awareness of a disappeared time, when these individuals were at their physical peak and presumably more central to the on-going cultural life of the city.

Absence pervades the most recent work by Irish visual artist and singer Ceara Conway. Dochas: Hope (Part 1) (2018) is a film performance project in three parts, based on the story of Connemara fishermen who took five boats back to their community in the 1950s. Two of Conway's films were screened as part of the Remembering programme of short works at Light Moves. The voices of the community whose history inspired the work were absent, and yet we heard and saw the artist's voice, someone who was not part of the real-life events. In her social research, Conway had also noted the absence of women's voices in the telling of the community's story. As an artist film-maker, Conway harnesses such absences to striking effect in the pared down edit and vocal soundtracks of the films. Dochas: Hope. (Part 1) (2018) comprises only two shots: a medium wide shot of a woman (Conway) singing to camera as she is lowered down the concrete wall of a canal lock, and a point-of-view shot of the barge, as it enters the coffin-like cavern of the same lock. The simplicity of the work belies its complexity. Seen and discussed in the context of the festival, it revealed further ideas of montage as lack, loss, or absence. The artist's formal choices force us to come face to face with a story whose characters, details, and even truths are no longer there, or perhaps never even existed.

Who is-and is not-present is in itself a pertinent question that speaks to the very nature of festivals. At a time when more and more screendance festivals are taking place every year, it is more important than ever to reflect on their nature: Why do they exist? Who and what do they include? Who are they for? In an essay in her latest collection Call Them by Their True Names, ${ }^{10}$ the American writer Rebecca Solnit analyses the value of "preaching to the choir."11 She says that whilst "The phrase ... properly means hectoring your listeners with arguments they already agree with," ${ }^{12}$ the term can have a more 
generous interpretation - the idea of a "common ground .... [which is] not the destination; it's the starting point." ${ }^{13}$ I find this helpful when thinking about the value of festivals in that preaching to the choir can be a way of describing the behaviour of people who agree about the existence of something, collectively attempting to deepen their understanding of that thing. When people who are invested in the common subject are speaking, Solnit points out, they have the opportunity to articulate, excavate and practice that subject in-depth and to a level of specificity that would be lost, even wasted, on anyone else.

Given my experience as a regular participant of screendance festivals, I recognize clearly the way curated events (that include incidental and accidental interactions) enable us to shape, assess, critique, and articulate what it is that we do-or want to do, or want not to do, or want not to be done-regarding our chosen art form. When at their best, festivals-such as Light Moves-create the space for us to test out ideas, and to challenge each other to watch, make, think, speak, and write differently.

\section{Biography}

Katrina is a director and screendance artist whose creative, scholarly and educational work is at the forefront of the international field. Her collaborative films, installations and on-line works have been presented at venues and festivals worldwide. Since the early 1990s, she has been regularly awarded funding from public and private organisations, institutions and arts councils.

A much-sought after teacher and lecturer, Katrina has taught screendance and related subjects, both practice-based and academic, in the UK, Australia, Germany, USA, Canada and China. Katrina is currently Associate Lecturer at Bath Spa University, England, Visiting Lecturer at the University of Limerick in Ireland and Visiting Teacher of Graduate Screendance at the University of Utah, USA. Katrina is the author of Making Video Dance, a step-by-step guide to creating dance for the screen (2006), the second edition of which was released in 2019.

Email: katrinamcpherson@mac.com

Website: www.katrinamcpherson.com; www.makingvideodance.com 


\section{Notes}

${ }^{1}$ lightmoves.ie, 8-11 November, 2018.

${ }^{2}$ In Memoriam. Dir. Helen Poynor \& Annie Pfingst.

${ }^{3}$ This is How l'd Like to Die, Dir. Laura Taler.

${ }^{4}$ Idem.

${ }^{5}$ Idem.

${ }^{6}$ Between Faces, Simon Ellis.

${ }^{7}$ Idem.

${ }^{8}$ Idem.

${ }^{9}$ Idem.

${ }^{10}$ Rebecca Solnit, Call Them by Their True Names.

${ }^{11}$ Idem, 72.

${ }^{12}$ Ibid.

${ }^{13}$ Idem, 73.

\section{References}

Between Faces. Choreographer: Simon Ellis. Performance-presentation. Light Moves, 2018. Vimeo. https://vimeo.com/300770210.

Dance Goes On. Dir. Stanley Wong. Choreographer: Hugh Co. Film. Hong Kong. 2017.

Dochas: Hope (Part 1). Director/Choreographer: Ceara Conway. Film. Ireland. 2018

Entangled. Dir. Marisa Zanotti. Composer: Matthew Whiteside. Film. UK. 2018.

In Memoriam. Dir. Helen Poynor \& Annie Pfingst. Choreographer: Helen Poynor. Film. UK. 2016.

Man With A Movie Camera. Dir. Dziga Vertov. Film. Soviet Union. 1929. 
Solnit, Rebecca. Call Them by Their True Names: American Crises (and Essays). London, England: Granta Publications, 2018.

Taler, Laura. This is How l'd Like to Die. Presentation. Light Moves, 2018.

Time Reversal Symmetry. Director/Choreographer: Evann Siebens. Film. Canada. 2018. 


\section{Consuming Dance: Choreography and Advertising by Colleen Dunagan. 2018. Oxford: Oxford University Press. 264 pp.48 screen stills. Paperback \$29.95. Hardcover \$99.00. ISBN: 9780190491376}

Xiomara Forbez, University of California, Riverside

Keywords: advertisements, affect, dance, identity, consumers

Colleen Dunagan's monograph Consuming Dance: Choreography and Advertising explores ways in which "dance fuels advertising," By "fueling," Dunagan aptly refers to the ways in which dance serves to produce material, energy, affect, and power for advertisements. Dunagan's method focuses on descriptive analysis and close readings of 'dance-in-advertisements' ${ }^{2}$ of US products: she describes costumes, appearance of dancers and actors, mise-en-scène, actions of the camera, and choreography including facial expressions and movements of the body (at times using Laban/Bartenieff terminology and Susan Foster's definition of choreography). Products range from beverages to electronics, yet Dunagan's focus is on "the cultural and discursive work that [advertisements] do"3 and not necessarily on advertisements' effectiveness in generating profit. Consuming Dance addresses broader questions, such as: What makes dance a suitable medium for selling products? How is dance used in advertisements? How do advertisements make meaning within popular culture and lead to the constructions of consumer identities?

Consuming Dance exists as a print book and a linked companion website. The print book is divided into five chapters with a short introduction and conclusion. Black and white still images and screenshots are included alongside the text to help illustrate Dunagan's analytical points. The companion website is separated into four sections, comprising a short author biography, a book summary, an archive of advertisements (also available as a downloadable PDF), and a separate web page with links to the videos mentioned in the text. The advertisement archive includes a list with the following details: the product/brand, title, duration of advertisement (e.g. 30 seconds), year of release, producing agency, director, and choreographer/artist. Dunagan notes that the information and production credits for dancers, actors, and choreographers is limited, therefore the archive has some gaps. Nevertheless, this does not diminish the valuable contribution that this web archive provides for the field. The video section of the companion website is divided according to the book chapters, with links to YouTube versions of the advertisements discussed in the text. It is helpful to watch the videos 
before or after the reading of her analysis, though Dunagan's descriptions and close readings are vivid, detailed, and provide plenty of information. She points out that there are many possible readings for these advertisements, thus leaving space for the reader to consider other interpretations.

In Chapter 1, Dunagan lays out the theoretical foundation for her analytical work, drawing on different theories of affect, kinesthesia, kinesthetic empathy, enaction, cognition, dance, and relational aesthetics. She argues that dance is used in advertisements because it produces affect, or feeling, that can be transmitted across bodies, spaces, and times. Advertisements use dance as spectacle to draw on notions of excess. The excess allows for "dance [to] align the body's potential for movement with agency, giving form to our ability to affect and be affected by the world". ${ }^{4}$ Dance in advertisements then acts as a way of capitalizing on potentiality: "through movement's rhythm and flow, advertising taps into this potential to affectively and effectively link products and brands to the lived experience of consumers". ${ }^{5}$ This chapter highlights the power of dance to create feeling in those watching it and to connect people, experiences, and products. Building on this conceptual base, Chapter 2 provides an analysis of aesthetic conventions used in advertising, including borrowing from other "television and film genres." Dunagan distinguishes between advertisements and 'advertisements in disguise, ${ }^{7}$ or advertisements that use other genre conventions to mask their "agenda" ${ }^{8}$ as commercials. The dancing in these advertisements, along with "the incorporation of choreographic, filmic, and theatrical conventions," helps them to cross into and become akin to musicals, performances, music videos, or works of screendance and film. ${ }^{9}$ The merging of these conventions is a way for advertisements to enter into the realm of popular culture and exist as products themselves. Dunagan explains that by having advertisements operate as mechanisms for selling, entertainment, and cultural products, more entry points are created to reach as many consumers as possible.

After establishing the context of popular culture, Chapter 3 shows how dancing in advertisements may create new meanings via "correspondence to and difference from prior cultural products". ${ }^{10}$ Here Dunagan uses a Volkswagen 2005 campaign as an example because the advertisement parodies Singin' in the Rain (1952), ${ }_{1}^{11}$ but clarifies that parodic commercials are not necessarily derisive, but rather nostalgic. Dancing bodies are thus able to reference the past while still being in the present. In turn, such an approach encourages consumers to interact with advertisements as active spectators who interpret these new meanings as connected to the present, as well as referents of earlier, culturally significant moments. Chapter 4 then discusses how, in creating new meanings, advertisements are also complicit in the commodification of culture-by turning landmark events into products, they encourage forms of crosscultural appropriations. This process produces the "colonial consumer;" ${ }^{\prime 2}$ one who 
operates with white privilege to use any and all cultural artefacts for personal consumption.

In the final Chapter 5 Dunagan explains how consumption consequently becomes an act of identity formation, whereby dance serves to blur the line between spectacle and everyday life. In such developments, identity and subjectivity are performed, flexible, and accessible to anyone who consumes the right products. Dunagan argues that dance in advertisements promotes "consumption as performance of identity" while also claiming identity as a static marker of authenticity. ${ }^{13}$ In other words, even as advertisements promote identity as a performance open to "anyone," they still often ascribe and use stereotypes to sell certain "authentic" ways of being. ${ }^{14}$ After her indepth analysis of the ways in which dance fuels advertisements, Dunagan's conclusion signals new avenues for analytical exploration. She calls for "a comprehensive examination of dancers' and choreographers' bodily labor in relation to capitalism," thus highlighting a rich line of inquiry for future scholars of dance, advertising and, more broadly, of popular culture. ${ }^{15}$

Consuming Dance is important because, as the title implies, the consumption of advertisements and the products they sell, results in dance also being consumed and further incorporated into bodies, popular culture, and society, and within US neoliberal capitalist frameworks. Dunagan's discussions about the role and function of cultural and labor appropriation in advertisements, particularly through dance, are vital in conversations about the propagation of dance in consumer industries. In this respect, it would be interesting to hear more about the particular manners in which dance is being appropriated to sell specific products. Dunagan's work, therefore, prompts further questions, such as: How does dance help to sell a beverage versus a piece of clothing? How does dance in advertisements for US products reveal and produce "Americanness" and US national identity?

At the intersections of media and culture studies, dance studies, marketing and advertising, and screen/film/digital studies, Consuming Dance provides a valuable and exciting exploration of dance-in-advertisements, especially for scholars and students, as well as for those interested in popular culture, affect theory, concepts of identity-asperformance, and neoliberal capitalism and consumerism. With digital consumption of dance increasingly prevalent and accessible, this book's release in 2018 is particularly timely and relevant. Dunagan provides readers with different tools and interpretations to interact with advertisements as products in and of themselves, proposing various ways through which dance is constituent and complicit in advertisements, popular culture, and in our everyday lives. 


\section{Biography}

Xiomara Forbez is a Ph.D. Candidate in Critical Dance Studies at the University of California, Riverside. Her dissertation research includes the intersections and negotiations of dance, space, and identity, focusing particularly on the technique and training of amateur and nonprofessional dancers in ballet, bachata, and hula. Prior to graduate school, she completed her B.A. in Linguistics and French Language and Literature at Boston University and then proceeded to work in Research Administration for four and a half years. When not dancing or dissertating, Xiomara can be found watching movies, dreaming of travel, and crafting.

Email:xforb001@ucr.edu

\section{Notes}

${ }^{1}$ Colleen Dunagan, Consuming Dance, 4.

${ }^{2}$ Idem, 13.

${ }^{3}$ Idem, 11.

${ }^{4}$ Idem, 20.

${ }^{5}$ Idem, 26.

${ }^{6}$ Idem, 13.

${ }^{7}$ Ibid.

${ }^{8}$ Ibid.

${ }^{9}$ Idem, 87.

${ }^{10}$ Idem, 116.

${ }^{11}$ Singin' in the Rain, Donen and Kelly.

${ }^{12}$ Dunagan, 123.

${ }^{13}$ Idem, 173-174.

${ }^{14}$ Idem, 174.

${ }^{15}$ Idem, 197. 


\section{References}

Dunagan, Colleen. Consuming Dance: Choreography and Advertising. Oxford: Oxford University Press, 2018. https://doi.org/10.1093/oso/9780190491369.001.0001

Singin' in the Rain. Dir. Stanley Donen and Gene Kelly. 1952. Film. 


\section{Charles Atlas. Edited by Lauren Wittels. Contributions by Charles Atlas, with the assistance of Johanna Fateman, Stuart Comer, Douglas Crimp, Douglas Dunn, Lia Gangitano. 2015. Munich, New York: Prestel, 303 pp, chiefly color screen stills. \$75 hardcover. ISBN: 9783791381008}

Kyle Bukhari, Sarah Lawrence College

Keywords: Charles Atlas, Merce Cunningham, postmodern dance, screendance, video art

Throughout his career as a filmmaker and visual artist, Charles Atlas' work has expanded the boundaries of film and video, with projects and collaborations that have spanned concert dance, performance and visual art, music, and underground club and drag subculture. In doing so, Atlas has moved across genres, techniques, and styles, forging an aesthetic approach that is uniquely his own. As the recent monograph from Prestel, titled Charles Atlas (2015), ${ }^{1}$ makes clear, Atlas is a central, if not the central, figure in the development of what is known today as the distinct genre of screendance, choreography conceived within the technical parameters of film and video. ${ }^{2}$ Yet who would have known that when he collaborated with Merce Cunningham on the groundbreaking dance film Channels/Inserts (1981), ${ }^{3}$ Atlas' original inspiration was the wedding scene in Francis Ford Coppola's The Godfather (1972)? ${ }^{4}$ Or, that when Atlas was approached by UK's Channel 4 to make the arts documentary that became Hail the New Puritan (1987), he proposed to showcase the then relatively unknown twenty-one-yearold Michael Clark whom Atlas had met while working with Karole Armitage during her "punk ballet" period of the early 1908s? ${ }^{5}$ This new volume combines just such anecdotal revelations by the artist and his collaborators in tandem with a richly visual selection of color and black-and-white screen stills drawn from his archive. Along with the scholarly, art historical essays and interviews, the overall effect is robustly multivocal, providing the reader with a valuable and nuanced perspective on Atlas' work that not only encapsulates the artist's often surprising intentions, but also the historical significance and critical reception of his expansive artistic oeuvre.

With the assistance of writer and musician Johanna Fateman who helped turn Atlas' thoughts and memories into a continuous narrative presence within the book, the reader is led through his works for film and video from 1970 to 2014 . What ensues is both a comprehensive and personal look into his archive that encompasses his carefully cultivated collaborations with some of the key innovators in dance postmodernism on The International Journal of Screendance 10 (2019).

https://doi.org/10.18061/ijsd.v10i0.6824

(c) 2019 Bukhari. This article is published under a Creative Commons Attribution 4.0 International License (https://creativecommons.org/licenses/by/4.0/) 
both sides of the Atlantic, including Cunningham, Clark, Karole Armitage, Yvonne Rainer, Douglas Dunn, and Phillipe Decoufflé, as well as performance artists such as Leigh Bowery, Marina Abramovic, DANCENOISE, Mika Tajima/New Humans, and the singer ANOHNI.

The major portion of the book is dedicated to Atlas' film and videography and is divided into seven thematic and chronologically structured chapters. They contain the author's earliest work (1970-1974), most notably with Dunn; his initial collaborations with Cunningham (1975-1983); documentary works (1983-2012) that feature artists such as Armitage, Decoufflé, Clark, Abramovic, and Bowery; live video/multimedia performance works (2003-2013) that showcase his work with Tajima/New Humans among others; and, video shorts, collages, featurettes (1990-2010) that include a cast of wickedly brilliant New York downtown performance artists such as Richard Move, John Kelly, Joey Arias, and Lucy Sexton and Anne lobst of DANCENOISE. These temporally overlapping yet distinct chapters include works such as his film of Cunningham's Walkaround Time (1972) and Torse (1977), his collaboration with Clark for Hail the New Puritan (1986), the live video portrait project Instant Fame! (2003/2006) that took place in the galleries of Participant Inc. in New York and Vilma Gold in London, and the historical and witty "featurette" on postmodern dance, titled Rainer Variations (2002), consisting of reedited material from Rainer's personal film archive. More recent video installations are also represented. Those include the haunting The Hanged One (1997, the Whitney Museum), Martha, Martha, Martha (2000) culled from what Atlas screened at the New York underground nightclub Martha@Mother's, hosted by performance artist and Martha Graham impersonator Move. Also included are his most recent, highly abstracted numerically based works for video-Plato's Alley (2008) and 143652 (2012). Atlas' survey ends with his late Cunningham collaborations (2000-2010), when the two artists reunited in 2000 to film a documentary of the choreographer Merce Cunningham: $A$ Lifetime of Dance (2000), and to create several films that document the iconic choreographer's last phase of production such as Melange (2000), Biped (2000/2005) and their final work together completed after Cunningham's death, Ocean (2010).

Across the chapters, fascinating historical details and new insights abound. For instance, in chapter seven: Cunningham Collaborations and Documents, we learn that in 2010, Atlas discovered his lost $16 \mathrm{~mm}$ footage of Exchange (1978) that had been mislabeled and stored in an off-site archive by the Cunningham company after Atlas' departure in 1983. Upon rediscovery, Atlas transferred the footage to high-definition video with sound and released it in 2013 under the video art label Electronic Arts Intermix. As Atlasthe narrator reveals, the work is important, as it captures Merce at age sixty, dancing his own choreography at full capacity with his company, dressed in the pollution-inspired "sooty grey" costumes designed by collaborator Jasper Johns. ${ }^{6}$

As the book clearly reveals, Atlas' work in the technological medium spans both analog and digital production, and the overview in the monograph allows the reader to make 
insights into the development of the screendance form. We can track Atlas' relationship to technology from his early use of Super $8 \mathrm{~mm}$ film in the 1970 s, to the early video system used to capture Cunningham dancing in the iconic Blue Studio: Five Segments (1976). Seeing the incorporation of live video monitors on the stage in Cunningham's Fractions 1 (1978), the reader witnesses a vanguard experiment that combined simultaneous live and broadcast action. The introduction of the Steadicam into the actual choreography with Locale (1980), as well as the use of a moving-crane camera in Coast Zone (1983) created entirely new ways of thinking about the space of the spectator. In a remarkable creative full circle-through the use of digital technologies in live performance in the 2000s-with works like Dunn's Muscle Shoals (2003) and more recent performances at The Tanks at the Tate Modern (2013), Atlas reveals that he had taken up John Cage's chance procedures, something he had rejected when he worked with the composer many years earlier. ${ }^{7}$

The book is highly visual, with each of the sections replete with multiple still images alongside textual, often-humorous and insightful recollections and musings on the production and editing process. In some cases, Atlas' stills reveal the progression of a single image, as in his collaborations with Dunn in the color-saturated, Édouard Manetinspired Mayonnaise Number One (1973), or the more minimal and formal black and white film Floor (1974/2010). ${ }^{8}$ In other instances, such as in the film of Cunningham's Torse (1977), Atlas presents close-ups and more distant shots of the same moments of the dance in a split-screen, showing the flesh-colored, unitard-clad dancers as if floating against a black, two-dimensional background. On those pages, the idea of choreography in the abstract is brought into stark relief within the video diptych. ${ }^{9}$ Ultimately, the relationship between the image and the text throughout the book creates a perspectival parallax on the individual works themselves that adds both depth and nuance to their contemplation. This dialogue between media enhances and enriches the aesthetic discourse on the visual medium of film and video in relation to dance, working together in a way that prioritizes the optics of Atlas' work while punctuating it with delightful and irreverent textual insights.

In addition to Atlas' voice, the monograph includes several text by other authors, selected by the editor Lauren Wittels, of Luhring Augustine Gallery in New York. These include essays by art historian Douglas Crimp, and Lia Gangitano (founder of the New York Lower East Side Gallery known as Participant Inc.), and two interviews with Stuart Comer (curator of Media and Performance at the Museum of Modern Art in New York), as well as with Atlas' long-time collaborator Douglas Dunn. Each of these voices adds depth and perspective to the reader's understanding of Atlas' work. In particular, Crimp's substantial essay on Atlas' early films for Cunningham provides an art historical context within which to consider this prolific collaboration, and Cunningham's lasting influence on Atlas, as well as Atlas' impact on the choreographer and the legacy of Atlas' films and video of Cunningham's oeuvre. For Crimp, Atlas provided Cunningham not 
only with the new two-dimensional realm of film and video as a platform for choreographic experimentation, but also with the possibility to visually realize a dynamic method of framing the dance that mirrored the unpredictable movement of the human eye as it views Cunningham's non-hierarchical and spatially decentralized choreography. Crimp's detailed and technical discussion of the ways in which Atlas' integration of the Steadicam in Cunningham's Locale (1980) makes explicit how Atlas' choreographed movements for the camera inserted directly into the dance were a key innovation in both the technical development of dance film and video, and the way that the effect of being inside of the choreographic action offered a new way of looking at dance.

Comer's two interviews with Atlas, the first reprinted from frieze magazine (2011), the second (2014) conducted especially for this book, provide further biographical and sociocultural background for the reader. ${ }^{10}$ The discussion of Atlas' early cinematic influences of D.W. Griffith, Stan Brakhage, and Andy Warhol, alongside references to other influential films and directors reiterate the influence of both popular and experimental cinema on the artist's work. To understand Atlas' aesthetic is also to grasp the social aspect of his work, his artistic milieu and taste for the subcultural in New York and London, and Comer brings this to the foreground, prompting Atlas to confess that in the 1980s "London was so much more fun than New York". ${ }^{11}$ Atlas also speaks to Comer about the role his own homosexuality has played in his aesthetic choices, and how his films expose a variety of possible sexual identities that exist outside the realm of the heteronormative. In their second interview, the lesser known subject of Atlas' work as a lighting and costume designer comes up, as well as the artist's somewhat reluctant move into the blue-chip art world of museums and galleries. We also learn that this reconsideration of his artistic value systems coincides with Atlas' recent video works, including Painting by Numbers (2011) and Plato's Alley (2012). These are works that could be described as purely numerical abstractions, and are the product of Atlas imagining himself to be a completely different artist from what he has been up to that point. Speaking of his recent large scale shows with multiple screens distributed throughout the exhibition spaces, Atlas discusses his evolving practice of choreographing the performance space itself, where the spectators travel through what he describes as "the fixed moving images," an experience not far from the memories of the "haunted-house rides" at the amusement park from his childhood. ${ }^{12}$ In the interviews with Comer, we learn about Atlas' look into the future of his work, as well as about his present-day concerns with artistic contexts and economies, revealing the profound influence that choreographic thinking, and his work with so many different choreographers, has imprinted on Atlas himself.

This splendid book will hold interest for a broad readership including but not limited to those who work within the fields of dance, performance and visual art. Similarly, it is essential reading for cultural historians of late twentieth and early twenty-first century 
subcultures as expressed through technologically mediated artistic spaces, and is indispensable reading for scholars and researchers interested in the technological and aesthetic development of dance for film and video. As the book was published in 2015, it predates Atlas' more recent collaboration Tesserract (2017), ${ }^{13}$ a spectacular 3-D dance film and performance made with former Cunningham dancers Rashaun Mitchell and Silas Riener. With all the existing rich insights in this book, a final essay to round up the plethora of ideas offered might be helpful to the reader, although a more recent book, also entitled Charles Atlas (2019), seems to address this discursive gap. ${ }^{14}$ Nevertheless, the value of the book is the many voices it contains, all of whom paint a multidimensional portrait of the artist, each in their own words. Prestel's Charles Atlas is a plentiful resource to explore the artist's trajectory and oeuvre, to learn more about his collaborative process and about the innovations that his encounters with dance and choreography sparked for his use of the camera, film, and video technology. The constellation of strikingly vivid still images in the book veer from the formally choreographic to the gender fluid, the surreal and high camp, the violent and the absurd, and taken together enthuse the reader to better understand Atlas' integral role in the history and development of screendance and its engagement with the broader social and artistic discourses from the late twentieth century up until today.

\section{Biography}

Kyle Bukhari studied Anthropology and Philosophy of Art at Columbia University, and Dance Studies at the University of Roehampton, London where he was a 2013-14 USUK Fulbright Fellow in Dance. He has danced with the Joffrey Ballet, New York, and the Zurich Ballet, Switzerland and was a winner of the Best German Dance Solo (1998). In 2013 Kyle performed at the Whitney Museum, New York with anthropologist Michael Taussig and currently collaborates with New York choreographers Jodi Melnick and Yanira Castro. Kyle is on the faculty at Sarah Lawrence College, New York where he supervises the written MFA thesis module.

Email: kbukhari@sarahlawrence.edu

\section{Notes}

${ }^{1}$ Lauren Wittels, Charles Atlas. 
${ }^{2}$ Douglas Rosenberg, "Introduction", 1-2.

${ }^{3}$ Charles Atlas, Merce Cunningham, and David Tudor. Channels/Inserts.

${ }^{4}$ Francis Ford Coppola and Mario Puzo. The Godfather.

${ }^{5}$ Charles Atlas and Johanna Fateman, 64.

${ }^{6}$ Idem., 256.

${ }^{7}$ Charles Atlas in Conversation with Stuart Comer, 271.

${ }^{8}$ Wittels, 14-19.

${ }^{9}$ Idem., 30-31.

${ }^{10}$ Charles Atlas in Conversation with Stuart Comer, 264-71, 272-79.

${ }^{11}$ Idem., 270.

${ }^{12}$ Idem., 276.

${ }^{13}$ Charles Atlas, Rashaun Mitchell, Silas Riener Tesseract, Walker Art Center (2017).

${ }^{14}$ Raphael Gygax. (Ed.) Charles Atlas.

\section{References}

Channels/Inserts Dirs. Charles Atlas, Merce Cunningham and David Tudor. 1981. Film. https://dancecapsules. mercecunningham.org/overview.cfm?capid=46038.

The Godfather. Dirs. Francis Ford Coppola and Mario Puzo. 1972. Los Angeles: Paramount Pictures.

Gygax, Raphael (Ed.) Charles Atlas. Zurich: JRP Ringier, 2019.

Rosenberg, Douglas. "Introduction." The Oxford Handbook of Screendance Studies. New York: Oxford University Press, 2016, 1-2.

https://doi.org/10.1093/oxfordhb/9780199981601.001.0001

Tesserract. Rashaun Mitchell, Silas Riener, and Charles Atlas. 2017. Minneapolis: Walker Art Center.

Wittels, Lauren (Ed.) Charles Atlas. Munich/New York: Prestel, 2015. 


\section{Dance's Duet with the Camera: Motion Pictures. Edited by Telory D. Arendell and Ruth Barnes. 2016. London: Palgrave MacMillan. 263 pp. Hardcover \$99.99. ISBN 978-1-137-59609-3}

Elisa Frasson, University of Roehampton

Keywords: screendance, context, edited volume, duet

Dance's Duet with the Camera: Motion Pictures (2016), edited by Telory D. Arendell and Ruth Barnes, ${ }^{1}$ is a collection of essays on the relationship between dance and film. It adds to the growing number of written sources present in the fields of Screendance and Dance Studies, including The Oxford Handbook of Screendance Studies (2016) ${ }^{2}$ and The Oxford Handbook of Dance and the Popular Screen (2014). ${ }^{3}$ Dance's Duet inserts itself into this discourse through historical analysis, considering the dance/camera relationship in the digital sphere, and by discussing issues of representations and inclusion in dance on film.

The edited volume includes fourteen chapters which are organized into five thematic sections: 'Site / Sight and the Body,' 'Movement Beyond the I / Eye,' 'Querying Praxis,' 'Bodies, Space, Camera,' and 'New Technologies: Dance as 3D's Ultimate Agent.'

The first part, on 'Site' in screendance, includes texts by Melanie Kloetzel, Cara Hagan and Frances Hubbard. Kloetzel's chapter investigates the setting of the video dance. She notes this genre's commonalities with the site-specific performance methodologies of the 1960s-1970s, both in the use of location and in the involvement of non-trained dancers. Hagan, in her chapter, traces an intersection between dance film and contemporary, intersectional, and womanist feminism, and suggests that "for many women and feminist allies, dance film has created a space apart from mainstream media and the traditions of professional dance to practice principles of feminism." ${ }^{4}$ Positioning herself as an African-American female screendance artist, and emphasizing the potential of accessible production in today's digital world, Hagan highlights the value of screendance as a sophisticated platform for social commentary, one that can counter the historical lack of inclusion of women of color in the film industry. Hagan's chapter is followed by Hubbard's partly contrasting, yet complementary feminist discussion that looks specifically into the Hollywood cinema high-budget production, Black Swan (2010). ${ }^{5}$ Hubbard analyzes the film through a feminist and psychoanalytic frame, demonstrating the ways in which this film plays into misogynist, queer, and lesbian stereotypes. ${ }^{6}$ 
The focus of the book's second part is the 'I,'-or individuality of first-person perspectives-of the creators of the works of dance for the camera. Izabella PruskaOldenhof uses Julia Kristeva's concept of "subject in process," connecting semiotic aspects which reveal how meaning is created in a pre-subjective mode, with symbolic elements in the poetics of Loïe Fuller. Pruska-Oldenhof discusses the "destabilization of the subject" in Fuller's works in which images in movement are based on "multiplying persona and dances," ${ }^{77}$ and where the subjectivity of the author almost disappeared, and with it disappeared the "physical/psychological body." ${ }^{8}$ In his chapter in the same section Peter Sparling raises issues of the dancing body as a primary subject of the dance film, analyzing two of his works, where he positioned a human naked body in front of the camera.

With texts by Arendell, Barnes, and Heather Coker, the third section seeks to answer the question: "When dance and moving projected images intersect, what do those intersections create and why?" In "Theoretical Duets," Arendell and Barnes explore through dialog their own work in mixed media production. They notice the augmented possibilities created by Virtual Reality, including the fact that human body weight could become more explicitly perceived. ${ }^{10}$ Their particular focus is on 3D technology as analysed through Walter Benjamin's concept of "Aura," and by thinking through VR in relation to more conceptually-driven Judson Church Theatre performances in the 1960s. Arendell and Barnes's dialogue also elaborates on the terminology in use to define this field-'screendance' or 'dance film' - and they introduce an ontology of dance and film. They criticize Rosenberg's use of the term screendance, ${ }^{11}$ and suggest that by placing the term 'screen' before dance, he risks elevating the medium over the body in movement. ${ }^{12}$

In her single-authored chapter, Barnes continues the study of dance film in reference to Walter Benjamin by focusing on the concept of the flâneur. She describes the concept as an "excellent model for audience members" to experience different visual perspectives by moving inside a video installation work. ${ }^{13}$ Barnes questions Rosenberg's idea of the "privileged position" of the camera which he suggests allows the spectator to "participate in a work" from multiple viewpoints. ${ }^{14}$ Barnes questions this assumption, as the approach forces the spectator's involvement, controlling his/her point of view. In contrast, Barnes proposes that spectators move through the works, allowing them to choose their points of view, just as the flâneur does in wandering the city. Heather Coker's text is an ontological discussion on dance and film. Coker uses her own work to consider a hybrid form between dance and film, featuring "three simultaneous elements: live dance composition, video composition and stage composition." ${ }^{15}$ Coker engages with John Berger's concept of camera and cinematic time, comparing it to the perception of time in the film as a "construction of the past."

The fourth section comprises texts by Arendell, Angela Kassel, and Carol-Lynne Moore. Kassel focuses on the structural elements of videodance such as space, time, body, 
editing, perspective framing, layering, duplication, and fragmentation. Theorising the notion of 'camera' as a fixed concept, Kassel suggests that thanks to the film medium, dance could be seen from below, disrupting theatrical space and gravity, expanding the point of view of the audience, and modifying the frontal stage perspective. Arendell analyses the extent to which the use of movement in the works of Maya Deren represents the language of the unconscious through the film medium. She stresses Deren's position as "Imagist,"17 which Deren derived from the poetic movement developed by Thomas Ernest Hulme and Ezra Pound. Arendell further examines the extent to which Deren's works could escape the male gaze, proposing E. Ann Kaplan's definition, of the film subject as both "observer and observed." ${ }^{18}$ Following Arendell's discussion, Moore's portrait of Fred Astaire's artistry of both "shooting and editing his work"19 adds a number of praxis-focused insights into dance-making in relation to film.

The final section-just one chapter-mostly explores new technologies and a new possible market of 3D dance works. Drawing from their experience with choreographer Crystal Pite, Philip Szporer and Marlene Millar reflect on ways in which dance is enhancing the three-dimensional format and vice versa. Although its distribution is still limited, they consider dance as an optimal format for a 3D experience-for the choreographer, the film maker, and the audience, who could be fully involved in the movement actions.

In the conclusion, Barnes delineates a concise map of multimedia performance history, highlighting Wim Wenders's Pina (2011) as a remarkable example of a 3D film and dance duet. Drawing on the words of Roland Barthes (1977) she contemplates whether dance and film could be considered an "interdisciplinary duet."

In Dance's Duet with the Camera, Arendell and Barnes set out to balance dance and film, and to highlight metaphoric 'duets' between the two media. They do this at the expense of introducing new modes and evolving relationships between dance and cameras. Missing also are filmographies and visual materials that could be useful to the readers. It's an expensive book, particularly given the lack of visual materials, but nevertheless it will be useful to artists, academics, archivists and students in Film and Dance Studies.

\section{Biography}

Elisa Frasson (Italy) is a PhD candidate in Dance Studies at Roehampton University. She has taught Dance History at IUAV University in Venice and at Liceo Coreutico in Trento. She is a Somatic Movement Educator $\left(\mathrm{BMC}^{\odot}\right)$ and certified Pilates instructor. She co-manages VeNe with which she has co-organized various events on screendance 
under the name [SET.mefree] Dance \& Movement on Screen in Italy, UK, and Malta. She received the Santander and Ede \& Ravenscroft Research Funding in 2016.

Email: frassone@roehampton.ac.uk

\section{Notes}

${ }^{1}$ Telory D. Arendell and Ruth Barnes, Dance's Duet with the Camera.

${ }^{2}$ Douglas Rosenberg, The Oxford Handbook of Screendance Studies.

${ }^{3}$ Melissa Blanco-Borelli, The Oxford Handbook of Dance and the Popular Screen.

${ }^{4}$ Cara Hagan, "The Feminist Body Reimagined in Two Dimensions," 49.

${ }^{5}$ Daren Aronofsky, Black Swan.

${ }^{6}$ Frances Hubbard, "Hollywood Cinematic Excess," 81.

${ }^{7}$ Izabella Pruska-Oldenhof, "Loïe Fuller and the Poetics of Light, Colour, and Rhythm," 113.

${ }^{8}$ Idem, 114.

${ }^{9}$ Arendell and Barnes, Dance's Duet with the Camera, 127.

${ }^{10}$ Arendell and Barnes, "Theoretical Duet," 130.

${ }^{11}$ Rosenberg, The Oxford Handbook of Screendance Studies.

${ }^{12}$ Arendell and Barnes, "Theoretical Duet," 130.

${ }^{13}$ Ruth Barnes, "Turning Around the Gaze in the Age of Technological Proliferation," 163.

${ }^{14}$ Rosenberg, Video Space: A Site for Choreography, cited in idem, 161.

${ }^{15}$ Heather Coker, "Wrestling the Beast," 143.

${ }^{16}$ John Berger (London 1926, Paris 2017) was a painter, art critic and writer. Coker, 152.

${ }^{17}$ Telory D. Arendell, “Maya Deren,” 200.

${ }^{18}$ Idem, 206. 
${ }^{19}$ Carol-Lynne Moore, “Valentine for Dance Historians," 213.

${ }^{20}$ Ruth Barnes, "Conclusion," 250.

\section{References}

Arendell, Telory D., "Maya Deren: Leaping Across Frames and Framing Leaps." In Dance's Duet with the Camera: Motion Pictures. Eds. Telory D. Arendell and Ruth Barnes. London: Palgrave MacMillan, 2016. 199-209. https://doi.org/10.1057/978-1-137-596109_11

Arendell, Telory D. and Ruth Barnes, eds. Dance's Duet with the Camera: Motion Pictures. London: Palgrave MacMillan, 2016. https://doi.org/10.1057/978-1-137-59610-9

."Theoretical Duet." In Dance's Duet with the Camera: Motion Pictures. Eds. Telory D. Arendell and Ruth Barnes. London: Palgrave MacMillan, 2016. 49-68. https://doi.org/10.1057/978-1-137-59610-9_7

Barnes, Ruth. "Turning Around the Gaze in the Age of Technological Proliferation; or, Things Are Seldom What They Seem." In Dance's Duet with the Camera: Motion Pictures. Eds. Telory D. Arendell and Ruth Barnes. London: Palgrave MacMillan, 2016. 159-171. https://doi.org/10.1057/978-1-137-59610-9_9

. "Conclusion: Where the Gaze Lands." In Dance's Duet with the Camera: Motion Pictures. Eds. Telory D. Arendell and Ruth Barnes. London: Palgrave MacMillan, 2016. 239-250. https://doi.org/10.1057/978-1-137-59610-9_14

Barthes, Roland. Music-Image-Text. New York: Hill and Wang. 1977.

Benjamin, Walter. The Work of Art in the Age of Mechanical Reproduction. London: Penguin. 2008 [1936].

Black Swan. Dir. Darren Aronofsky. Film. 2011.

Blanco-Borelli, Melissa, ed. The Oxford Handbook of Dance and the Popular Screen. New York: Oxford University Press. 2014.

https://doi.org/10.1093/oxfordhb/9780199897827.001.0001

Coker, Heather. "Wrestling the Beast... and Not Getting Too Much Blood on Your Skirt: Integration of Live Performance and Video Projection." In Dance's Duet with the Camera: Motion Pictures. Eds. Telory D. Arendell and Ruth Barnes. London: Palgrave MacMillan, 2016. 141-155. https://doi.org/10.1057/978-1-137-59610-9_8 
Dodds, Sherill. Dance on Screen: Genres and Media from Hollywood to Experimental Art. Basingstoke: Palgrave Macmillan, 2001. https://doi.org/10.1057/9780230509580

Hagan, Cara. "The Feminist Body Reimagined in Two Dimensions: An Exploration of the Intersections Between Dance Film and Contemporary Feminism." In Dance's Duet with the Camera: Motion Pictures. Eds. Telory D. Arendell and Ruth Barnes. London: Palgrave MacMillan, 2016. 49-68. https://doi.org/10.1057/978-1-137-59610-9_3

Hubbard, Frances. "Hollywood Cinematic Excess: Black Swan's Direct and Contradictory Address to the Body/Mind." In Dance's Duet with the Camera: Motion Pictures. Eds. Telory D. Arendell and Ruth Barnes. London: Palgrave MacMillan, 2016. 69-93. https://doi.org/10.1057/978-1-137-59610-9_4

Kristeva, Julia. Polylogue. Paris: Éditions du Seuil. 1977.

Moore, Carol-Lynne, "Valentine for Dance Historians: Astaire on Film." In Dance's Duet with the Camera: Motion Pictures. Eds. Telory D. Arendell and Ruth Barnes. London: Palgrave MacMillan, 2016. 211-220. https://doi.org/10.1057/978-1-137-59610-9_12

Pina. Dir. Wim Wenders. Film. 2011.

Pruska-Oldenhof, Izabella. "Loïe Fuller and the Poetics of Light, Colour, and Rhythm: Some Thoughts on the Making of fugitive I(i)ght." In Dance's Duet with the Camera: Motion Pictures. Eds. Telory D. Arendell and Ruth Barnes. London: Palgrave MacMillan, 2016. 97-113. https://doi.org/10.1057/978-1-137-59610-9_5

Rosenberg, Douglas. "Video Space: A Site for Choreography." Leonardo Music Journal 33.4 (2000): 275-280. https://doi.org/10.1162/002409400552658 ed. The Oxford Handbook of Screendance Studies. New York: Oxford University Press, 2016. https://doi.org/10.1093/oxfordhb/9780199981601.001.0001 


\section{Making Video Dance: A Step-by-Step Guide to Creating Dance for the Screen (2nd ed), by Katrina McPherson. 2018. London and New York: Routledge. 280 pp. Black and white images. \$120 hardcover. ISBN 978-1-13-869912-0. \$31.96 paperback. ISBN 978-1-13-869913-7. Website: www.makingvideodance.com.}

Robin Gee, University of North Carolina, Greensboro

Keywords: video dance, process, editing, production, distribution

As an art-maker, media-lover and would-be researcher I am always on the hunt for works that support the making of art and the people who endeavor to do so. Books that excite and inspire while also providing insight are always high on my list as I scour the aisles of my university library.

The first edition of Making Video Dance by Katrina McPherson is such a text for me - like an old friend, pages worn with highlighted notes, I return to it periodically in the process of both delivering content in university courses and in the making of my own work. The text itself, oft borrowed by both students and colleagues alike, is the quintessential dance film production handbook. I have used it to support the teaching of screendance for several years and have found it to be one of my most treasured guides.

When asked why the first edition was written McPherson stated, "because I could not find one like it... whilst there [were] many texts on film and video making in general, I found none focusing on the specific and unique concerns and possibilities that arise when you make dance for the screen." ${ }^{1}$ Thus, she set out to write a book that aimed to fill a need: to help dancers, choreographers and filmmakers begin the process of collaborating with and in the context of this new medium, finding common ground in both language and approach.

The newest edition of Making Video Dance does just that-it provides the reader with a forthright yet thoughtful look at making dance on film that expands on its predecessor with new insights, contexts and resources that will help artists gain new ground in the areas of pre-production, production, post-production and "flight" - the art of sending one's work out into the world. The chapters have been fleshed out, adapted and contain new material more relevant to a digital age. It is clear that McPherson's years as a filmmaker, curator and choreographer are informing these new sections, from devising and using a score to the history of manifestos in screen dance, she is artfully preparing us for the worlds of presentation and distribution of this medium in the 21 st century. The International Journal of Screendance 10 (2019).

https://doi.org/10.18061/ijsd.v10i0.6851

(c) 2019 Gee. This article is published under a Creative Commons Attribution 4.0 International License (https://creativecommons.org/licenses/by/4.0/) 
Each chapter ends with exercises designed to accompany key stages of the process, "intended to enhance understanding of the topics covered." ${ }^{2}$ The introductions by Ellen Bromberg and Bob Lockyer are beautifully written and provide some overarching historical context to both the need for and need filled by this work.

The book is divided into eleven chapters that take the reader from introductory lessons on how to begin ("Getting Started"), to the importance of having a clear idea when starting a project. That, along with examples of how to develop ideation and creativity if one doesn't have an idea or project in mind constitute the early chapters, asking the questions Where do ideas come from? How are they developed? How are we inspired? McPherson leads the reader through a series of queries that evenly outline the initial stages of the creative process. She challenges us to "make work that interests you," to develop ideas no matter how simple, whether new work or reworked. ${ }^{3}$ As a pedagogue who often interacts with students in the early stages of filmmaking, I inevitably encounter someone who fervently wants to take a live work and translate it to the screen, somehow imaging that the live work will remain the same by simply becoming a film. McPherson reminds us to honor the hybridity of the form, of all the possibility that lies within and to be willing to allow our work to transform.

Chapters 2-3 ("Dance and the Camera" and "Developing the Work") continue with this foundational work, further exploring ways to develop movement material and the basics of how the camera works "in relation to human movement." 4 "Developing the Work" has quite a few new sections and exercises designed to get us to a richer movement experience, including using and devising scores as a way to dig into movement. The role of the camera and how to "see" movement in this new way is also highlighted. These chapters go beyond the first edition with updated illustrations, scores, exercises and commentary. The ways in which we choreograph the camera is extremely important and McPherson deftly traverses this content with ease.

Chapters 4-7 are directed at the process of production and how to take the idea from the page to the set. She illuminates the necessity of "Creating Your On Screen World" and delves into the importance of intentionality and mise-en-scène in clearly articulating the world of a film. Also included in this chapter is more detailed information on the "people who might be involved and what they might do" on a set in "Next Steps."

Chapters 8-10 begin the post-production and editing portion of the book. Here she takes us through the "Preparation and Choreography of The Edit" and the detailed and important work of structuring post, layering in sound, color correction, dubbing and the conspicuous "Future Proofing" of work.

The second edition's chapters largely correspond to the first edition with the most notable additions being expanded exercises, revamped language, and supplementary sections within in the larger chapters. The revision feels broader than its companion and 
the exercises are more closely related to the chapters in which they reside. It is an overall finely tuned updated version of the original text and I am excited to work through the exercises and readings with my students. New to this addition is also the ways in which McPherson allows us entry into her process by including some of her most notable works as examples in specific chapters. When discussing "Themes" in chapter 1 she shares with us her creative processes in the making of Moment where she uses the concept of time and our perception of it as an entry point to thematic choices in filmmaking.

"Out in the World," the last chapter in the revised edition, would likely be my favorite. Here the author goes beyond the perfunctory "handbook" structure to position larger aesthetic questions about art and art making, thoughtfully engaging readers with questions of who we are as artists and how our work may come to define us or be perceived. We are left to imagine a way forward and urged to develop an ongoing practice. She ends this section by connecting the idea of developing this ongoing creative practice, one that is conscious and responsible, with that of creating a manifesto as a way of formalizing one's intentions. She includes examples of several manifestos along with a brief history of those that have existed in screendance.

Overall the sections are robust, and thoroughly cover the material in ways that will keep both novice and professional engaged. The text also has a website included that highlights much of McPherson's work - a treat indeed. Sadly, the films featured on the companion website (https://www.makingvideodance.com) are only trailers and there is a nominal fee to view full versions of the films. Teachers working with the text should keep this in mind when connecting the content to the website examples.

McPherson's experiences as a video dance maker and arts programmer for television give her a unique perspective on the field as a whole, as well as its storied development in Europe in general and the UK in particular. She is of the age of BBC Dance programming, dance broadcast live on television screens in the UK and she brings that knowledge and experience to bear as she prepares this work. She is an also an honest and experienced writer and adroitly leads us through the processes of making dance exclusively with the camera in mind. The work thoroughly and cohesively provides makers and teachers of film avenues further inquiry into this expanding genre. It continues to be the preeminent field-guide for makers of dance on film.

\section{Biography}

Robin Gee, Associate Professor of Dance at UNC Greensboro, holds an MFA in Dance Choreography and Performance from Sarah Lawrence College and specializes in African 
dance techniques, Modern and Caribbean dance forms, and dance designed for the screen. Ms. Gee has performed with several New York based dance companies, including: Ballet Bagata, Maimouna Keita Dance Company and the Cinque Folkloric Dance Company. She is the recipient of the numerous research grants and awards for her work in dance documentation and preservation including: the West African Research Associations' Post Doctoral Fellowship in African Research the Central Piedmont Regional Artists Hub Grant; the AAUW Postdoctoral Research Fellowship, US Fulbright Scholars Award and NC Choreographers Fellowship. She is also Director/Creator of the Greensboro Dance Film Festival.

Email: rmgee@uncg.edu

Website: https://www.greensborodancefilms.org

\section{Notes}

${ }^{1}$ Katrina McPherson, Making Video Dance, 1st edition, 1.

${ }^{2}$ McPherson, Making Video Dance, 2nd edition, 2.

${ }^{3}$ Ibid., 3

${ }^{4}$ Idem.

${ }^{5}$ lbid., 4.

\section{References}

McPherson, Katrina. Making Video Dance: A Step-by-Step Guide to Creating Dance for the Screen. 1st edition. London and New York: Routledge, 2006.

. Making Video Dance: A Step-by-Step Guide to Creating Dance for the Screen. 2nd edition. London and New York: Routledge, 2018.

https://doi.org/10.4324/9781315452654 